\title{
Biofouling in low pressure ultrafiltration modules for Point-of-Use applications
}

Charu Chawla 


\section{BIOFOULING IN LOW PRESSURE ULTRAFILTRATION MODULES FOR POINT-OF-USE APPLICATIONS}




\section{Promotion Committee}

Prof. dr. ir. R.G.H. Lammertink University of Twente

Prof. dr. ir. D.C. Nijmeijer

Dr. ir. A.J.B. Kemperman

Technical University of Eindhoven

Prof. dr. Maria Kennedy

University of Twente

Prof. dr. Guido Mul

UNESCO-IHE

Prof. dr. ir. Erik Roesink

University of Twente

Prof. dr. Arne Verliefde

University of Twente

Ghent University

The work described in this thesis is financially supported by Wetsus and the research in this thesis was carried out at Wetsus, Centre of Excellence for Sustainable Water Technology, Leeuwarden, The Netherlands.

ISBN : 978-90-365-4303-3

DOI : $10.3990 / 1.9789036543033$

Cover design by Indranil and Puneet

Printed by Gildeprint 


\title{
BIOFOULING IN LOW PRESSURE ULTRAFILTRATION MODULES FOR POINT-OF-USE APPLICATIONS
}

\section{Dissertation}

\author{
to obtain \\ the degree of doctor at the University of Twente, \\ on the authority of the rector magnificus, \\ prof. dr. T.T.M. Palstra,
}

on account of the decision of the graduation committee, to be publicly defended on

Friday the $3^{\text {rd }}$ of March 2017 at 12:45

by

\section{Charu Chawla}

born on $17^{\text {th }}$ January 1986

in Sonipat, India 
This thesis has been approved by :

Promoter Prof. dr. ir. R.G.H. Lammertink

Co-promoter Prof. dr. ir. D.C. Nijmeijer

Supervisor Dr. ir. A.J.B. Kemperman 
Dedicated to my Master and my family 

Science and Spirituality: Both begin with seeking and culminate into wonder 



\section{Contents}

Contents $\quad$ ix

List of Figures $\quad$ xiii

List of Tables $\quad$ xix

1 Introduction 1

1.1 General introduction . . . . . . . . . . . . . . . . . 1

1.2 Point-of-Use systems for drinking water treatment . . . . . . . . . . 2

1.3 Ultrafiltration (UF) as successful technology to deliver safe drinking water 5

1.4 Concentration polarization in ultrafiltration membranes . . . . . . . . 5

1.5 Fouling in ultrafiltration membranes . . . . . . . . . . . . . 8

1.5.1 Key parameters that affect fouling . . . . . . . . . . . . . 9

1.6 Objectives of the research . . . . . . . . . . . . . . . . 11

1.7 Outline of the thesis . . . . . . . . . . . . . . . . 12

2 Fouling in gravity driven Point-of-Use drinking water treatment systems 17

2.1 Introduction . . . . . . . . . . . . . . . . . . . . . 17

2.2 Materials and Methods . . . . . . . . . . . . . . . . . . 19

2.2.1 Experimental set-up . . . . . . . . . . . . . . . . 19

2.2.2 Membrane modules . . . . . . . . . . . . . . . . 20

2.2.3 Chemical analyses and feed water characteristics . . . . . . . . . 21

2.2.4 Sample preparation and Scanning Electron Microscopy (SEM) . . . 22

2.2.5 ATP and TOC analysis of the fouling layers . . . . . . . . . . . . . 22

2.2 .6 Variables . . . . . . . . . . . . . . . . . 23

2.3 Results and discussion . . . . . . . . . . . . . . . . . . . . . 23

2.3.1 Module operational modes and feed water . . . . . . . . . . . 23

2.3.2 Operational modes and discontinuous operation . . . . . . . . . 26

2.3 .3 Cross-flow effects . . . . . . . . . . . . . . . . . . . . 29

2.4 Conclusions . . . . . . . . . . . . . . . . . . . . . 32

Biofouling in low pressure ultrafiltration modules for Point-of-Use applications ix 
3 Influence of nematodes on biofouling in gravity driven membrane filtration

3.1 Introduction . . . . . . . . . . . . . . . . . . . 37

3.2 Materials and Methods . . . . . . . . . . . . . . . . . . . . . . . . . . . . . . 40

3.2 .1 Membrane filtration . . . . . . . . . . . . . . . . . . 40

3.2 .2 Water source ....................... 41

3.2 .3 Membrane autopsy . . . . . . . . . . . . . . . . . . . 41

3.2.4 Nematode enumeration . . . . . . . . . . . . . . . . 41

3.2.5 DNA extraction and Denaturing Gradient Gel Electrophoresis (DGGE)

3.3 Results and discussion . . . . . . . . . . . . . . . . . . 43

3.3.1 Flux behaviour of inside/out vs. outside/in operational mode . . . 43

3.3.2 Abundance of nematodes in I/O operational mode . . . . . . . . . 44

3.3.3 Inhibition of nematode activity using cycloheximide (CHX) . . . . . 48

3.3.4 Impact of nematodes on bacterial community dynamics in the biofouling layer . . . . . . . . . . . . . . . . . . . 50 50

3.3.5 Influence of seasonal variations on nematodes and correspondingly permeate fluxes . . . . . . . . . . . . . . . . 51

3.4 Conclusions . . . . . . . . . . . . . . . . . . 55

4 Hydraulic resistance of biofilms during ultrafiltration of drinking water: $\begin{array}{ll}\text { effect of monovalent to divalent ionic ratios } & \mathbf{6 1}\end{array}$

4.1 Introduction . . . . . . . . . . . . . . . . . . 61

4.2 Materials and Methods . . . . . . . . . . . . . . . . . . . . . . . . . . . . 63

4.2 .1 Experimental set-up . . . . . . . . . . . . . 63

4.2 .2 Materials ........................ 64

4.2 .3 Water quality . . . . . . . . . . . . . . . . 67

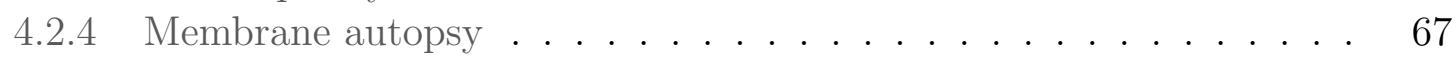

4.3 Results and discussion . . . . . . . . . . . . . . . . . . . . . . . . . . . . . . . . 69

4.3.1 Comparing MF and UF at M:D- 1.31:1 . . . . . . . . . . . . . 69

4.3.2 Varying ratios of Monovalent to Divalent (M:D) ions . . . . . . . . 72

4.4 Conclusions . . . . . . . . . . . . . . . . . . . 82

5 Polyelectrolyte coated ultrafiltration membranes for reduced membrane $\begin{array}{ll}\text { fouling } & 87\end{array}$

5.1 Introduction . . . . . . . . . . . . . . . . . . . . . . . . . . . . . 87

5.2 Materials and Methods . . . . . . . . . . . . . . . . . 89

5.2 .1 Materials ........................... 89

5.2 .2 Membrane modification by LBL-PEMs . . . . . . . . . . . . . . . . . . 90

5.2 .3 Membrane characterization . . . . . . . . . . . . . . . . . 90

5.2 .4 Fouling studies . . . . . . . . . . . . . . . . . . . . . . 92

5.3 Results and discussion . . . . . . . . . . . . . . . . . . . . 93

5.3.1 Membrane characterization . . . . . . . . . . . . . 93 
5.3.2 Fouling potential of modified membranes . . . . . . . . . . . . . . 95

5.4 Conclusions . . . . . . . . . . . . . . . . . . 104

6 Summary and outlook $\quad 111$

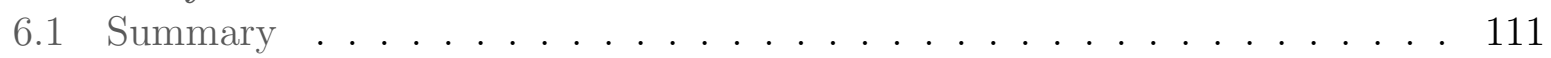

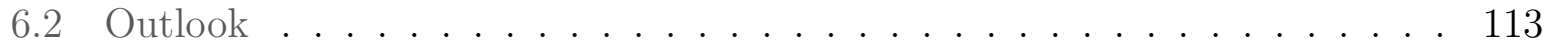

$\begin{array}{ll}\text { Samenvatting } & 119\end{array}$

$\begin{array}{ll}\text { Acknowledgements } & 123\end{array}$

$\begin{array}{ll}\text { Curriculum Vitae } & 127\end{array}$ 



\section{List of Figures}

1.1 Distribution of earths fresh water resources, image taken from [2]. . . . . .

1.2 The chart shows the distribution of earths fresh water resources, image taken from $[2] \ldots \ldots \ldots \ldots \ldots \ldots \ldots \ldots$

1.3 The effect of applied pressure on fluxes of ultrafiltration membranes. The gel layer formation occurs beyond applied pressure P3, Adapted from [15].

1.4 Schematic showing various resistances encountered during transport of a bulk solution through a porous membrane, the arrows depict the direction of fluid flow. . . . . . . . . . . . . . . . . . . . . .

2.1 Experimental scheme of the simulated Point-of-Use (PoU) system showing four modules A-D. Perm (permeate) is collected in flasks as shown in the figure; black lines with arrows indicate direction of the water flow through the set-up. . . . . . . . . . . . . . . . . . .

2.2 Flux data (a) and hydraulic resistance (b) of hollow fiber (O/I) and flat sheet membrane configurations using Potmarge (surface) water as feed for an operational run of 30 days. . . . . . . . . . . . . . . . .

2.3 Biopolymer retention and humic acids retention for hollow fiber and flat sheet membrane filtration after an experimental run of 30 days using Potmarge surface water as feed. . . . . . . . . . . . . . . . .

2.4 Hydraulic resistances at the end of the experimental runs (26 days) for outside/in (O/I) (left) and inside/out (I/O) (right) operational modes at 4 different operational conditions a) $4 \mathrm{hrs}$ on $/ 20 \mathrm{hrs}$ off b) $2 \mathrm{hrs}$ on $/ 5 \mathrm{hrs}$ off $/ 2$ hrs on/15 hrs off c) 9 hrs on/15 hrs off d) 24 hrs on. In all cases, Potmarge surface water was used as feed. . . . . . . . . . . . . . .

2.5 Cumulative DOC (Dissolved Organic Carbon) at the end of the experimental runs (26 days) for outside/in (O/I) and inside/out (I/O) operational modes at 4 different operational conditions a) $4 \mathrm{hrs}$ on $/ 20 \mathrm{hrs}$ off b) $2 \mathrm{hrs}$ on $/ 5$ hrs off $/ 2$ hrs on $/ 15$ hrs off c) 9 hrs on/15 hrs off d) 24 hrs on. In all cases, Potmarge surface water was used as feed. . . . . . . . . . . . . .

2.6 SEM images of (a) clean hollow fiber membrane surface, inside at 5000x, (b) outside at 1000x, (c,d) inside of a fouled inside/out (I/O) operated hollow fiber membrane at 5000x, and (e,f) the outside of a fouled outside/in (O/I) operated hollow fiber membrane at 5000x. . . . . . . . . . . . . 
2.7 ATP and TOC values at the end of the experimental runs (26 days) for outside/in (O/I) and inside/out (I/O) operational modes at 4 different operational conditions a) $4 \mathrm{hrs}$ on $/ 20 \mathrm{hrs}$ off b) $2 \mathrm{hrs}$ on $/ 5 \mathrm{hrs}$ off $/ 2 \mathrm{hrs}$ on $/ 15$ hrs off c) 9 hrs on/15 hrs off d) 24 hrs on. Potmarge surface water was used as feed. . . . . . . . . . . . . . . . . . . .

2.8 Hydraulic resistance versus cumulative permeate volume filtered during 40 days of $\mathrm{O} / \mathrm{I}$ operation under four different conditions: dead end continuous, $24 \mathrm{hrs}$ ON (continuous); intermittent, 9 hrs ON/15 hrs OFF (intermittent); continuous operation with crossflow with recirculation of feed, $24 \mathrm{hrs}$ ON (continuous + cross flow) and intermittent operation with crossflow with recirculation of feed, 9 hrs ON/15 hrs OFF (intermittent+cross flow), all using Potmarge surface water as feed. . . . . . . . . . . . . . . . .

3.1 Experimental set-up using outside/in (O/I) and inside/out (I/O) hollow fiber membrane modules operated at 0.1 bar gravity pressure for 35 days using secondary wastewater effluent (WWEf) as feed. . . . . . . . . . .

3.2 Nematodes (eukaryotic organism of interest) as seen under SEM (on left) at 400x and under optical microscope (on right) at 20x. . . . . . . . .

3.3 Flux data for hollow fiber membrane modules operated for 35 days (July 2014) using wastewater effluent (WWEf) as feed in both inside/out (I/O) and outside/in $(\mathrm{O} / \mathrm{I})$ modes. . . . . . . . . . . . . . . .

3.4 Fluxes for four 35 days filtration runs with wastewater effluent (WWEf) for I/O membrane modules during the periods Oct-Nov, 2013 (Run 1), Jan-Feb 2014 (Run 2), May-July 2014 (Run 3), Nov-Dec 2014 (Run 4). . . . . . . .

3.5 Average flux data and nematode density (for Run 3) for hollow fiber membrane modules operated I/O for 36 days using wastewater effluent (WWEf) as feed, red circles show a spike in nematode counts. . . . . . . . . . . . .

3.6 Active (control) in (a), (c) and dead (treated) nematodes in (b), (d) as seen under a light microscope at 100x magnification for two consecutive time periods (60 seconds) from the samples collected at the end of the experimental

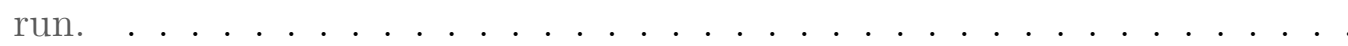

3.7 Comparison of flux behavior between I/O systems fed with waste water and with waste water with added CHX (growth inhibitor). Control refers to the system without cycloheximide (CHX) addition (July 2014) and treated refers to the system with addition of cycloheximide (CHX) to the feed water

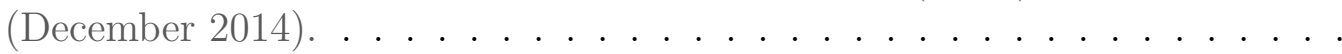

3.8 Denaturing Gradient Gel Electrophoresis (DGGE) displaying the molecular diversity based in control (lanes C1-C8) and treated (lanes T1-T6) systems. L stands for ladder lane. Control refers to the system without addition of cycloheximide (CHX) and treated refers to the system with addition of CHX to the feed water. . . . . . . . . . . . . . . . . 
3.9 Variations in fluxes in 4 systems operated in parallel in I/O operational mode with secondary wastewater effluent as feed water under identical operating conditions in December 2014. Systems I/O-1 to I/O-4 are replicates of each

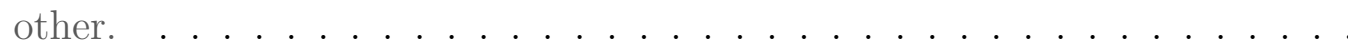

3.10 Nematodes as observed under light microscope from scraped biofouling layer at the end of experimental run of 35 days (Dec 2014); a) and b) a fully grown nematode, c) intermediate stage d) juvenile nematode, seen at 100x (a) and

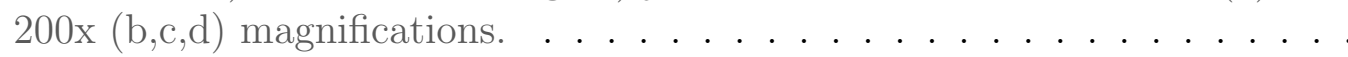

3.11 Temperature data recorded during the year 2014 in the aeration tank at the municipal wastewater treatment plant, Leeuwarden (NL). Red arrows indicate the time period when the wastewater effluent was withdrawn for conducting experiments. . . . . . . . . . . . . . . .

4.1 Schematic diagram of the membrane fouling simulators (MFS) operated in parallel at transmembrane pressure of 0.5 bar, $Q_{1}$ is the tap water flow, $Q_{2}$ the nutrient solution flow, $\mathrm{Q}_{3}$ the final feed inflow (tap water plus nutrient solution), $\mathrm{Q}_{4}$ the concentrate flow and $\mathrm{Q}_{5}$ the permeate flow. $\mathrm{F}_{1}$ is the flow controller. Cell A and C are fed with nutrients, cell B (blank) is without nutrient dosing. . . . . . . . . . . . . . . . . . .

4.2 Normalized permeate flux decline (where $\mathrm{J}$ is final flux and Jo is initial flux) for MF and UF fed with tap water (M:D 1.31:1) with and without nutrients at a TMP of 0.5 bar $(50 \mathrm{kPa})$, closed symbols show normalized flux data on the left y-axis, and open symbols show resistance data on the right y-axis. Squares and circles: MF. Triangles: UF. . . . . . . . . . . . . . .

4.3 ATP and accumulated TOC after 6 days of operation on MF and UF membranes fed with tap water (M:D 1.31:1) with and without nutrients at a constant TMP of 0.5 bar $(50 \mathrm{kPa}) . \ldots \ldots \ldots$

4.4 SEM images taken after autopsy after 6 days of operation for MF and UF fed with tap water (M:D 1.31:1); a) clean membrane, b) UF-blank without nutrients, c) biofouled MF with nutrients, d) biofouled UF-with nutrients. .

4.5 Extracted and total polysaccharides in the biofilm measured after 6 days of operation on UF fed with tap water (M:D 1.31:1) with and without nutrients

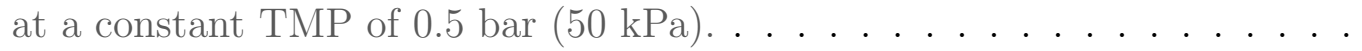

4.6 Normalized permeate flux decline (where $J$ is final flux and $J_{o}$ is initial flux) for UF fed with ion exchanged tap water (monovalent ions only, no divalent ions) with and without nutrients at a TMP of 0.5 bar $(50 \mathrm{kPa})$, closed symbols show normalized flux data on the left y-axis and open symbols show resistance data on the right y-axis. . . . . . . . . . . . .

4.7 Extracted and total polysaccharides measured after 6 days of operation on UF fed with ion exchanged tap water (monovalent ions only, no divalent ions) with and without nutrients at a TMP of 0.5 bar $(50 \mathrm{kPa}) . .$. . . 
4.8 ATP and TOC accumulated after 6 days of operation on UF fed with ion exchanged tap water (monovalent ions only, no divalent ions) with and without nutrients at a TMP of 0.5 bar $(50 \mathrm{kPa}) . \ldots \ldots$

4.9 Normalized permeate flux decline (where $\mathrm{J}$ is final flux and $\mathrm{J}_{\mathrm{o}}$ is initial flux) for UF fed with ion exchanged tap water (M:D 2.23:1) with and without nutrients and additional $\mathrm{Mg}$ at a TMP of 0.5 bar $(50 \mathrm{kPa})$ closed symbols show normalized flux data on the left y-axis and open symbols show resistance data on the right y-axis. . . . . . . . . . . . . . .

4.10 Extracted and total polysaccharides measured after 6 days of operation on UF fed with ion exchanged tap water (M:D 2.23:1) with and without nutrients and additional $\mathrm{Mg}$ at a TMP of 0.5 bar $(50 \mathrm{kPa}) . \ldots . . . . .$.

4.11 ATP and TOC accumulated on UF fed with ion exchanged tap water (M:D 2.23:1) with and without nutrients and additional Mg at a TMP of 0.5 bar

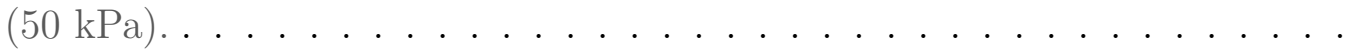

4.12 SEM images for autopsied UF membrane after 6 days of operation fed with tap water at different M:D ratios a) monovalent ions only, no divalent ions, without nutrients (no divalent ions), b) monovalent ions only, no divalent ions, with nutrients (no divalent ions), c) M:D 2.23:1, with nutrients (addition of $\mathrm{Mg}) \ldots \ldots \ldots \ldots \ldots \ldots$

5.1 Coating procedure for layer-by-layer deposition of polyelectrolyte multilayers on a negatively charged PES membrane. $0.05 \mathrm{M} \mathrm{NaCl}$ solution was used for rinsing steps 2 and $4 \ldots \ldots \ldots \ldots \ldots$

5.2 Zeta potential measurements for uncoated PES membrane and membranes coated with 2 layers i.e. (PDADMAC/PSS) 2 and 2.5 layers i.e. (PDAD$\mathrm{MAC} / \mathrm{PSS})_{2} / \mathrm{PDADMAC} \ldots \ldots \ldots \ldots$

5.3 Cumulative water production of an uncoated PES membrane and membranes coated with 2 layers i.e. (PDADMAC/PSS) 2 and 2.5 layers i.e. (PDADMAC/ PSS) 2 PDADMAC. Feed solution: $5 \mathrm{mg} / \mathrm{L}$ BSA at pH 6.0. .

5.4 Variation of $\mathrm{t} / \mathrm{V}$ vs $\mathrm{V}$ (where $\mathrm{V}$ is cumulative permeate volume at a given time t) for uncoated membrane and coated membrane with 2 layers i.e. $(\mathrm{PDADMAC} / \mathrm{PSS})_{2}$ and 2.5 layers i.e. (PDADMAC/PSS $)_{2} / \mathrm{PDADMAC}$, Feed solution: $5 \mathrm{mg} / \mathrm{L} \mathrm{BSA}$ at $\mathrm{pH} 6.0 \ldots \ldots . . . \ldots$

5.5 AFM images show changes in membrane surface where a-c are at an 80 nm height scale, a) Uncoated PES b) (PDADMAC/PSS) $)_{2}$ coated PES, and c) $(\mathrm{PDA} \text { DMAC/PSS })_{2}$ coated and BSA fouled PES. . . . . . . . . . . . .

5.6 Flux trends for biofouled a) coated (PDADMAC/PSS $)_{2}$, b) coated (PDAD$\mathrm{MAC} / \mathrm{PSS})_{2} / \mathrm{PDADMAC}$ and $\mathrm{c}$ ) uncoated membranes operated in dead end mode at 1 bar feed pressure. Feed solution: tap water with additional nutrients. 
5.7 Resistance vs cumulative permeate production for biofouled a) coated (PDAD$\left.\mathrm{MAC} / \mathrm{PSS})_{2}, \mathrm{~b}\right)$ coated (PDADMAC/PSS $)_{2} / \mathrm{PDADMAC}$ and c) uncoated membranes, corresponding to a membrane area of $200 \mathrm{~cm}^{2}$ for all membranes. Feed solution: tap water with additional nutrients. . . . . . . . . . 100

5.8 Flux recovery with forward flushing is shown for uncoated and coated membranes for biofouled a) uncoated, b) coated (PDADMAC/PSS) ${ }_{2}$ and c) coated (PDADMAC/PSS) $2 /$ PDADMAC membranes. Forward flushing : closed permeate valve and opened crossflow valve for 30 min daily, once per day. Feed solution: tap water with additional nutrients. Red arrows indicate the permeate fluxes measured immediately after forward flushing. . . . . . 101

5.9 SEM images showing the coated membranes a, c) before and b, d) after biofilm fouling. Images a) and b) are for membranes with a (PDADMAC/PSS $)_{2}$ layer, and images c) and d) are membranes with a (PDADMAC/PSS $)_{2} / \mathrm{PDADMAC}$ layer. . . . . . . . . . . . . . . . . . . . 103

5.10 AFM images show changes in membrane surface where a-c are at a 250 $\mathrm{nm}$ height scale, a) Uncoated PES before biofouling b) (PDADMAC/PSS $)_{2}$ coated PES before biofouling, c) (PDADMAC/PSS) $)_{2}$ coated and biofilm fouled PES. . . . . . . . . . . . . . . . . . . . 103 



\section{List of Tables}

1.1 Commercial Point-of-Use (PoU) systems for decentralized drinking water production with their respective performance assessment in terms of pathogen removal, adapted from $[10] \ldots \ldots \ldots \ldots$

2.1 Potmarge water characteristics used as feed water for the experiments. Values averaged over a period of 30 days. . . . . . . . . . . . . . .

2.2 Four different intermittent time intervals are shown using Potmarge water as feed for both $\mathrm{O} / \mathrm{I}$ and $\mathrm{I} / \mathrm{O}$ operational modes. . . . . . . . . . . .

4.1 Feed water characteristics without and with nutrients, after passing through the ion exchanger and further addition of Magnesium for different monovalent to divalent $(\mathrm{M}: \mathrm{D})$ ionic ratios. . . . . . . . . . . . . . . .

4.2 Overall comparison of various parameters at three different monovalent to divalent (M:D) ionic ratios for UF operated with and without nutrients at TMP 0.5 bar. . . . . . . . . . . . . . . . .

5.1 Surface characterization of coated membranes as contact angle, zeta potential and roughness measurements. AFM mode Peakforce QNM, area scanned $5 \times 5 \mu \mathrm{m}$ (an average of 5 different locations on a sample). . . . . . . . .

5.2 ATP and TOC values for uncoated and coated biofouled membranes after the autopsy at the end of the experimental run of 6 days. . . . . . . . . . . 101 



\section{Chapter 1}

\section{Introduction}

\subsection{General introduction}

Water related issues pose a global challenge that suppresses both social and economic growth. In particular the availability of clean drinking water has affected millions in developing countries. Though water as a natural resource is present in abundance, only $2.5 \%$ of it is fresh water while the remaining $97.5 \%$ is locked up in saline surface water bodies [1]. The fresh water distribution is shown in Figure 1.1, clearly depicting the scarcity of fresh water available for human consumption.

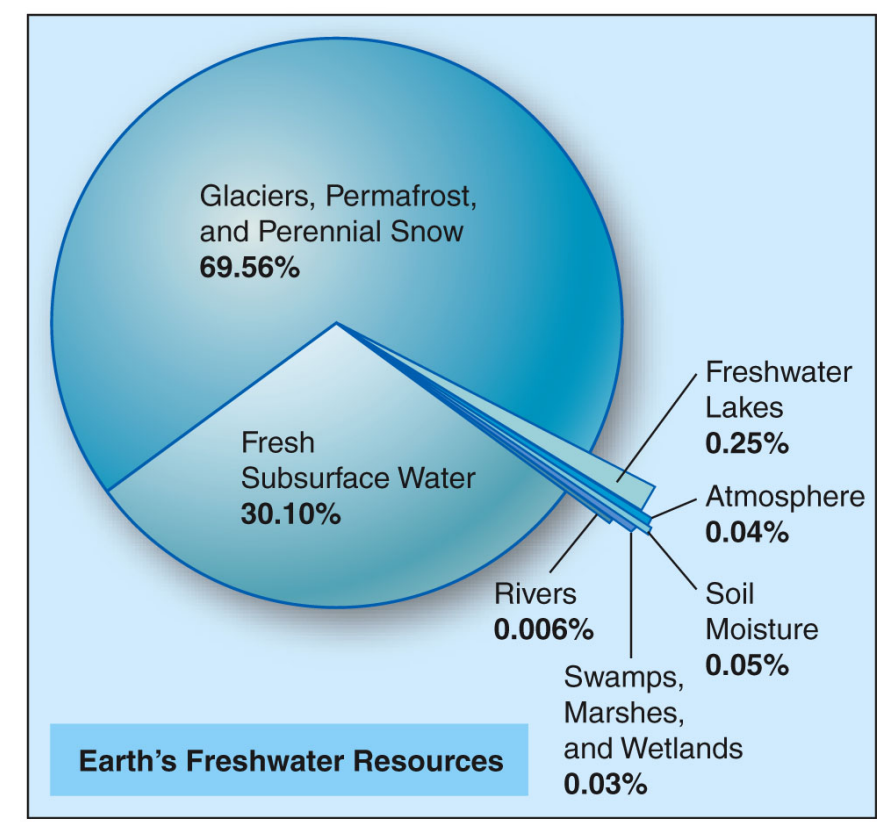

Figure 1.1: Distribution of earths fresh water resources, image taken from [2].

The amount of freshwater used for human consumption has increased 40-fold in the past 300 years out of which half of the increase occurred since 1950 [3]. The two main reasons 
for this rapid increment in water consumption are a) the constantly rising population in developing countries and b) depleting fresh water sources and contamination of existing sources by water pollution. The growing population and pollution accompanied by climate change poses a big threat to 7.1 billion people thriving on this planet today, especially in developing countries.

The vicious cycle of water scarcity, untreated wastewater and unsafe drinking water has exacerbated the existing poverty in developing countries. In 2000 the United Nations (UN) adopted the Millennium Development Goals (MDGs), a set of human development targets, MDGs number 7 stated to halve the proportion of the population without sustainable access to safe drinking water and basic sanitation by 2015 [4]. Yet, 1.8 billion people use a drinking water source that is contaminated with faeces [5]. Inadequate drinking water and sanitation commonly lead to around 842000 diarrheal deaths each year [5]. These deaths mainly occur due to the presence of pathogenic microorganisms in potable water leading to gastrointestinal infections in infants and adults.

Asian and African countries are severely plagued by water quality issues, not only in terms of available resources but also proper infrastructure to deliver safe, clean drinking water to the majority of its population. Especially in the Asian region, both China and India collectively hold almost one-third of world population and face the worst water crisis [3]. In Sub Saharan Africa, the number of people without access to clean drinking water increased by $23 \%$ from 1990 to 2004 [6]. A case study on the availability of drinking water and sanitation in Ghana shows that the poor water treatment infrastructure is a limiting factor for potable water consumption, and not the scarcity of water resources [6]. The Asian Development Bank (ADB) stated in the water security framework that in the Asia-Pacific region, $60 \%$ of the households do not have access to safe, piped water supply and improved sanitation [7]. The lack of water treatment infrastructure and distribution networks worsens the burden of unsafe water, sanitation and hygiene on diarrheal deaths. The UN adopted a set of new goals in September 2015 aiming to end poverty, protecting the planet and ensuring prosperity for all. Out of the 17 Sustainable Development Goals (SDGs) envisioned for 2030, clean water and sanitation is the 6th goal aiming to achieve universal and equitable access to safe and affordable drinking water for all [8]. Therefore, to alleviate the situation of clean drinking water, the World Health Organization (WHO) established the International Network to Promote Household Water Treatment and Safe Storage (HWTS) in 2003. HWTS systems are discussed in the forthcoming section.

\subsection{Point-of-Use systems for drinking water treatment}

Developing an effective water treatment infrastructure is capital intensive and requires both funds and long term planning. Approximately 1.9 billion population worldwide rely on water sources that are either fecally contaminated or not treated at all [9]. The statistics on water related deaths amongst infants in developing countries necessitates a rapid 
solution to deliver safe, clean drinking water to the underprivileged. To tackle the challenge of delivering potable water quality, individual or community based water treatment options have been evaluated and highlighted by the WHO. These are also called Household Water Treatment and Safe Storage (HWTS) technologies or Point-of-Use treatment (PoU) (terms used interchangeably henceforth) that treat potable water at the point of consumption either on community level or at individual households. PoU treatment systems are of utmost importance in emergency situations, especially during natural disasters. On-site water treatment has a greater potential to become a long term, sustainable solution to supply potable water to the communities as the responsibility of maintaining the system lies either on individuals or the community itself. It makes the people more responsible towards their own health, thereby considerably reducing health related risks originating from water borne diseases. To reduce the number of people exposed to risks by water borne diseases, it is evident that HWTS technologies need to be implemented and used correctly and consistently by the communities. This requires involvement of all stakeholders including end users, local governments, technology experts, educational institutions, and organizations such as the WHO that provide a platform for all stakeholders to work in a network.

The key advantages of a PoU system are compactness, low maintenance requirements, and a minimal to zero usage of both chemicals as well as electricity. Due to a variety of water pollutants present in water sources, the treatment technology is region specific. For example, chemically contaminated water with high arsenic or fluoride levels cannot be treated with chemical disinfection. Application and type of PoU systems can also vary depending upon the socio-economic condition of the communities. PoU treatment options include membrane filtration, chemical disinfection, and solar/UV disinfection, as shown in Table 1.1. The awareness of end users on the potential health gains of safe, clean drinking water and their ability to afford the technologies has brought exponential growth in the PoU treatment options in the past decade. The WHO has also recognized a strong growth of the filter market in Asian countries such as India, China, South Korea, Vietnam. However, compared to Asian regions only $20 \%$ of the population in sub-Saharan Africa use HWTS, mainly during emergency situations such as disease outbreak or natural disasters [10].

Increased commercialization and market growth of PoU technologies has urged the need for their evaluation on the basis of their effectiveness to remove microbial contaminants, cost of treatment with respect to production capacity and environmental impacts. The WHO established the International Scheme to Evaluate Household Water Treatment Technologies to obtain health gains and ensure effective pathogen removal by the available treatment technologies [10].

An example of HWTS technologies evaluated by WHO in the first round is shown in Table 1.1 (adapted from [10]). 
Table 1.1: Commercial Point-of-Use (PoU) systems for decentralized drinking water production with their respective performance assessment in terms of pathogen removal, adapted from [10].

\begin{tabular}{|c|c|c|c|c|}
\hline Technology & Product & Manufacturer & $\begin{array}{l}\text { Performance } \\
\text { target met }\end{array}$ & $\begin{array}{l}\text { Performance Classifica- } \\
\text { tion }\end{array}$ \\
\hline $\begin{array}{l}\text { Membrane } \\
\text { ultrafiltration }\end{array}$ & $\begin{array}{l}\text { Lifestraw } \\
\text { Com- } \\
\text { munity }\end{array}$ & $\begin{array}{l}\text { LifeStraw } \\
\text { SA }\end{array}$ & $\star \star \star$ & $\begin{array}{l}\text { Comprehensive protec- } \\
\text { tion: very high removal } \\
\text { of bacteria, viruses and } \\
\text { protozoa }\end{array}$ \\
\hline $\begin{array}{l}\text { Flocculation- } \\
\text { disinfection }\end{array}$ & $\begin{array}{l}\text { P\&G Puri- } \\
\text { fier of Wa- } \\
\text { ter }\end{array}$ & $\begin{array}{l}\text { The Proc- } \\
\text { tor and } \\
\text { Gamble } \\
\text { Company }\end{array}$ & $\star \star \star$ & $\begin{array}{l}\text { Comprehensive protec- } \\
\text { tion: high removal of } \\
\text { bacteria, viruses and } \\
\text { protozoa }\end{array}$ \\
\hline UV disinfection & $\begin{array}{l}\text { Waterlogic } \\
\text { Hybrid/Edge } \\
\text { purifier }\end{array}$ & $\begin{array}{l}\text { Qingdao } \\
\text { Waterlogic } \\
\text { Manu- } \\
\text { facturing } \\
\text { Company }\end{array}$ & $\star \star \star$ & $\begin{array}{l}\text { Comprehensive protec- } \\
\text { tion: high removal of } \\
\text { bacteria, viruses and } \\
\text { protozoa }\end{array}$ \\
\hline $\begin{array}{l}\text { Chemical disin- } \\
\text { fection }\end{array}$ & Aquatabs & $\begin{array}{l}\text { Medentech } \\
\text { Limited }\end{array}$ & $\star$ & $\begin{array}{l}\text { Targeted protection: } \\
\text { high removal of bacteria } \\
\text { and viruses, no/limited } \\
\text { removal of protozoa }\end{array}$ \\
\hline $\begin{array}{l}\text { Chemical disin- } \\
\text { fection }\end{array}$ & $\begin{array}{l}\mathrm{H} 2 \mathrm{gO} \text { pur- } \\
\text { ifier }\end{array}$ & $\begin{array}{l}\text { Aqua Re- } \\
\text { search } \\
\text { LLC }\end{array}$ & $\star$ & $\begin{array}{l}\text { Targeted protection: } \\
\text { high removal of bacteria } \\
\text { and viruses, no/limited } \\
\text { removal of protozoa }\end{array}$ \\
\hline $\begin{array}{l}\text { Solar disinfec- } \\
\text { tion }\end{array}$ & WADI & $\begin{array}{l}\text { Helioz } \\
\text { GmBH }\end{array}$ & $\star$ & $\begin{array}{l}\text { Targeted protection: } \\
\text { high removal of bacteria } \\
\text { and protozoa and some } \\
\text { removal of viruses }\end{array}$ \\
\hline
\end{tabular}

$\star \star \star$ removes at least $4 \log _{10}$ of bacteria, at least $5 \log _{10}$ of viruses and at least $4 \log _{10}$ of protozoa,

$\star \star$ removes at least $2 \log _{10}$ of bacteria, at least $3 \log _{10}$ of viruses and at least $2 \log _{10}$ of protozoa

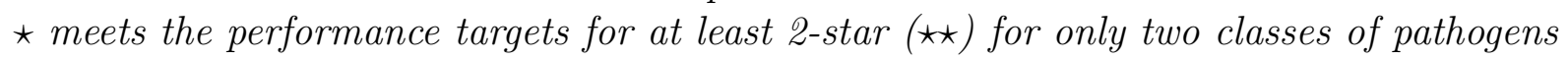

As seen in Table 1.1, membrane filtration (ultrafiltration) scores high as a HWTS or PoU treatment technology due to its robustness to effectively remove pathogens. In present thesis, we evaluated the performance of ultrafiltration based PoU system in terms of permeate flux decline and fouling development under varying operational parameters such as feed water quality, operational modes, operational time intervals and membrane 
surface modification to be discussed further.

\subsection{Ultrafiltration (UF) as successful technology to deliver safe drinking water}

Membrane filtration is a successful and highly innovative technology for separation processes. The economical operation, modular construction and flexible design makes it an attractive option for removing various types of water pollutants such as particles, colloids, biological substances, organics, and more recently even pharmaceuticals and micropollutants using modified UF membranes [11]. Increased competitiveness and technological improvements in membrane material and production has considerably reduced the membrane market prices [12]. Technologically, membranes have the advantage over conventional surface water treatment in terms of smaller footprint, lower energy consumption, no chemical dosing, and the ability to handle seasonal fluctuations in feed water quality [13]. Depending upon the separation characteristics and applied pressures, membranes for pressure driven water treatment processes can be classified as reverse osmosis (RO), nanofiltration (NF), ultrafiltration (UF) and microfiltration (MF). Though all types of membranes have been used in PoU based membrane modules, UF and MF are most commonly employed to meet the minimum requirements of pathogen removal (as seen in Table 1.1) and to assure lower costs of potable drinking water per capita. UF membranes are known to retain macromolecules, and reject bacteria and viruses. The pore size range of UF membranes (5 to 40 $\mathrm{nm}$ ) is smaller than those of bacteria (size range of 1-10 $\mu \mathrm{m}$ ) and viruses (in the range of 10-100 nm). This effectively leads to $>6 \log$ bacterial removal and $>4 \log$ virus removal [14]. UF is also preferred since it only requires low pressures of $0.5-4$ bar, thereby reducing the pumping and energy requirements. Low pressure operation and effective pathogen removal makes UF an ideal choice for Point-of-Use applications [14].

\subsection{Concentration polarization in ultrafiltration mem- branes}

The performance of ultrafiltration membranes is severely affected by a phenomenon called concentration polarization, which occurs due to the formation of concentration gradients of solute particles either on the feed side or on both feed and permeate sides of the membrane. Concentration polarization may cause membrane fouling, discussed later, due to the deposition of macromolecules and colloidal particles on the ultrafiltration membrane surface [15]. There are two approaches used in literature which describe the effect of concentration polarization on permeate flux. In the first approach, the resistances to permeation across the membrane and boundary layers at the fluid-membrane interface are considered as resistances in series. Assuming concentration polarization occurs only on the feed side of the membrane, the flux $J_{i}$ across membrane and boundary layers in terms of combined 


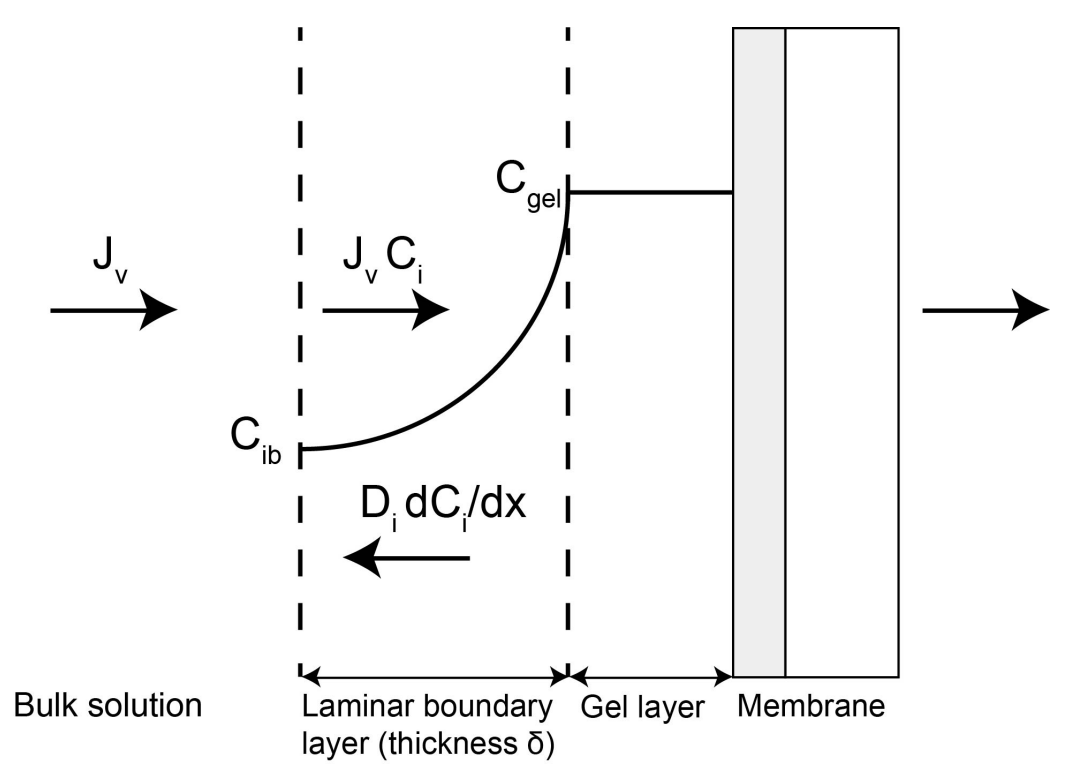

Figure 1.2: The chart shows the distribution of earths fresh water resources, image taken from $[2]$.

resistances can be defined as follows [15]:

$$
J_{i}=k\left(C_{i b}-C_{i p}\right)
$$

where $k$ is overall mass transfer coefficient, $C_{i b}$ is concentration of solute $i$ in the bulk feed solution, and $C_{i p}$ is the concentration of solute $i$ in the bulk permeate solution.

Similarly, the flux across the feed boundary layer is identical to $J_{i}$ and can be written as

$$
J_{i}=k_{b l}\left(C_{i b}-C_{i o}\right)
$$

where $k_{b l}$ is the boundary layer mass transfer coefficient and $C_{i o}$ is the concentration of solute $i$ at the interface.

The flux across the membrane can be expressed as:

$$
J_{i}=k_{m}\left(C_{i o}-C_{i p}\right)
$$

where $k_{m}$ is the mass transfer coefficient of the membrane.

The overall concentration drop is the sum of the concentration drops across boundary layer and the membrane surface. Hence by combining equations (1.1)-(1.3), we obtain equation (1.4), showing the resistance-in-series model for concentration polarization:

$$
\frac{1}{k}=\frac{1}{k_{b l}}+\frac{1}{k_{m}}
$$


The second approach towards describing the phenomenon of concentration polarization in ultrafiltration starts by assuming that a gel layer of unmixed fluid exists between the bulk feed solution and membrane surface [16]. As filtration of the feed solution proceeds, solvent permeates through the membrane whereas solute particles such as macromolecules and colloids are retained on the membrane surface. At a certain moment during filtration, depending upon operating conditions as well as solute and membrane properties, the concentration of these particles at the membrane surface becomes 20-50 times higher than the bulk feed solution [15]. The concentrated layer of accumulated solute particles consolidates to form a gel layer. The layer acts as a secondary barrier to the fluid flow leading to solvent flux decline. Eventually, the resistance grows as the gel layer consolidates further and finally contributes towards membrane fouling, described later in this section. The gel layer model for concentration polarization is schematically shown in Figure 1.2.

The convective flux of solute to the membrane surface is $J_{v}$ multiplied by $C_{i}$, where $J_{v}$ is the volume flux of the feed solution through the membrane and $C_{i}$ is the concentration of solute particles in the feed solution. At steady state, there is a balance between the convective flux of solutes towards the gel layer and the back diffusion of retained solutes in the opposite direction, which can be expressed as

$$
J_{v} C_{i}=D_{i} \frac{d C_{i}}{d x}
$$

where $D_{i}$ is the diffusion coefficient of the solute in the boundary layer.

After the formation of a gel layer on the membrane surface, the concentration of solute particles at both surfaces of boundary layer, i.e. feed solution and membrane surface, are fixed. Integrating equation 1.5 over the boundary layer thickness $(\delta)$ gives the following expression,

$$
\frac{C_{g e l}}{C_{i b}}=\exp \left(\frac{J_{v} \delta}{D_{i}}\right)
$$

where $C_{g e l}$ is the concentration of retained solute on the membrane surface where it forms the gel, and $C_{i b}$ is the concentration in the bulk solution.

Equation 1.6 shows that the volumetric flux, $J_{v}$ is quite independent of the intrinsic permeability of the membrane since at given experimental conditions $C_{g e l}, C_{i b}, D_{i}$ and $\delta$ are fixed. A membrane with a higher intrinsic permeability causes a thicker gel layer to develop on its surface. A thick gel layer decreases the membrane flux until the convective flux of solute towards the membrane surface is in equilibrium with the diffusive flux of solute towards the bulk solution. The formation of a gel layer on the ultrafiltration membrane surface leads to a limiting flux value that cannot be exceeded by increasing the applied pressure. As shown schematically in Figure 1.3, at low applied pressure P1 the flux is low and close to the clean water flux values. At this point, concentration polarization does not occur, hence there is no gel layer formation as well. With an increase in applied 


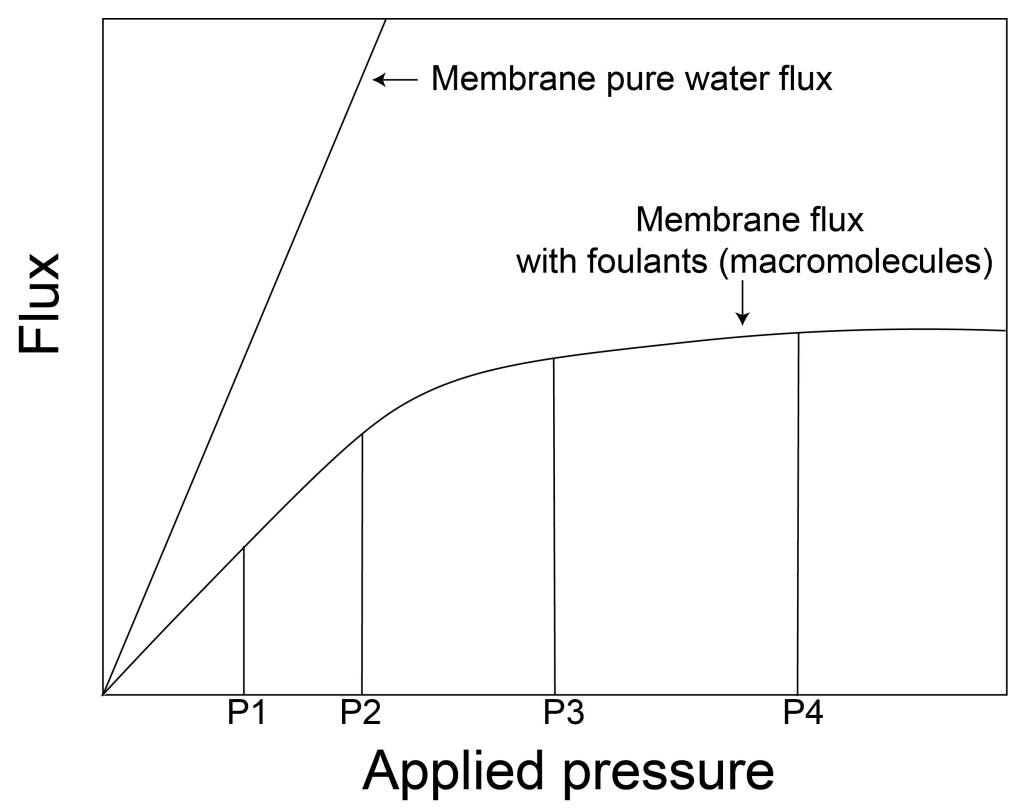

Figure 1.3: The effect of applied pressure on fluxes of ultrafiltration membranes. The gel layer formation occurs beyond applied pressure P3, Adapted from [15].

pressure from P1 to P2 and further on to P3, the flux increases correspondingly but deviates more from the clean water flux values. The concentration of macromolecules (solute particles) increase at the surface due to concentration polarization, but still below the gel concentration. At pressure P3 and beyond, concentration polarization becomes stronger and the solute concentration increases above the gel concentration and gel layer formation occurs. The gel layer acts as a secondary barrier layer to permeation. Beyond P3, there is no further increase in flux with the increase in applied pressure. This is the limiting or plateau flux at the given conditions and any further increase in pressure does not increase flux but only the thickness of the gel layer.

\subsection{Fouling in ultrafiltration membranes}

The Achilles heel of membrane technology as a water treatment technology is membrane fouling. Fouling is defined as the settlement and adsorption of solutes present in the feed on the membrane surface during filtration, resulting in an increased resistance towards flow and leading to a temporal permeate flux decline. These so called foulants adsorb either reversibly or irreversibly to the membrane surface, leading to membrane pore constriction/blocking and/or cake layer formation. The nature and composition of foulants deposited on a membrane surface vary considerably depending upon the operational conditions, feed water quality and membrane properties. Most commonly observed foulants during ultrafiltration for drinking water production are natural organic matter (NOM) [17], inorganic and organic colloids [18], microorganisms [19] and protozoa [20]. NOM 
compounds mainly consist of humic acids, polysaccharides and protein like substances (biopolymers), low molecular weight (LMW) acids and neutral substances. NOM substances can be further segregated into hydrophobic NOM and hydrophilic NOM [21]. The resistances corresponding to cake layer formation, adsorption, pore constriction, and pore blocking are shown in Figure 1.4.

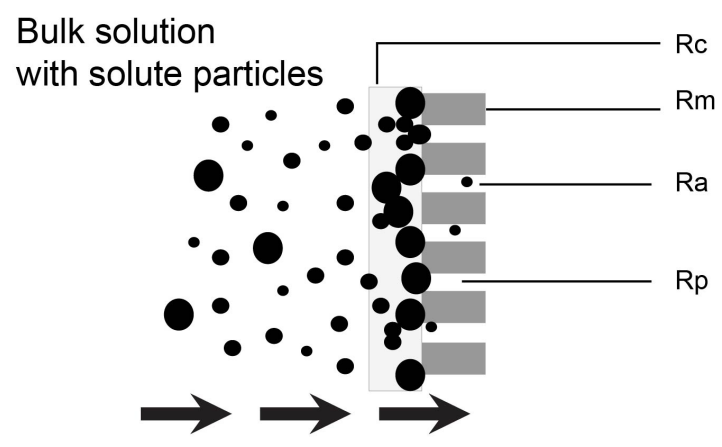

1) Rc : cake layer formation, resistance due to cake layer

2) $\mathrm{Rm}:$ membrane resistance

3) Ra : adsorption or pore constriction resistance

4) Rp : pore blocking resistance

Figure 1.4: Schematic showing various resistances encountered during transport of a bulk solution through a porous membrane, the arrows depict the direction of fluid flow.

\subsubsection{Key parameters that affect fouling}

Fouling is a complex phenomenon and various parameters influence fouling development on a membrane surface. The main parameters that affect membrane performance are briefly discussed in the next sections.

\section{Operational parameters}

Operational parameters affecting permeation rates include continuous and intermittent operation [22], membrane configuration and geometries [23] and hydrodynamics [24]. Fouling has been shown to alleviate by intermittent operation of membrane modules, especially when combined with forward flushing [22]. During continuous operation, ultrafiltration of the feed solution leads to continuous deposition of macromolecules and colloidal particles on the membrane surface. The continuous deposition of solute particles build up the cake layer or the gel layer that exerts considerable resistance to permeation. However, during intermittent operation there is no transport of solute particles to the membrane surface at standstill periods. During these periods, the cake layer undergoes structural changes such as transformation or aggregation of small particles into larger ones, and an overall 
relaxation of the layer takes place [22]. Besides relaxation and aggregation, the cumulative transport of new solute particles to the fouling layer also decreases as there is no permeation at standstill periods. Though the permeate production is lower in intermittent operation than during continuous filtration, it can be easily compensated by lower fouling tendency and longer operational periods when combined with forward flushing.

The second factor that affects membrane performance and permeate flux is the membrane geometry and configuration [23]. It is shown in literature that the mass transfer increases significantly for curved membrane geometries such as helical or twisted geometries, compared to straight ones. Limiting flux values were reported to be higher for curved membranes than straight membranes at a given Reynolds number $\left(R e=\frac{u L}{\nu}\right)[23]$. The feed water flow hydrodynamics in the module also influences membrane fouling. The positive effect of the cross-flow velocity on decreasing fouling is demonstrated well in literature [24-29]. It was shown that the secondary flows introduce turbulence within the boundary layer, thereby decreasing the thickness of the boundary layer on the membrane surface. As per equation (1.6) mentioned above, a decrease in the boundary layer thickness reduces the resistance to permeate flow and increases the corresponding volumetric flux. Hence, low fouling and high permeate production can be achieved by changing the hydrodynamics of the feed flow.

\section{Feed water quality}

Nature and composition of macromolecules and particles present in the feed water determine the retention of foulants, permeate flux decline and severity of fouling during ultrafiltration (UF). Ultrafiltration applied for drinking water treatment mostly uses surface water as the feed solution. In some cases, UF is also applied for wastewater re-use applications. Surface water mostly contains natural organic matter (NOM), inorganic particles and microorganisms. Peter-Varbanets et al. showed that water quality has a significant influence on stabilized flux values [19]. The authors studied the ultrafiltration of surface water with varying amounts of organic carbon and biological contaminants. They observed the highest stable flux values of $11 \mathrm{~L} / \mathrm{m}^{2} \cdot \mathrm{hr}$ at $65 \mathrm{mbar}$ for river water pretreated with biological sand filtration and the lowest stable flux values of $0.8 \mathrm{~L} / \mathrm{m}^{2} \cdot \mathrm{hr}$ for wastewater diluted with river water (50\% dilution factor). It was shown that inert or inorganic particles did not influence the resistance of the cake layer formed on the membrane surface during ultrafiltration. The NOM composition in river water greatly differed from diluted waste water, which resulted in significant differences between the stable flux values of the two feed waters. Similarly, for wastewater re-use applications, biological activity by the microorganisms and protozoas present in the feed water are shown to influence the resistance of cake layers and corresponding permeate fluxes [30]. Active biological processes create channels and cavities within the fouling layer, and thereby reducing the resistance towards permeation. 
Apart from dissolved and suspended particles, the structure of macromolecules, $\mathrm{pH}$ and ionic content of the feed water also affects retention of solute particles, fouling development, and permeation rates. Macromolecules with a globular shape such as proteins have a much higher retention during ultrafiltration than linear molecules such as polydextran at similar molecular weights [15]. pH affects the permeation rates of big molecules such as polyelectrolytes. Poly(acrylic acid) (PAA) is rejected well during ultrafiltration at $\mathrm{pH}$ 5 and above, but it permeates completely through the membrane at $\mathrm{pH} 3$ and below. The change in rejection behavior is due to the configurational changes that PAA undergoes with respect to the $\mathrm{pH}$ of the solution. Feed water quality in terms of ionic strength greatly influences the transport resistance of the fouling layer developed on the membrane surface. For example, the absence of divalent cations in the feed water leads to a loosely bound biofilm without structural integrity [31, 32]. The loosely bound biofilm layer has a much lower resistance than a tightly held biofilm layer.

\section{Membrane properties}

Membrane properties such as membrane material, surface charge, hydrophobicity, surface roughness, pore size, surface porosity, and pore morphology directly affect the adhesion of foulants to the membrane surface. Surface charge of the membrane plays an important role in interactions between the surface and the charged foulants. Most foulants that exist in surface water, including NOM and bacteria, are negatively charged [33]. Hence, to reduce fouling the membrane surface preferably is rendered negatively charged. Literature shows that negatively charged membranes had significantly lower bacterial adhesion compared to positively or neutrally charged membrane surfaces [34]. Besides charges, hydrophobicity also influences foulant retention on a membrane surface. Hydrophobic membranes are reported to have lower permeate fluxes due to more fouling than the hydrophilic membranes [33]. Nabe et al. studied the fouling potential of surface modified UF membranes (cut-off $10 \mathrm{kDa}$ ) using $0.08 \mathrm{~g} / \mathrm{L} \mathrm{BSA}$ solution [35]. It was shown that the more hydrophilic the surface (lower contact angle) was, the lower was the flux decline with BSA solution [35].

\subsection{Objectives of the research}

The aim of the research highlighted in this thesis is to study fouling development under low pressure ultrafiltration for drinking water production. Limited studies are available in literature on low pressure ( $\leq 1$ bar) ultrafiltration for drinking water production [36]. A great advantage of low pressure operation is that it causes delay in consolidation of the gel (fouling) layer formed on the membrane surface during ultrafiltration, as was explained in section 1.4 in Figure 1.3. Specifically, hollow fiber ultrafiltration (UF) membranes operated under gravity pressures (100 mbar) for drinking water treatment have not been investigated before. Considering fouling development as a transient phenomenon, understanding the 
long term effects of the factors mentioned in above on fouling becomes essential in order to accurately assess its overall impact on the efficiency of PoU systems. Thirdly, unlike previous studies performed on gravity driven ultrafiltration using feed water with a low total organic carbon content (TOC), we specifically challenged our in-house constructed PoU modules by using feed water with a high TOC content of $15 \pm 5 \mathrm{mg} / \mathrm{L}$, defined as a challenge test water for PoU systems by the WHO [10]. To fill in the existing scientific knowledge gaps and to allow the development of more efficient and self-sustainable Pointof-Use devices (without the need for chemical or physical cleaning), the current research evaluated the performance of hollow fiber based UF systems simulating PoU treatment.

The goals of the thesis were to investigate fouling development in low pressure hollow fiber ultrafiltration membranes modules simulating PoU treatment for drinking water production and the key parameters that affect its performance. General research questions identified in this research are listed as follows

1. How do inside/out vs. outside/in, and discontinuous vs. continuous modes of operation of hollow fiber membranes affect fouling development and permeate fluxes under gravity driven ultrafiltration of surface water? (Chapter 2);

2. How the biotic foulants present in wastewater effluent affect fouling development and permeate fluxes in inside/out vs. outside/in filtration modes? (Chapter 3);

3. How are the hydraulic resistances of biofouling on membranes affected by changing feed water composition in terms of the monovalent to divalent ionic ratio? (Chapter $4)$

4. How does membrane surface modification via polyelectrolyte coatings affect fouling development? (Chapter 5).

\subsection{Outline of the thesis}

In this work, we studied fouling development in low pressure (mostly gravity driven) hollow fiber membrane based systems to treat surface water and secondary wastewater effluent for drinking water production. These systems are to be implemented as decentralized line of treatment for drinking water production in developing countries.

Chapter 1 entitled General introduction gives a brief introduction to the research topic and key research questions identified during the course of the project. 
Chapter 2 is entitled Fouling in gravity driven Point-of-Use drinking water treatment systems. In this chapter, we study various operational parameters such as discontinuous vs. continuous filtration, and inside/out vs. outside/in operational modes to study their effects on fouling and permeate production with surface water as feed. Membrane modules using hollow fiber ultrafiltration membranes will be constructed to simulated Point-of-Use (PoU) systems and operated under gravity pressures of 0.1 bar.

Chapter 3 is entitled Influence of nematodes on biofouling in gravity driven membrane filtration, and investigates the influence of secondary wastewater effluent (WWEf) on fouling development. WWEf from a local municipal wastewater treatment plant will be used as feed to compare flux decline in inside/out vs. outside/in operational mode. Hollow fiber based membrane modules will be constructed to simulate Point-of-Use $(\mathrm{PoU})$ systems and operated under gravity pressures of 0.1 bar.

Chapter 4 is entitled Hydraulic resistance of drinking water biofilms: effect of monovalent to divalent ion ratios. The first chapters in this thesis focus on utilizing gravity pressures for ultrafiltration, as it is relevant for the areas where water supply infrastructure is not in place. However, urban areas in countries like India and China do have piped water supply. Hence, in the forthcoming sections, we apply tap pressure ( $\leq 1$ bar) as driving force for ultrafiltration. In this chapter, we will describe the effects of varying monovalent to divalent (M/D) cationic ratios on biofilm resistance and EPS production using a natural consortium of bacteria available in drinking water. The flat sheet based ultrafiltration membranes are operated at low pressures of 0.5 bar to simulate the pressures applied to under the tap Point-of-Use (PoU) devices.

Chapter 5 is entitled Polyelectrolyte coatings on ultrafiltration membranes for reduced membrane fouling. In this part of the research, we explore the effect of membrane surface modification on biofouling development by a natural consortium of bacteria native to drinking water. We used polyelectrolytes poly(diallyldimethylammonium)chloride (PDADMAC) and poly(styrenesulphonic acid) (PSS) for layer by layer (LBL) deposition on flat sheet ultrafiltration membranes. Besides biofouling, BSA was also studied as a model protein foulant.

In the Summary and outlook chapter 6 , an overview of the most important scientific findings of the thesis are given, as well as an outlook towards future scientific studies based on these findings.

\section{References}

[1] Vital water graphics: An overview of the state of the world's fresh and marine waters- 2nd edition, Chapter 1-State of the world's water, 2008, http://www.unep.org/dewa/ vitalwater/ article5.html. 
[2] Water resources, geology and non renewable mineral : Week 10, Access date 29 November 2016, https://tmacauley.wordpress.com/2013/04/14/week-10-water-resources-geologynon renewable-mineral/.

[3] R.M. Pink, Introduction, Chapter 1, Water Rights in Southeast Asia and India, Palgrave Macmillan US, New York, 2016, pp. 1-14.

[4] United Nations Millennium Development Goals Access date 28 November 2016, http:// www. who.int/topics/millennium_development_goals/mdg7/en/.

[5] World Health Organization, Access Date 11 November 2016, http://www.who.int/ mediacentre/factsheets/fs391/en/.

[6] M. Thompson, An integrated approach to scale up the market penetration of low carbon technologies in developing countries and water scarce regions, Civil Engineering 0300, UCLA, 2016.

[7] Asian Water Development Outlook : Measuring water security in Asia and the Pacific, A.D. Bank, the Philippines, 2013.

[8] Sustainable Development Goals, United Nations. Goal 6: Ensure access to water and sanitation for all, Access date 29 November 2016, http://www.un.org/sustainabledevelopment/ water-and-sanitation/.

[9] Progress on sanitation and drinking water-2015 update and MDG assessment, WHO and UNICEF 2015, http://www.who.int/water_sanitation_health/publications/jmp-2015update/en/.

[10] Results of round 1 of the WHO International Scheme to Evaluate Household Water Treatment Technologies, World Health Organization, 2016, http://www.who.int/household water/scheme/ household-water-treatment-report-round-1/en/.

[11] J. de Grooth, B. Haakmeester, C. Wever, J. Potreck, W.M. de Vos, K. Nijmeijer, Long term physical and chemical stability of polyelectrolyte multilayer membranes, Journal of Membrane Science 489 (2015) 153-159.

[12] J.M. Lan, D. Vial, P. Moulart, Status after 10 years of operation overview of UF technology today, Desalination 131 (2000) 17-25.

[13] J.G. Jacangelo, R. Rhodes Trussell, M. Watson, Role of membrane technology in drinking water treatment in the United States, Desalination 113 (1997) 119-127.

[14] J. Davey, A.I. Schfer, Ultrafiltration to Supply Drinking Water in International 
Development: A Review of Opportunities, in: E.K. Yanful (Ed.), Appropriate Technologies for Environmental Protection in the Developing World: Selected Papers from ERTEP 2007, July 1719 2007, Ghana, Africa, Springer Netherlands, Dordrecht, 2009, pp. 151-168.

[15] R.W. Baker, Membrane Technology and Applications, John Wiley \& Sons, Ltd, 2004, pp. 237-274.

[16] R. Baker, H. Strathmann, Ultrafiltration of macromolecular solutions with highflux membranes, Journal of Applied Polymer Science 14 (1970) 1197-1214.

[17] W. Yuan, A.L. Zydney, Humic acid fouling during ultrafiltration, Environmental science \& technology 34 (2000) 5043-5050.

[18] K.J. Howe, M.M. Clark, Fouling of microfiltration and ultrafiltration membranes by natural waters, Environmental Science and Technology 36 (2002) 3571-3576.

[19] M. Peter-Varbanets, J. Margot, J. Traber, W. Pronk, Mechanisms of membrane fouling during ultra-low pressure ultrafiltration, Journal of Membrane Science 377 (2011) $42-53$.

[20] N. Derlon, M. Peter-Varbanets, A. Scheidegger, W. Pronk, E. Morgenroth, Predation influences the structure of biofilm developed on ultrafiltration membranes, Water Research 46 (2012) 3323-3333.

[21] N. Lee, G. Amy, J.-P. Croué, H. Buisson, Identification and understanding of fouling in low-pressure membrane (MF/UF) filtration by natural organic matter (NOM), Water Research 38 (2004) 4511-4523.

[22] M. Peter-Varbanets, W. Gujer, W. Pronk, Intermittent operation of ultra-low pressure ultrafiltration for decentralized drinking water treatment, Water Research 46 (2012) 3272-3282.

[23] J.N. Ghogomu, C. Guigui, J.C. Rouch, M.J. Clifton, P. Aptel, Hollow-fibre membrane module design: comparison of different curved geometries with Dean vortices, Journal of Membrane Science 181 (2001) 71-80.

[24] N. Shamsuddin, D.B. Das, V.M. Starov, Filtration of natural organic matter using ultrafiltration membranes for drinking water purposes: Circular cross-flow compared with stirred dead end flow, Chemical Engineering Journal 276 (2015) 331-339.

[25] G. Amy, Fundamental understanding of organic matter fouling of membranes, Desalination 231 (2008) 44-51. 
[26] R. Bian, K. Yamamoto, Y. Watanabe, Effect of shear rate on controlling the concentration polarization and membrane fouling, Desalination 131 (2000) 225-236.

[27] S. Lee, C.H. Lee, Effect of operating conditions on CaSO4 scale formation mechanism in nanofiltration for water softening, Water Research 34 (2000) 3854-3866.

[28] S. Bhattacharjee, G.M. Johnston, A model of membrane fouling by salt precipitation from multicomponent ionic mixtures in crossflow nanofiltration, Environmental Engineering Science 19 (2002) 399-412.

[29] H. Choi, K. Zhang, D.D. Dionysiou, D.B. Oerther, G.A. Sorial, Influence of crossflow velocity on membrane performance during filtration of biological suspension, Journal of membrane science 248 (2005) 189-199.

[30] N. Derlon, N. Koch, B. Eugster, T. Posch, J. Pernthaler, W. Pronk, E. Morgenroth, Activity of metazoa governs biofilm structure formation and enhances permeate flux during Gravity-Driven Membrane (GDM) filtration, Water Research 47 (2013) 2085-2095.

[31] A.J. de Kerchove, M. Elimelech, Calcium and Magnesium Cations Enhance the Adhesion of Motile and Nonmotile Pseudomonas aeruginosa on Alginate Films, Langmuir 24 (2008) 3392-3399.

[32] G.G. Geesey, B. WigglesworthCooksey, K.E. Cooksey, Influence of calcium and other cations on surface adhesion of bacteria and diatoms: A review, Biofouling 15 (2000) 195-205.

[33] D. Rana, T. Matsuura, Surface modifications for antifouling membranes, Chemical reviews 110 (2010) 2448-2471.

[34] X. Zhu, D. Jańczewski, S. Guo, S.S.C. Lee, F.J. Parra Velandia, S.L.-M. Teo, T. He, S.R. Puniredd, G.J. Vancso, Polyion Multilayers with Precise Surface Charge Control for Antifouling, ACS Applied Materials \& Interfaces 7 (2015) 852-861.

[35] A. Nabe, E. Staude, G. Belfort, Surface modification of polysulfone ultrafiltration membranes and fouling by BSA solutions, Journal of Membrane Science 133 (1997) 57-72.

[36] M. Peter-Varbanets, F. Hammes, M. Vital, W. Pronk, Stabilization of flux during dead-end ultra-low pressure ultrafiltration, Water Research 44 (2010) 3607-3616. 


\title{
Chapter 2
}

\section{Fouling in gravity driven Point-of-Use drinking water treatment systems}

\begin{abstract}
This chapter describes fouling in simulated Point-of-Use (PoU) systems based on low pressure hollow fiber ultrafiltration membranes. Various operational parameters such as recirculation of feed, discontinuous vs. continuous filtration, and inside/out vs. outside/in were compared to study their effects on fouling and permeate production. Flux values stabilized around $2 \mathrm{~L} / \mathrm{m}^{2} \cdot \mathrm{hr}$ for gravity driven (100 mbar) ultrafiltration. Intermittent operation resulted in lower overall hydraulic resistances compared to continuously operated systems. This was due to the low organic loading and relaxation of the fouling layer during periods of standstill. In most experiments the fouling layer mainly consisted of diatoms, inorganic particles and few microbial clusters. The PoU systems investigated can be operated for longer duration without the need for strong chemical cleaning.
\end{abstract}

\subsection{Introduction}

Lack of potable water remains a major concern for most developing countries. Household Water Treatment (HWT) technologies are increasing in popularity to meet the safe drinking water needs of people. These so-called Point-of-Use (PoU) technologies utilize physical and/or chemical treatment (for surface water and wastewater re-use) to remove contaminants. Physical sieving by membrane filtration is one of the most favorable of all the product technologies due to its robustness in handling different types of feed water and its user friendliness. Membrane technology accounts for the largest market share in manufactured PoU systems [1]. 
Low pressure ultrafiltration has proven to be an effective technology for potable water production due to its low energy consumption, effective removal of microbes and ease of use [2]. However, fouling still remains a major challenge and adversely affects the water production capacity and operational lifetime of membranes. Major foulants comprise natural organic matter, inorganic elements, and microorganisms present in the feed water, which interact with the membrane surface and attach to it either reversibly or irreversibly. Membrane fouling behavior depends upon various factors such as continuous /intermittent operation [3], membrane configuration/geometries [4] and hydrodynamics [5]. It has been reported that during gravity driven ultrafiltration of surface water, intermittent operation facilitates relaxation of the fouling layer deposited on the membrane surface and leads to increased fluxes [3]. It was also observed that intermittent operation when combined with forward flushing further enhances the performance of the membrane system [3]. On the other hand, fouling was observed to be more severe under continuous operation [3]. In another study, the effect of hollow fiber membrane module design based on 4 different module geometries i.e. straight, helically coiled, twisted and sinusoidal was investigated [4]. It was shown that the mass transfer increased significantly for curved membrane geometries compared to straight ones (as reflected in the correlation between the Dean number (De) and the limiting permeate fluxes). Yet another study on membrane configuration compared the response of flat sheet modules against hollow fiber membrane modules during treatment of industrial wastewater [6]. It was observed that for similar feed water characteristics, fouling in the flat sheet membrane was dominated by pore blocking as opposed to cake/gel layer formation observed in case of the hollow fiber configuration [6]. The effect of hydrodynamics has also been investigated by employing different feed water flow patterns with respect to the membrane orientation, such as cross-flow and secondary flow. The positive effect of cross-flow velocity on abated fouling has been demonstrated well in literature [5, 7-11]. Shamsuddin et al. [5] showed that cross-flow introduced by circular channels, with spirals on the membrane surface, reduced the boundary (fouling) layer thickness on the membranes surface and improved foulant re-dissolution, thereby enhancing fluxes.

The present work concerns hollow fiber configurations that are frequently implemented in PoU systems, due to their relative higher specific membrane filtration area per unit module volume [15]. One experimental study [14] on the use of hollow fiber membranes during gravity driven membrane filtration can be found, reporting the application of hollow fibers in a membrane bioreactor for onsite greywater treatment [14]. The authors observed severe flux decline during one week of operation and stabilizing fluxes within 15 days. The influence of different aeration rates on biological degradation and biomass development was studied to improve wastewater treatment efficiency [14].Considering biofouling development as a temporal phenomenon, understanding the long term effects of the aforementioned factors on fouling becomes essential in order to accurately assess its overall impact on the efficiency of PoU systems. Despite this fact, most studies available in the literature investigate fouling development over short time scales i.e. for periods of $1 \mathrm{hr}$ to 24 hrs. Especially for low pressure filtration, fouling development is slow and a minimum period of 1 week has been shown to stabilize flux rates [12]. 
The present work hence highlights the fouling behavior in hollow fiber PoU systems operated over longer durations unlike previous studies ( $>20$ days). The specific objectives of the study were to optimize and understand the effects of various operational parameters that affect the fouling development as discussed above, such as intermittent use of the system, inside/out vs. outside/in operational mode of the hollow fiber configuration, and recirculation of feed water over the membrane surface. These parameters can be useful in designing more efficient hollow fiber based PoU systems. There are only a few studies [1213] addressing fouling under gravity pressures for flat sheet membrane configurations using surface water as feed. We know from literature that membrane geometry and configuration affect fouling development [4]. Hence, in the present work fouling development is studied under gravity pressures using hollow fiber membranes simulating PoU systems. The advantages of low-pressure membrane operation, in this case gravity pressure, are minimal energy consumption since pumping is not required, and almost no manual maintenance . This broadens the applicability of PoU systems.

In the present work we constructed hollow fiber modules to simulate PoU systems for onsite drinking water treatment applications. In the study, we used surface water containing higher natural organic matter and lower biomass content compared to Jabornig et al.[14] as key foulants. Two hollow fiber operational modes with 3 different intermittent intervals of operation and the effect of feed recirculation on fouling development were investigated.

\section{$2.2 \quad$ Materials and Methods}

\subsubsection{Experimental set-up}

A schematic representation of the experimental set-up is shown in Figure 2.1. A hydrostatic head provides 100 mbar as transmembrane pressure. Each experimental run was duplicated using two identical modules. All the experiments were conducted at $20 \pm 2^{\circ} \mathrm{C}$. Intermittent operations were performed using magnetic valves (M\&M International, Italy) coupled with automatic timers (Grassini, Germany). The permeate flux was measured manually every day using a graduated cylinder and a stopwatch. At least two measurements were recorded each day and the average value of the flux was considered.

The viscosity was temperature corrected and plugged in expression 2.1 to calculate the hydraulic resistance using the following equation [15].

$$
R=\Delta P / \eta J_{s}
$$

where $R$ is the total hydraulic resistance $(1 / \mathrm{m}), \Delta P$ is the transmembrane pressure $(\mathrm{Pa}), \eta$ is the dynamic viscosity of the permeate $(\mathrm{Pa} . \mathrm{s})$ and $J_{s}$ is the flux $\left(\mathrm{m}^{3} / \mathrm{m}^{2} \cdot \mathrm{s}\right)$. 


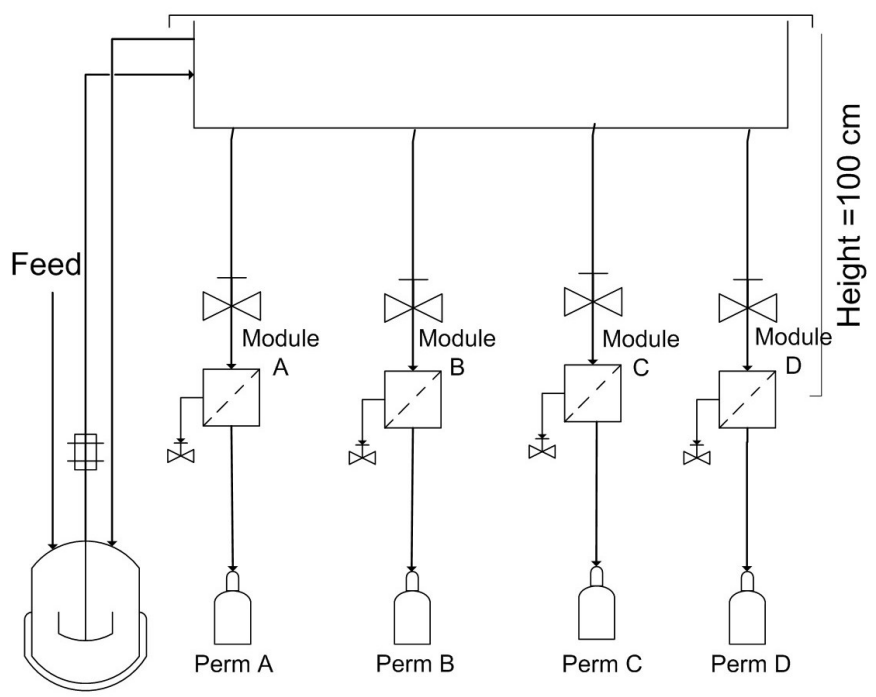

Figure 2.1: Experimental scheme of the simulated Point-of-Use (PoU) system showing four modules A-D. Perm (permeate) is collected in flasks as shown in the figure; black lines with arrows indicate direction of the water flow through the set-up.

\subsubsection{Membrane modules}

Polyethersulphone (PES) inside/out (I/O) hollow fiber membranes (3 mm ID, $4.5 \mathrm{~mm}$ OD) with a MWCO of 100-150 kDa were kindly supplied by Pentair X-Flow BV (Enschede, The Netherlands). These I/O hollow fibers were used to construct membrane modules mimicking commercial PoU systems, with a membrane area of $0.15 \mathrm{~m}^{2}(\mathrm{O} / \mathrm{I})$ and $0.07 \mathrm{~m}^{2}$ (I/O). For module construction, the membranes were stacked inside a PVC housing, and subsequently potted into the housing with an epoxy resin cured overnight. Clean water permeability for these hollow fiber membrane modules ranged from $260-400 \mathrm{~L} / \mathrm{m}^{2} \cdot \mathrm{hr} \cdot \mathrm{bar}$.

Flat sheet PES membranes (type UP 150, MWCO $150 \mathrm{kDa}$ ) were purchased from Microdyn Nadir (Germany). Its clean water permeability is $>286 \mathrm{~L} / \mathrm{m}^{2} \cdot \mathrm{hr} \cdot \mathrm{bar}$ as per manufacturer. Polycarbonate membrane holders $(48 \mathrm{~mm}$, Whatman, VWR, The Netherlands) were used for flat sheet experiments (membrane filtration area $0.0018 \mathrm{~m}^{2}$ ).

Prior to filtration, all membrane modules were soaked in demi water overnight, and then rinsed once with $20 \%$ ethanol and twice with demi water as recommended by the manufacturer to remove conservation agents prior to the filtration experiments. Hollow fiber modules were checked for leakages by an air-leak test before installing them in the experimental set-up. All installed modules were subsequently checked for leakage at the start of each experiment by determining the number of total coliforms in feed and permeate samples, whereby leaking modules were discarded. 
Table 2.1: Potmarge water characteristics used as feed water for the experiments. Values averaged over a period of 30 days.

\begin{tabular}{lll}
\hline Parameter & Value & Unit \\
\hline Total Carbon & $55 \pm 3$ & $\mathrm{mg} / \mathrm{L}$ \\
Total Organic Carbon & $15 \pm 3$ & $\mathrm{mg} / \mathrm{L}$ \\
Inorganic Carbon & $40 \pm 3$ & $\mathrm{mg} / \mathrm{L}$ \\
$\mathrm{pH}$ & $8.0 \pm 0.5$ & \\
Conductivity & $790 \pm 70$ & $\mu \mathrm{S} / \mathrm{cm}$ \\
Dissolved Oxygen & $8.0 \pm 0.5$ & $\mathrm{mg} / \mathrm{L}$ \\
Turbidity & $5 \pm 3$ & $\mathrm{NTU}$ \\
Chemical Oxygen Demand & $35 \pm 3$ & $\mathrm{mg} / \mathrm{L}$ \\
Humic acids & $13 \pm 3$ & $\mathrm{mg} / \mathrm{L}$ \\
Biopolymers & $0.8 \pm 0.2$ & $\mathrm{mg} / \mathrm{L}$ \\
\hline
\end{tabular}

\subsubsection{Chemical analyses and feed water characteristics}

Surface water from the Potmarge river (Leeuwarden, The Netherlands) was collected once every 2-3 days and used directly. The total carbon, total organic carbon (TOC) and inorganic carbon of feed and permeate were analyzed by a TOC analyzer (Shimadzu Scientific instruments, Kyoto, Japan). Chemical oxygen demand (COD) of feed and permeate were measured daily using a Hach Lange cuvette test kit (LCK 414 effluent 5-60 mg/L). pH and conductivity were measured using portable meters (WTW, Germany). Turbidity was measured using a Hach 2100N-IS Turbidity meter (ISO Method 7027). Dissolved Oxygen (DO) was measured using a DO probe (HQ30d, Hach). Natural Organic Matter (NOM) fractions were analyzed by Liquid Chromatography-Organic Carbon Detection (LC-OCD) with a UV and organic nitrogen detector (OND) attached to it (Model 8, DOC Labor, Germany). NOM comprises of biopolymers, humic acids, low molecular weight acids and neutrals. Separation of NOM fractions in LC-OCD takes place according to their molecular weight cut off (MWCO) on a size exclusion chromatographic column. Larger molecules have the lowest retention time and smaller molecules have the longest retention times. The average raw water characteristics of the Potmarge river water are shown in Table 2.1.

Total coliform and E.Coli in feed and permeate samples were determined using the USEPA method 10029 for coliform detection for drinking water applications. m-Coli broth (Hach) was used as medium for incubation. A sample volume of $5 \mathrm{~mL}$ was filtered through a sterilized $0.45 \mu \mathrm{m}$ white gridded filter paper (Pall Life Sciences, The Netherlands). The filter paper was incubated in a sterile petri dish containing adsorbent pads (Pall Life Sciences, The Netherlands) and broth at $35 \pm 2{ }^{\circ} \mathrm{C}$ for 24 hours. The petri dish was placed in an incubator (Innova 42, New Brunswick Scientific). Colony counting was performed the following day at 10x magnification using a Leica MZ9.5 optical microscope. Red colonies were total coliforms, except E. Coli that appeared as blue colonies. 


\subsubsection{Sample preparation and Scanning Electron Microscopy (SEM)}

Fixation of membrane samples was done using $2.5 \%$ (v/v) glutaraldehyde solution (Sigma Aldrich, Steinheim, Germany) and incubating them overnight at $4^{\circ} \mathrm{C}$. On the subsequent day, samples were washed with Phosphate-buffered saline (PBS) and dehydrated with ethanol. The washing step was performed three times for 7 minutes per step with 1X PBS (10 $\mathrm{mM}$ ), followed by dehydration with $30 \%, 50 \%, 70 \%$, and $90 \%$ (v/v with Milli-Q) ethanol solutions for $20 \mathrm{~min}$ each, and finally twice with $100 \%$ ethanol for $30 \mathrm{~min}$ each. Milli-Q water $(>18 \mathrm{M} \Omega \cdot \mathrm{cm})$ used in the experiments was obtained from a Millipore Milli-Q Biocel with a Q-grade $\AA$ column. The dehydrated samples were air-dried in a drying chamber overnight at $37^{\circ} \mathrm{C}$ (MMM Group, Venticell, Brno, Czech Republic). Finally, the samples were sputtered with gold (Jeol JFC-1200 Fine Coater, Japan) and visualized under an SEM (JSM6480LV microscope, JEOL Technics Ltd., Japan) operated at an accelerating voltage of $6 \mathrm{kV}$ in a high vacuum mode.

\subsubsection{ATP and TOC analysis of the fouling layers}

Adenosine triphosphate or ATP gives the measure of living cellular material and in the present study refers to the living biomass within the fouling layer on the membrane surface [17]. For ATP measurements, membrane samples were centrifuged for 40 min at $1500 \mathrm{rpm}$ (Heidolph MultiReax) in 1X PBS to remove reversible fouling from the surface. Afterwards, the samples were stored in ice and brought immediately to the local water supply company (Vitens, Leeuwarden, The Netherlands) for further analysis. The refrigerated samples were sonicated in an ultrasonic water bath at $37 \mathrm{kHz}$ for 5 minutes to remove the remaining cells from the membrane surface and subsequently vortexed for a few seconds at a maximum velocity of $2500 \mathrm{rpm}$. An ATP Biomass Kit HS (Biothema, Sweden) with a lysis agent 'Celsis LuminEX' ATP Releasing Agent (Celsis, USA) was used to quantify ATP levels in the samples. The final concentrations were measured using an ATP microplate reader (CentroXS3, Berthold technologies, Germany). The error margin for the ATP measurements reported is $10 \%$.

Membrane samples for TOC analysis were placed in $15 \mathrm{~mL}$ centrifuge vials containing $10 \mathrm{~mL}$ of Milli-Q water. Next, the samples were treated with an ultrasonic probe (Branson Sonifier 250, G. Heinemann Ultraschall- und Labortechnik, Germany) for 1 min to release all TOC attached to the membrane into the solution. Afterwards, the samples were placed in a TOC free glass vial and an additional $10 \mathrm{~mL}$ Milli-Q was added to make up $20 \mathrm{~mL}$ of sample volume. TOC was measured using a TOC analyzer, as described previously in section 2.2.3. The measurement error for TOC analysis was less than $10 \%$. 
Table 2.2: Four different intermittent time intervals are shown using Potmarge water as feed for both $\mathrm{O} / \mathrm{I}$ and I/O operational modes.

\begin{tabular}{cccccc}
\hline & Operational condition & $\begin{array}{c}\text { Feed on } \\
\text { (hours) }\end{array}$ & $\begin{array}{c}\text { Feed off } \\
\text { (hours) }\end{array}$ & $\begin{array}{c}\text { Permeation on } \\
\text { (hrs) }\end{array}$ & $\begin{array}{c}\text { Permeation off } \\
\text { (hrs) }\end{array}$ \\
\hline 1 & $4 / 20$ & 4 & 20 & $09: 00-13: 00$ & $13: 00-09: 00$ \\
2 & $2 / 5 / 2 / 15$ & 4 & 20 & $09: 00-11: 00$ & $11: 00-16: 00$ \\
& & & & $16: 00-18: 00$ & $18: 00-09: 00$ \\
3 & $9 / 15$ & 9 & 15 & $09: 00-18: 00$ & $18: 00-09: 00$ \\
4 & $24 / 0$ & 24 & 0 & $09: 00-09: 00$ & 0 \\
\hline
\end{tabular}

\subsubsection{Variables}

The effects of membrane configuration, operational modes, feed recirculation and (dis)continu ous operation on fouling behavior of the low pressure ultrafiltration PoU systems were investigated. Two types of membrane configurations i.e. flat sheets and hollow fibers, are compared and results are shown in section 2.3.1. PoU systems are usually operated intermittently in real life applications [18, 19]; hence 2 different run times (4 hrs/day and 9 hrs/day, respectively) were compared to continuous (24 hrs) hollow fiber membrane operation.In section 2.3.2, three modes of intermittent operation were studied on two different operational modes (O/I and $\mathrm{I} / \mathrm{O}$ ) as shown in Table 2.2, using Potmarge water (surface water) as feed. Table 2.2 shows the duration and time intervals for permeate production for different operational conditions; 4/20 for example refers to a feed supply duration of 4 hrs (from 09:00-13:00 hrs), with a standstill period of $20 \mathrm{hrs}$ between 13:00 and 09:00 hrs. In order to study the effect of feed flow on fouling, cross-flow experiments using the hollow fiber configuration were designed wherein the feed stream is recirculated at $1,200-1,500$ $\mathrm{mL} / \mathrm{min}$ using a peristaltic pump to introduce shear stress (around $9 \times 10^{-4} \mathrm{~Pa}$ along the walls of the hollow fibers) on the membrane surface. A large feed tank volume ensured there was no change in composition of feed when recycling the feed stream. Reynolds number was calculated to be around 400 inside the module around the hollow fibers. The results are presented in section 2.3.3.

\subsection{Results and discussion}

\subsubsection{Module operational modes and feed water}

To address the influence of membrane module configuration on the flux behavior, two different membrane configurations i.e. hollow fiber and flat sheet type were assessed in terms of permeate production and hydraulic resistance. Both modules were operated in dead-end mode; the hollow fiber module was tested in outside/in mode. Figure 2.2 illustrates the variation of flux and hydraulic resistance as a function of time, for both configurations. The results correspond to an operational duration of 30 days. Both configurations exhibit qualitatively similar trends. During the first few days of filtration the flux values show a 
a)

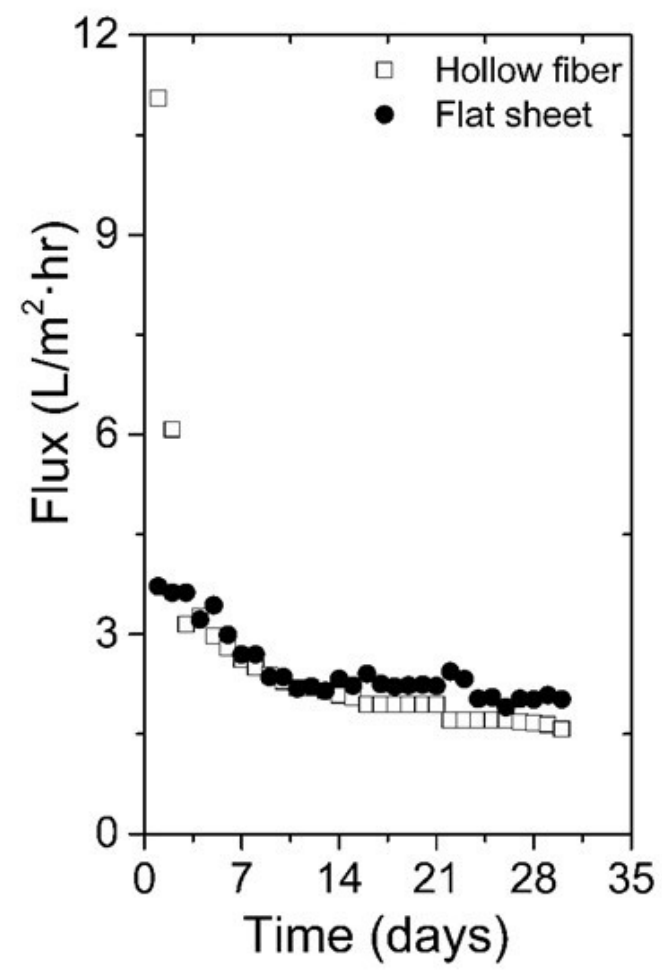

b)

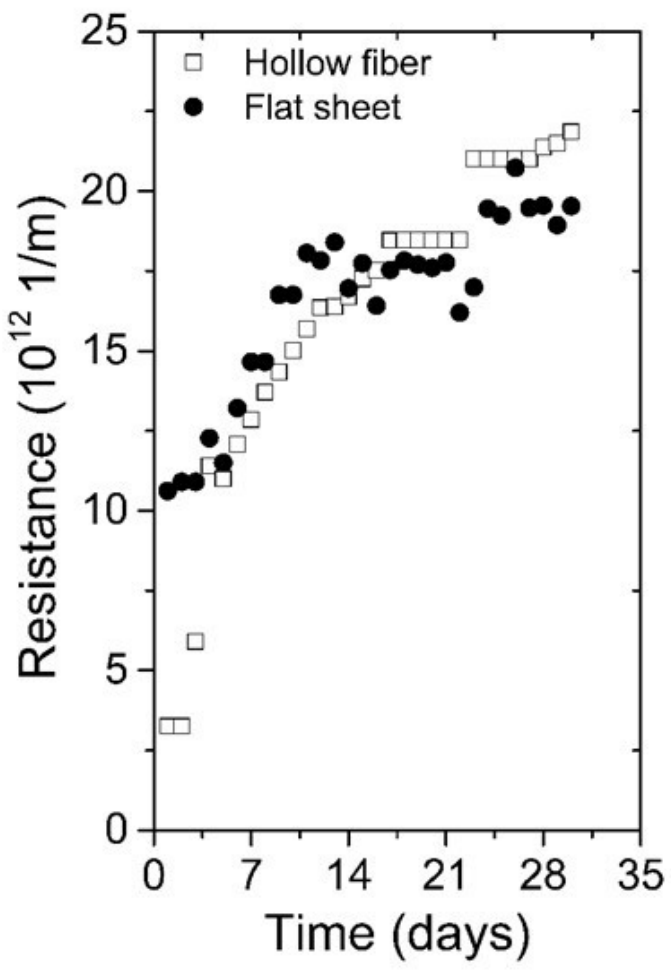

Figure 2.2: Flux data (a) and hydraulic resistance (b) of hollow fiber (O/I) and flat sheet membrane configurations using Potmarge (surface) water as feed for an operational run of 30 days.

steady drop: a $\sim 4$ fold decrease for the hollow fiber configuration and a $\sim 2$ fold decrease for the flat sheet configuration. Over longer durations the rate of flux change gradually declines, eventually achieving a constant flux level indicated by the plateau region extending until the end of the experimental run (Figure 2.2). As expected, the hydraulic resistance values display exactly opposite trends with respect to the flux variation. Interestingly, quantitative comparison between the hydraulic resistance values of the flat sheet and hollow fiber during the first 4 days of filtration reveals approx. 5 times higher values in case of the flat sheet configuration. Moreover, the rate of flux decline is considerably higher for the hollow fiber in comparison with the flat sheet membrane. Such deviations are most likely attributed to different flow dynamics and hence fouling mechanisms prevalent in the two configurations.

The time dependent flux variation during membrane filtration can be physically classified into three stages: a) initial foulant adsorption and deposition, b) pore constriction and blockage and c) cake or gel layer formation $[15,20]$. In case of the hollow fiber configuration, it is suggested that the high volumetric permeate flows of around $40 \mathrm{~L} / \mathrm{m}^{2} \cdot \mathrm{hr}$ during 
the first 24 hours accelerates solute transport to the membrane surface. High solute deposition and adsorption rates in turn rapidly clog the membrane pores, leading to a sharp initial decrease in permeate flow rates and a transition into a more gradual decline during intermediate stages. While the sharp decline observed in the beginning is attributed to an internal pore blocking mechanism, the intermediate stage is dominated by deposition and accumulation of foulants. Flow rates continue to decline until the rate of deposition and accumulation of foulants is equilibrated by back diffusion and re-dissolution of foulants [21]. This appears as a plateau in the flux and hydraulic resistance trends (Figure 2.2).

Initial permeate flows in the flat sheet configuration displayed significantly lower values in comparison to the hollow fiber membranes (Figure 2.2a). Contrary to the steep drop observed in the flux values for hollow fiber configuration, the rate of flux decline was much slower and more steady during the flat sheet membrane filtration. More gradual flux decline in the flat sheet configuration suggests fouling development to take place by formation of a cake layer, which thickens over time and restricts the membrane permeability.

The type of fouling mechanisms i.e. pore blocking and/or cake formation in ultrafiltration as also observed in the present study primarily depends upon pore size distribution and pore structure [22], foulant composition and concentration in the feed water [21], operational conditions and membrane material. Since the same feed was fed to both configurations in our study, it is likely that the pore structure of the membranes determines the mode of fouling. In this respect, the hollow fiber membranes starting at a higher initial flux are assumed to comprise of larger and more open pores that suffer from severe pore blocking within the first week of operation. On the other hand, the flat sheet configuration displaying lower initial fluxes and a steady decrease in flow rates tend to foul by formation of a cake layer.

Depending upon the type of feed and the MWCO of membranes used, the composition of the cake layer can be either dominated by inorganics or natural organic matter (NOM) molecules $[7,23,24]$. In this study, one of the major components of fouling layer based on retained fractions of NOM are biopolymers, and to some extent humic acids, as these were the only measurable dissolved organic carbon (DOC) fractions (as calculated from the difference in feed and permeate concentrations). Figure 2.3 shows the overall retention of biopolymers and humic acids after 30 days of filtration for both hollow fiber and flat sheet membranes. Macromolecules, such as biopolymers, are known to cause severe fouling during low pressure ultrafiltration [25-28]. In the present study, we used open and low pressure ultrafiltration membranes, hence it was observed that the cake layer comprised of mainly biopolymers and a small fraction of humic acids. Besides NOM fractions, feed and permeate analysis of inorganic carbon and ions ( $\mathrm{Si}, \mathrm{Ca}, \mathrm{Na}, \mathrm{Mg}, \mathrm{K}, \mathrm{Fe}, \mathrm{P}$ ) showed negligible retention of inorganics on the membrane surface. To conclude, both hollow fiber and flat sheet membranes suffered from mainly NOM fouling, specifically biopolymers. 


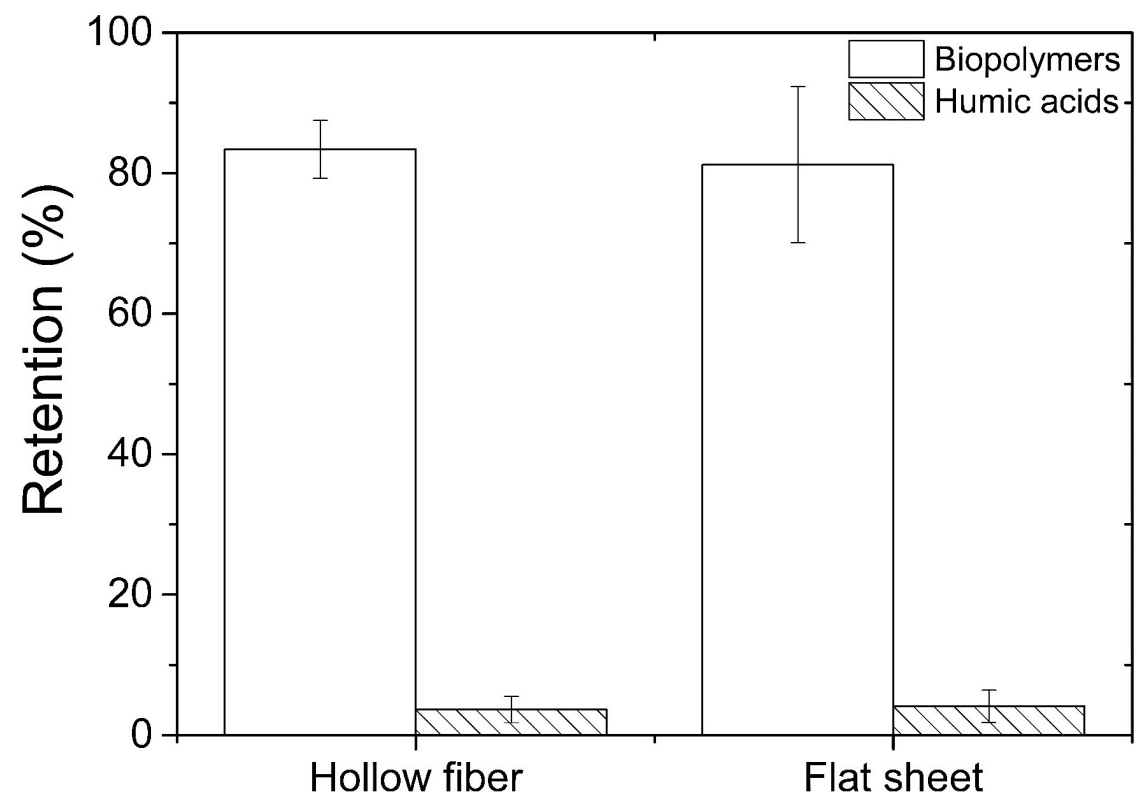

Figure 2.3: Biopolymer retention and humic acids retention for hollow fiber and flat sheet membrane filtration after an experimental run of 30 days using Potmarge surface water as feed.

\subsubsection{Operational modes and discontinuous operation}

The influence of mode of operation on fouling development was investigated by operating the systems intermittently vis-à-vis continuously. Four different modes were investigated, as summarized in Table 2.2. All three intermittent systems were turned on/off exactly at the same time every day using automatic timers and magnetic valves (described in section 2.2.1). Two different operational modes were employed for all intermittent operations: $\mathrm{O} / \mathrm{I}$ and I/O mode. Figure 2.4 graphically represents the hydraulic resistances at the end of the run for each operational mode. The corresponding fluxes for two different operational modes with their respective operational time intervals (in hours, given in brackets) are as follows a) for $\mathrm{O} / \mathrm{I}$ mode 1) $3.6 \mathrm{~L} / \mathrm{m}^{2} \cdot \mathrm{hr}$ (4 on $/ 20$ off) 2) $2.7 \mathrm{~L} / \mathrm{m}^{2} \cdot \mathrm{hr}(2 \mathrm{on} / 5 \mathrm{off} / 2 \mathrm{on} / 15 \mathrm{off}$ ) 3) $2.5 \mathrm{~L} / \mathrm{m}^{2} \cdot \mathrm{hr}(9 \mathrm{on} / 15 \mathrm{off})$ 4) $1.6 \mathrm{~L} / \mathrm{m}^{2} \cdot \mathrm{hr}(24 \mathrm{on} / 0$ off $) \mathrm{b}$ ) for I/O mode 1) $20.2 \mathrm{~L} / \mathrm{m}^{2} \cdot \mathrm{hr}$ (4 on $/ 20$ off) 2) $22.7 \mathrm{~L} / \mathrm{m}^{2} \cdot \mathrm{hr}\left(2 \mathrm{on} / 5 \mathrm{off} / 2 \mathrm{on} / 15 \mathrm{off}\right.$ ) 3 ) $13.6 \mathrm{~L} / \mathrm{m}^{2} \cdot \mathrm{hr}$ (9 on $/ 15 \mathrm{off}$ ) 4 ) 2.8 $\mathrm{L} / \mathrm{m}^{2} \cdot \mathrm{hr}(24 \mathrm{on} / 0$ off $)$. The trends evince a significant lower hydraulic resistances when membranes are operated intermittently in contrast to the continuous mode. Furthermore, the $\mathrm{O} / \mathrm{I}$ mode results in overall higher hydraulic resistance than the I/O mode.

The accumulated DOC on the membrane surface for intermittently and continuously operated membrane systems is shown in Figure 2.5. An important factor for intermittent operations is the lower foulant load delivered per unit membrane area due to discontinuous use of the system (Figure 2.5) and lower permeate production capacity than a continuous system. It is observed that although an intermittent system has $1 / 6^{\text {th }}$ of permeate produc- 

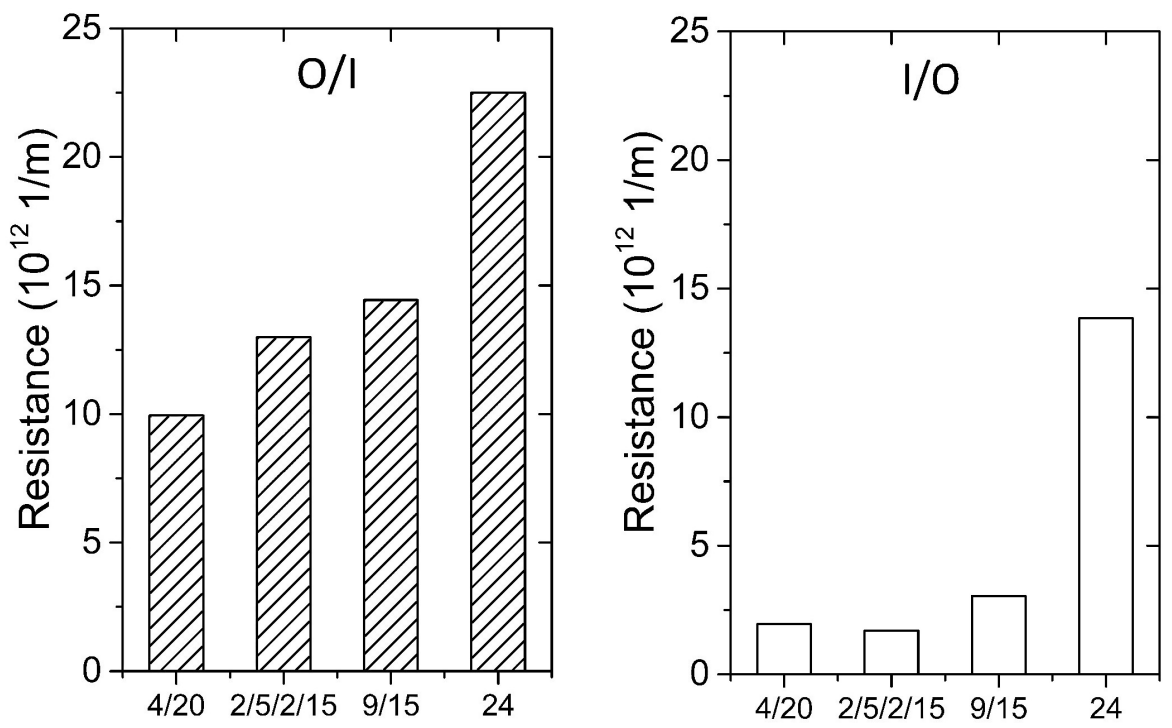

Figure 2.4: Hydraulic resistances at the end of the experimental runs (26 days) for outside/in (O/I) (left) and inside/out (I/O) (right) operational modes at 4 different operational conditions a) $4 \mathrm{hrs}$ on $/ 20 \mathrm{hrs}$ off b) $2 \mathrm{hrs}$ on $/ 5 \mathrm{hrs}$ off $/ 2 \mathrm{hrs}$ on $/ 15 \mathrm{hrs}$ off c) $9 \mathrm{hrs}$ on $/ 15$ hrs off d) 24 hrs on. In all cases, Potmarge surface water was used as feed.

tion compared to a continuous system, the accumulated DOC for intermittent system is half of the continuous system. Hence, a significant portion of the fouling is not permeation related. The effects of intermittent operation on drinking water production are reported in literature for slow sand filtration [19, 29] and membrane filtration based PoU systems [3]. A secondary effect of intermittent operation is the relaxation of the fouling layer during standstill periods. It has been shown that absence of permeate flow for a defined time interval leads to relaxation of the fouling layer deposited on the membrane surface [30-32]. Hong et al. [33] showed that relaxation of the fouling layer can lead to $100 \%$ flux recovery in a membrane bioreactor. During such standstill periods when the fouling layer relaxes, it is assumed that reversibly bound particles diffuse away from the membrane surface to the bulk fluid [33]. This further leads to a lower hydraulic resistance of the accumulated fouling layer and correspondingly higher fluxes.

Comparing the inside/out (I/O) with outside/in (O/I) operational mode, we observe that the hydraulic resistances of I/O systems are much lower than those of O/I systems. Figure 2.4 also shows that intermittently operated O/I systems $(4 / 20,2 / 5 / 2 / 15$, and 9/15 in Figure 2.4) show similar hydraulic resistances as observed for the continuously operated $\mathrm{I} / \mathrm{O}$ system (24). It is important to stress that the same I/O membranes were used in both I/O as well as in the O/I modes and the same membrane area was assumed for both. Membrane permeability is dependent upon the internal pore structure of the membranes, which in this case is asymmetric with the larger pores being on the outside and the separation layer on the inside. As the location of the fouling layer is not known, this may affect the effective membrane area as well. Initial permeation rates are crucial in determining the 

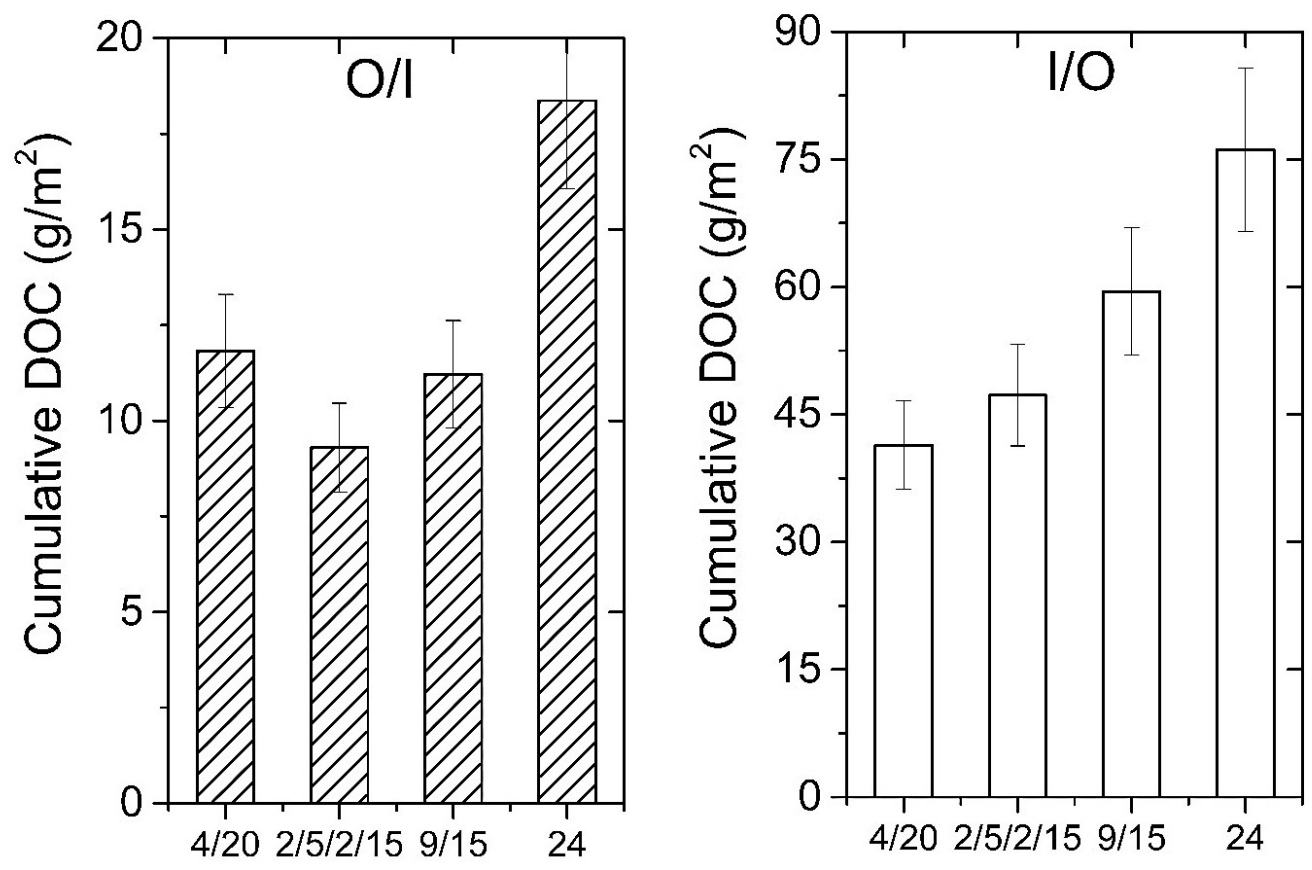

Figure 2.5: Cumulative DOC (Dissolved Organic Carbon) at the end of the experimental runs (26 days) for outside/in (O/I) and inside/out (I/O) operational modes at 4 different operational conditions a) $4 \mathrm{hrs}$ on $/ 20 \mathrm{hrs}$ off b) $2 \mathrm{hrs}$ on $/ 5 \mathrm{hrs}$ off $/ 2 \mathrm{hrs}$ on $/ 15 \mathrm{hrs}$ off c) 9 hrs on/15 hrs off d) 24 hrs on. In all cases, Potmarge surface water was used as feed.

extent and type of fouling mechanism occurring at the beginning of the filtration process, which plays a critical role in defining the severity of flux decline [32]. Pore blocking/constriction occurs due to accumulation of foulants within the internal structure of membrane whereas cake layer forms on the membrane surface. During O/I operation pore blocking/constriction is assumed to be the first fouling mechanism to evolve. Cake layer formation leads to severe flux decline and fouling on the membrane surface during I/O operation, as illustrated in Figure 2.6. Varying fouling mechanisms such as pore constriction followed by severe pore blocking and cake layer formation in the $\mathrm{O} / \mathrm{I}$ operational mode lead to larger hydraulic resistances compared to I/O operated membrane modules. Figure 2.6c and Figure 2.6d show the cake layer formation on the I/O inside membrane surface whereas extensive pore blocking/constriction is observed in Figure 2.6e and Figure 2.6f for the O/I outside membrane surface. Similar findings are reported in literature [6], wherein it was observed that pore blocking leads to higher flux decline compared to cake layer formation. Additionally, physical cleaning was found to be more effective for recovering fluxes when the membranes were fouled by cake layer formation compared to internal pore blocking [6].

Figure 2.7 shows the accumulated ATP and TOC amounts on the membrane surface for two different operational modes $(\mathrm{O} / \mathrm{I}$ and $\mathrm{I} / \mathrm{O})$. Generally, the $\mathrm{O} / \mathrm{I}$ mode revealed a higher amount of ATP on their surfaces $\left(50-80 \mu \mathrm{g} / \mathrm{m}^{2}\right)$ compared to the I/O systems (10-30 


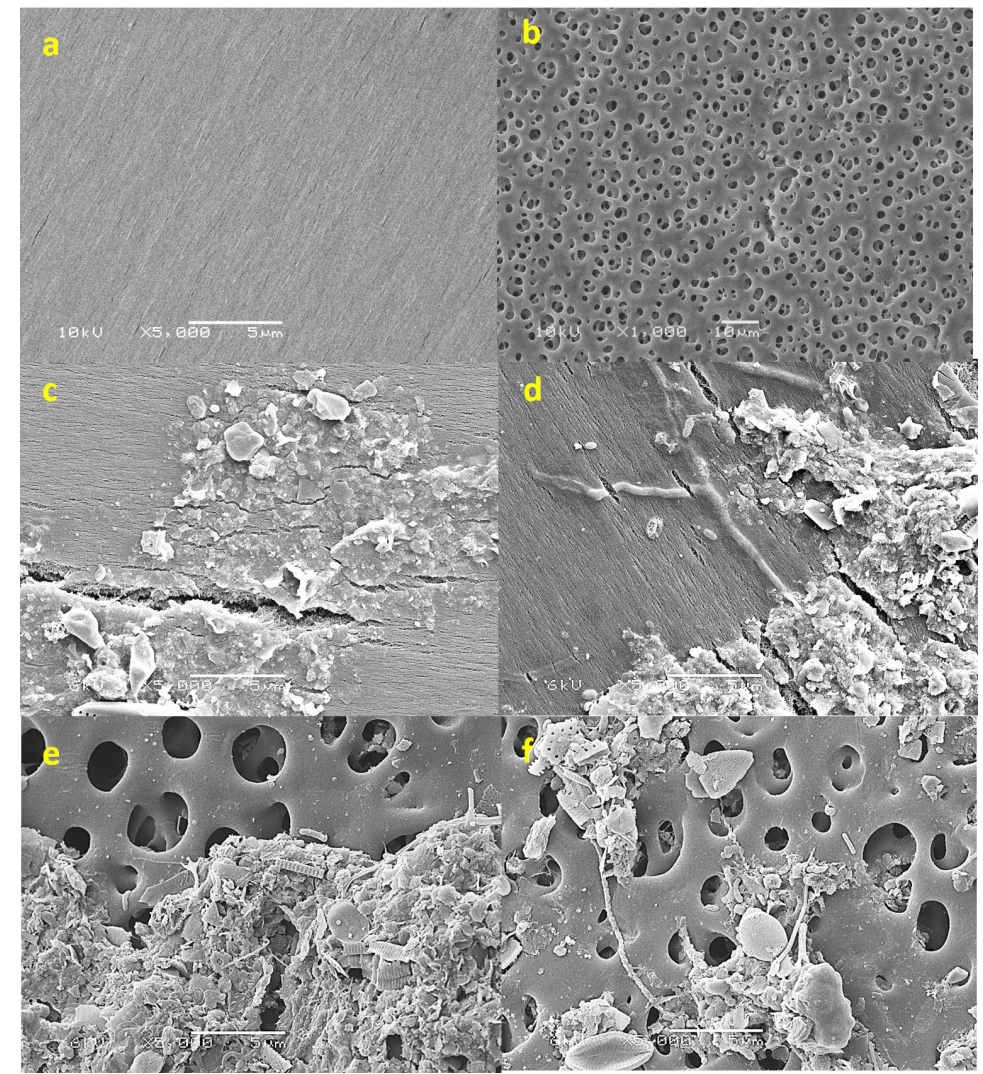

Figure 2.6: SEM images of (a) clean hollow fiber membrane surface, inside at 5000x, (b) outside at $1000 \mathrm{x},(\mathrm{c}, \mathrm{d})$ inside of a fouled inside/out (I/O) operated hollow fiber membrane at $5000 \mathrm{x}$, and $(\mathrm{e}, \mathrm{f})$ the outside of a fouled outside/in $(\mathrm{O} / \mathrm{I})$ operated hollow fiber membrane at 5000x.

$\mu \mathrm{g} / \mathrm{m}^{2}$ ). A suggestive explanation for higher ATP in the case of $\mathrm{O} / \mathrm{I}$ operation could be the presence of bigger pores on the outer surface that can potentially allow small bacteria and living organisms to access the internal membrane structure, thereby contributing to higher ATP accumulation. In contrast, the I/O operational mode retains most of the living biomass on the surface itself. In contrast, TOC for the I/O mode was always higher than that for the $\mathrm{O} / \mathrm{I}$ mode, as shown in Figure 2.7. In the I/O mode the foulants remain confined inside the lumen of the hollow fiber membrane. On the other hand, the O/I mode has a stagnant volume around the fibers that keeps the foulants in suspension [34]. Hence, less organic matter is deposited on the membrane surface in the $\mathrm{O} / \mathrm{I}$ modes resulting in a lower TOC amount accumulated per unit membrane area.

\subsubsection{Cross-flow effects}

Cross-flow or recirculation of feed over the membrane surface was introduced in order to understand its role on fouling. Membrane modules in $\mathrm{O} / \mathrm{I}$ operational mode were simultan- 

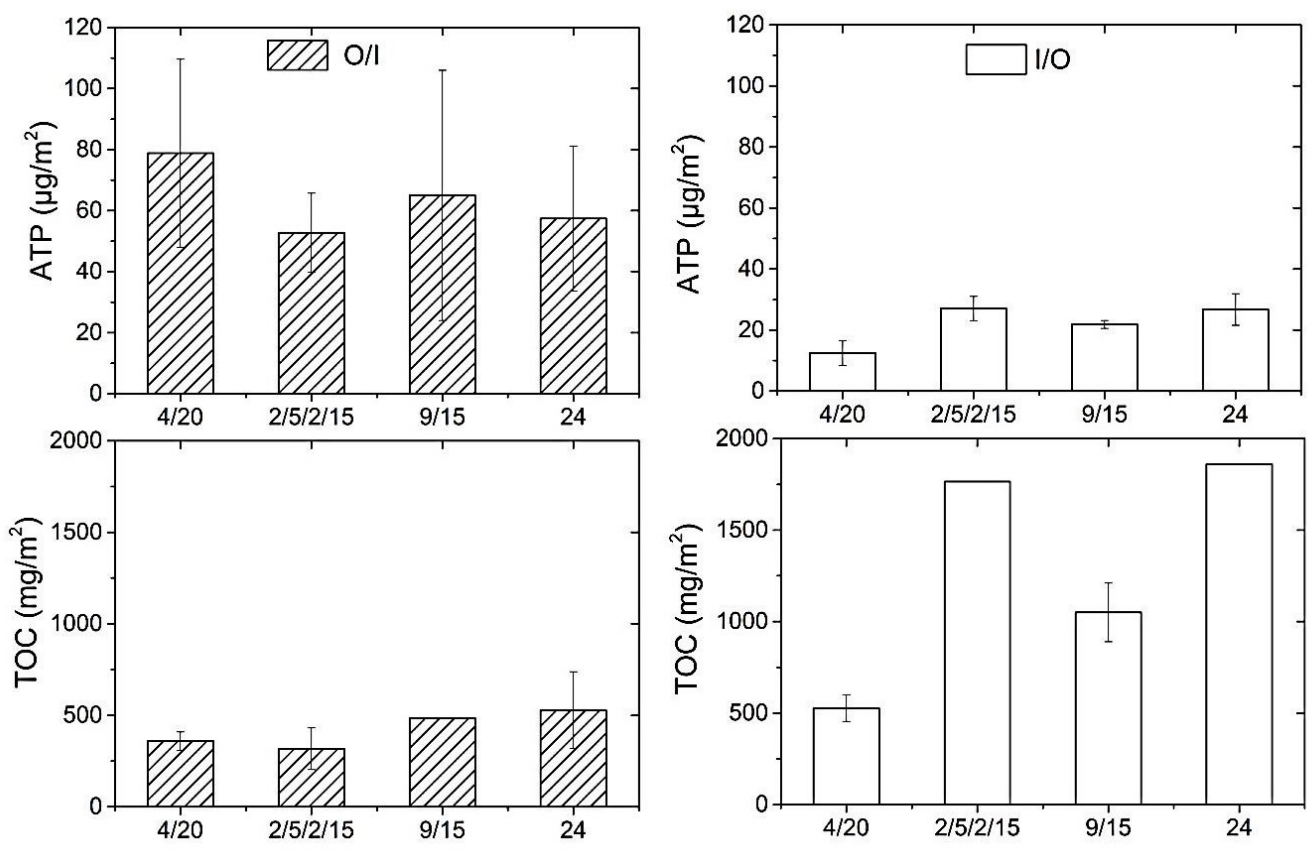

Figure 2.7: ATP and TOC values at the end of the experimental runs (26 days) for outside/in (O/I) and inside/out (I/O) operational modes at 4 different operational conditions a) $4 \mathrm{hrs}$ on $/ 20 \mathrm{hrs}$ off b) $2 \mathrm{hrs}$ on $/ 5 \mathrm{hrs}$ off $/ 2 \mathrm{hrs}$ on $/ 15 \mathrm{hrs}$ off c) $9 \mathrm{hrs}$ on $/ 15 \mathrm{hrs} \mathrm{off} \mathrm{d}) 24$ hrs on. Potmarge surface water was used as feed.

eously operated in four different modes: 1) a continuous dead-end operation as reference for $24 \mathrm{hrs} /$ day; 2) an intermittent system, operated intermittently in dead end mode for $9 \mathrm{hrs} /$ day followed by $15 \mathrm{hrs}$ off/day (no feed supply); 3) a continuous+cross flow system with recirculation of the feed operated continuously $24 \mathrm{hrs} /$ day, and 4) intermittent+cross flow with recirculation of the feed and operated intermittently for 9 hrs/day followed by $15 \mathrm{hrs} /$ day without feed supply.

For all operational modes, a sharp decline in flux was observed, similar to the trends shown in section 2.3.1. The final stabilized permeate fluxes were around $2 \pm 1 \mathrm{~L} / \mathrm{m}^{2} \cdot \mathrm{hr}$ under all experimental conditions. Figure 2.8 shows the hydraulic resistances as a function of the cumulative permeate production volumes for the four different $\mathrm{O} / \mathrm{I}$ operational modes. Initially at a given hydraulic resistance, intermittent modules (intermittent and intermittent+cross flow) reveal a lower production capacity due to shorter operational time periods compared to the continuous systems (continuous and continuous+cross flow). At the end of the 40 days experimental run, continuous systems had produced around 550-600 liters of permeate ending up in slightly higher hydraulic resistances in comparison with intermittent systems that produced 400-450 liters of permeate. Though the amount of water filtered through all the four systems varies, we observe comparable resistances for all systems. Within the accuracy of experiments, no significant differences are observed in 


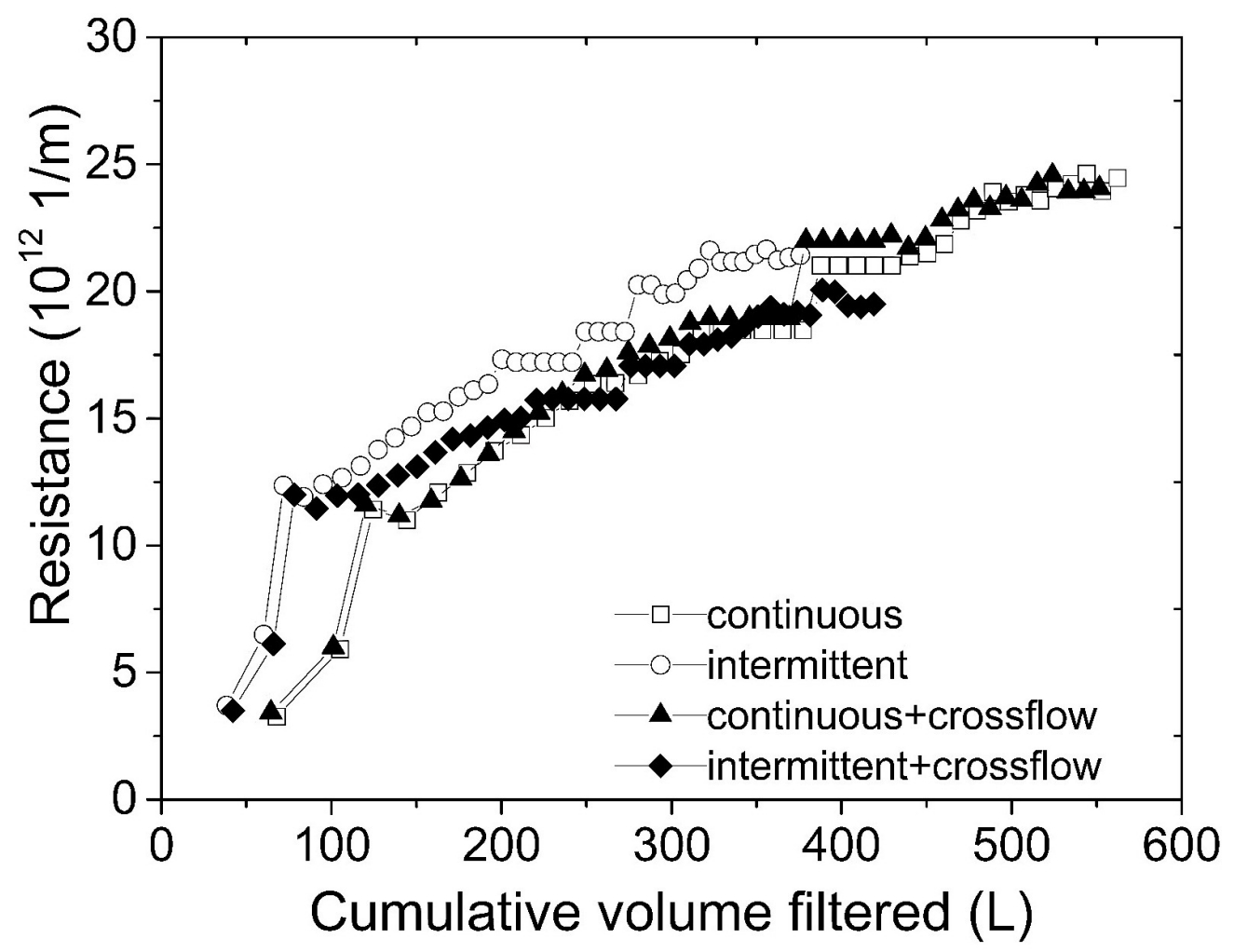

Figure 2.8: Hydraulic resistance versus cumulative permeate volume filtered during 40 days of $\mathrm{O} / \mathrm{I}$ operation under four different conditions: dead end continuous, $24 \mathrm{hrs} \mathrm{ON}$ (continuous); intermittent, 9 hrs ON/15 hrs OFF (intermittent); continuous operation with crossflow with recirculation of feed, $24 \mathrm{hrs}$ ON (continuous+cross flow) and intermittent operation with crossflow with recirculation of feed, $9 \mathrm{hrs}$ ON/15 hrs OFF (intermittent+cross flow), all using Potmarge surface water as feed.

resistance growth and at end of the run, all the four systems approach the stabilization stage (Figure 2.8).

At the end of the experimental run, membranes were autopsied for TOC and ATP analysis. TOC accumulated on the membrane surface in modules without crossflow was $120 \mathrm{mg} / \mathrm{m}^{2}$ for a continuous system and $20 \mathrm{mg} / \mathrm{m}^{2}$ for an intermittent system. On the other hand, TOC accumulated on the membrane surface in modules with cross flow was $70 \mathrm{mg} / \mathrm{m}^{2}$ for the continuous system and $60 \mathrm{mg} / \mathrm{m}^{2}$ for the intermittent system. The continuously operated system showed higher accumulated TOC compared to the intermittent and cross flow systems. Cross flows lead to shear stress on the bacterial biomass. According to literature, shear stresses are known to enhance microbial growth in biological systems [35]. ATP accumulated on the membrane in a module without cross-flow was $7.5 \mu \mathrm{g} / \mathrm{m}^{2}$ for the continuous and $5 \mu \mathrm{g} / \mathrm{m}^{2}$ for the intermittent system without crossflow. ATP accumulated on the membrane surface in the modules with cross-flow was $13 \mu \mathrm{g} / \mathrm{m}^{2}$ for continuous and 
$12 \mu \mathrm{g} / \mathrm{m}^{2}$ for intermittent operation. The data shows that applying a crossflow led to two times higher ATP content accumulated on the membrane surface. However, the higher ATP content (living biomass) is assumed not to have a large influence on the fouling layer as the hydraulic resistances for continuous systems with and without crossflow are similar (Figure 2.8).

\subsection{Conclusions}

In the present study various operational conditions affecting permeate production and fouling development on membranes in a PoU system, such as flat sheets vs hollow fiber membrane configuration, intermittent vs. continuous operation, inside/out vs. outside/in operational modes, and cross-flow pattern were investigated. Additionally, the phenomenon of flux stabilization was extended to hollow fiber membrane filtration based home-made PoU systems. The following key conclusions can be derived from our experiments:

- Pore blocking initiates the fouling in the hollow fiber membranes studied followed by cake layer formation, whereas fouling begins with cake layer for the flat sheet membrane configuration tested. Hence, a sharp flux decline is observed in the former case compared to the latter

- Cake layer formation is the main fouling mechanism for inside/out mode, and pore blocking dominated the outside/in mode operated systems using an asymmetric membrane with the denser (separating) layer on the inside; the fouling layer comprised of mainly biopolymers and humic acids.

- The intermittent inside/out operational mode resulted in lower hydraulic resistances compared to outside/in due to lower foulant load per unit membrane area and relaxation of fouling layer.

Based on these results, either forward or backward flush as a cleaning strategy is recommended as it can greatly enhance the operational time period of a PoU device based on membrane filtration system operated under gravity pressures.

\section{References}

[1] World Health Organization, Results of WHO survey on demand for testing in WHO Scheme to Evaluate Household Water Treatment Technologies, Geneva, Switzerland 2014.

[2] M.J. Pryor, E.P. Jacobs, J.P. Botes, V.L. Pillay, A low pressure ultrafiltration membrane system for potable water supply to developing communities in South Africa, Desalination 119 (1998) 103-111. 
[3] M. Peter-Varbanets, W. Gujer, W. Pronk, Intermittent operation of ultra-low pressure ultrafiltration for decentralized drinking water treatment, Water Research 46 (2012) $3272-3282$.

[4] J.N. Ghogomu, C. Guigui, J.C. Rouch, M.J. Clifton, P. Aptel, Hollow-fibre membrane module design: comparison of different curved geometries with Dean vortices, Journal of Membrane Science 181 (2001) 71-80.

[5] N. Shamsuddin, D.B. Das, V.M. Starov, Filtration of natural organic matter using ultrafiltration membranes for drinking water purposes: Circular cross-flow compared with stirred dead end flow, Chemical Engineering Journal 276 (2015) 331-339.

[6] F.I. Hai, K. Yamamoto, K. Fukushi, Different fouling modes of submerged hollowfiber and flat-sheet membranes induced by high strength wastewater with concurrent biofouling, Desalination 180 (2005) 89-97.

[7] G. Amy, Fundamental understanding of organic matter fouling of membranes, Desalination 231 (2008) 44-51.

[8] R. Bian, K. Yamamoto, Y. Watanabe, Effect of shear rate on controlling the concentration polarization and membrane fouling, Desalination 131 (2000) 225-236.

[9] S. Lee, C.H. Lee, Effect of operating conditions on $\mathrm{CaSO}_{4}$ scale formation mechanism in nanofiltration for water softening, Water Research 34 (2000) 3854-3866.

[10] S. Bhattacharjee, G.M. Johnston, A model of membrane fouling by salt precipitation from multicomponent ionic mixtures in crossflow nanofiltration, Environmental Engineering Science 19 (2002) 399-412.

[11] H. Choi, K. Zhang, D.D. Dionysiou, D.B. Oerther, G.A. Sorial, Influence of crossflow velocity on membrane performance during filtration of biological suspension, Journal of Membrane Science 248 (2005) 189-199.

[12] M. Peter-Varbanets, F. Hammes, M. Vital, W. Pronk, Stabilization of flux during dead-end ultra-low pressure ultrafiltration, Water Research 44 (2010) 3607-3616.

[13] M. Varbanets Peter, Ultra-low pressure ultrafiltration for decentralized drinking water treatment, DISS. ETH NO. 19134 - http://www.eawag.ch/fileadmin/Domain1/Abteil ungen/sandec/publikationen/WST/Peter_2010_Phd_Thesis.pdf, ETH, Zurich 2010.

[14] S. Jabornig, S.M. Podmirseg, A novel fixed fibre biofilm membrane process for onsite greywater reclamation requiring no fouling control, Biotechnology and Bioengineering 112 (2015) 484-493. 
[15] M. Mulder, Basic Principles of Membrane Technology, Second edition ed., Kluwer Academic Publisher, The Netherlands, 1996.

[16] J.C. Crittenden, R.R. Trussell, D.W. Hand, K.J. Howe, G. Tchobanoglous, MWH's Water Treatment: Principles and Design, John Wiley \& Sons2012.

[17] O. Holm-Hansen, The Use of ATP Determinations in Ecological Studies, Bulletins from the Ecological Research Committee (1973) 215-222.

[18] Schäfer, A. Broeckmann, Richards, Renewable Energy Powered Membrane Technology. 1.Development and Characterization of a Photovoltaic Hybrid Membrane System, Environmental Science \& Technology 41 (2007) 998-1003.

[19] S.-S.K. Tiwari, W.-P. Schmidt, J. Darby, Z.G. Kariuki, M.W. Jenkins, Intermittent slow sand filtration for preventing diarrhoea among children in Kenyan households using unimproved water sources: randomized controlled trial, Tropical Medicine \& International Health 14 (2009) 1374-1382.

[20] A.R. Costa, M.N. de Pinho, M. Elimelech, Mechanisms of colloidal natural organic matter fouling in ultrafiltration, Journal of Membrane Science 281 (2006) 716-725.

[21] M. Peter-Varbanets, J. Margot, J. Traber, W. Pronk, Mechanisms of membrane fouling during ultra-low pressure ultrafiltration, Journal of Membrane Science 377 (2011) 42-53.

[22] F. Wang, V.V. Tarabara, Pore blocking mechanisms during early stages of membrane fouling by colloids, Journal of Colloid and Interface Science 328 (2008) 464-469.

[23] Y. Ye, P. Le Clech, V. Chen, A.G. Fane, B. Jefferson, Fouling mechanisms of alginate solutions as model extracellular polymeric substances, Desalination 175 (2005) 7-20.

[24] L. Ji, J. Zhou, Influence of aeration on microbial polymers and membrane fouling in submerged membrane bioreactors, Journal of Membrane Science 276 (2006) 168-177.

[25] W.R. Bowen, F. Jenner, Theoretical descriptions of membrane filtration of colloids and fine particles: An assessment and review, Advances in Colloid and Interface Science 56 (1995) 141-200.

[26] J. Haberkamp, M. Ernst, U. Böckelmann, U. Szewzyk, M. Jekel, Complexity of ultrafiltration membrane fouling caused by macromolecular dissolved organic compounds in secondary effluents, Water Research 42 (2008) 3153-3161. 
[27] M.D. Kennedy, F.P. Muõz Tobar, G. Amy, J.C. Schippers, Transparent exopolymer particle (TEP) fouling of ultrafiltration membrane systems, Desalination and Water Treatment 6 (2009) 169-176.

[28] X. Zheng, M. Ernst, P.M. Huck, M. Jekel, Biopolymer fouling in dead-end ultrafiltration of treated domestic wastewater, Water Research 44 (2010) 5212-5221.

[29] M. Elliott, C. Stauber, F. Koksal, F. DiGiano, M. Sobsey, Reductions of E. coli echovirus type 12 and bacteriophages in an intermittently operated household-scale slow sand filter, Water Research 42 (2008) 2662-2670.

[30] P. van der Marel, A. Zwijnenburg, A. Kemperman, M. Wessling, H. Temmink, W. van der Meer, An improved flux-step method to determine the critical flux and the critical flux for irreversibility in a membrane bioreactor, Journal of Membrane Science 332 (2009) 24-29.

[31] S.P. Hong, T.H. Bae, T.M. Tak, S. Hong, A. Randall, Fouling control in activated sludge submerged hollow fiber membrane bioreactors, Desalination 143 (2002) 219-228.

[32] U. Metzger, P. Le-Clech, R.M. Stuetz, F.H. Frimmel, V. Chen, Characterisation of polymeric fouling in membrane bioreactors and the effect of different filtration modes, Journal of Membrane Science 301 (2007) 180-189.

[33] S. Hong, R.S. Faibish, M. Elimelech, Kinetics of permeate flux decline in crossflow membrane filtration of colloidal suspensions, Journal of Colloid and Interface Science 196 (1997) 267-277.

[34] R.W. Baker, Membrane Technology and Applications, John Wiley \& Sons, Ltd, 2004 .

[35] M. Van Loosdrecht, D. Eikelboom, A. Gjaltema, A. Mulder, L. Tijhuis, J. Heijnen, Biofilm structures, Water Science and Technology 32 (1995) 35-43.

[36] M. Peter-Varbanets, C. Zurbrügg, C. Swartz, W. Pronk, Decentralized systems for potable water and the potential of membrane technology, Water Research 43 (2009) $245-265$.

[37] D.-G. Kim, H. Kang, S. Han, J.-C. Lee, The increase of antifouling properties of ultrafiltration membrane coated by star-shaped polymers, Journal of Materials Chemistry 22 (2012) 8654-8661.

[38] S. Kumar, A. Groth, L. Vlacic, An analytical index for evaluating manufacturing cost and performance of low-pressure hollow fibre membrane systems, Desalination 332 
(2014) 44-51.

[39] J.R. Du, S. Peldszus, P.M. Huck, X. Feng, Modification of poly(vinylidene fluoride) ultrafiltration membranes with poly(vinyl alcohol) for fouling control in drinking water treatment, Water Research 43 (2009) 4559-4568. 


\title{
Chapter 3
}

\section{Influence of nematodes on biofouling in gravity driven membrane filtration}

\begin{abstract}
The current study investigates biofouling and flux behavior during ultrafiltration of secondary wastewater effluent (WWEf) under low transmembrane pressures. The results reveal a periodic reduction in hydraulic resistance during membrane filtration, giving rise to corresponding periodic fluctuations in permeate production rates. The biofouling layer accumulated on the membrane surface consists of biotic as well as abiotic components. Biotic components such as microorganisms, protozoas and metazoas interact with each other within the biofouling layer. It is proposed that the predator-prey relationship between nematodes (metazoas) and the microbial community present in secondary WWEf strongly influences the flux behavior. These findings lead to new research opportunities on utilizing naturally occurring biological interactions for improving the efficiency and robustness of existing membrane based Point-of-Use (PoU) systems operated under low transmembrane pressures.
\end{abstract}

\subsection{Introduction}

Membrane processes, and in particular ultrafiltration, are of considerable importance in Point-of-Use (PoU) systems. It serves as an excellent barrier against most bacteria, viruses and cysts that are difficult to remove otherwise. Unsafe drinking water has reportedly led to 2.2 million deaths/year due to diarrheal diseases [1]. In this regard, it has been reported that implementation of $\mathrm{PoU}$ treatment for the production of drinking water has resulted in a 35\% reduction of diarrheal diseases [2]. Moreover, unavailability of surface water resources in developing countries necessitates wastewater re-use to meet the drinking water needs. Membrane filtration fulfills the eligibility criteria of PoU systems as determined by World Health Organization (WHO) to provide safe and clean drinking water [3]. 
The excellent efficacy of membrane technology to treat various kinds of wastewater has been investigated by many researchers [4-7]. One of the major impediments of membrane technology is membrane biofouling, wherein deposition of biotic foulants occurs on the membrane surface. Such biofouling behavior over longer periods adversely affects membrane productivity. Biologically treated municipal wastewater still comprises of microbes and higher organisms such as protozoas and metazoas. These organisms can potentially become part of the membrane biofouling problem during tertiary treatment. The biofouling layer on a membrane surface in such cases is a combination of complex microbial communities and eukaryotes such as nematodes [8-10].

The microbiological characteristics of the fouling layer depend on symbiotic and pathogenic interactions existing between microbes and eukaryotes [11-12]. Bacteria either serve as a food source (predated by eukaryotes) or can be pathogenic for higher organisms. In certain cases, they can exist symbiotically with eukaryotes [12]. Grazing or predation by protozoas (protista kingdom) and metazoas (animalia kingdom) and their corresponding role in biofouling behavior has been studied by other researchers during the 1970s [13] and more recently $[11,14-16]$. Predation by higher organisms such as metazoas and oligochaetes on either organic particles [17] or bacteria [18] directly influences the structure and composition of a biofilm by making the film more porous and heterogeneous [11, 14-16].

Nematodes as eukaryotic predators are the most abundant metazoans in aquatic sediments and play a significant role in freshwater habitats [15]. Nematodes are multicellular organisms known to be opportunistic predators that can graze on a wide range of food sources such as (i) green algae and cyanobacteria [19], (ii) protozoans [20], (iii) bacteria [21], and (iv) extracellular polymeric substances (EPS) and organic detritus [22]. They have been observed to enhance the metabolism of microcosmic communities in lab scale systems [23]. Abrams and Mitchell found that the enhanced bacterial metabolic rate due to the presence of nematodes resulted in higher organic matter decomposition rates [23].

The effect of nematodes on the biofilm structure has been studied by a few researchers. Riemann and Helmke [24] hypothesized that, although nematodes and protozoas are predators of bacteria, they play different roles in biofilm structure formation related to their (a) size, (b) motility, (c) affinities for food resources, and (d) capability to engineer habitats. Derlon et al. investigated ultrafiltration of surface water in a flat sheet membrane configuration, wherein they showed that the presence of metazoans within the fouling layer enhanced permeate fluxes by altering the structure of the biofilm and making it more porous [14]. Interesting findings on the presence of nematodes and their positive influence on flux increase in flat sheet membrane filtration have been recently reported by Klein et al [16]. They reported that inoculating the membrane surface with nematodes led to a 119-164\% increase in fluxes. Additionally, the biofilm was observed to be highly heterogeneous after 50 days of filtration compared to the control (without nematode inoculation). Another scientific investigation on hollow fiber membrane filtration of grey 
water validated the positive role of nematodes in facilitating the formation of a spongy and porous biofilm layer. An open and porous biofilm with active biological processes led to a reduction in hydraulic resistance. An increase in hydraulic resistance occurred due to continuous deposition of foulants. Gradually, an equilibrium was attained between biological processes occurring within the fouling layer and accumulation of foulants, which lead to flux stabilization [15]. The study showed that at low transmembrane pressures of $0.3 \mathrm{bar}$, the fluxes stabilized at $1-2 \mathrm{~L} / \mathrm{m}^{2} \cdot \mathrm{hr}$ without any need for chemical cleaning or fouling control. In yet another study, the resistances of biofilm layers were shown to be directly affected by the presence and absence of nematode activity within the fouling layer on the membrane surface [16]. The aforementioned studies clearly demonstrate the beneficial effect of nematode predation and its effects on reducing fouling layer resistance and enhancing permeate fluxes. Unfortunately there are no studies available in literature with respect to the influence of nematodes on fouling in hollow fiber membrane filtration for secondary wastewater effluent. A hollow fiber membrane configuration is a preferred choice specifically for PoU applications due to the higher membrane filtration area per unit module volume, which results in a higher production capacity than a flat sheet configuration. Additionally, hollow fibers with their curved geometrical configuration are assumed to result in less fouling accumulation compared to flat sheet membranes during dead end filtration. Lack of available water sources has brought wastewater re-use and reclamation into considerable attention amongst the scientific community and water managements. Hence, wastewater effluent was used as a challenging feed to produce microbiologically safe water using ultrafiltration [25].

The aim of this study is to investigate biofouling in hollow fiber membranes treating municipal secondary wastewater effluent for PoU applications. To this end, in-house hollow fiber based membrane modules were constructed and secondary wastewater effluent from a local municipal treatment plant was used as feed water. Nematodes indigenous to the feed water entered the system along with feed water during the filtration process. The findings in the present work hence addresses the following questions:

- How does the presence of nematodes affect permeate fluxes in two different hollow fiber operational modes, i.e. inside/out and outside/in?

- What is the correlation between the nematode population density and corresponding fluxes, and how are they subject to seasonal variations?

- How does predation by nematodes influence bacterial composition of a fouling layer in hollow fiber membranes?

Finally, we will show that the effects investigated here can be critical in steering the development of more efficient and self-sustainable (without the need for chemical or physical cleaning) hollow fiber membrane based Point-of-Use devices. 


\subsection{Materials and Methods}

\subsubsection{Membrane filtration}

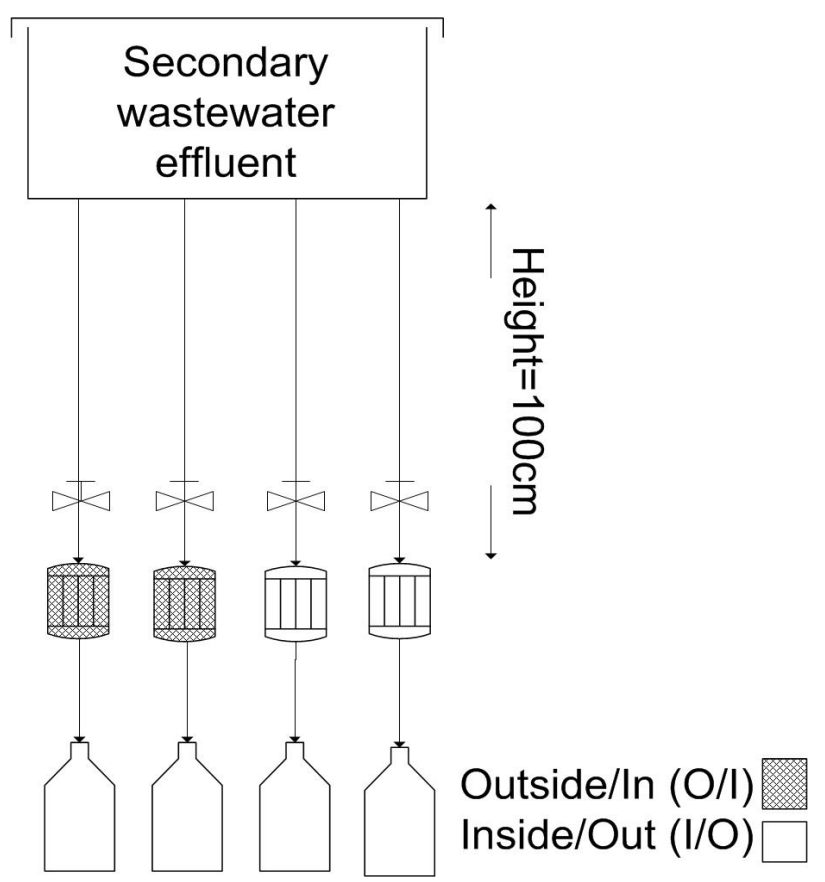

Figure 3.1: Experimental set-up using outside/in (O/I) and inside/out (I/O) hollow fiber membrane modules operated at 0.1 bar gravity pressure for 35 days using secondary wastewater effluent (WWEf) as feed.

The experimental set-up was comprised of 4 different hollow fiber membrane modules: 2 inside/out (I/O) modules, and 2 outside/in (O/I) modules operated at constant pressure in dead end mode as shown in Figure 3.1. The modules were operated at room temperature $\left(20-22^{\circ} \mathrm{C}\right)$ and 0.1 bar transmembrane pressure. Poly(ethersulphone) I/O membranes (molecular weight cut-off $150 \mathrm{kDa}$ ) from Pentair X-Flow (Enschede, The Netherlands) were used for construction of the hollow fiber modules. The procedure for module construction is described elsewhere [26]. Each membrane module contained 5-7 hollow fibers, with a membrane area per module of approximately 160-170 $\mathrm{cm}^{2}$. In order to rule out the effects of membrane material on biofouling layer development, the same membrane was used to construct both I/O and O/I modules. Four experimental runs, each spanning 35 days were performed under the same conditions. In order to account for seasonal variations, measurements were performed as per the following time periods: 1st run conducted from October 2013 - November 2013, $2^{\text {nd }}$ run from January 2014 - February 2014, $3^{\text {rd }}$ run from May 2014 - July 2014, and the $4^{\text {th }}$ run in the period November 2014 - December 2014. Duplicate measurements were performed for each run and the average values are reported. 


\subsubsection{Water source}

Secondary wastewater effluent (WWEf) was collected from the municipal wastewater treatment plant in Leeuwarden (The Netherlands). Analytical parameters i.e. total organic carbon (TOC), chemical oxygen demand (COD), pH, dissolved oxygen (DO) and natural organic matter (NOM) were analyzed using methods described elsewhere [26]. In one of the experiments cycloheximide (Sigma Aldrich, The Netherlands) was used as an inhibitory chemical to inactivate nematodes. It was spiked at $10 \mathrm{ppm}$ final concentration in the feed water. It has been previously used at similar concentrations by other researchers to induce inactivation of eukaryotes [27].

\subsubsection{Membrane autopsy}

At the end of the experimental run, the modules were opened and membranes were autopsied for further analysis. The protocols for SEM and ATP analyses are described in detail elsewhere [26]. Briefly, for SEM analysis membrane samples were fixated with $2.5 \%(\mathrm{v} / \mathrm{v})$ glutaraldehyde overnight at $4^{\circ} \mathrm{C}$ for SEM analysis. Fixated samples were dehydrated next day with increasing concentrations of ethanol (30\% to $100 \% \mathrm{v} / \mathrm{v})$. Finally, the samples were dried overnight in an air chamber at $37^{\circ} \mathrm{C}$. For ATP analysis, membrane samples of a defined length were shaken in $15 \mathrm{~mL}$ of 1x PBS solution (Phosphate Buffered Saline, $10 \mathrm{mM}$ ) at $1500 \mathrm{rpm}$ for 40 minutes. These samples were stored at $-20^{\circ} \mathrm{C}$ until they were analyzed for ATP by the Vitens Laboratory (Leeuwarden, The Netherlands).

\subsubsection{Nematode enumeration}

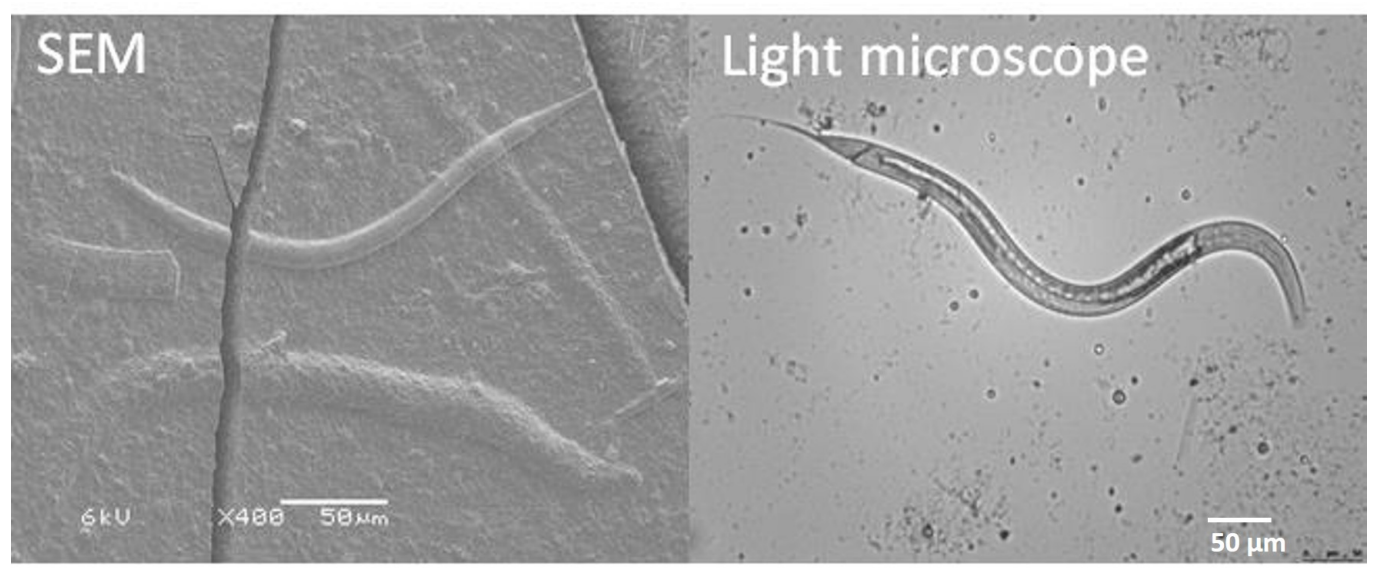

Figure 3.2: Nematodes (eukaryotic organism of interest) as seen under SEM (on left) at 400x and under optical microscope (on right) at 20x. 
Metazoans such as nematodes (Figure 3.2) already were present in the WWEf feed, and accumulated on the membrane surface during the filtration process. The biofouling layer was scraped off from the membrane surface (fiber length $5 \mathrm{~cm}$ ) at the end of the experimental run using a sterile scalpel and re-dissolved in 1x PBS (10 mM) solution in an autoclaved $2 \mathrm{~mL}$ tube. The solution was vortexed before analysis to homogenize the suspended material. A $10 \mu \mathrm{L}$ sample volume was pipetted in each well of a diagnostic slide (Thermo Fischer Scientific, The Netherlands). The nematodes were counted at 100x magnification using an inverted light microscope (Leica, The Netherlands). The counts per well were normalized by the corresponding membrane area from which the biofouling layer was removed.

\subsubsection{DNA extraction and Denaturing Gradient Gel Electro- phoresis (DGGE)}

Bacterial DNA extraction and DGGE analysis were performed to investigate the effects of predation on diversity of bacterial community within the biofouling layer. Similar to the nematode count procedure, the biofouling layer was scraped off from the membrane surface (fiber length $5 \mathrm{~cm}$ ) at the end of the experimental run using a sterile scalpel and re-dissolved in 1x PBS $(10 \mathrm{mM})$ solution. DNA extraction from the scraped biofouling layer was performed using a Power Biofilm DNA isolation kit (MoBio Laboratories, Snabio, The Netherlands) according to the suppliers protocol. Extracted DNA was stored for 1 week at $-20^{\circ} \mathrm{C}$ until analysis. The extracted DNA (16SrDNA) was further amplified by a polymerase chain reaction (PCR) in a thermocycler (Biorad, The Netherlands). The thermocycling parameters were adapted from literature and were as follows: predenaturation at $94^{\circ} \mathrm{C}$ for 5 minutes, followed by 30 cycles of denaturation at $94^{\circ} \mathrm{C}$ for 1 minute, primer annealing at $56^{\circ} \mathrm{C}$ for 40 seconds, and elongation at $72^{\circ} \mathrm{C}$ for 1 minute. The thermocycling post-elongation for denaturing gradient gel electrophoresis (DGGE) was held at $72^{\circ} \mathrm{C}$ for 7 minutes, followed by cooling at $12^{\circ} \mathrm{C}$. Primers used for PCR were 1401r/968f with GC clamp (MWG-Biotech, Ebersberg, Germany). Other chemicals such as PCR buffer, $\mathrm{MgCl}_{2}$ solution, deoxynucleotides and Taq polymerase were purchased from Invitrogen (Breda, The Netherlands) and used as received. Microbial diversity in the biofouling layer was visualized by DGGE. PCR products were checked on $1.5 \%$ agarose gel electrophoresis. Amplicons (PCR products) were run on $8 \%(\mathrm{w} / \mathrm{v}$ ) polyacrylamide (37.5:1 acrylamide/bisacrylamide) gels. The gels contained a linear denaturing gradient of $30-60 \%$, with $100 \%$ denaturant corresponding to $7 \mathrm{M}$ urea and $40 \%$ (v/v) formamide. Electrophoresis was performed at $60^{\circ} \mathrm{C}$ for 16 hours at a constant voltage of $85 \mathrm{~V}$ on a DCode system (Bio-Rad, Hercules, USA) in 0.5x Tris-Acetate-EDTA (TAE) buffer. At the end of the electrophoresis, the gel was taken out and dried overnight at $55^{\circ} \mathrm{C}$ on a glass plate and covered with a gel drying frame (Sigma-Aldrich, Germany). The gel was stained with $0.2 \%$ silver nitrate $(\mathrm{w} / \mathrm{v})$ solution to visualize DNA bands and scanned using a Canon scanner [28]. 


\subsection{Results and discussion}

\subsubsection{Flux behaviour of inside/out vs. outside/in operational mode}

This study compares permeate production in two different operational modes, i.e. inside/out (I/O) vs. outside/in (O/I). The waste water effluent (WWEf) used for the experiments contained $12 \pm 3 \mathrm{mg}$ TOC/L, and $30 \pm 2 \mathrm{mg} \mathrm{COD} / \mathrm{L}$. The first of the four experimental runs compared the $\mathrm{I} / \mathrm{O}$ and $\mathrm{O} / \mathrm{I}$ operational modes. Due to peculiar flux trends observed for the I/O mode, the subsequent three runs were performed in I/O mode only. Figure 3.3 represents the time dependent flux variations for both $\mathrm{I} / \mathrm{O}$ and $\mathrm{O} / \mathrm{I}$ modes. Both operational modes displayed a continuous decay in flux rates during the first 10 days of operation. After the first 10 days, the flux trends with respect to the I/O mode become very different from the $\mathrm{O} / \mathrm{I}$ operational mode. The flux in the $\mathrm{O} / \mathrm{I}$ mode is constant after day 10; the values stabilize to around $2 \mathrm{~L} / \mathrm{m}^{2} \cdot \mathrm{hr}$. Such a behavior is typical for membranes undergoing biofouling, where the growth of a biofouling layer results in an increased hydraulic resistance that finally stabilizes due to establishment of a dynamic equilibrium between the rates of formation and erosion of the biofouling layer [26].

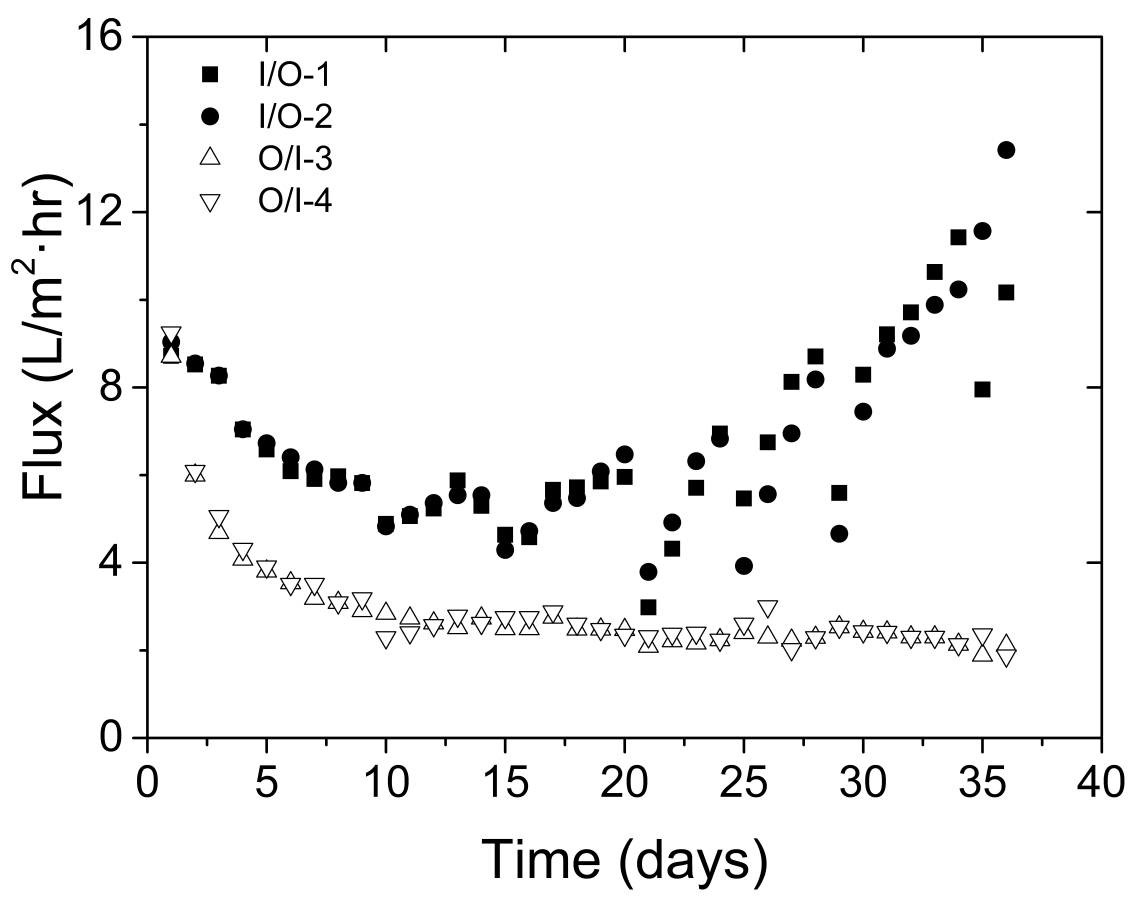

Figure 3.3: Flux data for hollow fiber membrane modules operated for 35 days (July 2014) using wastewater effluent (WWEf) as feed in both inside/out (I/O) and outside/in (O/I) modes. 
In contrast, flux values in the $\mathrm{I} / \mathrm{O}$ mode exhibit a strong and unexpected non-monotonic oscillating behavior for operational times beyond 10 days, with flux values showing unusual spikes over longer operational periods (Figure 3.3). The final fluxes after 35 days are as high as $14 \mathrm{~L} / \mathrm{m}^{2} \cdot \mathrm{hr}$ for the I/O system. Similar flux behaviour has been recently reported in another study [16]. Klein et al. inoculated the surface of flat sheet membranes with metazoas and oligochaetes and it showed that the presence of nematodes lead to an increase in the fluxes to an average of $15 \mathrm{~L} / \mathrm{m}^{2} \cdot \mathrm{hr}$ compared to $6 \mathrm{~L} / \mathrm{m}^{2} \cdot \mathrm{hr}$ for control systems without nematodes [16]. It was concluded by Klein et al. that higher organisms reduce the resistance of biofilms by altering the morphology and composition of bacteria and protists within the biofouling layer [16].

It is hypothesized that all nematodes from the feed water accumulate on the inside of the hollow fiber membrane surface for the I/O operational mode. In case of the O/I operational mode the nematodes can deposit over multiple surfaces i.e. the outer side of the hollow fiber membrane as well as on module casing. This implies that the areal density of nematodes is expected to be considerably higher for the I/O mode.

Due to unique flux trends observed in the I/O systems, further experiments were conducted for the I/O operational mode only. In order to quantify whether the observed tendencies show sufficient experimental reproducibility, an additional three runs at three different time periods were performed for an I/O operated module (Figure 3.4) that indeed indicate that these oscillating phenomena also can be observed in other periods of the year.

\subsubsection{Abundance of nematodes in I/O operational mode}

In order to investigate the factors responsible for the intriguing fluctuations in flux values in the I/O mode, membranes were autopsied at the end of the experimental run (May-June 2014, Run 3 in Figure 3.4). Light microscopy observations of the biofouling layer revealed an abundance of nematodes within the biofouling layer. The nematodes present in the feed water accumulated on the membrane surface over time during filtration. Corresponding to the operation times where a spike in the flux values was observed, ex-situ fouling layer analyses i.e. SEM and light microscopy for nematode counting were additionally performed, as explained in materials and methods section. Figure 3.5 shows the variation in nematode population with respect to the operation times where an increase (encircled in red) in flux rates was observed. The flux measurements and nematode counts are within $5-10 \%$ of measurement error. When flux behavior and nematode counts are compared, it is seen that the nematode population nicely mimics the flux trends (Figure 3.5). In general, higher fluxes corresponded to greater nematode counts except around day 14 which shows a low nematode density. This execption can be explained in terms of a minimal threshold in amount of nutrients required for nematode growth and activity. In the beginning the biofouling layer has less nutrition for nematodes, however as the filtration continues more biomass accumulates on the membrane surface providing sufficient nutrients for nematode growth and thus for an increase in flux. 


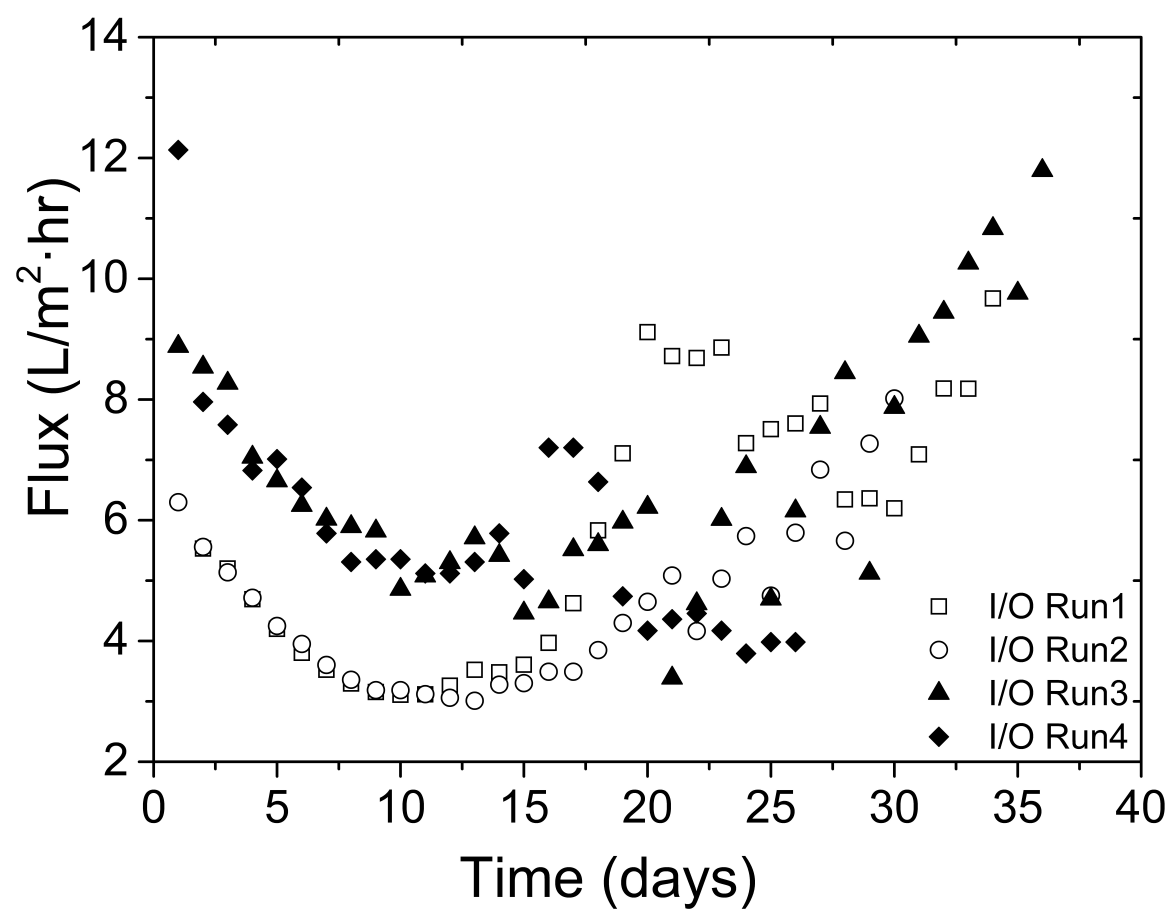

Figure 3.4: Fluxes for four 35 days filtration runs with wastewater effluent (WWEf) for I/O membrane modules during the periods Oct-Nov, 2013 (Run 1), Jan-Feb 2014 (Run 2), May-July 2014 (Run 3), Nov-Dec 2014 (Run 4).

It has been observed before that nematodes influence the structure of the biofouling layer during membrane filtration [15, 29]. Jabornig et al. reported flux stabilization due to a porous, sponge-like structure of the biofouling layer and correlated it to nematode activity in an MBR [15]. Nematodes are directly involved in biological processes such as desegration of biofilms, agglutination and removal of organic compounds that have an influence on the structure of the biofilm layer [15, 30]. However, such unique flux trends with local maxima and minima as seen in the present study have been reported only once in literature so far, and only for flat sheet membranes [29].

It is hypothesized that the observed fluctuations in the flux directly correspond to the growth and death cycle of nematodes inside the biofouling layer. During membrane filtration, it is quite likely that pre-existing juvenile or adult nematodes present in the WWEf feed-water enter the membrane modules and are deposited on the membrane surface. Initially, the nematode population however is still below the critical number required to significantly influence the flux behavior. It is known from literature that certain species of nematodes have a slower reproduction phase and/or higher threshold food (bacteria) requirements to thrive compared to other nematode species [18]. In the present study, there 


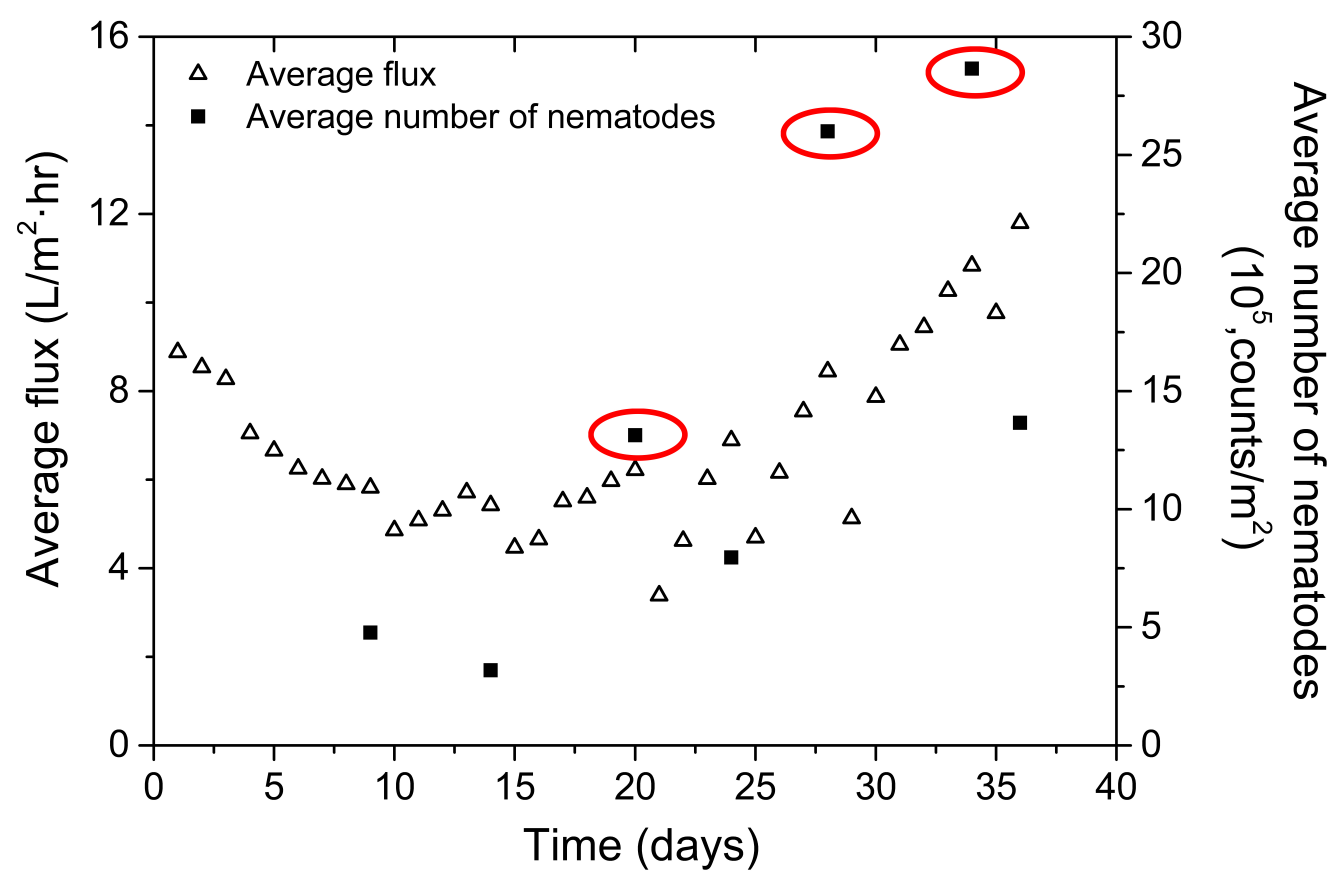

Figure 3.5: Average flux data and nematode density (for Run 3) for hollow fiber membrane modules operated I/O for 36 days using wastewater effluent (WWEf) as feed, red circles show a spike in nematode counts.

were nematodes present originating from the WWEf and we assume that it took around 2-3 weeks for these organisms to show influence on permeate fluxes. Once the nematode population is significant, it influences the structure and permeability of biofouling layer as also reported in literature [16].

Interestingly, over longer operational times (more than 15 days), with larger cumulative volumes of water being filtered through the membranes (around 45 liters), the population of nematodes on the membrane surface increases rapidly. Simultaneously, the availability of a rich and highly nutritious biofouling layer due to accumulation of foulants on the membrane surface makes it ideal for the nematodes to feed upon this conditioned layer. This phenomenon is known as grazing or predation, where the nematodes predate on the available bacterial population in the biofouling layer. The partial removal of the biofouling layer due to grazing of nematodes subsequently leads to a reduced hydraulic resistance of the biofouling layer. Apart from consuming biofoulants, nematodes increase the heterogeneity of the biofouling layer due to their better motility, by which the average surface area and microporosity within the biofouling layer increase. A more porous and open biofouling layer would in turn facilitate higher permeate flow rates.

The effect of sigmoidal movement of nematodes on surrounding environmental condi- 
tions has been investigated by other researchers as well. Abrams et al. reported that the activity of nematodes led to greater diffusion of oxygen within sludge layers, promoting bacterial presence in these layers [23]. Other researchers also showed that the activity of metazoans affect the structure of the biofouling layer on the membrane surface by making it more open and heterogeneous $[11,29]$. In the present study, the observed increase in the flux rates after day 17 is attributed to the aforementioned biological processes of grazing and motility of nematodes. Nematodes, being biological species, would display a definite life cycle i.e. they will grow and evolve over time. The consistent increase in the flow rates from day 17 onwards is hence hypothesized to be due to a simultaneous increase in the number of nematode colonies and their biological activity. On day 25, a sudden drop in both fluxes and nematode population is observed (Figure 3.5). With a consistent rise in nematode colonies, after a certain time period the amount of accessible nutrients in the biofouling layer may not be sufficient to sustain the overgrown population of nematodes. The exhaustion of food supply would lead to under-nourished nematodes becoming extinct or metabolically dormant, hence resulting in a waning nematode population. The correlation between nematode population and available nutrients or bacterial abundance has been clearly demonstrated in literature. Gaudes et al. investigated the stimulating effects of nutrients such as nitrogen $(\mathrm{N})$, phosphorous $(\mathrm{P})$, carbon $(\mathrm{C})$ and bacterial density on bacterivorous nematode populations [18]. Strong correlations between a nutrient enriched environment and bacterial density as well as between bacterial and nematodes populations were reported in the aforementioned study [18]. Sediments enriched with N and P lead to higher bacterial growth, which in turn increased nematode density in the microcosms studied [18].

Besides their abundance, the physiological state of nematodes is equally important for an active biological interaction. Rhabditidae, a family of freshwater and soil nematodes, quickly respond to malnourished or crowded environments by being metabolically dormant and forming dauer larvae [30]. Physiological parameters such as specific growth, feeding and respiration rates of nematodes typically depend upon their species, medium, temperature and available food source [31]. The secondary waste-water effluent feed water in the present study would typically comprise of much lower bacterial population and organic matter in comparison to sewage sludge or enriched environments. Hence, the replenishment rates of the biofouling layer would be limited as opposed to the constantly increasing grazing capacity of the growing nematodes. Such a scenario would further promote nematode decay within the biofouling layer. Depletion of nematodes in turn disturbs the equilibrium established between grazing and biofouling rates, such that the biofouling layer once again starts to develop on the membrane surface due to a reduced predator population. Increased biofouling then results in higher hydraulic resistance and hence the observed decrease in fluxes.

For even longer operational times (beyond 25 days), nematodes originating from the feed water as well as dormant ones begin to repopulate as the nutritional content in the biofouling layer is replenished over time, marking a transition from low to high flux rates 
until equilibrium is achieved once again. The simultaneous increase in flux levels and nematode population during the end stages of operation, i.e. from days 30 to 36 (Figure 3.5), can be attributed to the nematode abundance inside the biofouling layer. Hence, the present findings show a strong influence of predator-prey dynamics on biofouling layer resistance and thus the permeate production during membrane filtration.

\subsubsection{Inhibition of nematode activity using cycloheximide (CHX)}

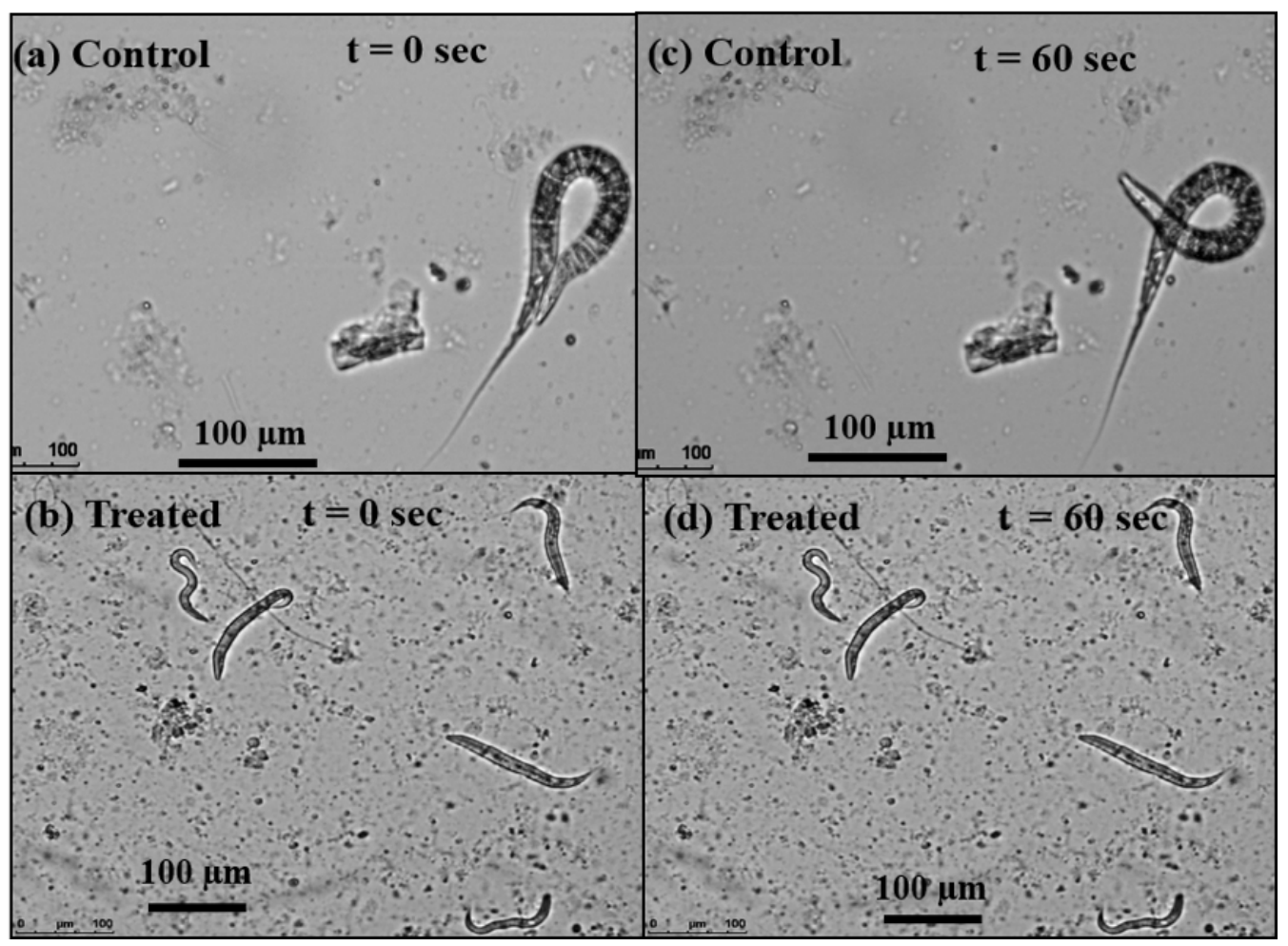

Figure 3.6: Active (control) in (a), (c) and dead (treated) nematodes in (b), (d) as seen under a light microscope at 100x magnification for two consecutive time periods (60 seconds) from the samples collected at the end of the experimental run.

\section{Flux behavior in the presence or absence of active nematodes:}

In order to gain further understanding of the influence of nematodes on membrane permeability during I/O membrane filtration and to confirm the previously stated hypotheses, additional experiments were performed. Cycloheximide (CHX) was added to the feed water as it hinders protein synthesis in higher organisms, whereby it makes eukaryotic species such as nematodes metabolically inactive. The inactive or dead nematodes neither graze on bacteria nor show any physical mobility [30]. Hence, it can be assumed that in absence of biological interactions between bacteria and nematodes, the biofouling layer would be more compact and dense $[11,16,32]$. In turn this would lead to a conventional flux decline 
without local maxima. Membranes were autopsied at the end of the experimental run and the biofouling layer was observed using light microscopy to characterize dead and active nematodes in control and treated systems. Active nematodes could be easily distinguished from dead ones by the observed changes in their spatial configuration over short time periods, indicating their motility. Dead nematodes lack motion. Figure 3.6 represents light microscopy snapshots of the control (without CHX addition) system to the feed water (a, c) and a treated (with CHX addition) system (b, d), acquired over a time period of 60 seconds. Nematodes exhibit motion by means of folding (Figure 3.6c) and unfolding (Figure 3.6a) movements and thus show in that way their activity. Inactive (dead) nematodes could be easily distinguished from the active ones by being immobile after 60 seconds, which can be seen when comparing Figure 3.6b with Figure 3.6d. In Figure 3.7, the flux trends corresponding to the base case without CHX addition to the feed are indicated as control, and membrane modules fed with WWEf treated with CHX are shown as treated. The trends reveal that the addition of CHX adversely affects permeate production. The flux levels showed a relative reduction greater than $50 \%$ when secondary wastewater treated with CHX was fed to the system. In addition, no flux fluctuations were observed for the treated system.

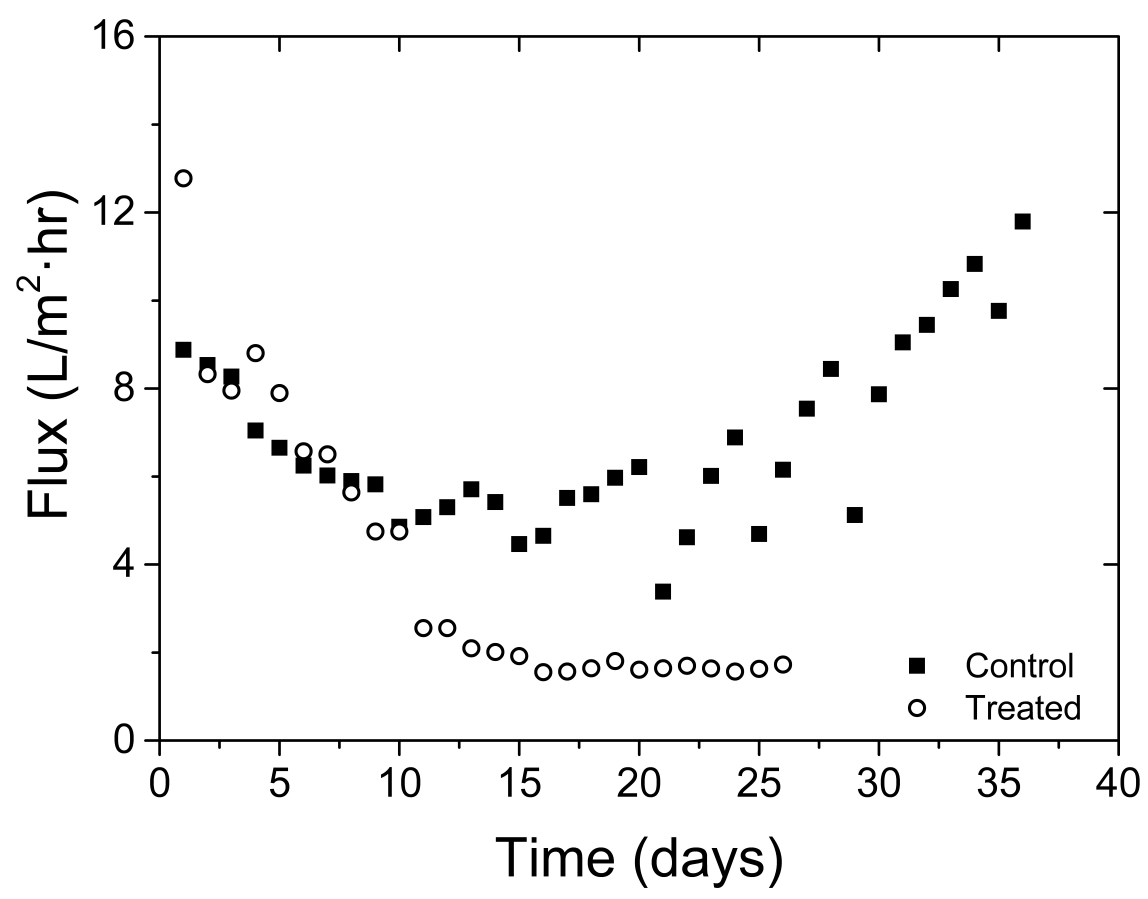

Figure 3.7: Comparison of flux behavior between I/O systems fed with waste water and with waste water with added CHX (growth inhibitor). Control refers to the system without cycloheximide (CHX) addition (July 2014) and treated refers to the system with addition of cycloheximide (CHX) to the feed water (December 2014). 
The results in Figures 3.6 and 3.7 explain the role of nematode activity on the nonmonotonic characteristic of flux trends (Figure 3.3). It is suggested that deactivated nematodes in the treated system act as organic debris contributing to the biofouling layer, thereby promoting biofouling and subsequently increasing the total hydraulic resistance. Hence, depending on the vitality of nematodes, they are able to either hinder (due to predation by active ones) or promote biofouling on the membrane surface.

\subsubsection{Impact of nematodes on bacterial community dynamics in the biofouling layer}

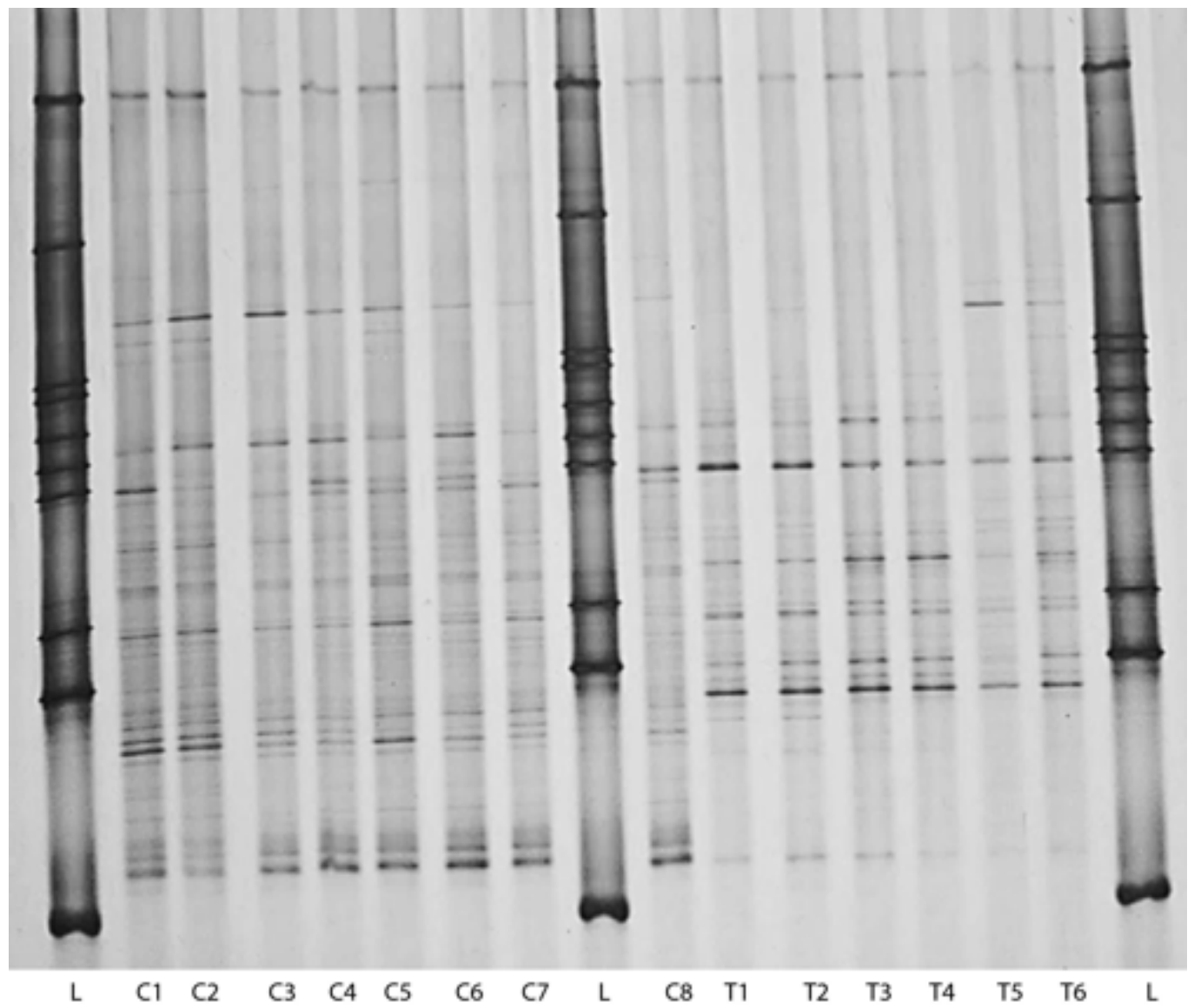

Figure 3.8: Denaturing Gradient Gel Electrophoresis (DGGE) displaying the molecular diversity based in control (lanes C1-C8) and treated (lanes T1-T6) systems. L stands for ladder lane. Control refers to the system without addition of cycloheximide (CHX) and treated refers to the system with addition of $\mathrm{CHX}$ to the feed water.

Figure 3.8 shows the Denaturing Gradient Gel Electrophoresis (DGGE) analysis of the biofouling layers of the treated and control systems during I/O operation. The bands ap- 
pearing on the DGGE indicate diversity of bacterial colonies (Figure 3.8). Lanes C1 to C8 represents the molecular diversity for the control experiment (without CHX), where the adjacent lanes denote replicate measurements (e.g. C1 and C2 are replicates of each other, as are C3 and C4 etc.). The CHX treated system is represented by lanes T1 to T6, where T1 and T2 are replicates of each other, similarly are T3-T4 and T5-T6. Lane ' $\mathrm{L}$ ' is a ladder that is used as a marker to compare two different gel runs at two different time periods. Absence of some bands in the control system, i.e. the system with active nematodes, indicate that certain bacterial colonies are not able to grow due to predation by the nematodes. However, the number density of bands corresponding to C1-C8 (control, with living nematodes) are higher than those witnessed for T1-T6 (treated, with inactive nematodes), suggesting a greater molecular diversity present during operation under control (no CHX) conditions. The result implies that active predation leads to a higher molecular diversity in the biofouling layer.

It has been shown in literature that predation affects the bacterial composition of a medium $[33,34]$. Such alteration is strongly supported by the results of the present study as well. Additionally, nematodes predate selectively upon bacterial population, resulting in a twofold effect, wherein new bacterial colonies are able to evolve at expense of those that fall prey. Such selective predation is primarily attributed to the growth rate of certain bacterial species, such that those with growth rates smaller than the grazing rate of nematodes tend to perish. On the other hand, certain bacterial colonies are able to adapt to the conditions and tend to proliferate in the presence of nematodes. This is very likely due to the fact that the predation process acts as a stress stimuli, triggering more rapid growth of these species. The process is quite similar to the Darwinians evolutionary theory describing natural selection to be essentially based upon the survival of the fittest. The higher microbial diversity is due to appearance of newer bacterial species that are able to cope better with the external environmental factors such as predation [35-38].

\subsubsection{Influence of seasonal variations on nematodes and corres- pondingly permeate fluxes}

To investigate fluctuations of nematode activity due to seasonal variations and its influence on flux behavior, the July 2014 experiment was duplicated in December 2014. Four membrane modules were operated in parallel under same operational conditions in $\mathrm{I} / \mathrm{O}$ operational mode. Out of the four parallel systems, only one (I/O-3) of them could reproduce the fluctuating flux trend observed before in the period February-July 2014. Fluxes measured for all four systems are shown in Figure 3.9, the measured values were within $5-10 \%$ of measurement error. Membrane autopsy after the flux experiments ended showed that 'I/O-3' (Figure 3.9, open triangles) produced a two times higher nematode population $\left(2.2 \times 10^{6}\right.$ counts $\left./ \mathrm{m}^{2}\right)$ as compared to the counts observed for the other three parallel systems, i.e. $5.6 \times 10^{5}, 7.7 \times 10^{5}$, and $2.8 \times 10^{5}$ counts $/ \mathrm{m}^{2}$. The nematode count for these three 


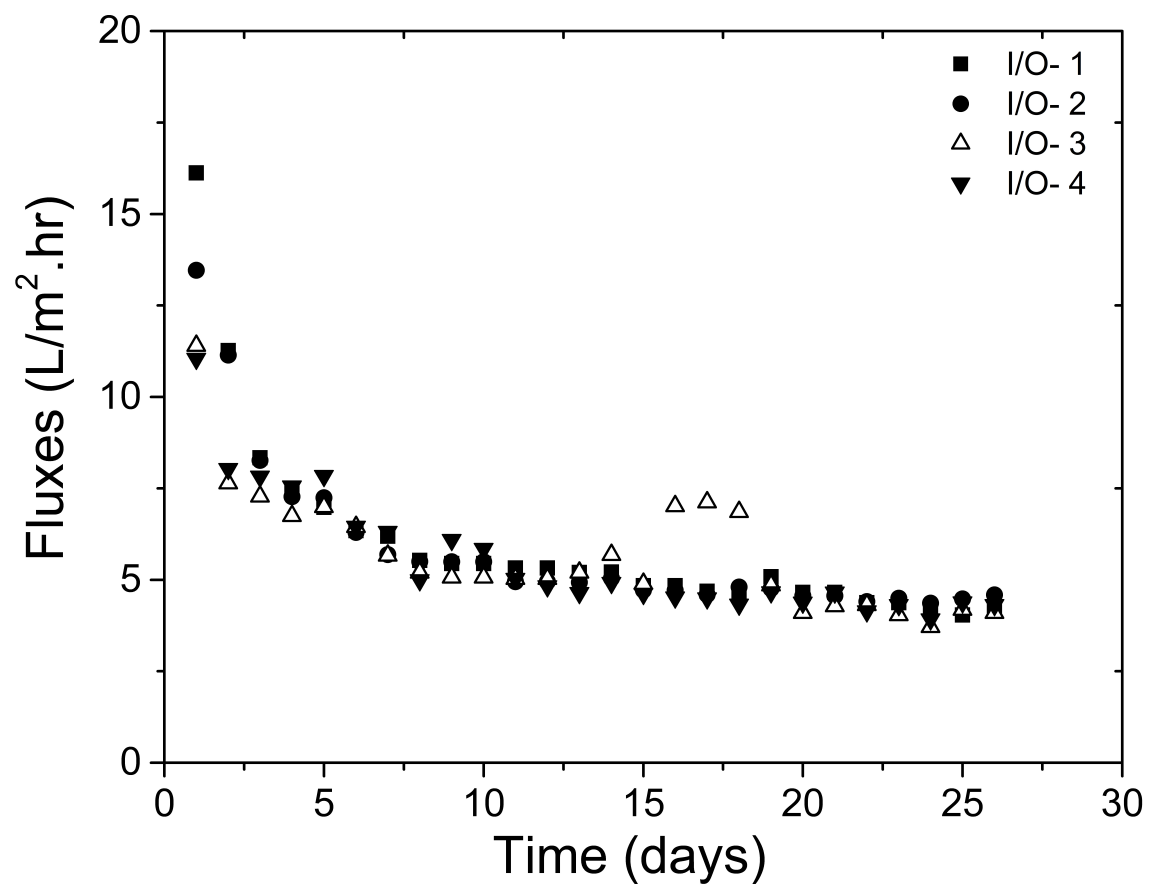

Figure 3.9: Variations in fluxes in 4 systems operated in parallel in I/O operational mode with secondary wastewater effluent as feed water under identical operating conditions in December 2014. Systems I/O-1 to I/O-4 are replicates of each other.

systems (I/O-1, I/O-2, and I/O-4) are one order of magnitude lower than that for I/O-3. Furthermore, the nematode count in 'I/O-3' from December $2014\left(2.2 \times 10^{6}\right.$ counts $\left./ \mathrm{m}^{2}\right)$ was comparable to the average nematode counts obtained in previous experimental run during July $2014\left(2.6 \times 10^{6}\right.$ counts $\left./ \mathrm{m}^{2}\right)$. It is to be noted that all the I/O systems were fed with the same feed water through the same feed tank, and the number of nematodes entering a membrane module is not artificially controlled. Hence, there are variations between the modules in the initial population entering the modules. The observed difference in population affected the final flux behavior of the systems as shown in Figure 3.9. This shows that a minimum nematode population is required to observe flux fluctuation effects. The nematode growth stages as observed under the light microscope are shown in Figure 3.10.

During the experimental run in December 2014, the average temperature measured in the aeration tank at the waste water treatment plant (WWTP) was around $12^{\circ} \mathrm{C}$, compared to $25^{\circ} \mathrm{C}$ in July 2014. The temperature fluctuations of the aeration tank recorded at the municipal wastewater treatment plant in 2014 are shown in Figure 3.11. The results indicate that the temperature at the WWTP significantly affects the population and biological development of nematodes in the secondary WWEf. Although the experiments were performed at ambient temperatures, the initial composition of the secondary WWEf used as feed water significantly alters the biological activity of nematodes on the membrane surface. Ambient temperatures at the treatment plant have been reported to impose a 
(a)

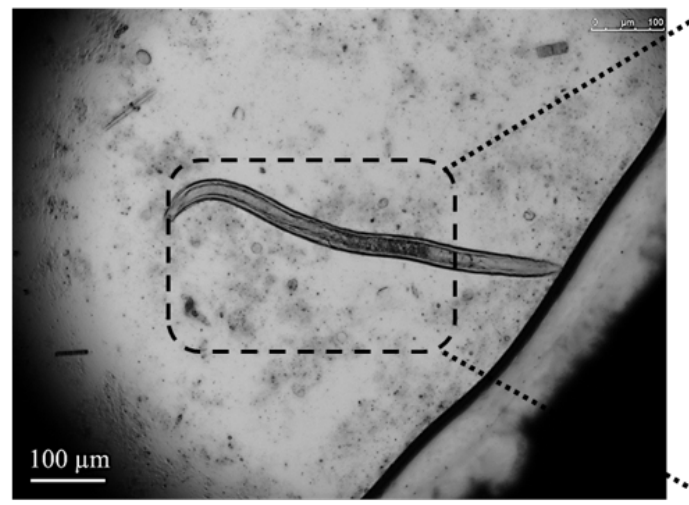

(c)

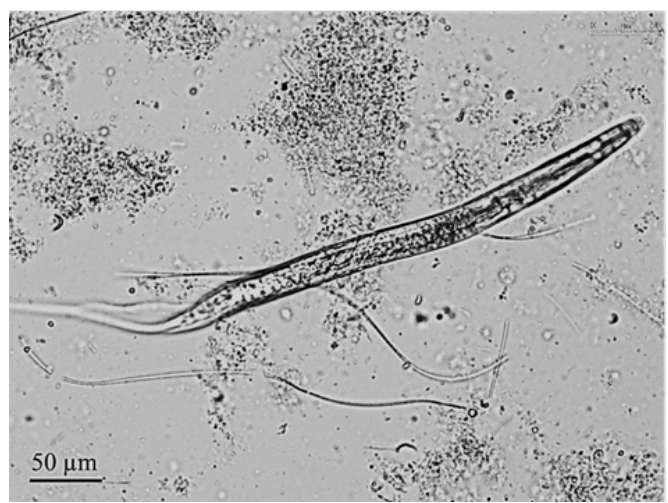

(b)

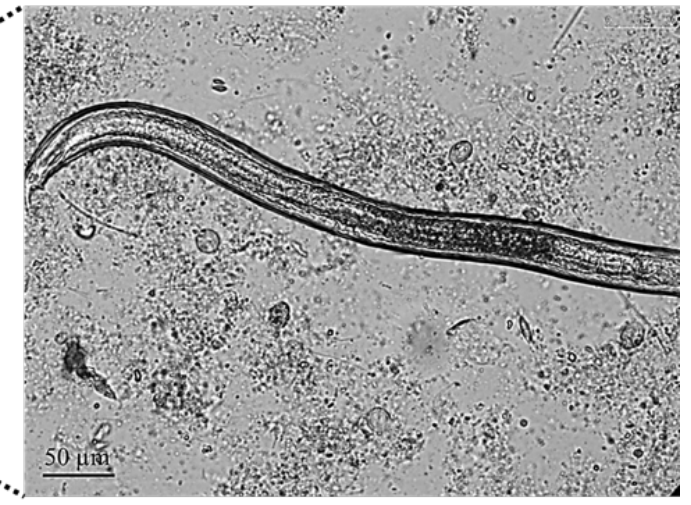

(d)

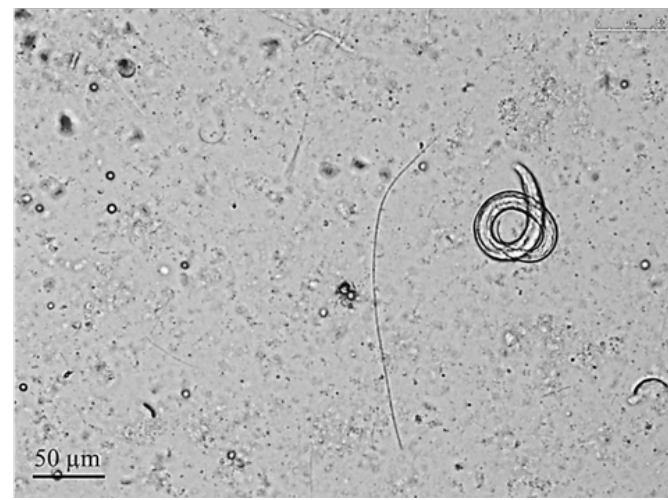

Figure 3.10: Nematodes as observed under light microscope from scraped biofouling layer at the end of experimental run of 35 days (Dec 2014); a) and b) a fully grown nematode, c) intermediate stage d) juvenile nematode, seen at 100x (a) and 200x (b,c,d) magnifications.

twofold effect on both predator and its prey, wherein it directly affects the growth and reproduction of nematodes and indirectly affects microbial population, serving as a food source for nematodes. At lower temperatures, where the incoming nematode density in feed water decreases, their subsequent activity within the biofouling layer is slowed down. This leads to a less open biofouling layer structure and hence lower permeate fluxes.

The effect of seasonal variations and temperature on population density and growth rates of nematodes is reported well in literature [23, 39]. Abrams and Mitchell observed that the doubling time of the nematode population increased from 2 days at $22^{\circ} \mathrm{C}$ to 24 days at $5^{\circ} \mathrm{C}[23]$. Similarly, in the present study the lower feed-water temperatures (around $12^{\circ} \mathrm{C}$ ) for the experiments conducted in December 2014 slowed down the growth rate of nematodes. This could be assumed to have led to more juvenile nematodes as was observed under the light microscope (Figure 3.10) rather than fully grown adults, thereby affecting overall reproduction and abundance. Figure 3.10 shows three different stages of nematode growth observed within the biofouling layer. For eukaryotic organisms such as nematodes, 


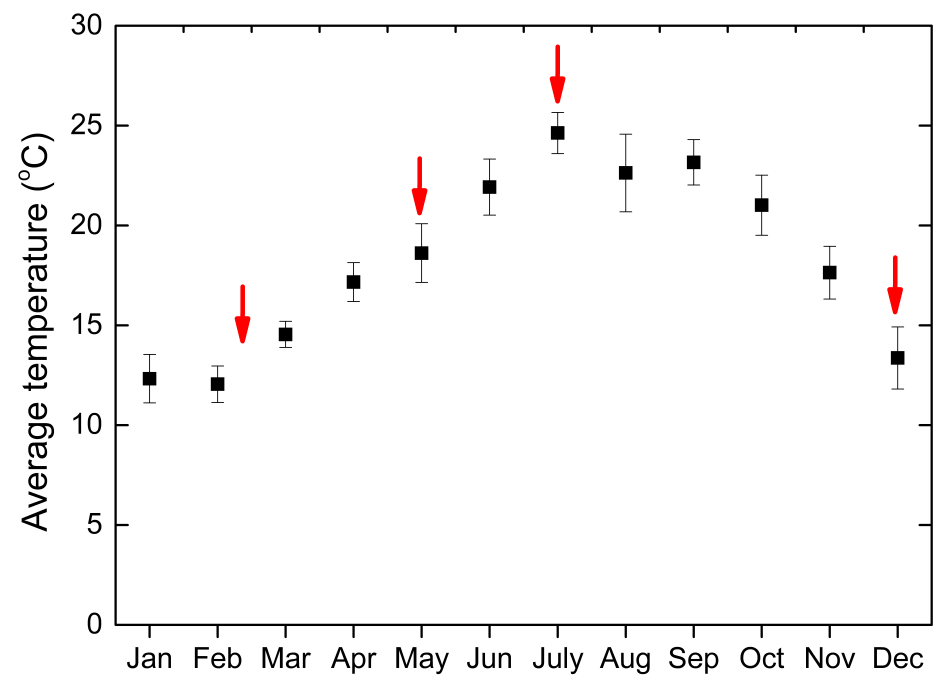

Figure 3.11: Temperature data recorded during the year 2014 in the aeration tank at the municipal wastewater treatment plant, Leeuwarden (NL). Red arrows indicate the time period when the wastewater effluent was withdrawn for conducting experiments.

the cell size is also an essential factor that determines their ingestion rate [40]. Juvenile nematodes have a reduced grazing potential compared to the adult ones. The reduced adult nematode population adversely affected their activity within the biofouling layer on the membrane surface.

Besides nematode growth, temperature variations also affect the prey organisms, leading to a lower microbial density at lower temperatures [41]. A reduced microbial population would further numerically decrease the active nematode community present on the membrane surface, as shown by Gaudes et al.[18]. It was reported that bacterial abundances and predominance of larger nematodes were interconnected. It was also shown that low nutrient levels slowed down nematodes growth, leading to a reduced number density and the presence of mainly small-medium sized juvenile nematodes [18]. Although the microbial community was not determined in the present study to observe its direct effects on nematode population, as explained above a lower nematode population density was reported in December 2014 as compared to July 2014. The findings described above clearly demonstrate that a certain threshold population size and physiological state of nematodes is required to significantly reduce the hydraulic resistance of the biofouling layer. 


\subsection{Conclusions}

The current work investigated the effect of nematodes on biofouling behavior during ultrafiltration of secondary wastewater effluent using hollow fiber membranes under low transmembrane pressures. With respect to the influence of nematodes on the overall permeate fluxes, the following key findings can be derived

- While the flux declined monotonically in outside/in (O/I) operational mode, a fluctuating flux trend was observed for inside/out (I/O) mode. It was shown that the fluctuations in the nematode population correlated well with the periodic flux trend in $\mathrm{I} / \mathrm{O}$ mode.

- Nematodes influence the permeate fluxes when present above a threshold density of $2.2 \times 10^{6}$ counts $/ \mathrm{m}^{2}$. The population of adult nematodes present has a larger influence on permeate production compared to juveniles.

- Seasonal variations affected nematode population density and growth. WWEf feed taken at $25^{\circ} \mathrm{C}$ led to a higher population density of nematodes, whereas WWEf feed taken at $12^{\circ} \mathrm{C}$ led to retarded growth of nematodes and reduced population density.

- The scientific findings based on the impact of biological interactions of bacterivorous nematodes on membrane biofouling can be helpful in engineering membrane technology. It is shown that the presence of active nematodes can lead to a $50 \%-75 \%$ increase in fluxes. Predation by biologically active and fully grown nematodes is suggested as a naturally occurring biofouling mitigation strategy during low pressure membrane filtration. The natural predator-prey interactions can be utilized for designing more efficient and self-sustainable Point-of-Use systems.

\section{References}

[1] M.A. Montgomery, M. Elimelech, Water and sanitation in developing countries: including health in the equation, Environmental Science \& Technology 41 (2007) 17-24.

[2] L. Fewtrell, R.B. Kaufmann, D. Kay, W. Enanoria, L. Haller, J.M. Colford Jr, Water, sanitation, and hygiene interventions to reduce diarrhoea in less developed countries: a systematic review and meta-analysis, The Lancet Infectious Diseases 5 (2005) 42-52.

[3] M.D. Sobsey, C.E. Stauber, L.M. Casanova, J.M. Brown, M.A. Elliott, Point of use household drinking water filtration: a practical, effective solution for providing sustained access to safe drinking water in the developing world, Environmental science \& technology 42 (2008) 4261-4267. 
[4] J.L. Cartinella, T.Y. Cath, M.T. Flynn, G.C. Miller, K.W. Hunter, A.E. Childress, Removal of natural steroid hormones from wastewater using membrane contactor processes, Environmental Science \& Technology 40 (2006) 7381-7386.

[5] T. Reemtsma, B. Zywicki, M. Stueber, A. Kloepfer, M. Jekel, Removal of sulfurorganic polar micropollutants in a membrane bioreactor treating industrial wastewater, Environmental Science \& Technology 36 (2002) 1102-1106.

[6] S. Weiss, J. Jakobs, T. Reemtsma, Discharge of three benzotriazole corrosion inhibitors with municipal wastewater and improvements by membrane bioreactor treatment and ozonation, Environmental Science \& Technology 40 (2006) 7193-7199.

[7] K. Kimura, H. Hara, Y. Watanabe, Elimination of selected acidic pharmaceuticals from municipal wastewater by an activated sludge system and membrane bioreactors, Environmental Science \& Technology 41 (2007) 3708-3714.

[8] B.-K. Hwang, W.-N. Lee, K.-M. Yeon, P.-K. Park, C.-H. Lee, i.-S. Chang, A. Drews, M. Kraume, Correlating TMP Increases with Microbial Characteristics in the Bio-Cake on the Membrane Surface in a Membrane Bioreactor, Environmental Science \& Technology 42 (2008) 3963-3968.

[9] M.-Y. Chen, D.-J. Lee, Z. Yang, X.F. Peng, J.Y. Lai, Fluorecent Staining for Study of Extracellular Polymeric Substances in Membrane Biofouling Layers, Environmental Science \& Technology 40 (2006) 6642-6646.

[10] Y. Miura, Y. Watanabe, S. Okabe, Membrane Biofouling in Pilot-Scale Membrane Bioreactors (MBRs) Treating Municipal Wastewater: Impact of Biofilm Formation, Environmental Science \& Technology 41 (2007) 632-638.

[11] N. Derlon, M. Peter-Varbanets, A. Scheidegger, W. Pronk, E. Morgenroth, Predation influences the structure of biofilm developed on ultrafiltration membranes, Water Research 46 (2012) 3323-3333.

[12] D.J. Clarke, L. Eberl, Interactions Between Bacteria and Nematodes, in: H. König, A. Varma (Eds.) Intestinal Microorganisms of Termites and Other Invertebrates, Springer Berlin Heidelberg, Berlin, Heidelberg, 2006, pp. 55-64.

[13] R.D. Holt, Predation, apparent competition, and the structure of prey communities, Theoretical Population Biology 12 (1977) 197-229.

[14] N. Derlon, N. Koch, B. Eugster, T. Posch, J. Pernthaler, W. Pronk, E. Morgenroth, Activity of metazoa governs biofilm structure formation and enhances permeate flux 
during Gravity-Driven Membrane (GDM) filtration, Water Research 47 (2013) 2085-2095.

[15] S. Jabornig, S.M. Podmirseg, A novel fixed fibre biofilm membrane process for onsite greywater reclamation requiring no fouling control, Biotechnology and Bioengineering 112 (2015) 484-493.

[16] T. Klein, D. Zihlmann, N. Derlon, C. Isaacson, I. Szivak, D.G. Weissbrodt, W. Pronk, Biological control of biofilms on membranes by metazoans, Water Research 88 (2016) 20-29.

[17] W.K. Dodds, Freshwater ecology: concepts and environmental applications, Academic press, 2002.

[18] A. Gaudes, I. Muñoz, T. Moens, Bottom-up effects on freshwater bacterivorous nematode populations: a microcosm approach, Hydrobiologia 707 (2013) 159-172.

[19] T. Moens, M. Vincx, Observations on the feeding ecology of estuarine nematodes, Journal of the Marine Biological Association of the United Kingdom 77 (1997) 211-227.

[20] I. Hamels, T. Moens, K. Muylaert, W. Vyverman, Trophic interactions between ciliates and nematodes from an intertidal flat, Aquatic Microbial Ecology 26 (2001) 61-72.

[21] W. Traunspurger, Bathymetric, seasonal and vertical distribution of feeding-type of nematodes in an oligotrophic lake, Vie et milieu 47 (1997) 1-7.

[22] N. Majdi, M. Tackx, W. Traunspurger, E. Buffan-Dubau, Feeding of biofilmdwelling nematodes examined using HPLC-analysis of gut pigment contents, Hydrobiologia 680 (2012) 219-232.

[23] B.I. Abrams, J.M. Myron, Role of Nematode-Bacterial Interactions in Heterotrophic Systems with Emphasis on Sewage Sludge Decomposition, Oikos 35 (1980) 404-410.

[24] F. Riemann, E. Helmke, Symbiotic Relations of SedimentAgglutinating Nematodes and Bacteria in Detrital Habitats: The EnzymeSharing Concept, Marine Ecology 23 (2002) 93-113.

[25] T. Wintgens, T. Melin, A. Schäfer, S. Khan, M. Muston, D. Bixio, C. Thoeye, The role of membrane processes in municipal wastewater reclamation and reuse, Desalination 178 (2005) 1-11.

[26] C. Chawla, A. Zwijnenburg, A. Kemperman, K. Nijmeijer, Biofouling assessment in simulated Point-of-Use(PoU) drinking water treatment systems, Submitted to Chemical Engineering Journal. 
[27] N.M. Lee, T. Welander, Influence of predators on nitrification in aerobic biofilm processes, Water Science \& Technology 29 (1994) 355-363.

[28] U. Michaelidou, A. ter Heijne, G.J.W. Euverink, H.V. Hamelers, A.J. Stams, J.S. Geelhoed, Microbial communities and electrochemical performance of titanium-based anodic electrodes in a microbial fuel cell, Applied and Environmental Microbiology 77 (2011) 1069-1075.

[29] T. Klein, D. Zihlmann, N. Derlon, C. Isaacson, I. Szivak, D.G. Weissbrodt, W. Pronk, Biological control of biofilms on membranes by metazoans, Water Research 88 (2016) 20-29.

[30] T. Bongers, The Maturity Index, the evolution of nematode life history traits, adaptive radiation and cp-scaling, Plant and Soil 212 (1999) 13-22.

[31] J. Laybourn, The effects of temperature on the respiration and production of the freshwater nematode Anonchus sp, Oecologia 41 (1979) 329-337.

[32] M. Peter-Varbanets, F. Hammes, M. Vital, W. Pronk, Stabilization of flux during dead-end ultra-low pressure ultrafiltration, Water Research 44 (2010) 3607-3616.

[33] L. Riemann, G.F. Steward, F. Azam, Dynamics of Bacterial Community Composition and Activity during a Mesocosm Diatom Bloom, Applied and Environmental Microbiology 66 (2000) 578-587.

[34] J. Jost, J. Drake, A. Fredrickson, H. Tsuchiya, Interactions of Tetrahymena pyriformis, Escherichia coli, Azotobacter vinelandii, and glucose in a minimal medium, Journal of Bacteriology 113 (1973) 834-840.

[35] J.H. Connell, On the role of natural enemies in preventing competitive exclusion in some marine animals and in rain forest trees, Dynamics of populations 298 (1971) 312.

[36] N. Cramer, R. May, Interspecific competition, predation and species diversity: a comment, Journal of Theoretical Biology 34 (1972) 289-293.

[37] J.L. Harper, The role of predation in vegetational diversity, Brookhaven Symposia in Biology, 1968, pp. 48-62.

[38] R.T. Paine, Food web complexity and species diversity, American Naturalist (1966) 65-75.

[39] M. Woombs, J. Laybourn-Parry, The role of nematodes in low rate percolating 
filter sewage treatment works, Water Research 20 (1986) 781-787.

[40] C. Ratsak, K. Maarsen, S. Kooijman, Effects of protozoa on carbon mineralization in activated sludge, Water Research 30 (1996) 1-12.

[41] R.E. Muck, C. Grady, Temperature effects on microbial growth in CSTRs, Journal of the Environmental Engineering Division 100 (1974) 1147-1163. 



\section{Chapter 4}

\section{Hydraulic resistance of biofilms during ultrafiltration of drinking water: effect of monovalent to divalent ionic ratios}

\subsection{Introduction}

Decentralized drinking water treatment is mostly based on ultrafiltration (UF) and/or microfiltration (MF) [1]. Such treatment options are also called Point-of-Use systems, and are commonly used in developing countries. They are mainly operated at low pressures $(<1$ bar), and hence experiencing lower fouling propensity compared to reverse osmosis or nanofiltration which are operated at higher transmembrane pressures. Lower fouling rates allows the performance of UF/MF systems to be easily elevated using simple cleaning strategies such as forward flushing or backflushing [2] and/or by intermittent operation $[2,3]$.

Despite abated fouling in low pressure membrane operations, the growth of biofilm on membrane surface leads to low permeate production. Besides growth on the feed side, there is a possibility of bacterial growth on the permeate side due to bacterial passage through the pores of low pressure membranes that could affect the permeate water quality [4]. Biofilm formation is one of the most preferred strategies of microbes to survive and withstand environmental stresses. Biofilm formation on a membrane surface can be defined as a 'living' cake layer that comprises of bacterial cells attached to the surface via gel like extra cellular polymeric substances (EPS) [5-10]. The EPS released by bacteria mainly contains polysaccharides, proteins, nucleic acids and lipids [11-13]. It not only mediates the bacterial adhesion to surfaces but also provides mechanical stability to biofilms and acts as an external digestive system for bacteria [13]. The biofilm formed contributes to membrane fouling, leading to flux decline and lower permeate production capacity. 
62 Hydraulic resistance of biofilms during ultrafiltration of drinking water: effect of monovalent to divalent ionic ratios

Biofilms are in themselves complex multicellular and multicomponent systems that make them difficult to mitigate once they grow and attain maturity. Previous studies suggest that biofilm formation on any given surface is mainly affected by the local environmental factors such as nutrients, electrolytes in the medium and hydrodynamic forces [14, 15]. Amongst medium composition, divalent cations are known to play an important role in biofilm formation and EPS production $[16,17]$.

Divalent cations such as $\mathrm{Ca}^{2+}$ and $\mathrm{Mg}^{2+}$ affect bacterial adhesion directly via electrostatic interactions and have an indirect effect on the bacterial physiology and growth. Cations act as cross-linkers of the biofilm polymeric matrix, thus providing structural integrity and stability to the matrix $[12,16,18,19]$. They reduce repulsive forces between negatively charged bacteria and negative groups present in EPS and surfaces [17], thereby decreasing separation distance between cells and surfaces [20]. Calcium ions have been reported to form a highly interconnected network of polysaccharides [21], and $\mathrm{Ca}^{2+}$ complexation with polysaccharides leads to a cohesive biofilm structure [22]. Moritaka et al. compared the rheological properties of gellan (an anionic polysaccharide released by bacteria) in the presence of monovalent (M) and divalent (D) cations. It is seen that divalent cations have a pronounced effect on the rheological properties of gellan compared to their monovalent counterparts [23]. It was further observed that gelation of gellan like polymers, is directly influenced by the type, valency and concentration of cations in a medium. Cations promote the molecular association between carboxyl groups in a gellan solution, by providing an electrostatic shield of repulsion between side groups of gellan molecules. The authors reported that divalent cations were more effective than monovalent cations in increasing the gel forming ability [23].

Besides the bridging effect, cations also influence biofilm formation by affecting the physiological aspects of bacterial growth, cell-aggregation, and twitching mobility. For example $\mathrm{Mg}^{2+}$ is also known to be an important cellular cation and an enzyme co-factor [20] Similarly, intracellular $\mathrm{Ca}^{2+}$ affects mechanisms which contribute to biofilm formation. It is shown in literature that the presence of $\mathrm{Ca}^{2+}$ enhances both twitching movement of bacterial cells, cell aggregation as well as adhesion. Twitching helps the bacteria to colonize surfaces, whereas the cell aggregation and adhesion determine the overall architecture of biofilms [24]. Both $\mathrm{Ca}^{2+}$ and $\mathrm{Mg}^{2+}$ also have been reported to play a role in regulation of bacterial gene expression related to virulence factors and biofilm formation $[22,25]$.

Extensive research has been conducted on studying the effect of divalent cations on biofilms. However, most of the studies mainly focused upon isolated single bacterial strains such as P.Fluorescens [14, 18, 20, 26, 27], Streptococci [28], Staphylococcus [29], P.aeruginosa [30] and their corresponding biofilm properties, as these are few of the most commonly occurring strains in industrial and environmental conditions. These studies reported contrasting results on the effect of cations on biofilm adhesion depending on the type of strain used in their investigations. For example, Tamura et al [28] did not see any effect of $\mathrm{Mg}^{2+}$ on Streptococci adhesion whereas Dunne et al. [29] observed enhanced 
adhesion of Staphylococcus in the presence of $\mathrm{Mg}^{2+}$. In yet another study, it is observed that single cells in small aggregates dominate in absence of $\mathrm{Mg}^{2+}$ while larger aggregates dominated in the presence of $\mathrm{Mg}^{2+}$ [14]. Larger aggregates lead to more expansive biofilm structures. The aforementioned literature and related research studies have not been conducted on biofilms as occurring in membrane applications.

There is a lack of studies on the effect of divalent cations on membrane biofouling especially in drinking water applications. There are a few studies on the effect of cations on biofouling in membrane bioreactors (MBRs) for wastewater applications [31, 32]. These studies focused on the effect of monovalent/divalent (M:D) ratios on fouling using activated sludge [31]. The authors reported lower fouling rates in the presence of $\mathrm{Mg}^{2+}$ via enhanced bioflocculation of EPS when monovalent and divalent ions were present at equal concentrations i.e. M:D 1:1. The effect of varying ionic strengths on alginate (a polysaccharide model component) fouling has been studied in literature [32, 33] Van den Brink et al. [32] focused on the effect of $\mathrm{Ca}^{2+}$ and ionic strength on alginate fouling in MBRs. They found that high $\mathrm{Ca}^{2+}(2 \mathrm{mM})$ and no alginate and high alginate combined with high $\mathrm{Ca}^{2+}$ concentrations (20 ppm alginate, $2 \mathrm{mM} \mathrm{Ca}^{2+}$ ) led to the highest fouling rates and final resistances. Despite aforementioned studies, the effect of divalent cations on naturally occurring drinking water biofilms and their EPS production has not been linked directly to hydraulic resistance of membranes so far in literature.

The main objective of the present study is to investigate biofilm adhesion on ultrafiltration membranes using naturally occurring bacterial strains present in drinking water. In this work, we studied the effects of varying monovalent to divalent (M:D) cationic ratios on biofilm resistance and EPS production. EPS production and accumulation on the membrane surface is known to be a major contributor towards the overall hydraulic resistance of membranes. Therefore, we also will correlate the amount of EPS components such as polysaccharides and proteins with the overall membrane hydraulic resistance. The ultrafiltration membrane is operated at low pressures of 0.5 bar to simulate the pressures used in Point-of-Use (PoU) devices. The findings are relevant to design membrane based filtration systems with lower fouling tendencies and higher permeate production for developing countries.

\subsection{Materials and Methods}

\subsubsection{Experimental set-up}

Biofouling experiments were conducted using flat sheet membrane fouling simulators (MFS). A complete description of the flow cells can be found elsewhere [34]. Briefly, the cells were made of PMMA with inlets and outlets for feed, permeate and concentrate streams. The filtration cell contained a permeate spacer and membrane (ultrafiltration or microfiltration) 
64 Hydraulic resistance of biofilms during ultrafiltration of drinking water: effect of monovalent to divalent ionic ratios

with an effective membrane area of $200 \mathrm{~cm}^{2}$. No feed spacer was used. The three test cells were operated simultaneously in parallel at constant transmembrane pressure of 0.5 bar $(50 \mathrm{kPa})$ (Figure 4.1). Two of the three cells were fed with nutrients to accelerate biofilm growth, and one of the cells served as a blank. Duration of the experiments was chosen to be 6 days, since after one week of operation the feed line had microbial growth inside the pipe. The flux and resistance data points are an average of duplicate measurements, and the deviation between duplicates was less than $10 \%$.

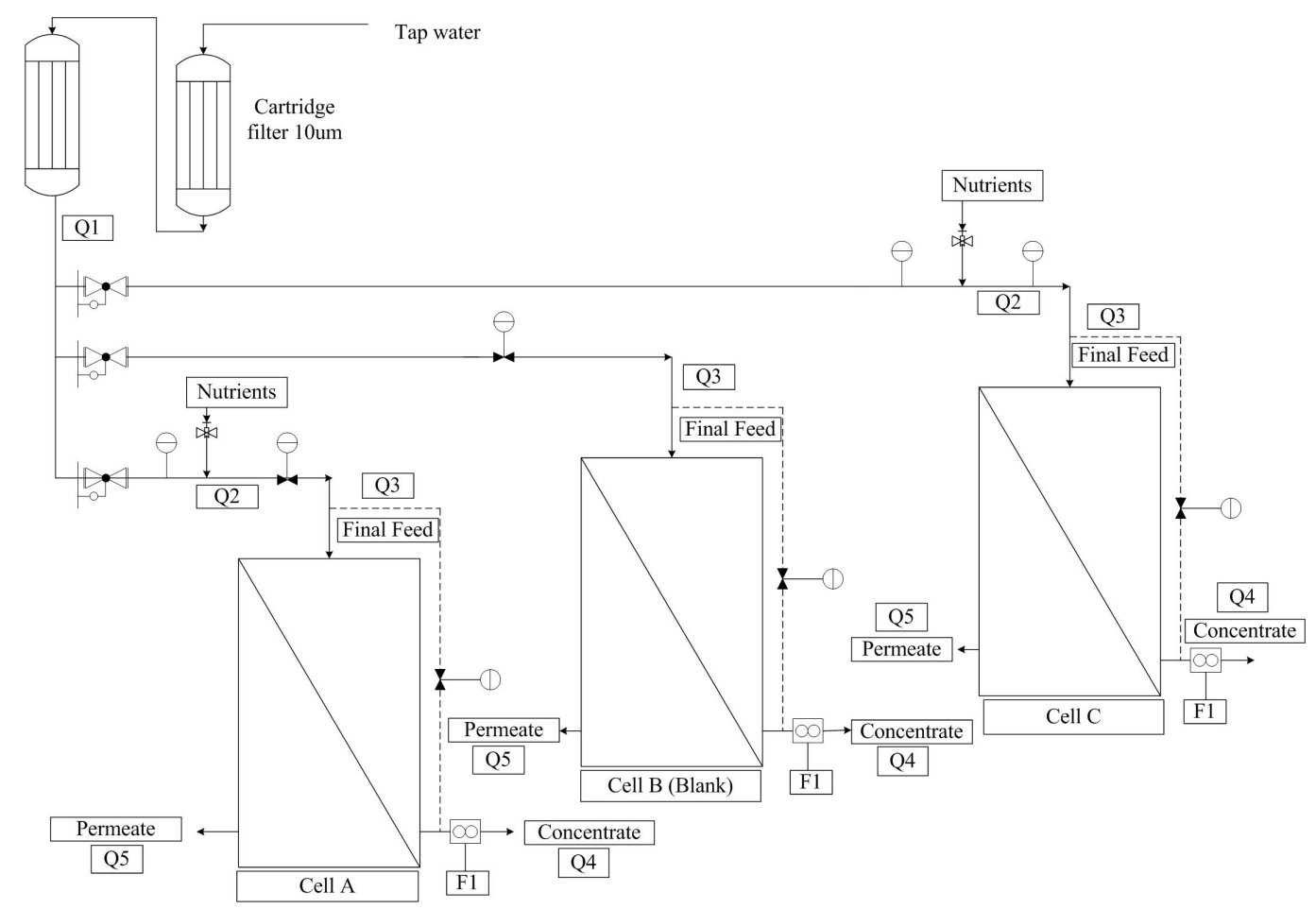

Figure 4.1: Schematic diagram of the membrane fouling simulators (MFS) operated in parallel at transmembrane pressure of 0.5 bar, $Q_{1}$ is the tap water flow, $Q_{2}$ the nutrient solution flow, $\mathrm{Q}_{3}$ the final feed inflow (tap water plus nutrient solution), $\mathrm{Q}_{4}$ the concentrate flow and $Q_{5}$ the permeate flow. $F_{1}$ is the flow controller. Cell $\mathrm{A}$ and $\mathrm{C}$ are fed with nutrients, cell B (blank) is without nutrient dosing.

\subsubsection{Materials}

Two different kinds of polyethersulphone (PES) membranes were used for the experiments flat sheet microfiltration (MF, $0.05 \mu \mathrm{m}$ pore diameter) and ultrafiltration (UF, $150 \mathrm{kDa}$ MWCO) membranes (Microdyn NADIR $\cap$, Wiesbaden, Germany). Clean water permeability for the MF and UF membranes were $>300 \mathrm{~L} / \mathrm{m}^{2} \cdot \mathrm{hr} \cdot$ bar and $>286 \mathrm{~L} / \mathrm{m}^{2} \cdot \mathrm{hr} \cdot$ bar, respectively, as per manufacturers data. We used the tightest MF and most open UF membranes supplied by Microdyn-Nadir. Membranes were soaked overnight in de-ionized water to 
remove any conservative agents prior to use.

Tap water (for the composition see Table 4.1) was used as feed and additional nutrients were dosed to accelerate microbial growth. Nutrients were added in different forms: $\mathrm{CH}_{3} \mathrm{COONa}$ as carbon source, $\mathrm{NaH}_{2} \mathrm{PO} 4$ as phosphorus source and $\mathrm{NaNO}_{3}$ as nitrogen source to achieve an overall C:N:P ratio of 100:20:10 and dissolved in Milli-Q water. All chemicals were purchased in analytical grade from VWR International B.V. (Amsterdam, The Netherlands). The $\mathrm{pH}$ of the nutrient solution was adjusted to 11 using $1 \mathrm{M}$ sodium hydroxide (VWR international, analytical grade) to prevent any microbial growth in the nutrient container. A similar nutrient composition has been reported in previous studies to be used on biofilms and biofouling [34].

Table 4.1: Feed water characteristics without and with nutrients, after passing through the ion exchanger and further addition of Magnesium for different monovalent to divalent (M:D) ionic ratios.

\begin{tabular}{|c|c|c|c|c|c|c|}
\hline Tap water & & $\begin{array}{l}\text { without } \\
\text { nutri- } \\
\text { ents }\end{array}$ & $\begin{array}{l}\text { with nu- } \\
\text { trients }\end{array}$ & $\begin{array}{l}\text { ion- } \\
\text { exchanged } \\
\text { without } \\
\text { nutrients }\end{array}$ & $\begin{array}{l}\text { ion- } \\
\text { exchanged } \\
\text { with nutri- } \\
\text { ents }\end{array}$ & $\begin{array}{l}\text { ion- } \\
\text { exchanged } \\
\text { with nu- } \\
\text { trients } \\
\text { and Mag- } \\
\text { nesium }\end{array}$ \\
\hline $\begin{array}{l}\text { Monovalent to } \\
\text { divalent ratio }\end{array}$ & $\begin{array}{l}{[\mathrm{mEq}} \\
\text { basis }]\end{array}$ & $1.33: 1$ & $1.31: 1$ & $\begin{array}{l}\text { No } \\
\text { divalent } \\
\text { cations }\end{array}$ & $\begin{array}{l}\text { No } \\
\text { divalent } \\
\text { cations }\end{array}$ & $2.23: 1$ \\
\hline $\begin{array}{l}\text { Inorganic Car- } \\
\text { bon (IC) }\end{array}$ & $\mathrm{mg} / \mathrm{L}$ & $56.2 \pm 1.6$ & $59 \pm 0.4$ & $53.1 \pm 4.7$ & $53.8 \pm 4.7$ & $44.9 \pm 9.1$ \\
\hline $\begin{array}{l}\text { Total Carbon } \\
\text { (TC) }\end{array}$ & $\mathrm{mg} / \mathrm{L}$ & $60.3 \pm 1.8$ & $67.5 \pm 3.3$ & $57.4 \pm 3.8$ & $59.4 \pm 4.7$ & $49.7 \pm 9.2$ \\
\hline $\begin{array}{l}\text { Total Organic } \\
\text { Carbon (TOC) }\end{array}$ & $\mathrm{mg} / \mathrm{L}$ & $3.5 \pm 0.6$ & $6.1 \pm 0.4$ & $4.4 \pm 0.18$ & $5.44 \pm 1$ & $4.97 \pm 0.5$ \\
\hline $\mathrm{NO}_{3}^{-}$ & $\mathrm{mg} / \mathrm{L}$ & $11.3 \pm 0.2$ & $12.1 \pm 0.2$ & $11.3 \pm 0.2$ & $12.1 \pm 0.2$ & $12.1 \pm 0.2$ \\
\hline $\mathrm{PO}_{4}^{-}$ & $\mathrm{mg} / \mathrm{L}$ & $<0.05$ & $0.12 \pm 0.07$ & $<0.05$ & $0.12 \pm 0.07$ & $0.12 \pm 0.07$ \\
\hline $\mathrm{Ca}^{2+}$ & $\mathrm{mg} / \mathrm{L}$ & $1.6 \pm 0.1$ & $1.6 \pm 0.1$ & $<0.005$ & $<0.005$ & $<0.005$ \\
\hline $\mathrm{Mg}^{2+}$ & $\mathrm{mg} / \mathrm{L}$ & $0.8 \pm 0.01$ & $0.78 \pm 0.01$ & $<0.005$ & $<0.005$ & $2.6 \pm 0.62$ \\
\hline $\mathrm{Na}^{+}$ & $\mathrm{mg} / \mathrm{L}$ & $3.2 \pm 0.18$ & $3.4 \pm 0.12$ & 5.7 & $5.9 \pm 0.15$ & $5.8 \pm 0.2$ \\
\hline $\begin{array}{l}\text { Chemical Oxy- } \\
\text { gen Demand } \\
(\mathrm{COD})\end{array}$ & $\mathrm{mg} / \mathrm{L}$ & $8.50 \pm 0.74$ & $13 \pm 2.3$ & $11.1 \pm 1.8$ & $14.4 \pm 3$ & \\
\hline $\mathrm{pH}$ & & $8.1 \pm 0.0$ & $7.9 \pm 0.1$ & $7.9 \pm 0.3$ & $7.9 \pm 0.0$ & $8.1 \pm 0.0$ \\
\hline Hardness & ${ }^{\circ} \mathrm{dH}$ & $7-8$ & $7-8$ & $<1$ & $<1$ & $<1$ \\
\hline
\end{tabular}

Additionally, a water softener was installed in the line of tap water to remove divalent 
66 Hydraulic resistance of biofilms during ultrafiltration of drinking water: effect of monovalent to divalent ionic ratios

ions for varying monovalent to divalent ion ratios (LT-Simples 5600-04, Lenntech, The Netherlands). The original monovalent to divalent (M:D, on $\mathrm{mEq}$ basis) ratio was 1.31:1 in the tap (feed) water. The softener replaces divalent cations such as calcium and magnesium with monovalent sodium ions, hence after passing through the ion exchanger the feed water contained only monovalent ions. Later on, magnesium chloride hexahydrate $\left(\mathrm{MgCl}_{2} \cdot 6 \mathrm{H}_{2} \mathrm{O}\right)$ (VWR international, analytical grade) was added to the feed water just containing monovalent ions until a M:D ratio of 2:1 was obtained. Magnesium was chosen as the divalent ion because it is known to have a severe impact on the biofilm formation via physiology-dependent attachment processes by acting as important cellular cation and enzyme cofactor for the production of EPS [14]. It was difficult to adjust the $\mathrm{pH}$ of the nutrient solution with $\mathrm{MgCl}_{2}$, as increasing the $\mathrm{pH}$ to 11 led to precipitate formation, hence the nutrient solution was refreshed every day and checked regularly for optical density at $600 \mathrm{~nm}$ to ensure no suspended growth occurred in the medium. All the experiments were conducted at a feed water temperature of $20 \pm 2^{\circ} \mathrm{C}$. As shown in Figure 4.1, the tap water was filtered through two cartridge filters (pore size $10 \mu \mathrm{m}$ ) before entering the test cells to remove suspended particles. Inline pressure reducers (V782, Vink Kunststoffen B.V., Didam, The Netherlands) were used to maintain a stable feed pressure of 0.5 bar $(50 \mathrm{kPa})$. Before entering the filtration cell, nutrients were added using a peristaltic pump and one way valve (Masterflex L/S pumps, Cole-Palmer Instrument Company, USA). Feed pressure was monitored using an inline pressure gauge (MAN-SD1S, Kobald, Arnhem, The Netherlands) mounted just before the cell. The feed channel pressure (FCP), which is the pressure difference between feed and concentrate line over the membrane surface, was measured using a differential pressure transmitter (Deltabar SPMD 70, Endress + Hauser, Maulburg, Germany) connected between the feed inlet and cross flow outlet. The linear flow velocity of the feed water over the membrane was controlled by a flow controller $(8805 / 8905$, Brooks Instrument, Hatfield, PA, USA), which was installed at the cross flow outlet of the filtration cell. The concentrate flow was kept at a constant value of $470 \mathrm{~mL} / \mathrm{min}$.

The amount of nutrient dosing required was calculated according to the mass balances below, and based on different flows shown in Figure 4.1, where $Q_{1}$ is the tap water flow, $Q_{2}$ the nutrient solution flow, $Q_{3}$ the final feed inflow (tap water plus nutrient solution), $Q_{4}$ the concentrate flow and $Q_{5}$ the permeate flow. $C_{1}$ is the concentration of acetate in the tap water, $C_{2}$ the concentration of acetate in nutrient solution and $C_{3}$ the concentration of acetate in final feed (tap water and nutrient solution). $F_{1}$ is the flow controller.

$$
\begin{gathered}
Q_{3}=Q_{1}+Q_{2} \\
Q_{1} \cdot C_{1}+Q_{2} \cdot C_{2}=Q_{3} \cdot C_{3} \\
Q_{3}=Q_{4}+Q_{5}
\end{gathered}
$$




\subsubsection{Water quality}

Total organic carbon (TOC) of permeate, feed and concentrate stream were measured on daily basis. $20 \mathrm{~mL}$ of sample was placed in a TOC free glass vial and analyzed with the TOC analyzer (Shimadzu Scientific instruments, Kyoto, Japan). The concentrations of monovalent $\left(\mathrm{Na}^{+}\right.$and $\left.\mathrm{K}^{+}\right)$and divalent cations $\left(\mathrm{Mg}^{2+}\right.$ and $\left.\mathrm{Ca}^{2+}\right)$ were measured using inductively coupled plasma atomic emission spectroscopy (ICP-OES, Optima 5300DV, PerkinElmer). Sample volumes of $10 \mathrm{~mL}$ for feed, permeate and concentrate were acidified with $1.5 \mathrm{~mL}$ nitric acid $(96 \%)$. For the measurement of anions $\left(\mathrm{NO}_{3}^{-}, \mathrm{NO}_{2}^{-}, \mathrm{SO}_{4}^{2-}\right.$ and $\mathrm{PO}_{4}^{3-}$ ) a sample volume of $2 \mathrm{~mL}$ from feed, permeate and concentrate was filtered through a $0.45 \mu \mathrm{m}$ syringe filter and analyzed with ion chromatograph (Compact IC 761, Metrohm, Herisau, Switzerland). Chemical oxygen demand (COD) of the permeate, feed and concentrate streams was measured daily using a Hach Lange cuvette tests kit (LCK 414 effluent 5-60 mg/L) and a Hach Lange photometer (DR 3900). Hardness of tap water and ion exchanged water was measured using a Hach Lange kit (LCK 327) on a daily basis. Calcium and magnesium ions react with metal phthalein to give a violet color. The light absorption was measured with a Hach Lange photometer (DR 3900).

\subsubsection{Membrane autopsy}

The membrane fouling simulators were opened either at the end of the experiment or before the experiment ended (sacrificial experiments). Membrane coupons were cut for further analysis including scanning electron microscopy (SEM), adenosine triphosphate (ATP), total organic compounds (TOC) and extracellular polymeric substances (EPS) as explained below.

\section{Scanning electron microscopy}

Membrane coupons were fixed in $2.5 \%$ (v/v) glutaraldehyde (SigmaAldrich, Steinheim, Germany) overnight at $4^{\circ} \mathrm{C} .25 \%$ glutaraldehyde was diluted 10 times with $1 \mathrm{x}$ phosphate buffered saline (PBS) $(10 \mathrm{mM})$ to prepare a $2.5 \%$ solution. The next day, fixated samples were washed three times for 7 minutes each in PBS $(10 \mathrm{mM})$ and subsequently dehydrated in increasing concentrations of ethanol $(30 \%, 50 \%, 70 \%, 90 \%$ for 20 min each and finally with $100 \%$ twice for 30 min each). Finally, the samples were air dried in a drying chamber overnight at $37^{\circ} \mathrm{C}$ (MMM Group, Venticell, Brno, Czech Republic). The samples were sputtered with gold (2-3 times at $<10 \mathrm{~Pa}$ and 40-45 mA) to enhance conductivity and to avoid the specimen from getting charged (Jeol JFC-1200 FineCoater, Tokyo, Japan). After the gold sputtering, the sample was visualized by SEM (JSM6480LV microscope JEOL Technics Ltd., Tokyo, Japan) in high vacuum mode (acceleration voltage $610 \mathrm{kV}$, operating distance $10 \mathrm{~mm}$ ). 
68 Hydraulic resistance of biofilms during ultrafiltration of drinking water: effect of monovalent to divalent ionic ratios

\section{ATP analysis}

Membrane samples were placed in $15 \mathrm{~mL}$ centrifuge vials containing $10 \mathrm{~mL} 1 \mathrm{x}$ PBS. The vials were shaken for 40 minutes at $1500 \mathrm{rpm}$ (Heidolph MultiReax). Afterwards, the samples were stored in ice and brought immediately to Vitens (Leeuwarden, The Netherlands) for further processing. At Vitens the samples were sonicated for 5 minutes to remove the cells from the surface in an ultrasonic water bath at $37 \mathrm{kHz}$. The samples were homogenized through vortexing for a few seconds with a maximum of $2500 \mathrm{rpm}$. For the ATP measurement the ATP Biomass Kit HS (Biothema, Sweden) was used. Instead of the lysis agent in the Biothema kit, Celsis LuminEX ATP Releasing Agent (Celsis, USA) was used as it gave better results. The final concentrations were measured with the ATP microplate reader (CentroXS3, Berthold technologies, Germany).

\section{TOC accumulated on membrane}

Membrane samples for TOC analysis were placed in $15 \mathrm{~mL}$ centrifuge vials containing 10 $\mathrm{mL}$ Milli-Q water. The samples were treated with an ultrasonic probe (Branson Sonifier 250, G. Heinemann Ultraschall- und Labortechnik, Germany) for 1 min for releasing all the attached TOC (both particulate and dissolved) on the membrane into the solution. Afterwards, the samples were placed in a TOC free glass vial and an additional $10 \mathrm{~mL}$ Milli-Q was added to make up $20 \mathrm{~mL}$ of sample volume. TOC was analyzed similar to the determination of the TOC of water samples as explained in section 4.2.3

\section{Extracellular polymeric substances (EPS)}

The biofilm layer on the membrane surface was scraped off using a cell scraper and dissolved in $1 \mathrm{x}$ PBS $(10 \mathrm{mM})$. The biofilm sample containing extracellular polymeric substances (EPS), i.e. polysaccharides and proteins, was divided into two equal parts to measure total and extracted components of EPS. The extracted EPS comprised of only extra cellular proteins and polysaccharides whereas total EPS included bacterial cells i.e. intracellular proteins and polysaccharides alongwith extracellular material. Total proteins and polysaccharides were directly measured following the protocols described below for protein and polysaccharides. To measure extracted EPS components, part of the sample was subjected to further treatment as described below. EPS was isolated from the sample following a procedure described in literature [34]. Briefly, the biofilm sample was mixed with a cation exchange resin (CER) in the $\mathrm{Na}^{+}$-form (Dowex, SigmaAldrich, Steinheim, Germany) in a ratio of $0.2 \mathrm{~g}$ resin per $1 \mathrm{~mL}$ of sample. The mixture containing biofilm sample and CER was shaken at $1500 \mathrm{rpm}$ for $2 \mathrm{hrs}$ at room temperature. During shaking the monovalent ion $\left(\mathrm{Na}^{+}\right)$of the CER was exchanged with $\mathrm{Ca}^{2+}$ attached to EPS matrix. This allows the EPS structure to disintegrate into individual chains and dissolve into the liquid medium. The suspension containing both bacterial cells as well as EPS was centrifuged at 9,000 g for 20 minutes at $4^{\circ} \mathrm{C}$ (Beckman \& Coulter, Avanti J-26 XP) to separate the bacterial cells from the EPS. The supernatant containing extra cellular polymeric substances (EPS) like proteins and polysaccharides was used for further analyses. 
The protein concentration was determined using the bicinchoninic acid (BCA) method as described in Pierce BCA Protein Assay Kit 23225 (Thermo Scientific, Rockford, IL, USA). Analysis was performed in 96 well plates and absorption was measured at $490 \mathrm{~nm}$ with a microtiter plate reader (1420 Multilabel counter Victor3, PerkinElmer, Waltham, MA, USA).

Polysaccharides were quantified by the phenol/sulfuric acid method [35]. Glucose and Glucuronic acid were used as standards to determine neutral and acidic polysaccharides respectively. $1 \mathrm{~mL}$ of sample (or standard) was mixed with $0.5 \mathrm{~mL}$ of a $5 \%$ phenol solution and $2.5 \mathrm{~mL}$ of $96 \%$ sulfuric acid in Schott glass tubes and placed in a water bath (TW8, Julabo, Seelbach, Germany) for 30 minutes at $30^{\circ} \mathrm{C}$. Afterwards, the absorption was measured at $490 \mathrm{~nm}$ with a spectrophotometer (UV-1650PC, Shimadzu, Japan).

\subsection{Results and discussion}

\subsubsection{Comparing MF and UF at M:D- 1.31:1}

As stated earlier, microfiltration (MF) and ultrafiltration (UF) are typically used in Pointof-Use applications, though UF is generally preferred due to the higher retention of bacterial contaminants than MF. In this section, the performance of MF and UF membranes are compared in terms of hydraulic resistance of biofilms at low transmembrane pressures (TMP) of 0.5 bar. The schematic of the feed flow and operational conditions is also shown in Figure 4.1. Tap (feed) water was filtered with a cartridge filter and fed to the membrane fouling simulators (MFS). It was further amended with additional nutrients like acetate, phosphate and nitrate as shown in Table 4.1. The monovalent to divalent (M:D) ionic ratio in these experiments was 1.31:1.

The performance of the MFS is evaluated in terms of feed channel pressure (FCP) and hydraulic resistances. The FCP increased from 25 mbar to 84 mbar for MF with nutrients and 21 mbar to 82 mbar for UF with nutrients. There was almost no increase in FCP for the MFS operated without nutrients, for the MF as well as for the UF blanks. This showed that the addition of nutrients accelerated the growth of bacteria on the membrane surface for both MF and UF [34].

Both MF and UF fed with nutrients showed a similar permeate flux decline of $95 \%$ and $93 \%$, respectively, over a duration of 6 days as shown in Figure 4.2. The decline was due to the formation of biofouling layer on the membrane surface. A permeate flux decline of $45 \%$ and $61 \%$ was observed for MF blank and UF blank membranes, respectively. Since there was almost no biofilm formation for blank systems as was revealed by SEM (discussed below), the flux decline was attributed to fouling by mainly humic acids present in tap water which was observed visually by the yellow-brownish coloring of the membrane surface. 
70 Hydraulic resistance of biofilms during ultrafiltration of drinking water: effect of monovalent to divalent ionic ratios

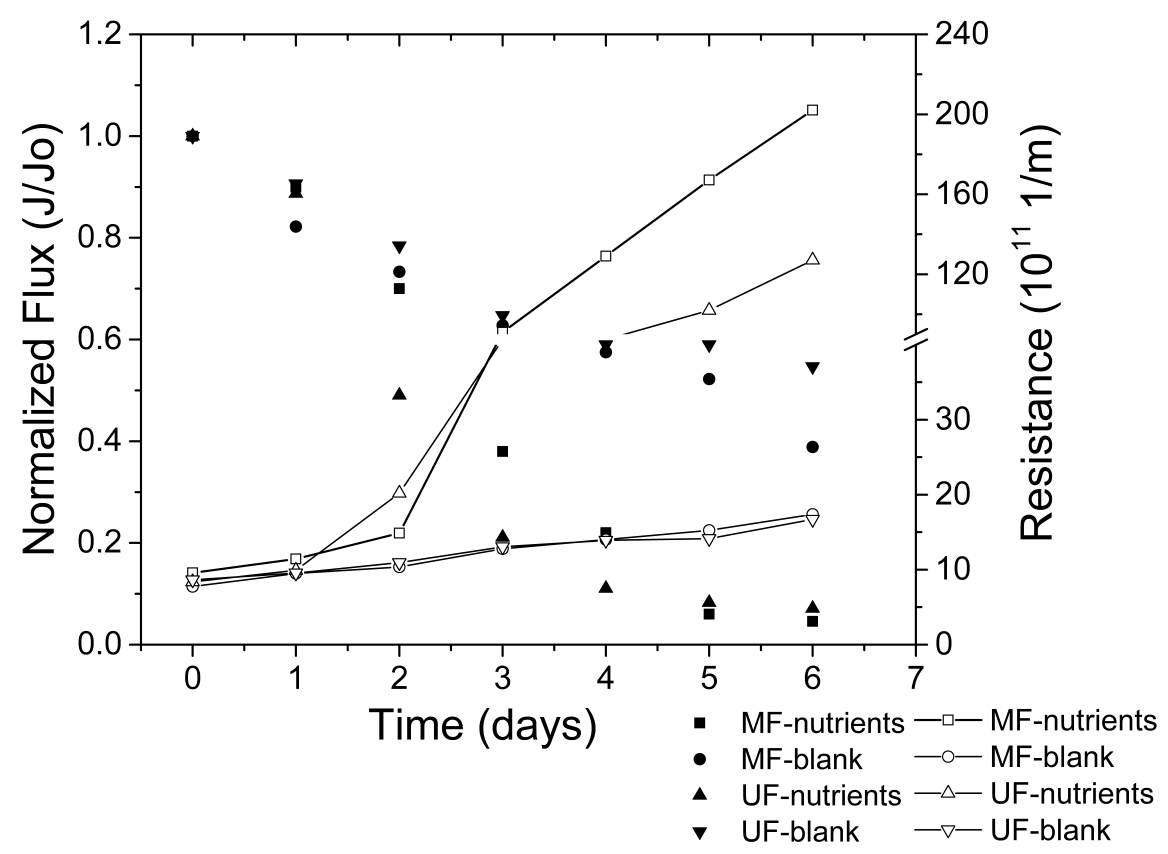

Figure 4.2: Normalized permeate flux decline (where $\mathrm{J}$ is final flux and Jo is initial flux) for MF and UF fed with tap water (M:D 1.31:1) with and without nutrients at a TMP of 0.5 bar $(50 \mathrm{kPa})$, closed symbols show normalized flux data on the left y-axis, and open symbols show resistance data on the right y-axis. Squares and circles: MF. Triangles: UF.

The final permeabilities after 6 days of operation were $20 \mathrm{~L} / \mathrm{m}^{2} \cdot \mathrm{hr} \cdot \mathrm{bar}, 30 \mathrm{~L} / \mathrm{m}^{2} \cdot \mathrm{hr} \cdot \mathrm{bar}, 210$ $\mathrm{L} / \mathrm{m}^{2} \cdot \mathrm{hr} \cdot$ bar, and $228 \mathrm{~L} / \mathrm{m}^{2} \cdot \mathrm{hr} \cdot$ bar for MF with nutrients, UF with nutrients, MF blank and UF blank, respectively. The final hydraulic resistances of MF and UF at the end of the experimental run of 6 days differed by $35 \%$ as seen in Figure 4.2 .

MF and UF membranes were autopsied at the end of the experimental run and analyzed on ATP, TOC and SEM. The measured ATP and TOC values are shown in Figure 4.3. ATP values give an indication of the amount of living biomass on the membrane surface. Average ATP values of UF with nutrients are higher than those for MF with nutrients. However, within the errors, Figure 4.3 shows there is no significant difference between the biomass accumulated on MF and UF. The blanks reveal the expected negligible amount of deposited ATP due to the absence of sufficient additional nutrients required for bacterial growth. Similar observations for both MF and UF are seen in Figure 4.3 for TOC deposited on the membrane surface. Normalized flux decline data for MF and UF fed with nutrients (Figure 4.2) reveal that the two membranes had similar filtration profile and permeate flux decline. Moreover, the aforementioned data for ATP deposition and TOC accumulation (Figure 4.3) demonstrate comparable bacterial growth and organic carbon accumulation for both MF and UF. It is interesting to note the similar flux decline measured for MF and 

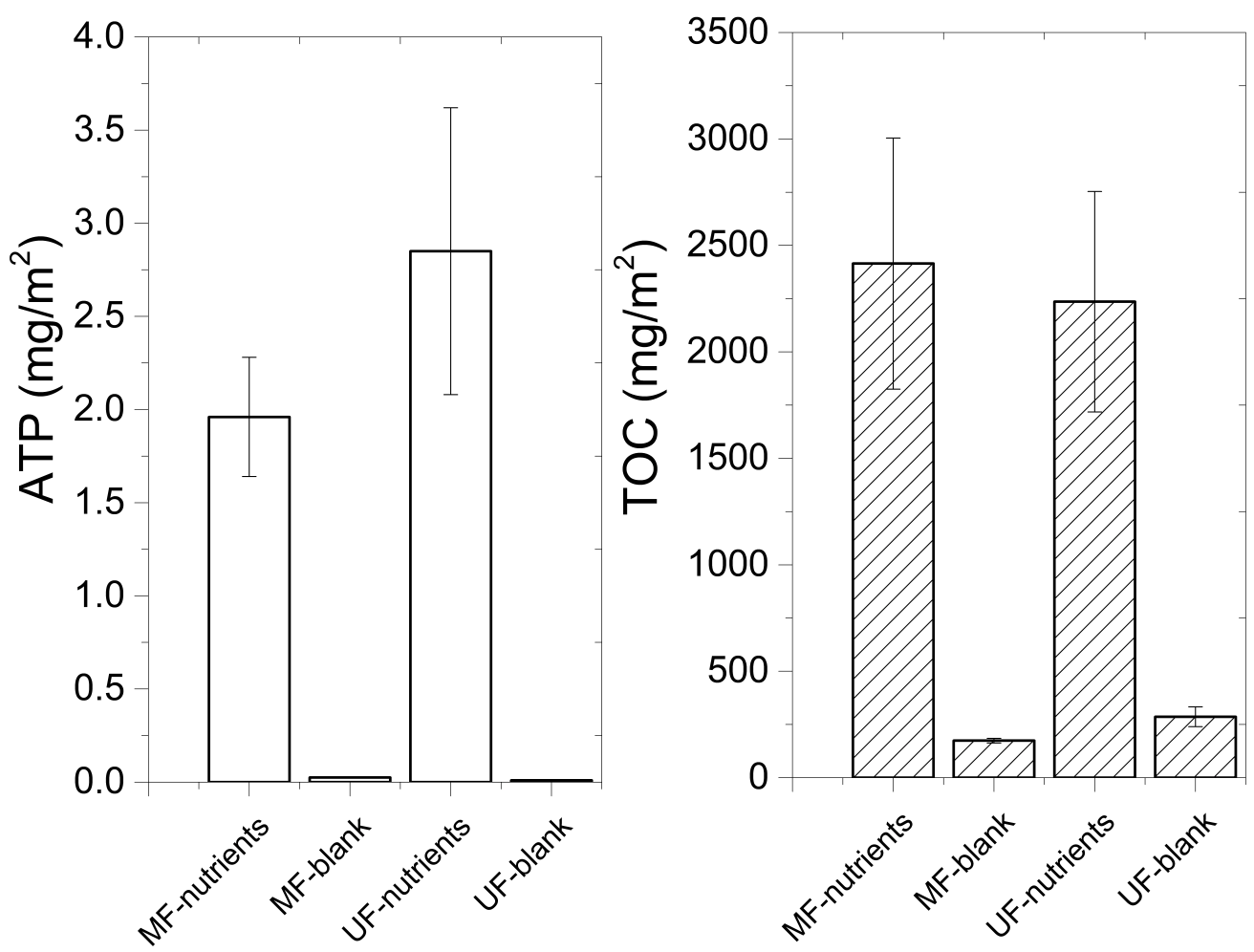

Figure 4.3: ATP and accumulated TOC after 6 days of operation on MF and UF membranes fed with tap water (M:D 1.31:1) with and without nutrients at a constant TMP of 0.5 bar $(50 \mathrm{kPa})$.

$\mathrm{UF}$, despite the fact that the pore diameter of the MF membrane used $(0.05 \mu \mathrm{m})$ is twice that of the pore size of the UF membrane used $(0.022 \mu \mathrm{m}, \mathrm{kDa}$ converted to $\mathrm{m}$ using the Einstein-Stokes equation given in [36]).

SEM images for clean and fouled membranes are shown in Figure 4.4. Though the membranes fed with tap water without additional nutrients had no significant bacterial growth, a few bacteria could be seen deposited on the membrane surface originating from the feed water (Figure 4.4b). Both MF and UF membranes fed with tap water containing added nutrients show similar biofilm formation with bacterial colonies as shown in Figures $4.4 \mathrm{c}$ and $4.4 \mathrm{~d}$.

Ultrafiltration has been shown to be more effective than microfiltration in pathogen removal from polluted water used for potable water production [37], and hence it finds UF has a broader application than MF in small scale Point-of-Use drinking water treatment systems. The results discussed above show similar performances of MF and UF under low transmembrane pressures (0.5 bar). So further experiments were conducted using UF only. 
72 Hydraulic resistance of biofilms during ultrafiltration of drinking water: effect of monovalent to divalent ionic ratios

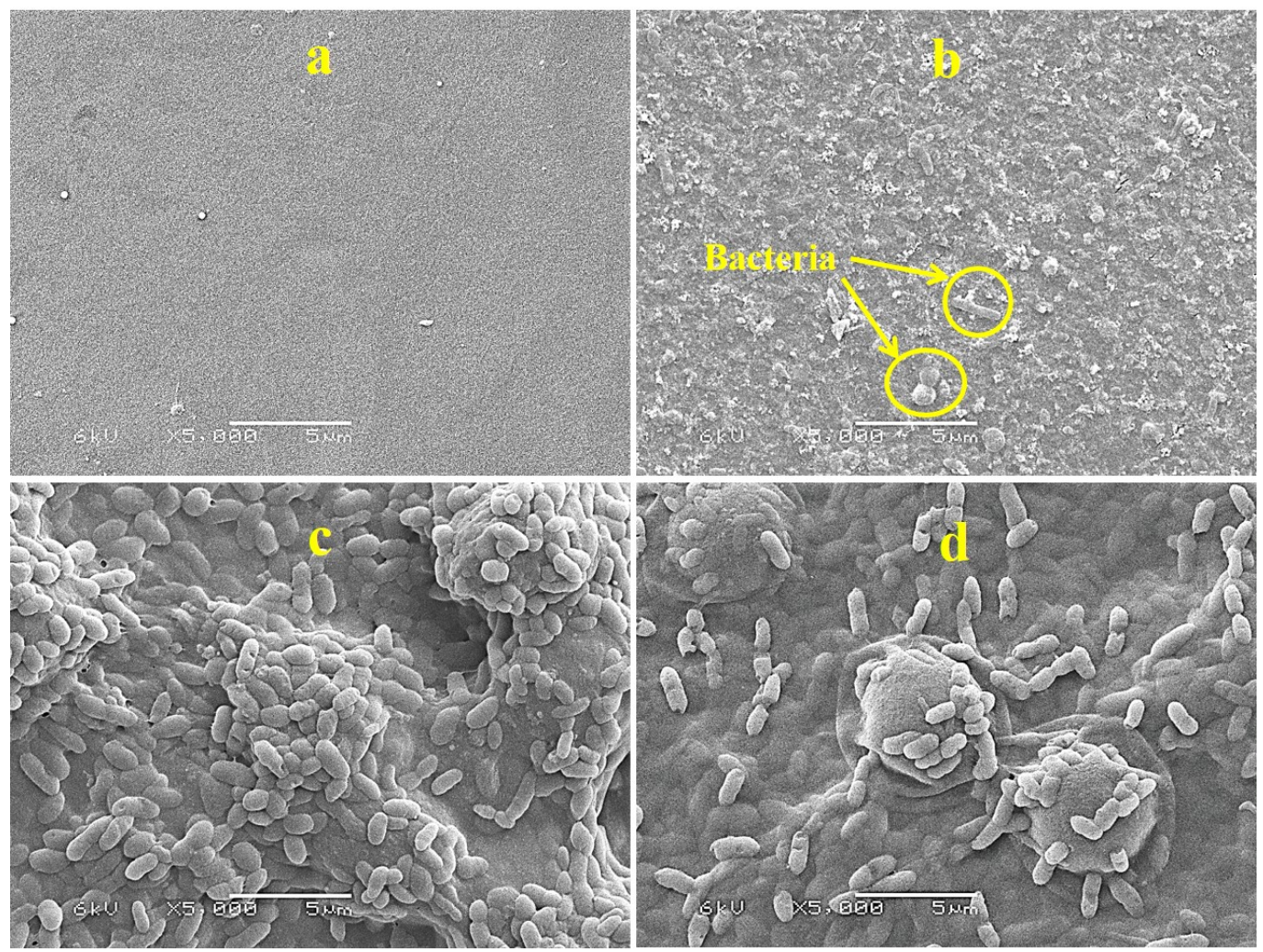

Figure 4.4: SEM images taken after autopsy after 6 days of operation for MF and UF fed with tap water (M:D 1.31:1); a) clean membrane, b) UF-blank without nutrients, c) biofouled MF with nutrients, d) biofouled UF-with nutrients.

An additional analysis on EPS-polysaccharides and proteins is performed only for UF in order to be able to compare these data with the results presented in the forthcoming experimental sections. The measured polysaccharide values for M:D 1.31:1 are shown in Figure 4.5 and protein data is shown in Table 4.2. Previously, ATP data (Figure 4.3) showed that there is more bacterial biomass in the presence of nutrients. The polysaccharides data supports that more bacterial biomass leads to more polysaccharide secretion, since 10 times more polysaccharides were found in the presence of nutrients as seen in Figure 4.5.

\subsubsection{Varying ratios of Monovalent to Divalent (M:D) ions}

\section{Absence of divalent ions}

In this section, the effect of the absence of divalent cations in the feed on hydraulic resistances is described. Divalent ions $\left(\mathrm{Ca}^{2+}\right.$ and $\left.\mathrm{Mg}^{2+}\right)$ were removed and ionexchanged with monovalent ions $\left(\mathrm{Na}^{+}\right)$using an ion exchange resin. The final concentration monovalent ions $\mathrm{M}$ in the feed water with nutrients was $5.9 \pm 0.15 \mathrm{mEq} / \mathrm{L}$ (see Table 4.1). The concen- 


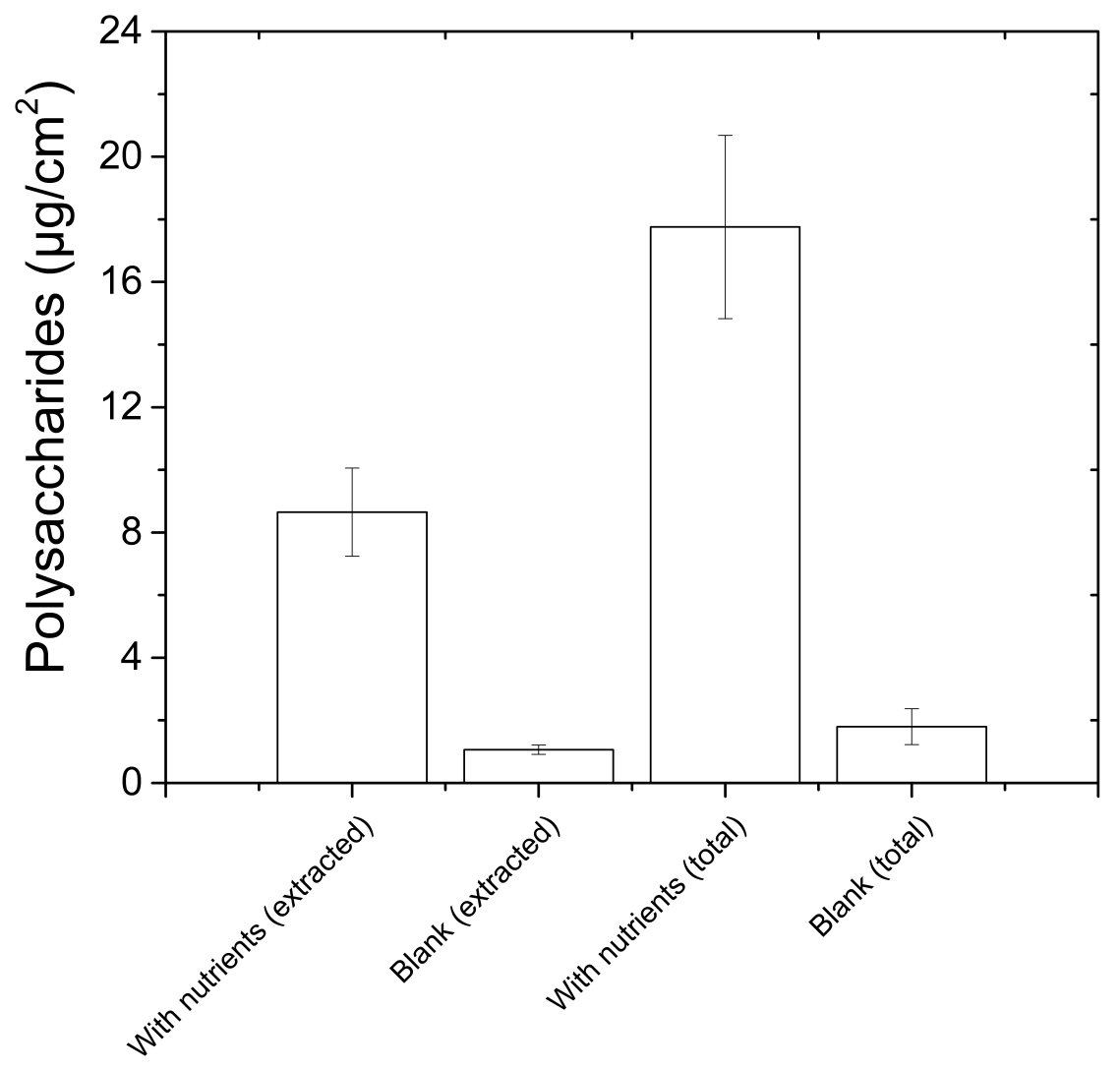

Figure 4.5: Extracted and total polysaccharides in the biofilm measured after 6 days of operation on UF fed with tap water (M:D 1.31:1) with and without nutrients at a constant TMP of 0.5 bar $(50 \mathrm{kPa})$.

tration of divalent ions decreased from $2 \mathrm{mEq} / \mathrm{L}$ to $<0.005 \mathrm{mEq} / \mathrm{L}$, and the corresponding hardness reduced from $8{ }^{\circ} \mathrm{dH}$ to $<1^{\circ} \mathrm{dH}$ (see Table 4.1). The UF membrane was operated with and without additional nutrients in ion-exchanged feed water, at a constant TMP of 0.5 bar. The schematics of the feed flow and operational conditions were similar to that described in section 4.3.1 (Figure 4.1).

An increase in feed channel pressure (FCP) is caused by the bacterial growth accompanied with excretion of extra cellular polymeric substances on the membrane surface [34, 38]. There was also almost no significant increase in FCP from day 1 ( 27 mbar) to day 6 (30 mbar) for the MFS fed with nutrients in the presence of only monovalent ions. This could indicate either there was no bacterial growth inside the feed channel, or the production and crosslinking of EPS components was greatly hampered by the absence of divalent cations in the feed water. Normalized flux declines in presence of monovalent ions only for MFS with and without nutrients are shown in Figure 4.6. The permeate flux decline is $68 \%$ for the UF membrane operated with nutrients in presence of only monovalent ions 
74 Hydraulic resistance of biofilms during ultrafiltration of drinking water: effect of monovalent to divalent ionic ratios

Table 4.2: Overall comparison of various parameters at three different monovalent to divalent (M:D) ionic ratios for UF operated with and without nutrients at TMP 0.5 bar.

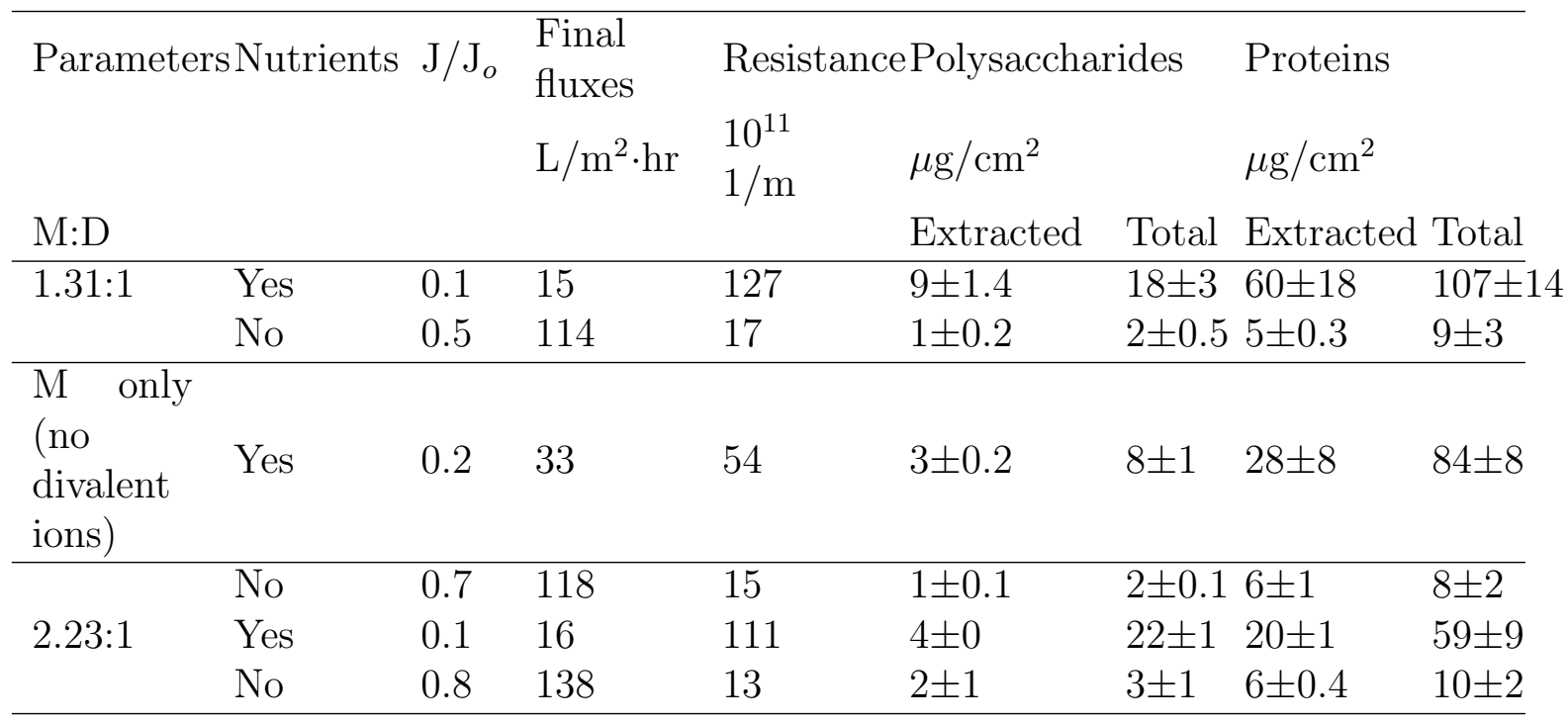

(Figure 4.6), compared to $93 \%$ for the UF membrane operated with nutrients at an M:D ratio of 1.31:1 (Figure 4.2). The final permeate fluxes in the presence of only monovalent ions are twice $\left(33 \mathrm{~L} / \mathrm{m}^{2} \cdot \mathrm{hr}\right.$, Table 4.2$)$ of those at M:D 1.3:1 $\left(15 \mathrm{~L} / \mathrm{m}^{2} \cdot \mathrm{hr}\right.$, Table 4.2$)$. The permeate flux decline observed for the MFS operated without nutrients in the presence of only monovalent ions is comparable to that at M:D 1.31:1. The final hydraulic resistances after 6 days of operation are calculated to be $54 \times 10^{11} 1 / \mathrm{m}$ and $15 \times 10^{11} 1 / \mathrm{m}$ for MFS with and without nutrients, respectively (Figure 4.6). The final hydraulic resistance at the end of the 6 days for the MFS with nutrients at M:D 1.3:1 (section 4.3.1) is almost 2.4 times higher than the final hydraulic resistance in presence of only monovalent ions, explained in this section.

Extracted and total polysaccharides measured after the membrane autopsy are shown in Figure 4.7. We notice that the presence of additional nutrients in feed led to bacterial growth as seen in the ATP data (Figure 4.8), but the hydraulic resistance of the biofilm developed on the membrane surface was small in absence of divalent cations. A plausible reason is the lower production of extracellular polymers such as polysaccharides in the absence of divalent cations (Figure 4.7) compared to the feed with M:D of 1.31:1 (Figure 4.5 , note the different y axis scale).

Similar to the hydraulic resistances, the total polysaccharides for the MFS operated with nutrient addition are also 2.4 times higher at M:D 1.31:1 than in the presence of monovalent ions only. An interesting correlation can be seen in the reduction of hydraulic resistances and corresponding total polysaccharides in the absence of divalent ions (in the presence of monovalent ions only). It is described in literature that excreted polysac- 


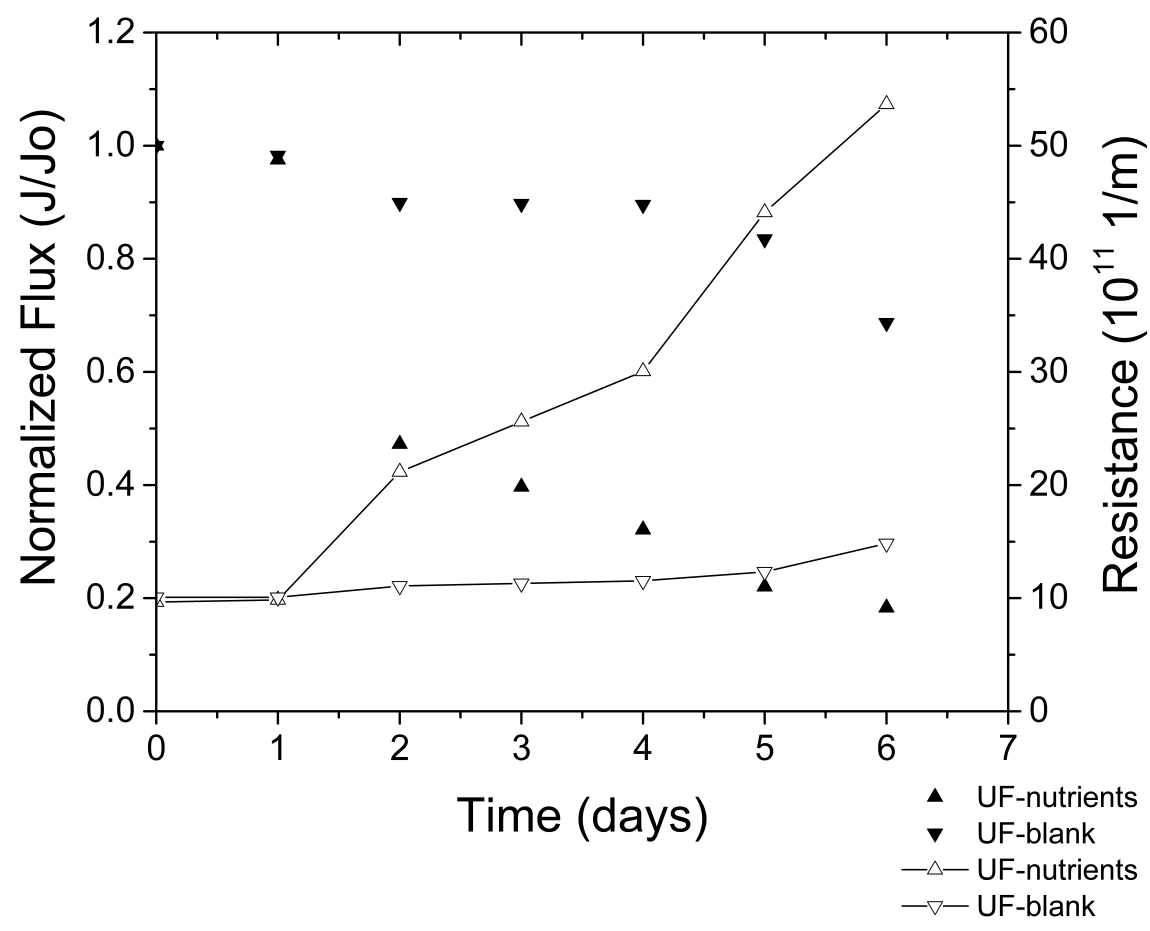

Figure 4.6: Normalized permeate flux decline (where $\mathrm{J}$ is final flux and $\mathrm{J}_{o}$ is initial flux) for UF fed with ion exchanged tap water (monovalent ions only, no divalent ions) with and without nutrients at a TMP of 0.5 bar $(50 \mathrm{kPa})$, closed symbols show normalized flux data on the left $\mathrm{y}$-axis and open symbols show resistance data on the right $\mathrm{y}$-axis.

charides contribute greatly to the hydraulic resistances of biofilms and membrane fouling [39-41]. Rosenberg et al. [42] reported a linear relation between the polysaccharide concentrations and corresponding fouling rates.

Two factors responsible for the reduction of hydraulic resistances and polysaccharides in absence of divalent ions are elaborated. Firstly, the direct influence of divalent cations on binding of polysaccharides and building a cohesive network of biofilm on the membrane surface is responsible for greater hydraulic resistances. The presence of divalent ions, specially $\mathrm{Ca}^{2+}$, leads to compaction of the electric double layer on the membrane surface and polysaccharide molecules. This results in lower electrostatic repulsions between the membrane surface and the polysaccharides, promoting gelation of the polysaccharides [33, $43,44]$. Research showed that the adhesion forces between negatively charged alginates (a polysaccharide like molecule) in the presence of $\mathrm{Ca}^{2+}$ are twice that in the absence of divalent cations [45]. In another study on model alginate macromolecules, it was shown that addition of $\mathrm{Ca}^{2+}$ promotes formation of calcium alginate complexes via crosslinking, leading to the formation of a hydrogel like layer on the membrane surface [33]. We can correlate the aforementioned literature findings on model polysaccharides (alginates) to 
76 Hydraulic resistance of biofilms during ultrafiltration of drinking water: effect of monovalent to divalent ionic ratios

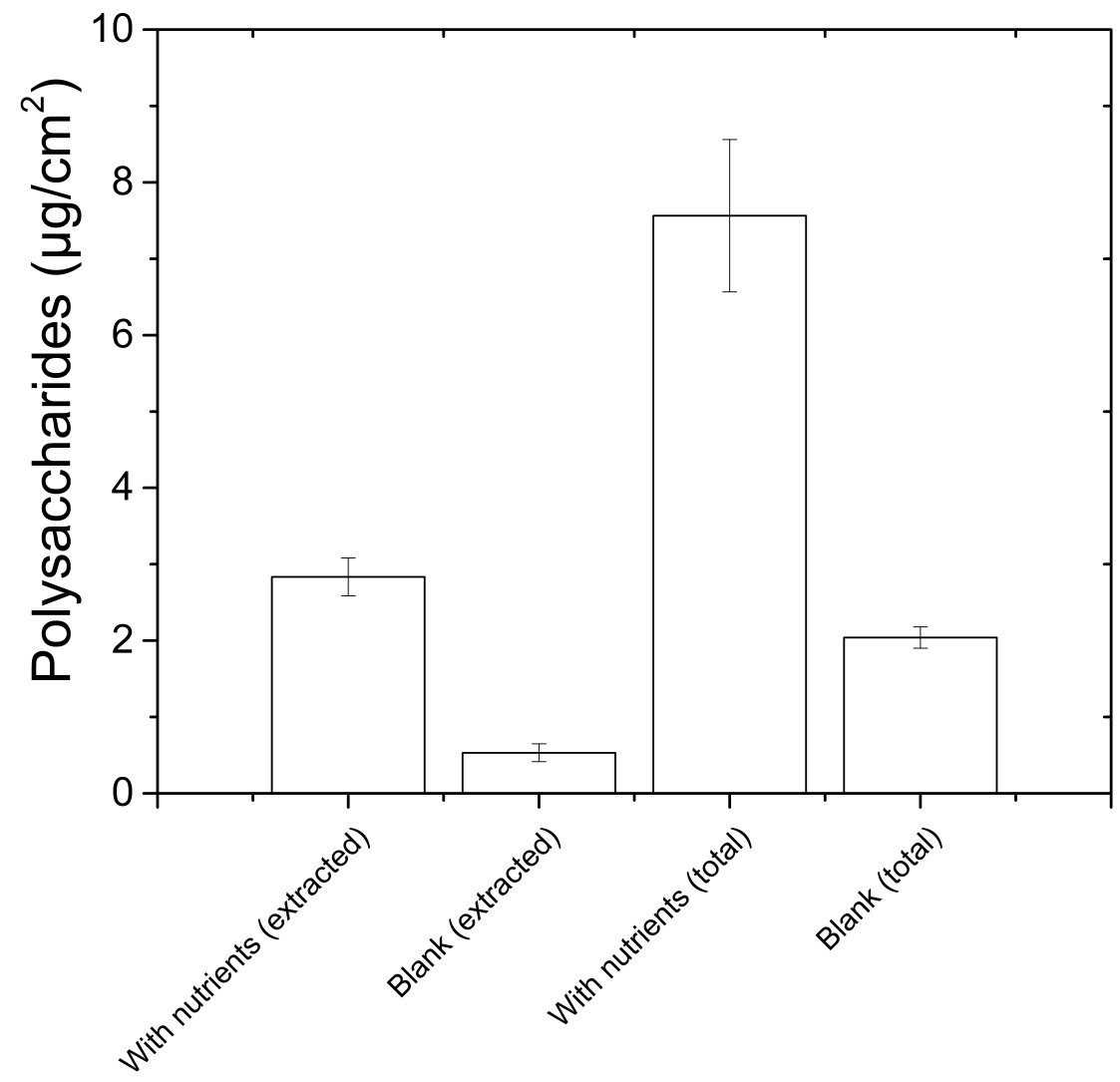

Figure 4.7: Extracted and total polysaccharides measured after 6 days of operation on UF fed with ion exchanged tap water (monovalent ions only, no divalent ions) with and without nutrients at a TMP of 0.5 bar $(50 \mathrm{kPa})$.

the present study, where we study real biofilms with the polysaccharides released by the natural consortium of bacteria in drinking water. Hence, we can state that due to crosslinking between divalent cations and polysaccharides a denser biofilm layer with a higher hydraulic resistance is formed in the presence of $\mathrm{Ca}^{2+}$.

Secondly, divalent cations act as intracellular cations and enzyme co-factors [20], and are involved in stimulating certain mechanisms within bacterial cells promoting biofilm formation, cell aggregation and adhesion, twitching mobility and EPS production [22, 24]. All these physiological phenomena contribute to the individual steps involved in biofilm formation. For example, twitching helps bacteria to colonize the surfaces, aggregation and adhesion initiate biofilm formation, and secreted EPS provides them with a sink of nutrients to thrive and eventually form a stable biofilm structure. We do not observe an FCP increase in the feed channel in the absence of divalent cations, which is most likely due to a the presence of a thinner biofilm layer. It also can be seen that polysaccharides concentrations decrease considerably in the absence of divalent cations. 


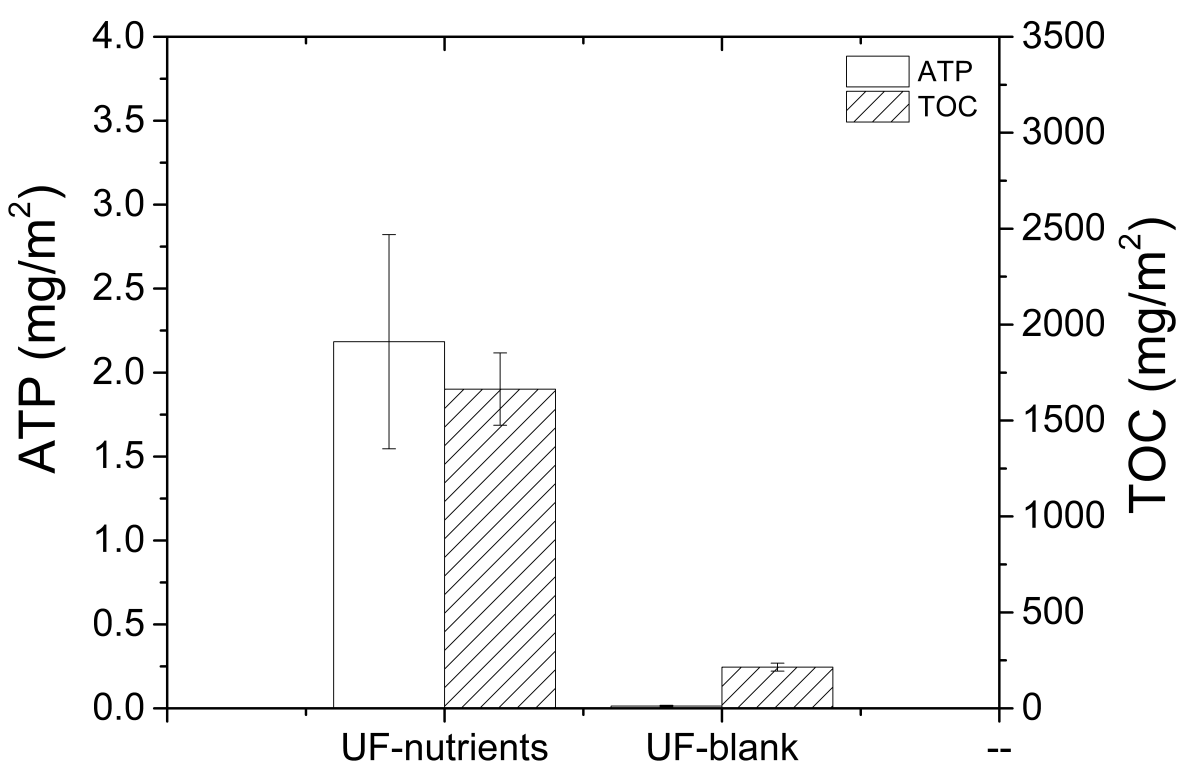

Figure 4.8: ATP and TOC accumulated after 6 days of operation on UF fed with ion exchanged tap water (monovalent ions only, no divalent ions) with and without nutrients at a TMP of 0.5 bar $(50 \mathrm{kPa})$.

Autopsied membranes were analyzed for ATP and TOC (Figure 4.8). There are no clear significant differences observed between ATP accumulated at M:D 1.31:1 vs. in the presence of monovalent ions only (Figures 4.3 vs. 4.8). Similar results are obtained for TOC deposited on the membrane surface, wherein an average TOC deposited is $1664 \pm 190$ $\mathrm{mg} / \mathrm{m}^{2}$ in the presence of monovalent ions only vs. $2236 \pm 520 \mathrm{mg} / \mathrm{m}^{2}$ at M:D 1.31:1. It shows that though the bacterial growth and accumulation occurred on the membrane surface, the absence of divalent cations restricted the production of EPS i.e. mainly polysaccharides. Formation of a biofilm layer along with EPS production by the bacteria poses a higher hydraulic resistance towards water transport. We can conclude that removing divalent cations decreases the resistance of real biofilms formed by natural bacterial consortia in drinking water, thereby demonstrating the potential to lower membrane biofouling.

\section{Addition of Magnesium ions (M:D 2.23:1)}

In this section, the effect of adding $\mathrm{Mg}^{2+}$ as divalent cation on hydraulic resistance is described. First, all the divalent ions were removed in a similar way as explained in section 4.2.2. Subsequently, $\mathrm{Mg}^{2+}$ was added to the feed along with other nutrients prior to the MFS to end up with a final M:D ratio in the feed water of 2.23:1. The concentration of divalent ions increased to $2.6 \mathrm{mEq} / \mathrm{L}$, as shown in Table 4.1. The UF membrane was operated for 6 days with and without additional nutrients at a constant TMP of 0.5 bar. 
78 Hydraulic resistance of biofilms during ultrafiltration of drinking water: effect of monovalent to divalent ionic ratios

The schematics of the feed flow and operational conditions were similar to section 4.3.1 (Figure 4.1).

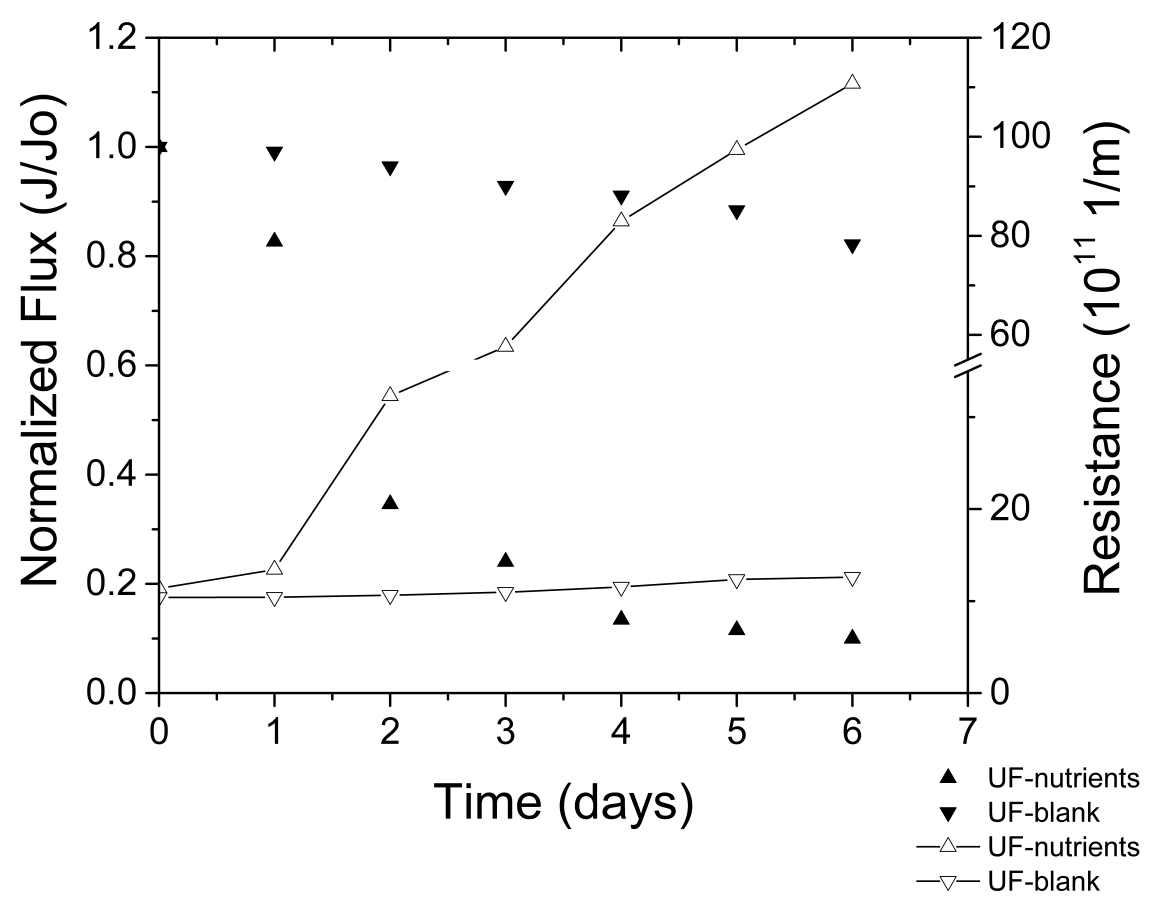

Figure 4.9: Normalized permeate flux decline (where $\mathrm{J}$ is final flux and $\mathrm{J}_{o}$ is initial flux) for UF fed with ion exchanged tap water (M:D 2.23:1) with and without nutrients and additional $\mathrm{Mg}$ at a TMP of 0.5 bar $(50 \mathrm{kPa})$ closed symbols show normalized flux data on the left $\mathrm{y}$-axis and open symbols show resistance data on the right $\mathrm{y}$-axis.

There was no significant increase in FCP during the 6 days of the experimental run in the presence of $\mathrm{Mg}^{2+}$ for both the MFS with and without nutrients. The permeate flux declined by $90 \%$ and $18 \%$ for MFS with and without nutrients, respectively (Figure 4.9). The final permeate fluxes after 6 days for the MFS with nutrients are $16 \mathrm{~L} / \mathrm{m}^{2} \cdot \mathrm{hr}$, and for the MFS without nutrients $138 \mathrm{~L} / \mathrm{m}^{2} \cdot \mathrm{hr}$ (Table 4.2). The final hydraulic resistances calculated for the MFS with nutrients at M:D 2.23:1 (110x10 11 1/m, Figure 4.9) are similar to the hydraulic resistances observed for MFS with nutrients at M:D 1.31:1 $\left(127 \times 10^{11} 1 / \mathrm{m}\right.$, Figure 4.2). Remarkably, we do not see an increase in FCP for MFS with nutrients at M:D 2.23:1 but we do observe that the hydraulic resistances are comparable to the MFS with nutrients at M:D 1.31:1.

A plausible reason for no change in FCP can be the difference between aggregation profiles of EPS molecules in the presence of $\mathrm{Ca}^{2+}$ versus $\mathrm{Mg}^{2+}$ which can possibly lead to completely different biofilm structures inside the feed channel. At M:D 1.31:1 (section 4.3.1), both the divalent cations are present, at M:D 2.23:1 (this section) only $\mathrm{Mg}^{2+}$ is 
present. It is known from literature that rapid gelation and growth of EPS aggregates occur in the presence of $\mathrm{Ca}^{2+}$ [46]. Ming et al. [46] reported the aggregation profiles of single strain bacterial EPS with $\mathrm{Ca}^{2+}$ and $\mathrm{Mg}^{2+}$. The hydrodynamic radius of EPS with $\mathrm{Ca}^{2+}$ was measured to be 3.3 times bigger than with $\mathrm{Mg}^{2+}$. Hence, larger aggregates formed in the presence of $\mathrm{Ca}^{2+}$. Additionally, the same authors also confirmed the complexation structures of bacterial EPS in the presence of both $\mathrm{Ca}^{2+}$ and $\mathrm{Mg}^{2+}$ via TEM. The images demonstrated that bacterial EPS attains a globular and thicker structure in the presence of $\mathrm{Ca}^{2+}$, while a rod shaped structure was revealed in the presence of $\mathrm{Mg}^{2+}$. Static light scattering measurements performed by Ming et al. [46] also showed much denser EPS aggregates in the presence of $\mathrm{Ca}^{2+}$ than in the presence of $\mathrm{Mg}^{2+}$. Correlating the aforementioned literature findings to our FCP data, we can assume that the complexes formed between polysaccharides and $\mathrm{Ca}^{2+}$ in the feed channel on the membrane surface are larger, and can be responsible for a significant increase in the FCP at M:D 1.3:1. On the other hand, the presence of thinner and patchy structures between polysaccharides in the presence of just $\mathrm{Mg}^{2+}$ did not affect FCP significantly.

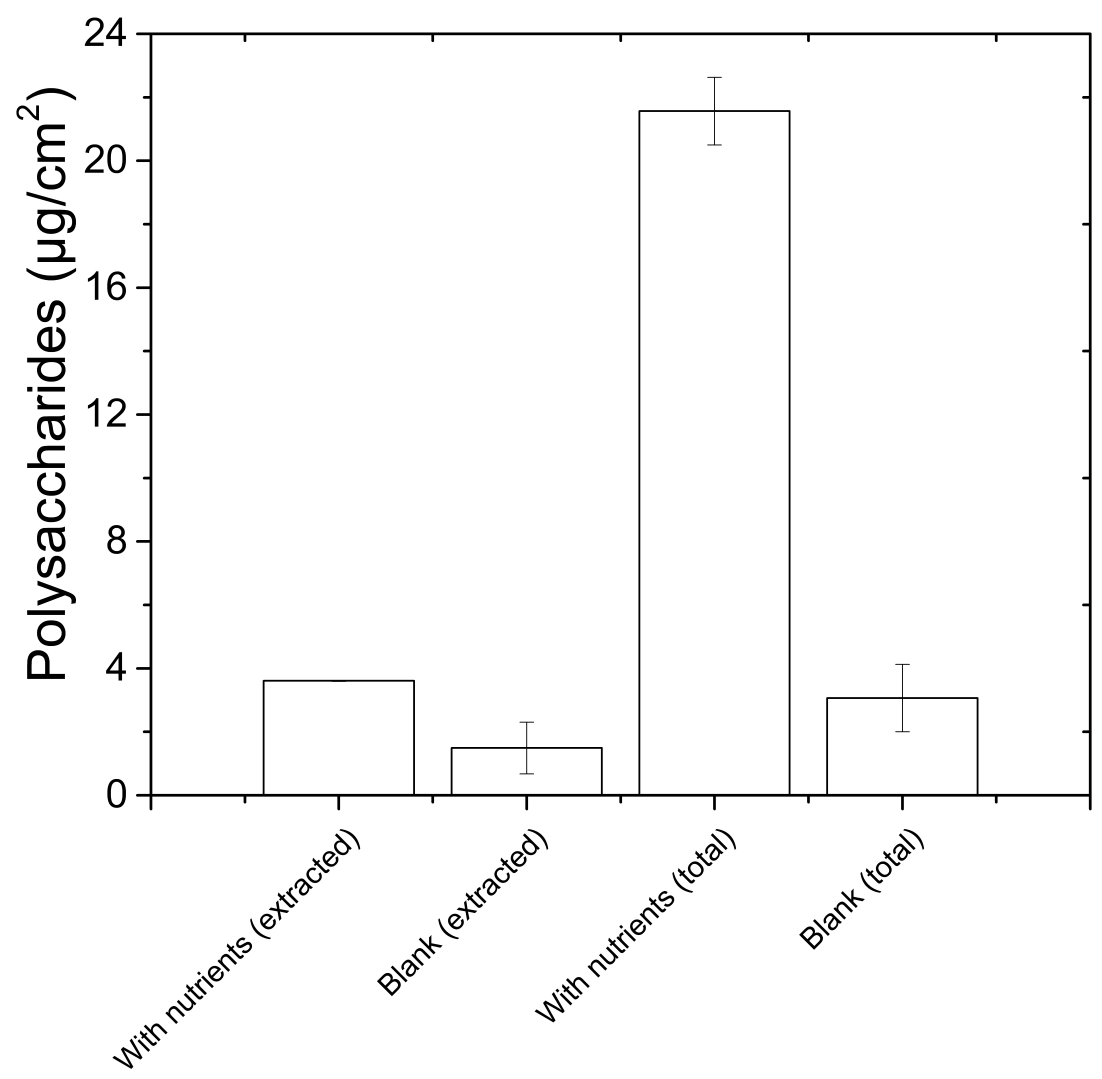

Figure 4.10: Extracted and total polysaccharides measured after 6 days of operation on UF fed with ion exchanged tap water (M:D 2.23:1) with and without nutrients and additional $\mathrm{Mg}$ at a TMP of 0.5 bar $(50 \mathrm{kPa})$. 
80 Hydraulic resistance of biofilms during ultrafiltration of drinking water: effect of monovalent to divalent ionic ratios

Total polysaccharide concentrations followed the similar trend as hydraulic resistances. Figure 4.10 shows the concentrations of extracted and total polysaccharides for the MFS operated with and without nutrients at M:D 2.23:1 (presence of $\mathrm{Mg}^{2+}$ as divalent ion). Total polysaccharides for the MFS with nutrients at M:D 2.23:1 are $22 \mu \mathrm{g} / \mathrm{cm}^{2}$, comparable to the concentrations of $18 \mu \mathrm{g} / \mathrm{cm}^{2}$ as measured at M:D 1.31:1 but significantly higher compared to the concentration of $8 \mu \mathrm{g} / \mathrm{cm}^{2}$ measured in the presence of monovalent ions only. A clear increase in total polysaccharides is seen after the addition of $\mathrm{Mg}^{2+}$ ions in feed water. Correlating total polysaccharides to hydraulic resistance, we notice that for higher polysaccharides concentration, a greater hydraulic resistance is obtained. Hence, the higher hydraulic resistance observed at M:D 2.23:1 can be explained by the secretion of more polysaccharides in the presence of divalent ion i.e. $\mathrm{Mg}^{2+}$.

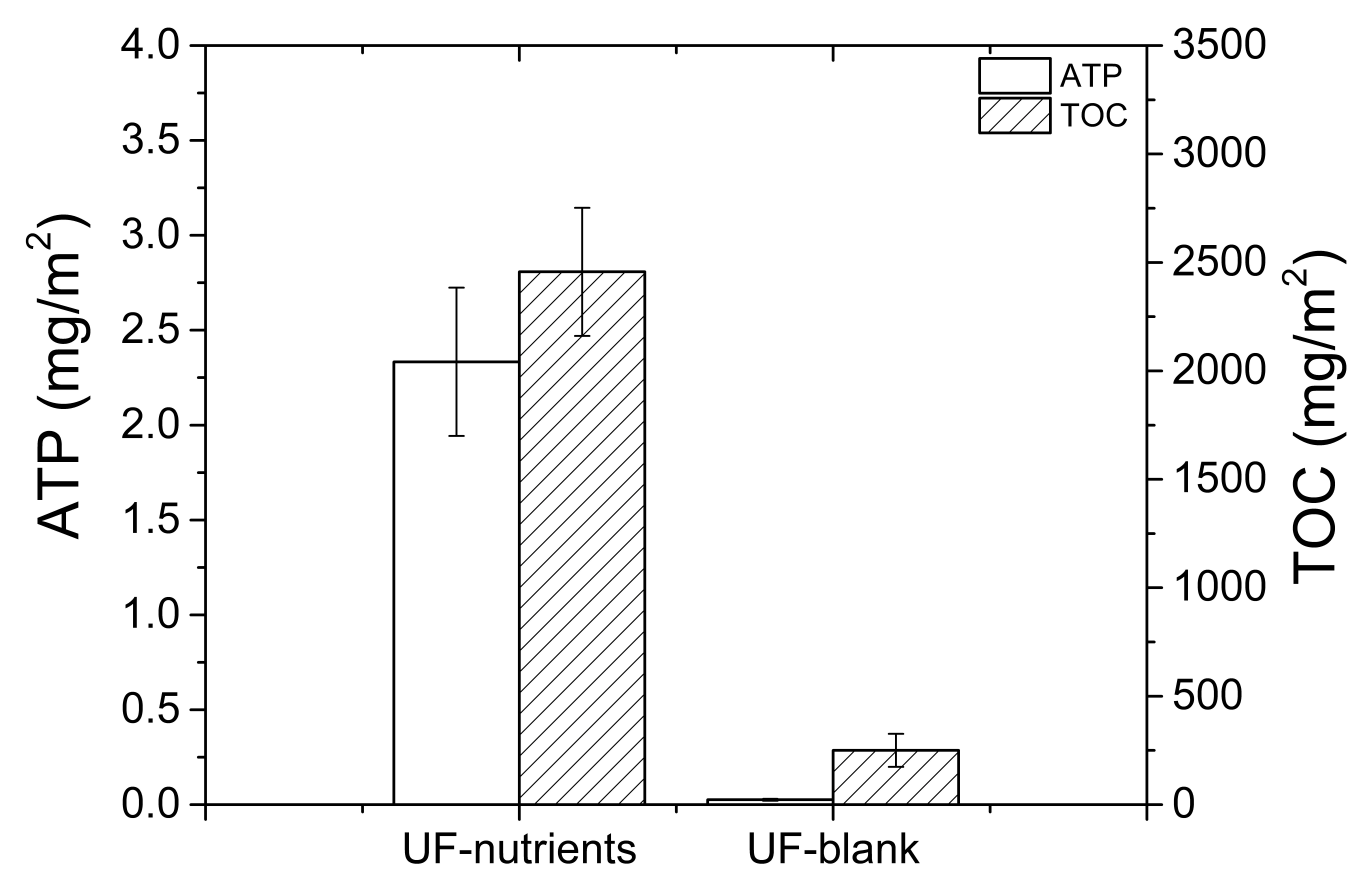

Figure 4.11: ATP and TOC accumulated on UF fed with ion exchanged tap water (M:D 2.23:1) with and without nutrients and additional $\mathrm{Mg}$ at a TMP of 0.5 bar (50 kPa).

Autopsied membranes were analyzed for ATP and TOC, and the results are shown in Figure 4.11. Average ATP values at M:D 2.23:1 are around $2.3 \mathrm{mg} / \mathrm{m}^{2}$ for the MFS with nutrients, comparable to the previously observed ATP values at M:D 1.31:1 and in the presence of monovalent ions only (Figures 4.3 and 4.8 respectively). The amount of TOC deposited is around $2460 \pm 295 \mathrm{mg} / \mathrm{m}^{2}$, which is also comparable to the TOC measured at M:D 1.31:1 $\left(2236 \pm 520 \mathrm{mg} / \mathrm{m}^{2}\right)$ and TOC in the presence of monovalent ions only $\left(1664 \pm 190 \mathrm{mg} / \mathrm{m}^{2}\right)$. The living biomass measured as ATP is comparable at the aforementioned 3 different M:D ratios, while the EPS-polysaccharide concentrations vary greatly. Clearly, EPS components secreted by bacteria contribute significantly to the hydraulic 
resistances compared to the bacterial biomass itself.

\section{Overall comparison of hydraulic resistances in the presence and absence of divalent ions}

An overall comparison for the three M:D ratios in terms of flux decline, final permeate fluxes, hydraulic resistances, polysaccharides and protein composition of biofouling layer (for ultrafiltration membrane operated with nutrients) is shown in Table 4.2. We observe a maximum flux decline in the presence of both divalent ions $\mathrm{Ca}^{2+}$ and $\mathrm{Mg}^{2+}$ at $\mathrm{M}: \mathrm{D}$ 1.31:1 (90-93\%). For different M:D ratios i.e. 1.31:1, only monovalent ions, and 2.23:1, we have three corresponding $\mathrm{Mg} / \mathrm{Ca}$ ratios i.e. 0.5, no divalent ions, 2.6 respectively. Arabi et al. [31] looked at the effects of varying $\mathrm{Mg} / \mathrm{Ca}$ and $\mathrm{M}: \mathrm{D}$ ratios on bioflocculation in MBRs. Their findings showed that a higher amount of $\mathrm{Mg}^{2+}$ leads to lower fouling by enhancing bioflocculation, provided the M:D ratios are 1:1. In the present study we observe that the highest $\mathrm{Mg} / \mathrm{Ca}$ ratio i.e. 2.6 (at M:D 2.23:1), has a lower hydraulic resistance compared to lowest $\mathrm{Mg} / \mathrm{Ca}$ ratio of 0.5 (at $\mathrm{M}: \mathrm{D}$ 1.31:1). This shows that highest hydraulic resistance at $\mathrm{M}: \mathrm{D}$ of $1.31: 1$ is caused by two effects i.e. the presence of divalent ions and the higher $\mathrm{Ca}^{2+}$ concentrations compared to $\mathrm{Mg}^{2+}$ in the feed water.
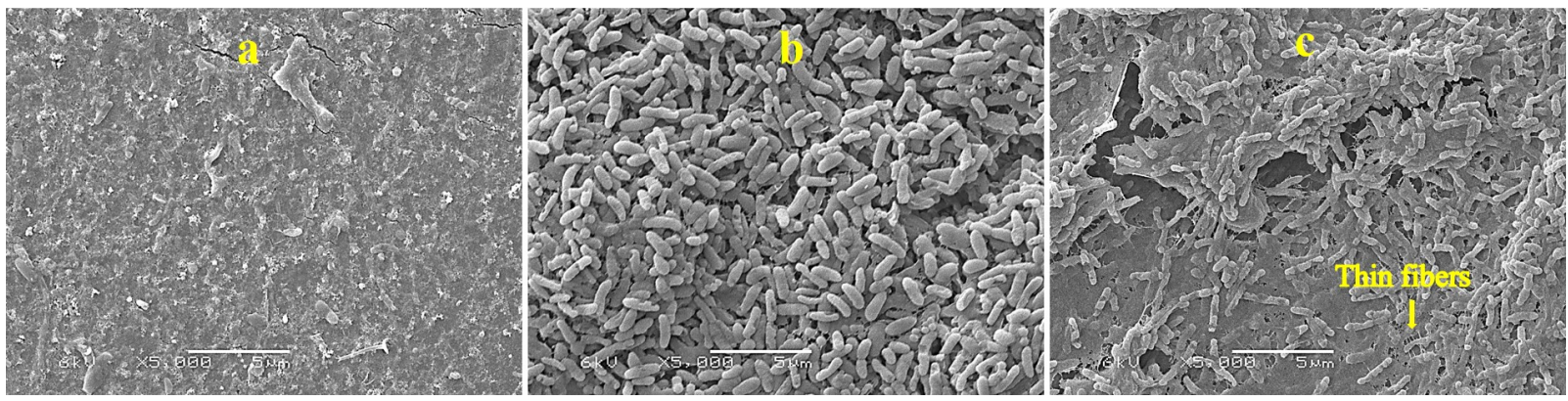

Figure 4.12: SEM images for autopsied UF membrane after 6 days of operation fed with tap water at different M:D ratios a) monovalent ions only, no divalent ions, without nutrients (no divalent ions), b) monovalent ions only, no divalent ions, with nutrients (no divalent ions), c) M:D 2.23:1, with nutrients (addition of $\mathrm{Mg}$ ).

An interesting correlation is seen between hydraulic resistances and polysaccharides concentrations. The removal of divalent ions leads to a decline in hydraulic resistances and a proportional decrease is observed for both extracted and total polysaccharides. In terms of percentage, extracted polysaccharides decrease by $67 \%$ and total polysaccharides decrease by $56 \%$ by removing divalent ions. Additionally, extracted proteins and total proteins are also shown in Table 4.2. Though extracted proteins decrease by $53 \%$, total proteins show somewhat smaller reduction (only 22\%) due to the removal of divalent ions which is difficult to explain and needs further investigation. SEM images also support the findings that the absence of divalent ions lowers the production of extracellular polymers 
82 Hydraulic resistance of biofilms during ultrafiltration of drinking water: effect of monovalent to divalent ionic ratios

(Figure 4.12). Figure 14.12a shows that the absence of additional nutrients in the presence of monovalent ions only does not lead to bacterial growth on the membrane surface. Similar images were obtained for M:D 1.31:1 and 2.23:1, hence these are not shown here. Figure $4.12 \mathrm{~b}$ shows that the presence of additional nutrients and the absence of divalent ions lead to considerable bacterial growth and an individual stacking of microbes. Contrastingly, Figure 4.12c shows that the presence of nutrients and the divalent ion $\mathrm{Mg}^{2+}$ leads to substantial growth as well as microbial colonies are connected via thin fibers which are most likely the polymeric substances excreted by bacteria.

Lower hydraulic resistances in the absence of divalent ions subsequently lead to higher permeate production. Cumulative permeate productions per unit membrane area are calculated from permeate fluxes. The cumulative permeate production is $13 \mathrm{~m}^{3} / \mathrm{m}^{2}$ in the absence of divalent ions for MFS operated for 6 days at 0.5 bar TMP (presence of monovalent ions only), compared to $7-8 \mathrm{~m}^{3} / \mathrm{m}^{2}$ in the presence of divalent ions (M:D 1.3:1 and 2.2:1) using similar operating conditions. Besides longer operational lifetime and safe drinking water delivered by membrane based PoU systems, production capacity also affects the overall acceptance and success of a membrane based PoU device in developing countries [1].

\subsection{Conclusions}

The effect of divalent cations on real drinking water biofilms grown under low pressure ultrafiltration has not yet been investigated. The present work provides useful insights into the effects of removing divalent cations on hydraulic resistances and production of polysaccharides, known to be major components of biofouling in membranes. In the present study, we studied hydraulic resistances of drinking water biofilms formed by natural consortium of bacteria on ultrafiltration at low operating pressures of 0.5 bar under three different monovalent to divalent (M:D) ratios: 1.31:1, monovalent (M) ions only, and 2.23:1. Removal of divalent cations from feed water considerably reduced the production of extracellular polymeric substances (EPS) such as polysaccharides. The hydraulic resistances of the biofilms were observed to be lowest in absence of divalent cations i.e. when only monovalent ions were present. Though the presence of magnesium as a divalent cation at M:D 2.23:1 promoted the secretion of polysaccharides, the hydraulic resistances were the highest when calcium was present in the feed and at M:D 1.31:1. This work shows the removal of divalent cations limits the secretion of EPS by the bacteria, which in turn reduces the hydraulic resistances of biofilms formed on the membrane surface. Therefore, including an ion-exchanger in PoU and decentralized drinking water systems could be seen as an effective strategy to deal with biofouling.

\section{References}

[1] M. Peter-Varbanets, C. Zurbrügg, C. Swartz, W. Pronk, Decentralized systems for potable water and the potential of membrane technology, Water Research, 43 (2009) 245- 
265.

[2] M. Peter-Varbanets, W. Gujer, W. Pronk, Intermittent operation of ultra-low pressure ultrafiltration for decentralized drinking water treatment, Water Research, 46 (2012) $3272-3282$.

[3] C. Chawla, A. Zwijnenburg, A. Kemperman, K. Nijmeijer, Biofouling assessment in simulated Point-of-Use(PoU) drinking water treatment systems, Submitted to Chemical Engineering Journal.

[4] S.B. Sadr Ghayeni, P.J. Beatson, A.J. Fane, R.P. Schneider, Bacterial passage through microfiltration membranes in wastewater applications, Journal of Membrane Science, 153 (1999) 71-82.

[5] H.-C. Flemming, Reverse osmosis membrane biofouling, Experimental Thermal and Fluid Science, 14 (1997) 382-391.

[6] J.S. Baker, L.Y. Dudley, Biofouling in membrane systems - a review, Desalination, 118 (1998) 81-90.

[7] D. De Beer, P. Stoodley, Microbial Biofilms, in: E. Rosenberg, E.F. DeLong, S. Lory, E. Stackebrandt, F. Thompson (Eds.) The Prokaryotes: Applied Bacteriology and Biotechnology, Springer Berlin Heidelberg, Berlin, Heidelberg, 2013, pp. 343-372.

[8] E. Bar-Zeev, K.R. Zodrow, S.E. Kwan, M. Elimelech, The importance of microscopic characterization of membrane biofilms in an unconfined environment, Desalination, 348 (2014) 8-15.

[9] M. Herzberg, M. Elimelech, Biofouling of reverse osmosis membranes: Role of biofilm-enhanced osmotic pressure, Journal of Membrane Science, 295 (2007) 11-20.

[10] M. Herzberg, S. Kang, M. Elimelech, Role of Extracellular Polymeric Substances (EPS) in Biofouling of Reverse Osmosis Membranes, Environmental Science \& Technology, 43 (2009) 4393-4398.

[11] J. Wingender, H.-C. Flemming, Biofilms in drinking water and their role as reservoir for pathogens, International Journal of Hygiene and Environmental Health, 214 (2011) 417-423.

[12] A.W. Decho, Overview of biopolymer-induced mineralization: What goes on in biofilms?, Ecological Engineering, 36 (2010) 137-144.

[13] H.C. Flemming, J. Wingender, The biofilm matrix, Nature Reviews Microbiology, 
84 Hydraulic resistance of biofilms during ultrafiltration of drinking water: effect of monovalent to divalent ionic ratios

8 (2010) 623-633.

[14] B. Song, L.G. Leff, Influence of magnesium ions on biofilm formation by Pseudomonas fluorescens, Microbiological research, 161 (2006) 355-361.

[15] M.M. Loosdrecht, J. Lyklema, W. Norde, A.B. Zehnder, Bacterial adhesion: A physicochemical approach, Microb Ecol, 17 (1989) 1-15.

[16] G.G. Geesey, B. WigglesworthCooksey, K.E. Cooksey, Influence of calcium and other cations on surface adhesion of bacteria and diatoms: A review, Biofouling, 15 (2000) 195-205.

[17] J.W. Costerton, Z. Lewandowski, D.E. Caldwell, D.R. Korber, H.M. Lappin-Scott, Microbial biofilms, Annual Reviews in Microbiology, 49 (1995) 711-745.

[18] V. Körstgens, H.-C. Flemming, J. Wingender, W. Borchard, Influence of calcium ions on the mechanical properties of a model biofilm of mucoid Pseudomonas aeruginosa, Water Science and Technology, 43 (2001) 49-57.

[19] A.J. de Kerchove, M. Elimelech, Calcium and Magnesium Cations Enhance the Adhesion of Motile and Nonmotile Pseudomonas aeruginosa on Alginate Films, Langmuir, 24 (2008) 3392-3399.

[20] M. Fletcher, Attachment of Pseudomonas fluorescens to glass and influence of electrolytes on bacterium-substratum separation distance, Journal of Bacteriology, 170 (1988) 2027-2030.

[21] Y. Fang, S. Al-Assaf, G.O. Phillips, K. Nishinari, T. Funami, P.A. Williams, L. Li, Multiple Steps and Critical Behaviors of the Binding of Calcium to Alginate, The Journal of Physical Chemistry B, 111 (2007) 2456-2462.

[22] S. Sarkisova, M. Patrauchan, D. Berglund, D. Nivens, M. Franklin, Calciuminduced virulence factors associated with the extracellular matrix of mucoid Pseudomonas aeruginosa biofilms, Journal of bacteriology, 187 (2005) 4327-4337.

[23] H. Moritaka, H. Fukuba, K. Kumeno, N. Nakahama, K. Nishinari, Effect of monovalent and divalent cations on the rheological properties of gellan gels, Food Hydrocolloids, 4 (1991) 495-507.

[24] L.F. Cruz, P.A. Cobine, L. De La Fuente, Calcium Increases Xylella fastidiosa Surface Attachment, Biofilm Formation, and Twitching Motility, Applied and Environmental Microbiology, 78 (2012) 1321-1331. 
[25] M.A. Patrauchan, S. Sarkisova, K. Sauer, M.J. Franklin, Calcium influences cellular and extracellular product formation during biofilm-associated growth of a marine Pseudoalteromonas sp, Microbiology, 151 (2005) 2885-2897.

[26] D. Lattner, H.-C. Flemming, C. Mayer, 13C-NMR study of the interaction of bacterial alginate with bivalent cations, International Journal of Biological Macromolecules, 33 (2003) 81-88.

[27] B. Song, L.G. Leff, Identification and characterization of bacterial isolates from the Mir space station, Microbiological Research, 160 (2005) 111-117.

[28] G.S. Tamura, J. Kuypers, S. Smith, H. Raff, C. Rubens, Adherence of group B streptococci to cultured epithelial cells: roles of environmental factors and bacterial surface components, Infection and immunity, 62 (1994) 2450-2458.

[29] W. Dunne, E.M. Burd, The effects of magnesium, calcium, EDTA, and pH on the in vitro adhesion of Staphylococcus epidermidis to plastic, Microbiology and immunology, 36 (1992) 1019-1027.

[30] S.F. Simoni, T.N.P. Bosma, H. Harms, A.J.B. Zehnder, Bivalent Cations Increase Both the Subpopulation of Adhering Bacteria and Their Adhesion Efficiency in Sand Columns, Environmental Science \& Technology, 34 (2000) 1011-1017.

[31] S. Arabi, G. Nakhla, Impact of cation concentrations on fouling in membrane bioreactors, Journal of Membrane Science, 343 (2009) 110-118.

[32] P. van den Brink, A. Zwijnenburg, G. Smith, H. Temmink, M. van Loosdrecht, Effect of free calcium concentration and ionic strength on alginate fouling in cross-flow membrane filtration, Journal of Membrane Science, 345 (2009) 207-216.

[33] W.J.C. van de Ven, K.v.t. Sant, I.G.M. Pünt, A. Zwijnenburg, A.J.B. Kemperman, W.G.J. van der Meer, M. Wessling, Hollow fiber dead-end ultrafiltration: Influence of ionic environment on filtration of alginates, Journal of Membrane Science, 308 (2008) 218-229.

[34] C. Dreszer, J.S. Vrouwenvelder, A.H. Paulitsch-Fuchs, A. Zwijnenburg, J.C. Kruithof, H.C. Flemming, Hydraulic resistance of biofilms, Journal of Membrane Science, 429 (2013) 436-447.

[35] M. Dubois, K.A. Gilles, J.K. Hamilton, P. Rebers, F. Smith, Colorimetric method for determination of sugars and related substances, Analytical chemistry, 28 (1956) 350-356.

[36] J. Davey, A.I. Schäfer, Ultrafiltration to Supply Drinking Water in International Development: A Review of Opportunities, in: E.K. Yanful (Ed.) Appropriate Technolo- 
86 Hydraulic resistance of biofilms during ultrafiltration of drinking water: effect of monovalent to divalent ionic ratios

gies for Environmental Protection in the Developing World: Selected Papers from ERTEP 2007, July 1719 2007, Ghana, Africa, Springer Netherlands, Dordrecht, 2009, pp. 151-168.

[37] W.H. Organization, WHO International Scheme to Evaluate Household Water Treatment Technologies in, 2016, pp. 64.

[38] C. Dreszer, A.D. Wexler, S. Drusová, T. Overdijk, A. Zwijnenburg, H.C. Flemming, J.C. Kruithof, J.S. Vrouwenvelder, In-situ biofilm characterization in membrane systems using Optical Coherence Tomography: Formation, structure, detachment and impact of flux change, Water Research, 67 (2014) 243-254.

[39] Y. Ye, P. Le Clech, V. Chen, A.G. Fane, B. Jefferson, Fouling mechanisms of alginate solutions as model extracellular polymeric substances, Desalination, 175 (2005) 7-20.

[40] H. Ping Chu, X.-y. Li, Membrane fouling in a membrane bioreactor (MBR): Sludge cake formation and fouling characteristics, Biotechnology and Bioengineering, 90 (2005) 323-331.

[41] J. Zhang, H.C. Chua, J. Zhou, A.G. Fane, Factors affecting the membrane performance in submerged membrane bioreactors, Journal of Membrane Science, 284 (2006) $54-66$.

[42] S. Rosenberger, H. Evenblij, S. te Poele, T. Wintgens, C. Laabs, The importance of liquid phase analyses to understand fouling in membrane assisted activated sludge processessix case studies of different European research groups, Journal of Membrane Science, 263 (2005) 113-126.

[43] G.T. Grant, E.R. Morris, D.A. Rees, P.J.C. Smith, D. Thom, Biological interactions between polysaccharides and divalent cations: The egg-box model, FEBS Letters, 32 (1973) 195-198.

[44] K.I. Draget, O. Smidsrød, G. Skjåk-Bræk, Alginates from Algae, in: Biopolymers Online, Wiley-VCH Verlag GmbH \& Co. KGaA, 2005.

[45] B. Mi, M. Elimelech, Chemical and physical aspects of organic fouling of forward osmosis membranes, Journal of Membrane Science, 320 (2008) 292-302.

[46] M. Xie, E. Bar-Zeev, S.M. Hashmi, L.D. Nghiem, M. Elimelech, Role of Reverse Divalent Cation Diffusion in Forward Osmosis Biofouling, Environmental Science \& Technology, 49 (2015) 13222-13229 


\section{Chapter 5}

\section{Polyelectrolyte coated ultrafiltration membranes for reduced membrane fouling}

\subsection{Introduction}

Membrane technology has clear advantages for both drinking water and waste water treatment compared to conventional technologies such as media filtration, disinfection and adsorption. Especially low pressure membrane filtration is favored due to its smaller footprint, lack of thermal inputs and its efficiency in removing pathogenic microorganisms and colloidal matter $[1,2]$. The efficacy of membranes in delivering a high permeate quality makes it a favorable option for water treatment [1]. Despite the aforementioned advantages, membrane performance is often greatly hampered by fouling [3]. This leads to a decline in membrane performance in terms of permeate quality, the need for frequent cleaning intervals, a short membrane life span and high operational costs [4]. Fouling can be mitigated in various ways such as modification of the membrane surface [5], pre-treatment [6,7], and physical and chemical cleaning $[8,9]$

Modification of the membrane surface has been a popular research area, and has gained a lot of additional attention with the introduction of polyelectrolyte multilayer membranes (PEMMs) made via layer-by-layer (LbL) assembly. Polyelectrolyte multilayers (PEMs) were first studied by Decher et al. [10-12] and have found various applications in biomaterials, bio-sensing, cell and protein attachment. However, PEMs can also be built upon a membrane surface by alternating deposition of polycations and polyanions. Various parameters such as the number of polyelectrolyte layers, the chosen polyelectrolytes, and the ionic strength and $\mathrm{pH}$ of the dipping solution determine the multilayer properties and thereby the final membrane properties $[2,13,14]$. PEM based membranes thus can be optimized for a given application by tuning these parameters. Furthermore, coating of the multilayers is independent of the membrane geometry, and thus can be applied to flat 
sheet, tubular and hollow fibre membranes.

PEM based membranes are therefore becoming increasingly popular, and have shown very promising separation performance for various types of membranes. LbL-PEMs have been extensively tested for aqueous applications including ion exchange membranes [1520], nanofiltration [21, 22], phosphate recovery (using microfiltration membranes) [23] and wastewater treatment [24]. Especially poly(diallyldimethyl ammonium)chloride (PDADMAC) and poly(styrenesulfonic acid) (PSS) coatings result in excellent NF membranes with a very high chemical stability compared to commercially available NF membranes [25]. Chemical stability towards chemical cleaning is a huge benefit for water treatment applications, where very regular cleaning often is necessary.

Another major benefit of the LbL approach is that it allows very reproducible surface modifications, leading to controlled surface chemistries. For example, with PSS and PDADMAC it is possible to create, on the same membrane, either a surface coating with a strong negative charge or a surface coating with a strong positive charge. Such variations of the outer charge of nearly identical membranes can also provide fundamental insights on how surface chemistry affects fouling. With PDADMAC/PSS multilayer based membranes being so promising for water treatment applications, it becomes important to also understand how these membranes behave in the presence of foulants such as proteins and bacteria. PDADMAC has charged quaternary ammonium groups that are known for their anti-microbial activity $[13,26]$. On the other hand, the strong negative charge of PSS might be very beneficial in keeping away negatively charged foulants.

The surface charge of a membrane is known to affect its susceptibility to fouling $[8$, 27-30]. The electrostatic interactions between a membrane surface and foulants influence permeate fluxes, retention of potential foulants, fouling tendency, and also cleaning methodologies. Since most of the foulants in nature are negatively charged, including bacteria, a charged membrane can either repel or attract a foulant depending upon its native charge [31-37]. Mortiz et al. [27] showed that during ultrafiltration of dextran molecules (negatively charged), the permeate fluxes were halved when the membrane surface had a positive charge as compared to when it had a negative charge. It was further shown that higher attractive electrostatic interactions between dextran and membrane surface occurred when the latter had a positive charge. This led to a smaller resistance towards deposition and formation of a dextran fouling layer, and consequently lower permeate fluxes were observed. A similar observation was reported by Ma et al. [8], who showed that $10 \%$ increase and $20 \%$ decrease in permeate fluxes occurred when the foulants and membrane surface carried like-charges and unlike-charges, respectively. Varying the surface charge density of PVDF membranes by the addition of sulfonic acid groups on the membrane surface was also shown to influence flux decline and cake layer resistance [30]. The effect of the number of sulfonic acid groups on microfiltration of a polystyrene latex (negatively charged) suspension on sulfonated PVDF membranes (negatively charged) was studied, and it was reported that permeate fluxes were proportional to the surface charge density. Both the cake layer 
resistance and the rate of flux decline decreased with increasing surface charge density, mainly due to higher electrostatic repulsions between the membrane surface and the latex suspension. In a yet another study, a positively charged RO membrane suffered significant flux loss in the presence of anionic surfactants compared to their neutral counterparts [34]. Besides charge [38], hydration [39] due to PEM coatings also make it difficult for bacteria to come in contact with the membrane surface. The aforementioned studies demonstrate the significant influence of surface charges on fouling development and permeate fluxes. The charge of potential foulants obviously depends on the exact conditions, where for example protein molecules can also attain a positive charge during filtration depending upon the $\mathrm{pH}$ [32] and the ionic strength of the feed solution [28, 40]. It is shown that high $\mathrm{pH}$ and low salt concentrations can lead to higher electrostatic repulsions between foulants and charged membrane surfaces. Elzo et al. showed that dissociation of silanol groups, and thus the charge, during filtration of silica particles is affected by the $\mathrm{pH}$ of the solution [28]. The interparticle repulsion between negatively charged silica particles prevents particles from depositing, leading to a more open cake layer with a lower resistance and higher permeate fluxes. On the other hand, a lower $\mathrm{pH}$, high salt concentration and the additional presence of cations such as calcium ions decreases the repulsive interactions, leading to a thicker cake layer, lower fluxes and increased fouling [28, 40].

Currently there is a lack of experimental data and knowledge on fouling of membranes based on multilayers. Therefore, in the present work we study the fouling of a PDADMAC/PSS based PEM membrane both with a model foulant and as well as biofouling formation on these membranes. This also includes the first long term (6 days) fundamental biofouling study under dynamic conditions on these very relevant PDADMAC/PSS based PEM membrane systems. All fouling experiments were performed for PEM layers ending with either the anionic PSS or the cationic PDADMAC, to study the effect of membrane charge on fouling behavior. All results are compared to fouling on the base membrane (ultrafiltration polyethersulphone).

\subsection{Materials and Methods}

\subsubsection{Materials}

Negatively charged (zeta potential $-34 \mathrm{mV}$, Table 5.1) flat sheet polyethersulphone (PES) membranes (molecular weight cut-off $100 \mathrm{kDa}$ ) were purchased from Microdyn Nadir (Germany). The pore diameter corresponding to $100 \mathrm{kDa}$ was calculated to be around $18 \mathrm{~nm}$ [41]. Poly(diallyldimethylammonium)chloride PDADMAC (molecular weight $<35 \%$ in water), poly(styrenesulphonic acid) PSS (75 kDa) and bovine serum albumin (BSA, molecular weight $66 \mathrm{kDa}$ ) were purchased from Sigma-Aldrich (the Netherlands) and used without further purification. Milli-Q water (resistivity $>18 \mathrm{M} \Omega \cdot \mathrm{cm}$ ) used in the experiments was obtained from a Millipore Milli-Q Biocel with a Q-grade@ column. Polyelectrolyte solu- 
tions at concentrations of $0.1 \mathrm{~g} / \mathrm{L}$ were prepared in a $0.05 \mathrm{M} \mathrm{NaCl}$ solution. Sodium chloride $(0.05 \mathrm{M})$ solutions were used for rinsing away excess polyelectrolyte solution from the membrane surface. BSA was used as a model foulant at a concentration of $5 \mathrm{mg} / \mathrm{L}$. The conductivity and $\mathrm{pH}$ of the BSA feed solution were $13.2 \mu \mathrm{S} / \mathrm{cm}$ and 6.0 , respectively, $\mathrm{BSA}$ is negatively charged at the given $\mathrm{pH}$ of 6.0. For the biofouling experiments, sodium acetate as carbon source, sodium nitrate as nitrogen source and sodium hydrogen phosphate as phosphorus source were added to tap water at a ratio of C:N:P of 100:20:10 with a final carbon concentration of $1 \mathrm{ppm}$ in feed water. These nutrients were added to accelerate biofilm growth.

\subsubsection{Membrane modification by LBL-PEMs}

The virgin UF membranes were initially soaked in deionized (DI) water overnight to get rid of conservation agents and for wetting the membrane. The next day, the membranes were rinsed with DI water three times prior to coating. PEMs were coated on the membrane surface (Figure 5.1) via dip coating. The membranes were completely soaked in the solution (step 1) i.e. $0.1 \mathrm{~g} / \mathrm{L} \mathrm{PDADMAC}$ in $0.05 \mathrm{M} \mathrm{NaCl}$ for 30 minutes, thereby acquiring a positive charge due to a layer of adsorbed PDADMAC on the membrane surface. This was followed by three times rinsing in different $0.05 \mathrm{M} \mathrm{NaCl}$ solutions (step 2), to remove any unbound and weakly bound polyelectrolyte chains. In a similar way, a layer of 0.1 $\mathrm{g} / \mathrm{L}$ PSS in $0.05 \mathrm{M} \mathrm{NaCl}$ was adsorbed on the membrane surface (step 3) followed by the same three times rinsing (step 4) in $0.05 \mathrm{M} \mathrm{NaCl}$ solutions. By repeating this process, any desired number of layers could be deposited on the membrane surface. In our study we coated membrane with 2 bilayers i.e. (PDADMAC/PSS) $)_{2}$ with the negatively charged PSS as the terminating layer, and 2.5 bilayers i.e. (PDADMAC/PSS) $)_{2} / \mathrm{PDADMAC}$ with positively charged PDADMAC as the terminating layer.

\subsubsection{Membrane characterization}

Coated and uncoated membranes were characterized on zeta potential, hydrophilicity and surface roughness. The zeta potential measurements were performed using an electrokinetic analyzer SurPASS system (Anton Paar, Graz Austria). The zeta potential was calculated by measuring the streaming current versus the pressure in a $5 \mathrm{mM} \mathrm{KCl}$ solution at room temperature using the following equation:

$$
\zeta=\frac{d I}{d P} \frac{\eta}{\varepsilon \varepsilon_{o}} \frac{L_{s}}{A_{s}}
$$

where $\zeta$ is zeta potential $(\mathrm{V}), I$ is the streaming current $(\mathrm{A}), P$ is the pressure $(\mathrm{Pa})$, $\eta$ is the dynamic viscosity of the electrolyte solution (Pa.s), $\varepsilon$ is the dielectric constant of the electrolyte, $\varepsilon_{o}$ is the vacuum permittivity $(\mathrm{F} / \mathrm{m}), L_{s}$ is length of the channel $(\mathrm{m})$ and 


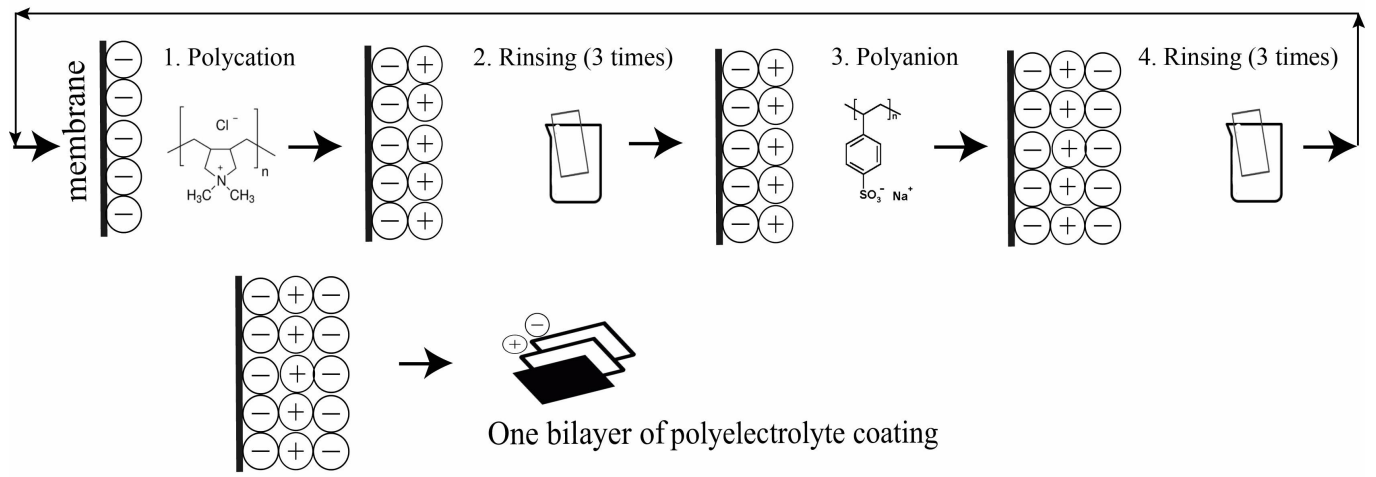

Figure 5.1: Coating procedure for layer-by-layer deposition of polyelectrolyte multilayers on a negatively charged PES membrane. $0.05 \mathrm{M} \mathrm{NaCl}$ solution was used for rinsing steps 2 and 4.

$A_{s}$ is the cross section of the streaming channel $\left(\mathrm{m}^{2}\right)$.

The coated UF membranes were dried and examined by atomic force microscopy (AFM) in air using a Dimension Icon AFM (Bruker, Leiderdorp, The Netherlands) and a ScanAsyst-Air probe (nominal spring constant $0.4 \mathrm{~N} / \mathrm{m}$ ); Bruker, Leiderdorp, The Netherlands). Five spots on each sample were randomly chosen and height sensor data were acquired on areas of $5 \times 5 \mu \mathrm{m}$ on each spot using PeakForce tapping mode at $2 \mathrm{kHz}$, with a scan rate of $1 \mathrm{~Hz}$ and $512 \times 512$ pixels. In post-processing, using the supplied Bruker Nanoscope Analysis software, a first order flattening of the data was performed and subsequently the average roughness was calculated of each $25 \mu \mathrm{m}^{2}$ scan. 3D images were created using the same flattened data.

The contact angle was measured by the captive bubble method using a dataphysics OCA 20 (Data Physics Instruments GmbH, Germany). Scanning Electron Microscopy (SEM) images were obtained using Jeol JSM-6010LA (Japan). The mechanical and chemical stability of PDADMAC and PSS multilayers previously have been tested in our group [25] and therefore were not determined again.

Sample preparation for SEM analysis of the biofouled membrane coupons was done differently than for virgin and BSA fouled membranes. Biological samples containing bacteria were fixated using glutaraldehyde to prevent the bacterial cell membrane from bursting under vacuum in SEM. Briefly, fixation of biofouled samples was carried out using 2.5\% (v/v) glutaraldehyde solution (Sigma Aldrich, Steinheim, Germany) and incubating them overnight at $4^{\circ} \mathrm{C}$. On the subsequent day, samples were washed with phosphate buffered saline (PBS) and dehydrated with ethanol. The washing step was performed three times for 7 minutes per step with 1X PBS (10 mM), followed by dehydration with $30 \%$, 50\%, 
$70 \%$, and $90 \%$ (v/v with Milli-Q) of ethanol solutions for 20 min each, and finally twice with $100 \%$ ethanol for 30 min each. BSA is abiotic hence did not require biological fixation with glutaraldehyde.

\subsubsection{Fouling studies}

Permeation experiments for fouling studies were conducted using two different systems. BSA fouling was studied using an Amicon type dead end filtration cell with a membrane area of $40 \mathrm{~cm}^{2}$ at constant pressure of 1 bar, using $5 \mathrm{mg} / \mathrm{L} \mathrm{BSA}$ at $\mathrm{pH} 6.0$ as feed. Biofouling studies were conducted using membrane fouling simulators (MFS) with flow cell height of $790 \mu \mathrm{m}$ and membrane filtration area of $200 \mathrm{~cm}^{2}$ operated in dead end mode without a feed spacer. The design of MFS was similar to the flow cells used by co-workers [42]. Each experimental run had one MFS with an uncoated membrane as the reference and two MFS with coated membranes. The data points for flux measurements are an average of duplicates for coated membranes. The uncoated membranes were highly reproducible between the runs, hence for each run we report single data point for flux measurements. Nutrients required for biofilm growth were supplied by a solution containing sodium acetate $\left(\mathrm{NaCH}_{3} \mathrm{COO}\right)$, sodium nitrate $\left(\mathrm{NaNO}_{3}\right)$ and sodium dihydrogen orthophosphate $\left(\mathrm{NaH}_{2} \mathrm{PO}_{4}\right)$ in a mass ratio C:N:P of 100:20:10. The nutrient solution was dosed to the tap water in front of the MFS to achieve a final organic carbon concentration of $1 \mathrm{ppm}$ in feed water. The nutrient supply was adjusted using a pump (Masterflex L/S pumps, Cole-Palmer Instrument Company, Vernon Hills, Illinois, USA). As the feed flow decreased in time due to fouling, accordingly the nutrient flow was reduced to keep the nutrient concentrations in the feed constant at $1 \mathrm{ppm}$ throughout the experimental run. The MFS were operated at a constant feed pressure of 1 bar. Forward flushing experiments were conducted by opening the crossflow valve and closing the permeate valve for 30 minutes. Forward flushing was carried out once a day. To assess the type of fouling and flux decline at constant pressure filtration, different blocking laws and cake filtration models are suggested [43]. Amongst the various plots proposed, we chose $t / V$ vs. $V$ assuming that cake filtration occurs for both uncoated and coated membranes. The cumulative permeate production $(V)$ and corresponding operational time intervals $(t)$ were plotted as per equation 5.2 adapted from literature [44]. The slope of the $t / V$ vs. $V$ graph i.e. the term $\frac{\eta I}{2 \Delta P A^{2}}$ in equation 5.2 corresponds to membrane fouling index (MFI) and was calculated from the graph using OriginPro 2016. MFI is based on cake filtration theory and is an index of the tendency of water containing colloids to foul a membrane. The reference temperature and pressure were $20^{\circ} \mathrm{C}$ and 1 bar respectively.

$$
\frac{t}{V}=\frac{\eta R_{m}}{\Delta P A}+\frac{\eta I}{2 \Delta P A^{2}} V
$$

Where $\eta$ is the viscosity of water (Pa.s), $R_{m}$ the membrane resistance $(1 / \mathrm{m}), \Delta P$ is the pressure drop across the membrane (bar), $A$ is the membrane surface area $\left(\mathrm{m}^{2}\right)$, and $I$ 
is a measure of the membrane fouling potential of water $\left(\mathrm{min} / \mathrm{mL}^{2}\right)$.

\subsection{Results and discussion}

\subsubsection{Membrane characterization}

Negatively charged PES ultrafiltration membranes (100 kDa molecular weight cut-off) were coated with PDADMAC/PSS as explained in the materials and method section 5.2.2. The coated membranes were characterized by clean water flux, SEM, zeta potential, AFM and contact angle measurements. Clean water fluxes for uncoated membranes were around $400 \mathrm{~L} / \mathrm{m}^{2} \cdot \mathrm{hr}$ which is in the range provided by the manufacturer, while for the coated membranes i.e. (PDADMAC/PSS) $)_{2}$ and (PDADMAC/PSS) $/$ PDADMAC, fluxes of 260 $\mathrm{L} / \mathrm{m}^{2} \cdot \mathrm{hr}$ and $200 \mathrm{~L} / \mathrm{m}^{2} \cdot \mathrm{hr}$ were obtained, respectively, all measured at 1 bar on $200 \mathrm{~cm}^{2}$ membrane filtration area. The observed decrease in flux shows that the membrane resistance increased somewhat after coating, providing a first indication of successful coating of the pore walls. Corresponding to the observed flux declines of $35 \%$ and $50 \%$ for clean water for (PDADMAC/PSS $)_{2}$ and (PDADMAC/PSS) $2 / \mathrm{PDADMAC}$ coatings, respectively, the reduction in pore diameter due to the coating was estimated to be $10 \%$ and $16 \%$, leading to the average coating thicknesses of $1 \mathrm{~nm}$ (2 layers) and $1.4 \mathrm{~nm}$ (2.5 layers) on the pore walls. The PEMs in the present study were coated from a $0.05 \mathrm{M} \mathrm{NaCl}$ solution. Under these conditions linear growth of PDADMAC/PSS multilayers was observed previously [45]. This particular ionic strength was chosen to keep the layers thinner and thereby keeping the hydraulic resistance increase to a minimum [45]. The pore radius was not measured in our study, however, there are several results on the effect of PEM coatings on the pore radius described in literature $[17,39,46,47]$. Often, surface modification by LBL deposition of polyelectrolytes leads to an increased hydraulic resistance towards water permeation [46].

The presence of the coating was further confirmed by zeta potential measurements. Results are shown in Figure 5.2. The uncoated membrane (open circles) remains negatively charged throughout $\mathrm{pH} 5$ to 9 , with no isoelectric point (IEP) observed in that $\mathrm{pH}$ range. PDADMAC with a high positive charge density reverses the surface charge as observed for the (PDADMAC/PSS) 2 /PDADMAC membrane (closed triangles). The membrane surface has a positive charge below and around neutral $\mathrm{pH}$, while a shift occurs around $\mathrm{pH}$ 8.1, the IEP of the coated membrane. Similar findings, where complexation of polycations such as PDADMAC reverses surface charge and an IEP appears at basic $\mathrm{pH}$, have been reported in literature [48]. The zeta potential for the PSS terminated (PDADMAC/PSS) 2 membrane (solid squares) was found to be stable in the $\mathrm{pH}$ range 6-9. The PSS terminated membrane does have a more negative charge than that of the uncoated membrane, at a value of about $-40 \mathrm{mV}$. In our fouling experiments described later, we used a $\mathrm{pH}$ around 6 , where our PDADMAC terminated membrane is positively charged and the PSS terminated 
membranes is negatively charged.

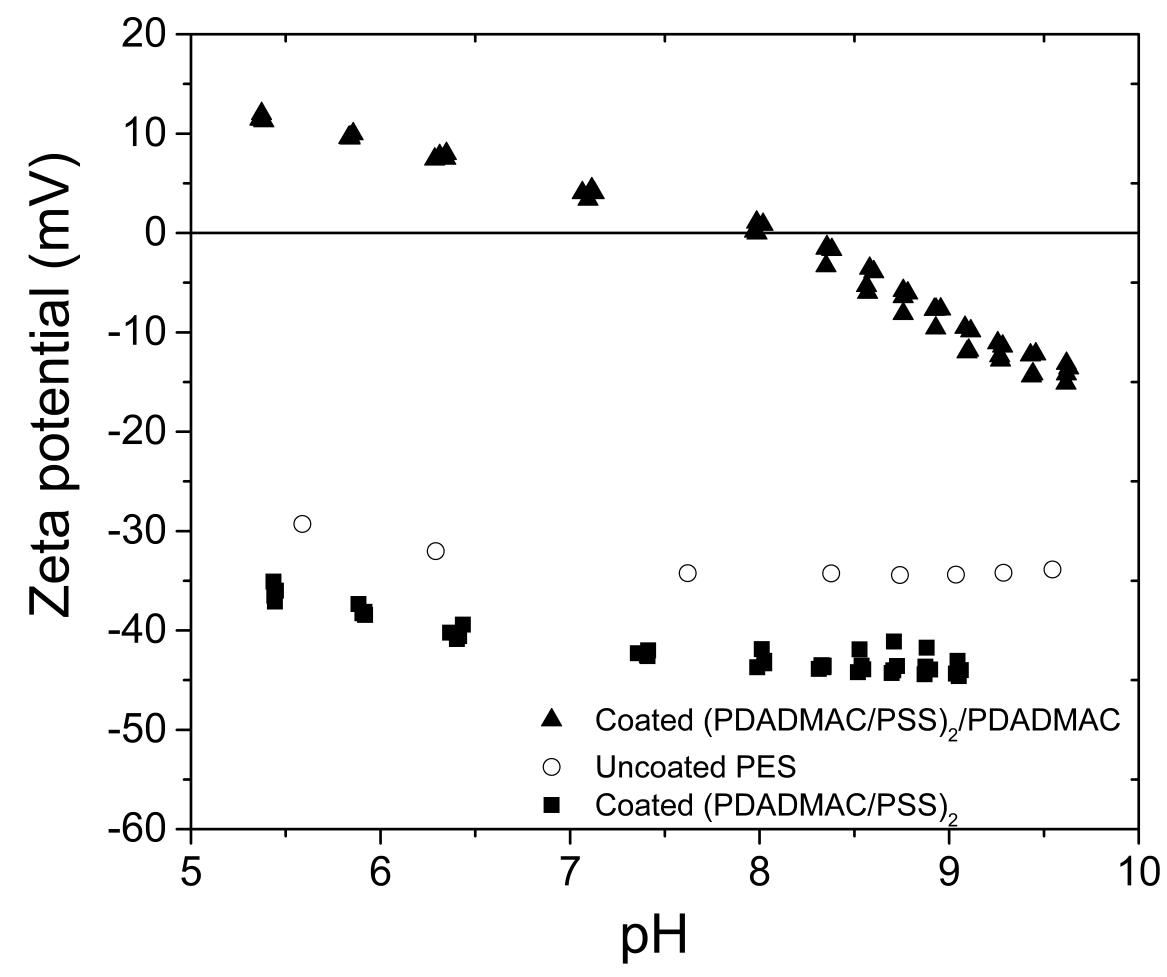

Figure 5.2: Zeta potential measurements for uncoated PES membrane and membranes coated with 2 layers i.e. (PDADMAC/PSS) 2 and 2.5 layers i.e. (PDADMAC/ $\mathrm{PSS})_{2} / \mathrm{PDADMAC}$.

The surface roughnesses of the uncoated and coated membranes were measured by AFM. Table 5.1 shows that coated membranes had almost twice the mean roughness as compared to the uncoated membrane. An increase in mean surface roughness from about $6 \mathrm{~nm}$ to $11 \mathrm{~nm}$ after coating was observed. This is in line with previous observations that PEM coatings can increase the roughness. For example, Tripathi et al. showed that after 10 polyelectrolyte bi-layers, the surface roughness increased from $24 \mathrm{~nm}$ to $39 \mathrm{~nm}$ due to the agglomeration and deposition of polyelectrolytes on the membrane surface [17]. Literature findings show that a rougher surface can lead to an increased fouling of the membrane surface [49].

The PEM did not affect the hydrophilicity of the membranes as is shown in Table 5.1. Uncoated membranes had an average contact angle of $32^{\circ} \pm 2.5$, similar to both types of coated membranes i.e. (PDADMAC/PSS) $)_{2}$ and (PDADMAC/PSS) $2 / \mathrm{PDADMAC}$. In the present study, coatings did not change the hydrophilicity of the membrane significantly in contrast to other studies where an increase in hydrophilicity was observed after PSS/PDADMAC coating [17]. This is most likely due to differences in the number of bilayers deposited on the membrane surfaces in the two studies, as we coated only 2 bi-layers in- 
Table 5.1: Surface characterization of coated membranes as contact angle, zeta potential and roughness measurements. AFM mode Peakforce QNM, area scanned 5x5 $\mu \mathrm{m}$ (an average of 5 different locations on a sample).

\begin{tabular}{cccc}
\hline Membrane type & $\begin{array}{c}\text { Contact angle } \\
\left(^{\circ}\right)\end{array}$ & $\begin{array}{c}\text { Zeta potential } \\
(\mathrm{mV})\end{array}$ & $\begin{array}{c}\text { Mean roughness } \\
(\mathrm{nm})\end{array}$ \\
\hline Uncoated PES & $32 \pm 2.5$ & -34 & $6 \pm 1$ \\
Coated (PDADMAC/PSS $)_{2}$ & $30 \pm 4.6$ & $42 \pm 0.3$ & $11 \pm 1$ \\
Coated (PDADMAC/PSS) $)_{2} /$ PDADMAC & $33 \pm 1.1$ & $3 \pm 1$ & $13 \pm 2$ \\
\hline
\end{tabular}

stead of the 10 bilayers used by Tripathi et al.[17]. The benefit of the observed constant hydrophilicity is that the major difference between the PSS terminated membrane and the PDADMAC terminated membranes is charge, allowing us to study just the effect of charge on the fouling propensity.

\subsubsection{Fouling potential of modified membranes}

\section{BSA fouling potential}

Coated membranes were evaluated on their macromolecular fouling potential, a commonly encountered phenomenon in ultrafiltration. Short term filtration tests were performed using a dead end filtration set-up. BSA at $5 \mathrm{mg} / \mathrm{L}$ and $\mathrm{pH} 6.0$ was used as a negatively charged foulant representing the class of protein foulants. As mentioned in section 5.3 .1 , clean water fluxes were around $400 \mathrm{~L} / \mathrm{m}^{2} \cdot \mathrm{hr}, 260 \mathrm{~L} / \mathrm{m}^{2} \cdot \mathrm{hr}$ and $200 \mathrm{~L} / \mathrm{m}^{2} \cdot \mathrm{hr}$ for uncoated, (PDADMAC/PSS) $)_{2}$ coated and (PDADMAC/PSS) $)_{2} /$ PDADMAC coated membranes respectively. The initial fluxes measured with BSA solution were $440 \mathrm{~L} / \mathrm{m}^{2} \cdot \mathrm{hr}$ for the uncoated membrane, $165 \mathrm{~L} / \mathrm{m}^{2} \cdot \mathrm{hr}$ for the (PDADMAC/PSS) $)_{2}$ coated membrane and $145 \mathrm{~L} / \mathrm{m}^{2} \cdot \mathrm{hr}$ for the (PDADMAC/PSS) $2 /$ PDADMAC coated membrane. So while for the uncoated membranes the BSA feed solution did not result in a significant decline in initial flux compared to the clean water flux, the coated membranes showed a substantial decline in initial fluxes compared to their clean water fluxes. It seems that the coated membranes are already fouled, even in the initial stages of our measurement.

The cumulative permeate production is relevant for practical application of membranes for drinking water treatment as it directly translates into the production capacity of a membrane module and provides an insight into membrane module performance. Hence, the cumulative permeate production of uncoated and coated membranes is plotted in Figure 5.3. We observe that in 60 minutes of filtration time, the uncoated membrane produced around $950 \mathrm{~mL}$ of permeate per unit membrane area compared to $400 \mathrm{~mL}$ of permeate per unit given membrane area produced by coated membranes. As explained above that a difference in the initial fluxes and higher permeability consequently leads to higher fluxes for uncoated membranes compared to coated membranes. This is most likely due to the increased resistance by PDADMAC/PSS coatings on the membrane surface and pore walls. 
A step wise increase in resistance with deposition of each bilayer of PDADMAC/PSS has been reported by our co-workers [25, 45].

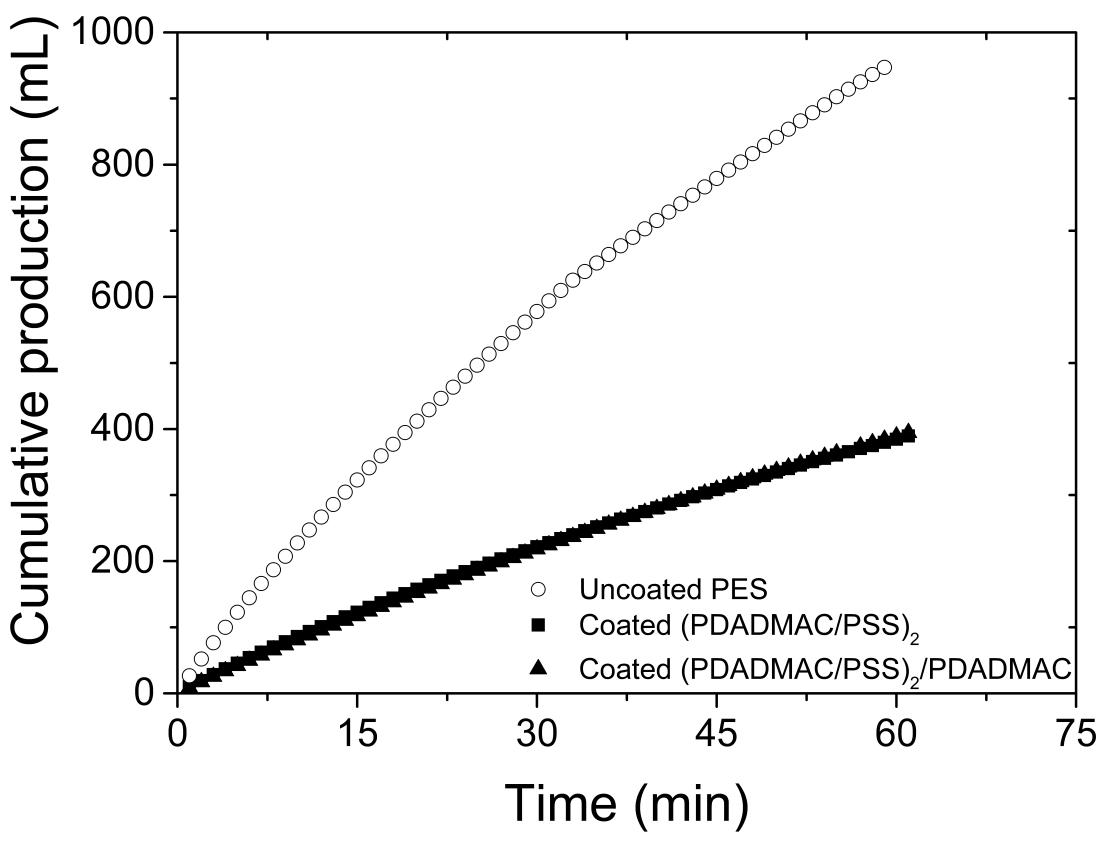

Figure 5.3: Cumulative water production of an uncoated PES membrane and membranes coated with 2 layers i.e. (PDADMAC/PSS) 2 and 2.5 layers i.e. (PDADMAC/ PSS $)_{2} / \mathrm{PDADMAC}$. Feed solution: $5 \mathrm{mg} / \mathrm{L} \mathrm{BSA}$ at $\mathrm{pH} 6.0$.

The membrane fouling index (MFI) was obtained graphically using the $t / V$ vs. $V$ plot (Figure 5.4), as explained in section 5.2.4. Using the $t / V$ vs. $V$ plot, membrane fouling index (MFI) can be derived as the gradient of the linear region of the plot from the general cake filtration equation [43]. The BSA filtration data in Figure 5.4 were fitted to linear equations for first $400 \mathrm{~mL}$ of filtered volume to calculate the slope referring to MFI [43]. MFI indices as calculated by these slopes were $2.9 \times 10^{-5} \mathrm{~min} / \mathrm{mL}^{2}\left(1740 \mathrm{~s} / \mathrm{L}^{2}\right)$ for the uncoated membrane, $1.4 \times 10^{-4} \mathrm{~min} / \mathrm{mL}^{2}\left(8400 \mathrm{~s} / \mathrm{L}^{2}\right)$ for the coated (PDADMAC/PSS $)_{2}$ membrane and $9.8 \times 10^{-5} \mathrm{~min} / \mathrm{mL}^{2}\left(5800 \mathrm{~s} / \mathrm{L}^{2}\right)$ for the coated (PDADMAC/PSS) $2 / \mathrm{PDAD}-$ MAC membrane. Comparable MFI values have been reported in literature for UF of tap water [43]. The linearity observed in $t / V$ vs. $V$ plots do indicate cake filtration for both uncoated and coated membranes. However, Boerlage et al. stated that MFI values of 6000 $\mathrm{s} / \mathrm{L}^{2}$ or above, similar to what we obtained for coated membranes, indicate severe blocking of UF membranes [43]. So, although we initially assumed cake filtration the above calculated high MFI values for coated membranes suggested pore blocking.

AFM images of the (PDADMAC/PSS $)_{2}$ membrane before and after BSA fouling are 
shown in Figure 5.5. The surface roughness of the coated membrane as measured by AFM was around $11 \mathrm{~nm}$ after coating (Table 5.1) and $10 \mathrm{~nm}$ after BSA fouling. There were no significant changes in the surface topography in terms of mean roughnesses after BSA fouling for both uncoated and coated membranes.

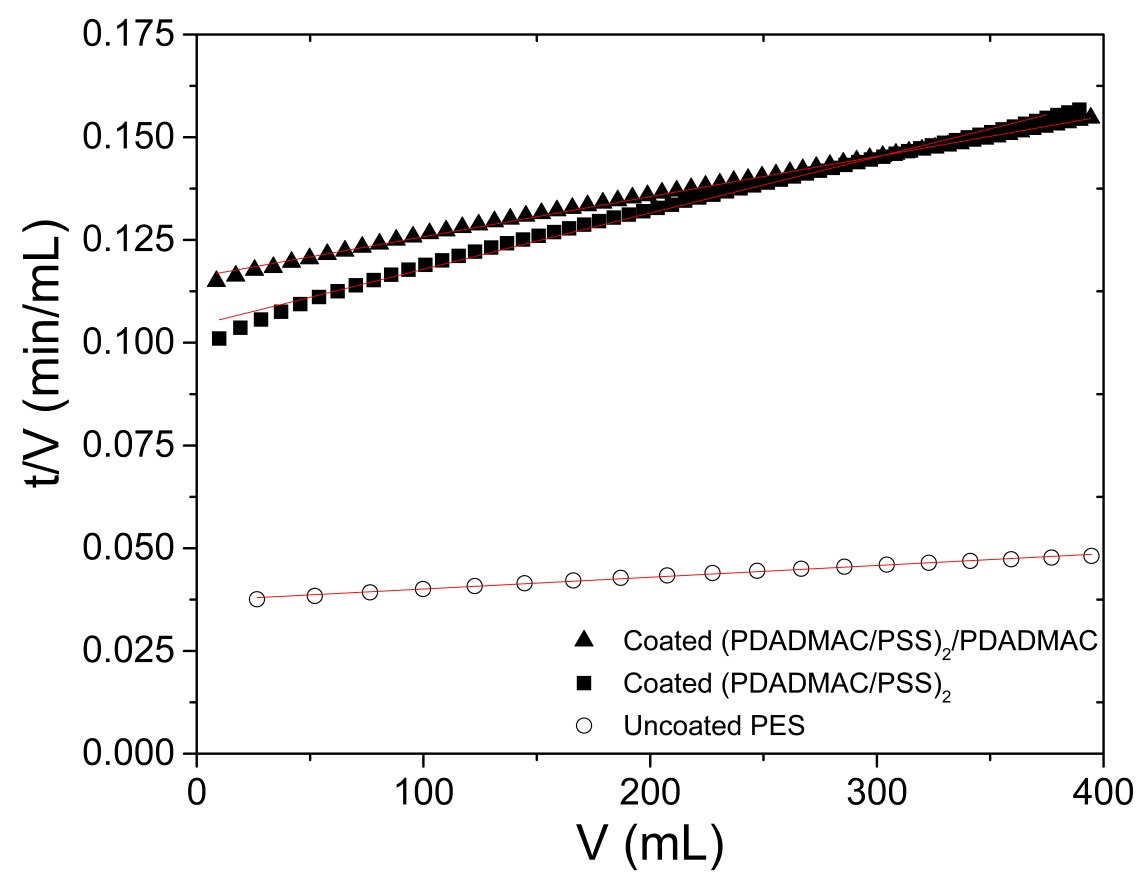

Figure 5.4: Variation of $\mathrm{t} / \mathrm{V}$ vs $\mathrm{V}$ (where $\mathrm{V}$ is cumulative permeate volume at a given time t) for uncoated membrane and coated membrane with 2 layers i.e. (PDADMAC/ PSS $)_{2}$ and 2.5 layers i.e. (PDADMAC/PSS) $2 / \mathrm{PDADMAC}$, Feed solution: $5 \mathrm{mg} / \mathrm{L} \mathrm{BSA}$ at $\mathrm{pH}$ 6.0 .

Coated membranes have narrower pores (and thus a lower surface porosity) compared to the substrate UF membrane, as was shown by a reduction in clean water fluxes for coated membranes. The reduced surface porosity of coated membranes has an effect on fouling development and subsequent permeate fluxes. Fane et al. have shown that membranes with lower surface porosity are susceptible to pore blocking leading to a significant loss of permeate fluxes [50]. Therefore, pore blocking has much more influence on the flux for the coated membranes due to narrowing of the pores after LBL coating. Additionally, BSA adsorption to polyelectrolyte chains can further increase fouling of PEM coated membranes. Surprisingly, the charge of the polyelectrolytes, i.e. PDADMAC (positive) terminated vs PSS (negative) terminated, does not affect fouling. Though negatively charged BSA is expected to adsorb to the positively charged PDADMAC, research also shows the possibility of adsorption of negatively charged BSA to strongly negative polyelectrolyte chains due to patchiness [51] or charge regulation [52] around $\mathrm{pH} 6$. We believe due to similar reasoning, 

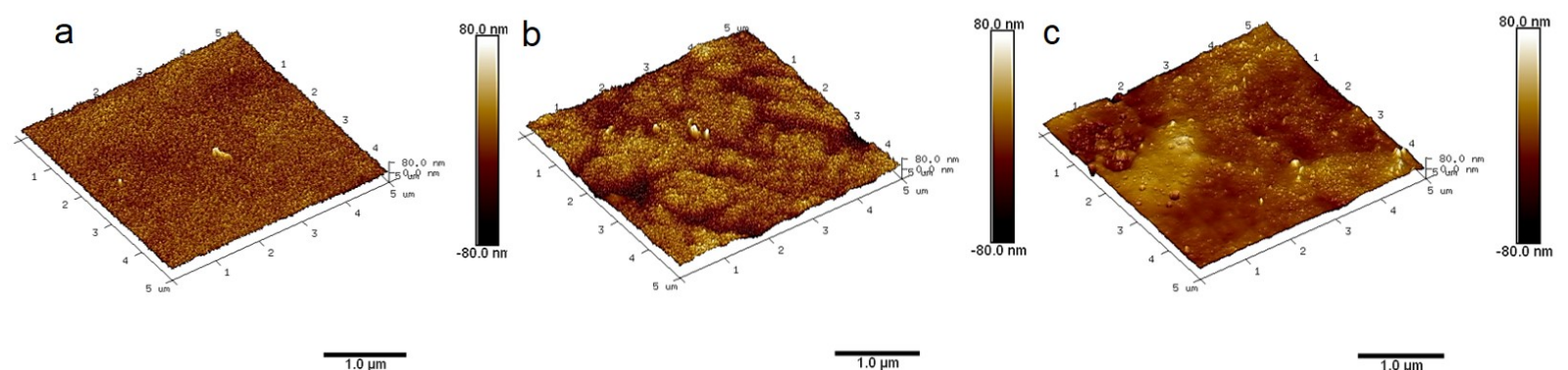

Figure 5.5: AFM images show changes in membrane surface where a-c are at an 80 $\mathrm{nm}$ height scale, a) Uncoated PES b) (PDADMAC/PSS $)_{2}$ coated PES, and c)(PDA DMAC/PSS $)_{2}$ coated and BSA fouled PES.

that both PDADMAC and PSS terminated membranes suffer from serious BSA fouling which is more severe than BSA fouling on uncoated membranes.

\section{Biofouling potential}

The coated and uncoated membranes were also tested during long term biofouling tests of 6 days using membrane fouling simulators (MFS). Coated membranes were compared to the uncoated membrane for their biofouling potential and flux recovery, without and with forward flushing. First, we focused on experiments without forward flushing. Flux trends and resistance profiles of uncoated and coated membranes are shown in Figures 5.6 and 5.7, respectively. Figure 5.7 shows that overall the uncoated membranes had a higher cumulative permeate production and lower resistance than both coated membranes. After $400 \mathrm{~L}$ permeate production (Figure 5.7), the resistance of uncoated membranes is $38 \%$ lower than that of the coated ones. As already explained in section 5.3.1, the increased resistance is due to pore narrowing of the membrane after the polyelectrolyte coating.

Surface charges are known to play an important role during interactions between bacterial cells and the membrane surface $[4,39,46]$. Bacterial cells are typically negatively charged hence initial attachment is expected to be more pronounced for positively charged surfaces [53]. In the present study, we also measured the amount of living bacterial cells on the membrane surface by ATP measurements (Table 5.2). We observed that coated membranes and uncoated membrane only have a marginal difference in deposited ATP amounts (Table 5.2). We do not observe the effect of charges on bacterial deposition (measured as ATP) on the membrane surface. The small difference in ATP amount despite the differences in membrane surface charges is remarkable and in sharp contrast to findings of Zhu et.al.[38]. Zhu et al. carried out SEM image analysis showing that when charged LbL membrane samples were incubated for an hour with bacterial suspensions of Pseudomonas, E.coli and S.aureus, positively charged membranes had more than $30 \%$ bacterial surface coverage for all three strains compared to less than $13 \%$ for both neutral and negatively charged membrane surfaces [38]. 


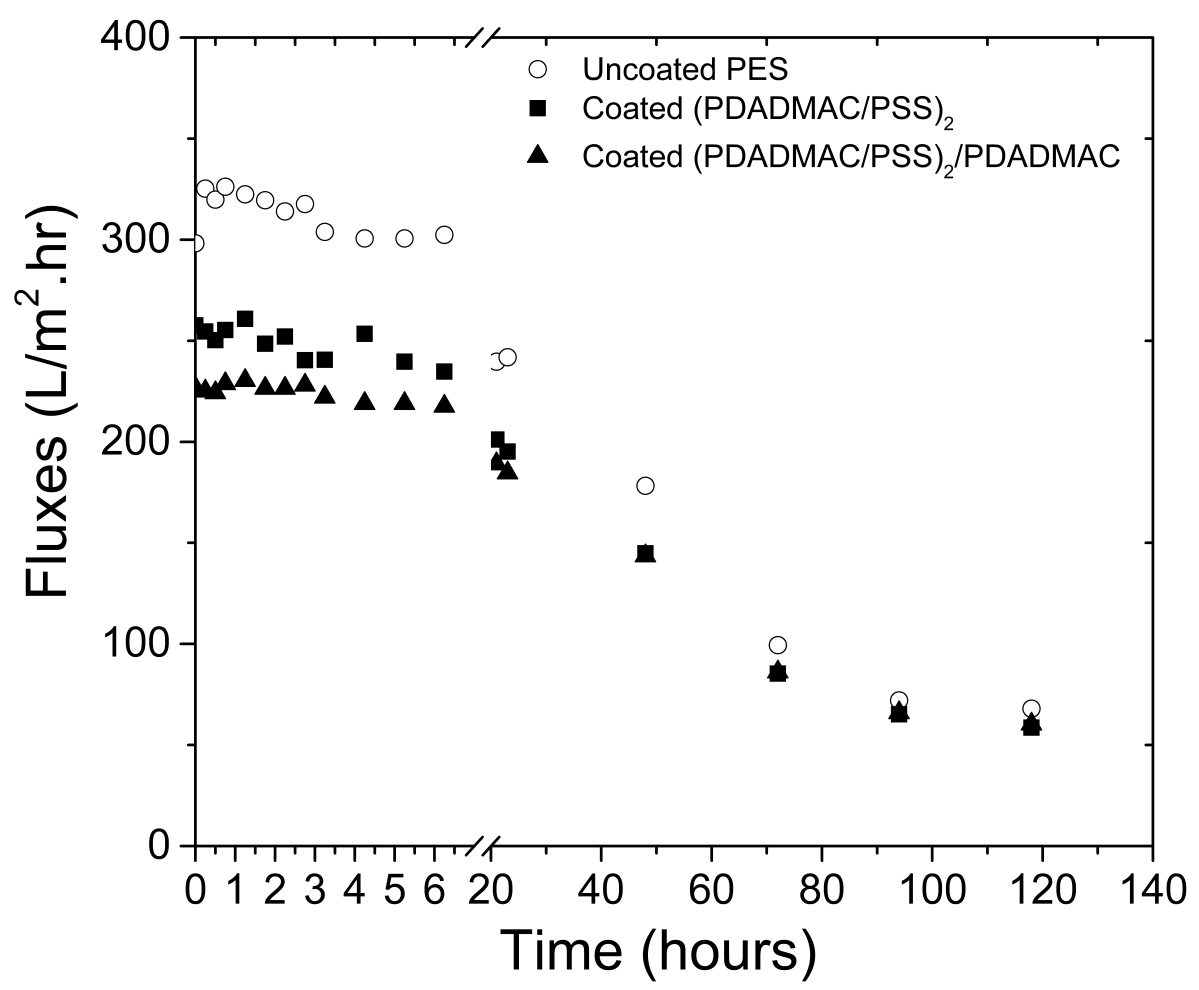

Figure 5.6: Flux trends for biofouled a) coated (PDADMAC/PSS) $)_{2}$, b) coated (PDAD$\mathrm{MAC} / \mathrm{PSS})_{2}$ /PDADMAC and c) uncoated membranes operated in dead end mode at 1 bar feed pressure. Feed solution: tap water with additional nutrients.

The main reasons for differences between these findings and our study are due to the difference of continuous filtration with tap water containing a native microbial consortium in the present study versus the membrane being exposed to a static attachment of suspended culture of a single strain of bacteria. The above findings show that bacterial attachment rates on a charged membrane surface can greatly vary depending upon the applied test conditions. In the present study, we tested PEM coated membranes under continuous filtration conditions relevant for practical applications, wherein literature most of the bacterial adhesion studies on membrane surfaces are conducted under static conditions lasting 10 minutes to a few hours. We observed little differences in ATP measurements between negatively and positively charged PEM membranes during continuous filtration, whereas Zhu et al. [38] show clear differences in bacterial attachment for their oppositely charged PEM coated membranes. We can say that under dynamic filtration conditions in dead end mode, the bacteria are forced towards the membrane surface due to permeation drag, thereby overcoming the charge effects, unlike static conditions where there is no driving force to overcome electrostatic repulsions between bacteria and charged membrane surfaces. We can conclude that modification of surface charges on its own is not enough to 


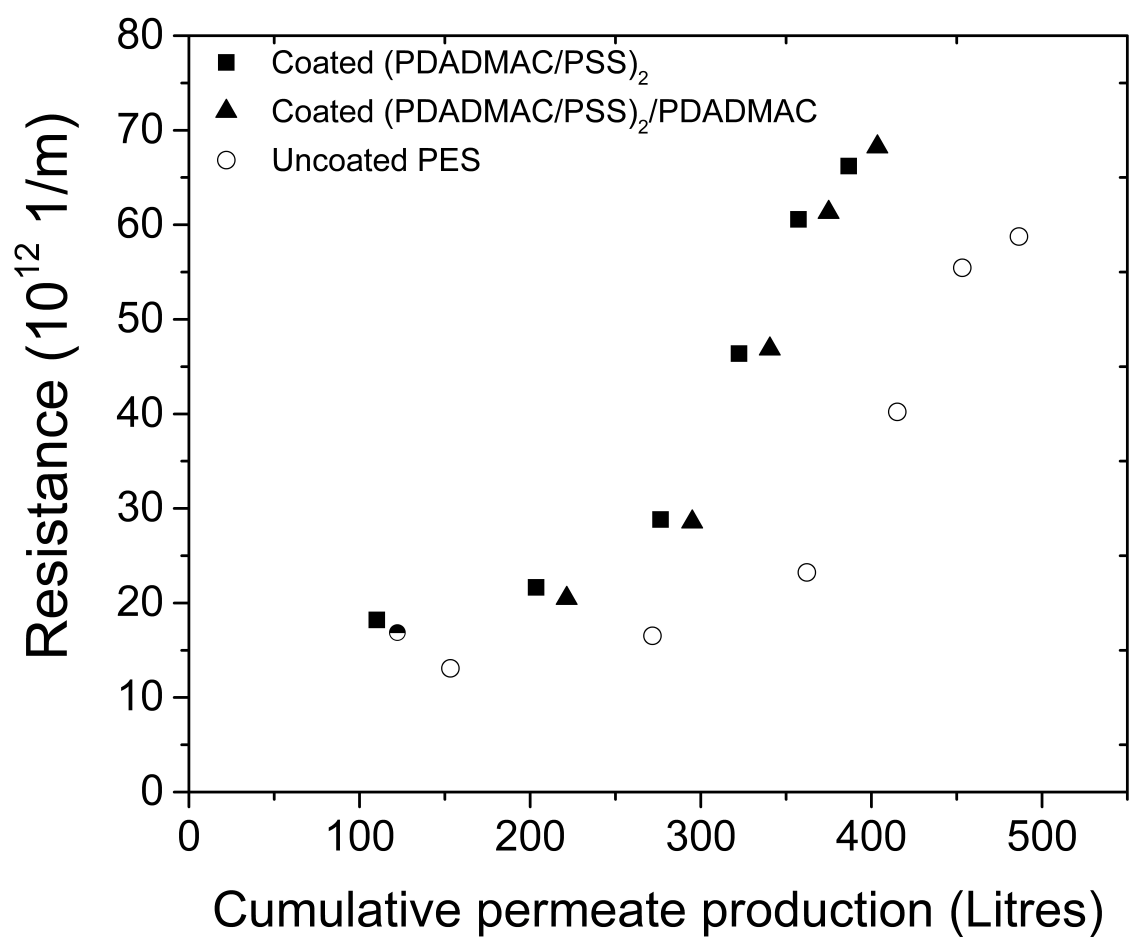

Figure 5.7: Resistance vs cumulative permeate production for biofouled a) coated (PDAD$\left.\mathrm{MAC} / \mathrm{PSS})_{2}, \mathrm{~b}\right)$ coated (PDADMAC/PSS $)_{2} / \mathrm{PDADMAC}$ and c) uncoated membranes, corresponding to a membrane area of $200 \mathrm{~cm}^{2}$ for all membranes. Feed solution: tap water with additional nutrients.

mitigate bacterial adhesion on the membrane surface under dynamic filtration conditions.

Having studied the fouling during filtration, we subsequently investigated the effect of regular cleaning procedures on flux recovery for the biofouled uncoated and coated membranes. Forward flushing for 30 minutes daily, once per day, was carried out to remove the biofouling layer from the membrane surface, by opening the crossflow valve and closing the permeate valve. The experiments were run under the same experimental conditions as mentioned in section 5.2.4, with tap water with nutrients as feed at a feed pressure of 1 bar. At the start of the biofouling experiment, a rapid flux decline is observed for all three types of membranes, as seen in Figure 5.8. This is due to continuous deposition and growth of bacteria on the membrane surface. The fluxes were measured before and immediately after forward flushing. We observe a sudden increase in flux values immediately after the membranes are forward flushed as shown by the red arrows in Figure 5.8.

Over the total filtration period of 250 hours with 8 cycles of forward flushing, the coated membranes showed higher flux recoveries than the uncoated membrane. The higher flux recoveries of coated vs. uncoated membranes are clearly observed from 50 hours of 
Table 5.2: ATP and TOC values for uncoated and coated biofouled membranes after the autopsy at the end of the experimental run of 6 days.

\begin{tabular}{ccc}
\hline Membrane samples (biofouled) & $\begin{array}{c}\text { ATP } \\
\left(\mathrm{ng} / \mathrm{cm}^{2}\right)\end{array}$ & $\begin{array}{c}\text { TOC } \\
\left(\mathrm{mg} / \mathrm{m}^{2}\right)\end{array}$ \\
\hline Uncoated PES & $75 \pm 2$ & $695 \pm 23$ \\
Coated (PDADMAC/PSS $)_{2}$ & $67 \pm 5$ & $567 \pm 65$ \\
Coated (PDADMAC/PSS $)_{2} /$ PDADMAC & $83 \pm 3$ & $627 \pm 122$ \\
\hline
\end{tabular}

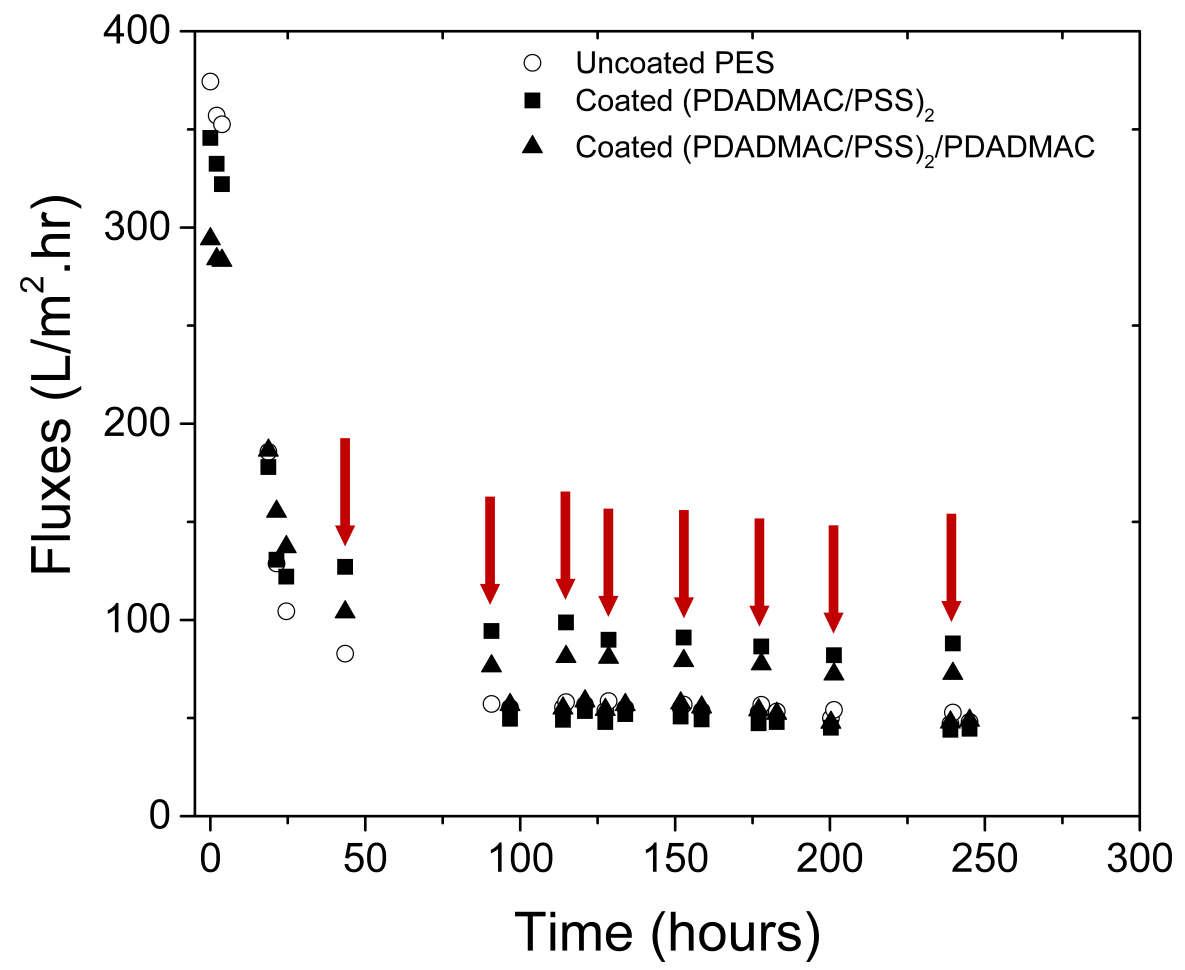

Figure 5.8: Flux recovery with forward flushing is shown for uncoated and coated membranes for biofouled a) uncoated, b) coated (PDADMAC/PSS) $)_{2}$ and c) coated (PDADMAC/PSS $)_{2} /$ PDADMAC membranes. Forward flushing : closed permeate valve and opened crossflow valve for 30 min daily, once per day. Feed solution: tap water with additional nutrients. Red arrows indicate the permeate fluxes measured immediately after forward flushing. 
filtration onwards. The fluxes immediately at the end of 8 cycles of forward flushing were $53 \mathrm{~L} / \mathrm{m}^{2} \cdot \mathrm{hr}, 88 \mathrm{~L} / \mathrm{m}^{2} \cdot \mathrm{hr}$ and $73 \mathrm{~L} / \mathrm{m}^{2} \cdot \mathrm{hr}$ for uncoated, (PDADMAC/PSS) ${ }_{2}$ coated and (PDADMAC/PSS) 2 /PDADMAC coated membranes, respectively. Coated membranes ended up with $38-66 \%$ higher absolute fluxes compared to the uncoated membrane.

In this study we did not observe differences in bacterial attachment and biofouling between positively and negatively charged membranes. However, the forward flush cleaning step clearly is influenced by the presence of a charged polyelectrolyte layer on the membrane surface. We believe that the higher flux recovery for the coated membranes stems from the weaker interaction between the PEM layer and the biofilm, as was also observed by Tang et al [39]. PEMs are highly hydrated layers and they enhance the reversibility of bacterial deposition. An increase from $10 \%$ to $100 \%$ in removal efficiencies of biofilms for PEM coated membranes with a negative charge has been reported in literature [39]. It was shown by Tang et al. that bacteria deposited on membranes coated with PAH/PAA were swept away instantly when a rinsing step was applied. Interaction forces measurements also confirmed that hydrated and swollen PEM layers prevented the bacteria from adhering to the membrane surface via strong short range van der Waals forces, making the release of bacterium cells from PEM coated membranes relatively easy compared to the release from uncoated membrane surfaces [39]. As both the positive and the negative polyelectrolyte multilayer resulted in a better flux after cleaning, compared to the uncoated membrane, it is the hydration of the multilayer layer that seems to be the dominating factor improving cleanability, not the sign of charge.

At the end of the biofouling experiments, the fouled membranes were autopsied by SEM and AFM. SEM images for coated membranes before and after biofouling are shown in Figure 5.9. Surface topography was observed to change considerably after the membranes were fouled due to biofilm formation. Mean roughnesses measured by AFM (Figure 5.10) for biofouled membranes were $22 \pm 6 \mathrm{~nm}$ for the uncoated membrane, $26 \pm 6 \mathrm{~nm}$ for the (PDADMAC/PSS $)_{2}$ coated membrane, and 36 $\pm 4 \mathrm{~nm}$ for the (PDADMAC/PSS $)_{2} /$ PDADMAC coated membrane. 


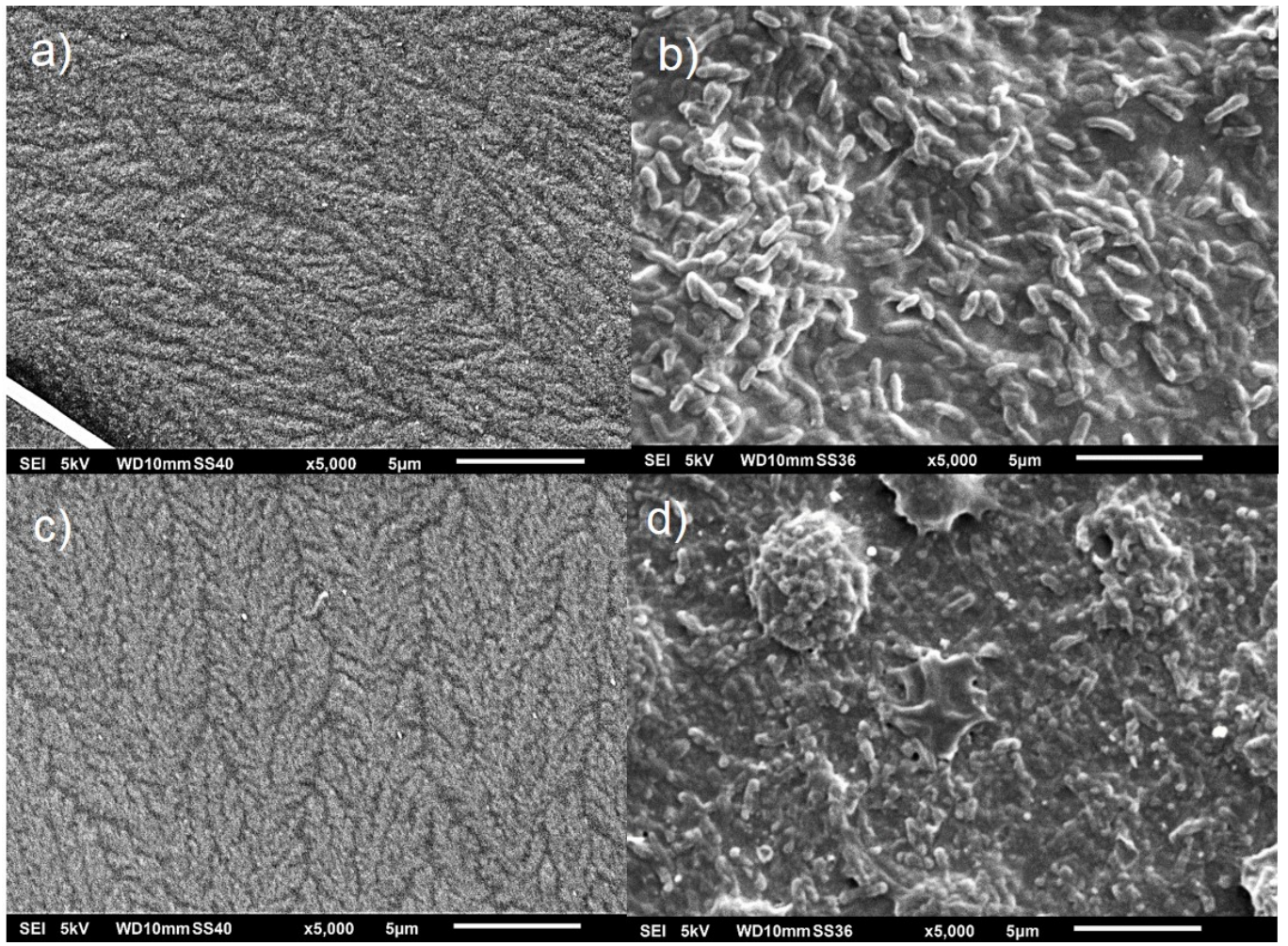

Figure 5.9: SEM images showing the coated membranes a, c) before and b, d) after biofilm fouling. Images a) and b) are for membranes with a (PDADMAC/PSS) $)_{2}$ layer, and images c) and d) are membranes with a (PDADMAC/PSS) 2 /PDADMAC layer.
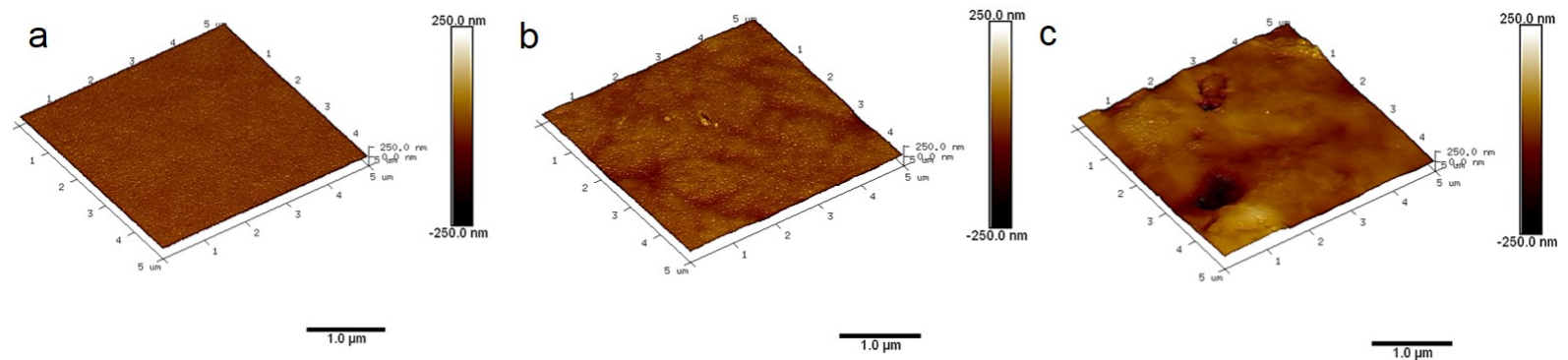

Figure 5.10: AFM images show changes in membrane surface where a-c are at a $250 \mathrm{~nm}$ height scale, a) Uncoated PES before biofouling b) (PDADMAC/PSS) $)_{2}$ coated PES before biofouling, c) (PDADMAC/PSS $)_{2}$ coated and biofilm fouled PES. 


\subsection{Conclusions}

Herein we have studied the fouling of PEM coated UF membranes, using both model foulants (BSA) and studying biofilm formation under long term (5-10 days) dynamic conditions, with and without cleaning steps. Two PEM coatings were prepared, one terminated with the cationic PDADMAC and one terminated with the anionic PSS, in all cases the results were compared to the unmodified and negatively charged PES UF membrane. Due to the reduced pore size of the UF membrane after PEM coating, PDADMAC and PSS coatings reduced the permeability of PES membranes as revealed by their clean water fluxes. Fouling studies conducted with BSA showed that coated membranes fouled faster with BSA than uncoated membranes. Surprisingly, no effect of the net surface charge (positive or negative) on BSA fouling was observed. The main reasons responsible for not observing any effect of negatively charged PSS surface towards BSA fouling was the possibility of adsorption of the negatively charged BSA to strongly negative polyelectrolyte chains due to patchiness or charge regulation. Similar observations were seen for biofouling, wherein coated membranes biofouled quicker with no effect of the net surface charges on biofouling potential under continuous filtration conditions. The bacterial growth on both positively charged and negatively charged surfaces was confirmed by SEM and ATP analysis. However, with the inclusion of a daily cleaning step (forward flushing) to simulate realistic conditions, we observed much higher flux recoveries for our coated membranes compared to the uncoated membrane. Though, bacterial attachment was similar for both coated membranes and uncoated membranes, due to the highly hydrated PEM layers present on coated membranes the biofouling layer could be easily removed from these membranes by a simple physical cleaning. Hydrated PEM layers prevents the irreversible adhesion of bacteria on the membrane surface. This work demonstrates that PDADMAC/PSS membranes have the potential to perform better than commercial membranes under realistic fouling situations combined with regular cleanings. The outcomes of the present study clearly demonstrate the importance of conducting bacterial adhesion tests on modified surfaces under dynamic conditions. Clear differences were seen between bacterial adhesion potential of modified surfaces exposed to dynamic experimental conditions in our study vs. static conditions reported in literature, which makes it difficult to translate the findings of a static study to more realistic dynamic conditions.

\section{References}

[1] H. Huang, K. Schwab, J.G. Jacangelo, Pretreatment for low pressure membranes in water treatment: A review, Environmental Science and Technology 43 (2009) 3011-3019.

[2] J. Kochan, T. Wintgens, J.E. Wong, T. Melin, Properties of polyethersulfone ultrafiltration membranes modified by polyelectrolytes, Desalination 250 (2010) 1008-1010.

[3] D. Jermann, W. Pronk, S. Meylan, M. Boller, Interplay of different NOM fouling mechanisms during ultrafiltration for drinking water production, Water Research 41 (2007) 
$1713-1722$.

[4] S.-T. Kang, A. Subramani, E.M. Hoek, M.A. Deshusses, M.R. Matsumoto, Direct observation of biofouling in cross-flow microfiltration: mechanisms of deposition and release, Journal of Membrane Science 244 (2004) 151-165.

[5] V. Kochkodan, N. Hilal, A comprehensive review on surface modified polymer membranes for biofouling mitigation, Desalination 356 (2015) 187-207.

[6] A. Maartens, P. Swart, E. Jacobs, Feed-water pretreatment: methods to reduce membrane fouling by natural organic matter, Journal of Membrane Science 163 (1999) 51-62.

[7] R. Fabris, E.K. Lee, C.W.K. Chow, V. Chen, M. Drikas, Pre-treatments to reduce fouling of low pressure micro-filtration (MF) membranes, Journal of Membrane Science 289 (2007) 231-240.

[8] H. Ma, C.N. Bowman, R.H. Davis, Membrane fouling reduction by backpulsing and surface modification, Journal of Membrane Science 173 (2000) 191-200.

[9] E. Zondervan, B. Roffel, Evaluation of different cleaning agents used for cleaning ultra filtration membranes fouled by surface water, Journal of Membrane Science 304 (2007) 40-49.

[10] G. Decher, J. Hong, Buildup of ultrathin multilayer films by a selfassembly process: II. Consecutive adsorption of anionic and cationic bipolar amphiphiles and polyelectrolytes on charged surfaces, Berichte der Bunsengesellschaft für physikalische Chemie 95 (1991) $1430-1434$.

[11] G. Decher, J. Hong, J. Schmitt, Buildup of ultrathin multilayer films by a selfassembly process: III. Consecutively alternating adsorption of anionic and cationic polyelectrolytes on charged surfaces, Thin solid films 210 (1992) 831-835.

[12] G. Decher, Fuzzy nanoassemblies: toward layered polymeric multicomposites, Science 277 (1997) 1232-1237.

[13] L. Zou, I. Vidalis, D. Steele, A. Michelmore, S.P. Low, J.Q.J.C. Verberk, Surface hydrophilic modification of RO membranes by plasma polymerization for low organic fouling, Journal of Membrane Science 369 (2011) 420-428.

[14] C. Magnenet, F.E. Jurin, S. Lakard, C.C. Buron, B. Lakard, Polyelectrolyte modification of ultrafiltration membrane for removal of copper ions, Colloids and Surfaces A: Physicochemical and Engineering Aspects 435 (2013) 170-177. 
[15] W. Shan, P. Bacchin, P. Aimar, M.L. Bruening, V.V. Tarabara, Polyelectrolyte multilayer films as backflushable nanofiltration membranes with tunable hydrophilicity and surface charge, Journal of Membrane Science 349 (2010) 268-278.

[16] R.H. Lajimi, A.B. Abdallah, E. Ferjani, M.S. Roudesli, A. Deratani, Change of the performance properties of nanofiltration cellulose acetate membranes by surface adsorption of polyelectrolyte multilayers, Desalination 163 (2004) 193-202.

[17] B.P. Tripathi, N.C. Dubey, M. Stamm, Functional polyelectrolyte multilayer membranes for water purification applications, Journal of Hazardous Materials 252253 (2013) 401-412.

[18] T. Ishigami, K. Amano, A. Fujii, Y. Ohmukai, E. Kamio, T. Maruyama, H. Matsuyama, Fouling reduction of reverse osmosis membrane by surface modification via layerby-layer assembly, Separation and Purification Technology 99 (2012) 1-7.

[19] S. Mulyati, R. Takagi, A. Fujii, Y. Ohmukai, H. Matsuyama, Simultaneous improvement of the monovalent anion selectivity and antifouling properties of an anion exchange membrane in an electrodialysis process, using polyelectrolyte multilayer deposition, Journal of Membrane Science 431 (2013) 113-120.

[20] S. Abdu, M.-C. Martí-Calatayud, J.E. Wong, M. García-Gabaldón, M. Wessling, Layer-by-Layer Modification of Cation Exchange Membranes Controls Ion Selectivity and Water Splitting, ACS Applied Materials \& Interfaces 6 (2014) 1843-1854.

[21] J. de Grooth, D.M. Reurink, J. Ploegmakers, W.M. de Vos, K. Nijmeijer, Charged Micropollutant Removal With Hollow Fiber Nanofiltration Membranes Based On Polycation/Polyzwitterion/Polyanion Multilayers, ACS Applied Materials \& Interfaces 6 (2014) 17009-17017.

[22] S. Ilyas, J. de Grooth, K. Nijmeijer, W.M. de Vos, Multifunctional polyelectrolyte multilayers as nanofiltration membranes and as sacrificial layers for easy membrane cleaning, Journal of Colloid and Interface Science 446 (2015) 386-393.

[23] V.J. Disha, C.T. Aravindakumar, U.K. Aravind, Phosphate Recovery by High Flux Low Pressure Multilayer Membranes, Langmuir 28 (2012) 12744-12752.

[24] O. Sanyal, Z. Liu, B.M. Meharg, W. Liao, I. Lee, Development of polyelectrolyte multilayer membranes to reduce the COD level of electrocoagulation treated high-strength wastewater, Journal of Membrane Science 496 (2015) 259-266.

[25] J. de Grooth, B. Haakmeester, C. Wever, J. Potreck, W.M. de Vos, K. Nijmeijer, 
Long term physical and chemical stability of polyelectrolyte multilayer membranes, Journal of Membrane Science 489 (2015) 153-159.

[26] J.A. Lichter, M.F. Rubner, Polyelectrolyte Multilayers with Intrinsic Antimicrobial Functionality: The Importance of Mobile Polycations, Langmuir 25 (2009) 7686-7694.

[27] T. Moritz, S. Benfer, P. Árki, G. Tomandl, Influence of the surface charge on the permeate flux in the dead-end filtration with ceramic membranes, Separation and Purification Technology 25 (2001) 501-508.

[28] D. Elzo, I. Huisman, E. Middelink, V. Gekas, Charge effects on inorganic membrane performance in a cross-flow microfiltration process, Colloids and Surfaces A: Physicochemical and Engineering Aspects 138 (1998) 145-159.

[29] D.J. Chang, F.C. Hsu, S.J. Hwang, Steady-state permeate flux of cross-flow microfiltration, Journal of Membrane Science 98 (1995) 97-106.

[30] M.J. Han, G.N.B. Baroña, B. Jung, Effect of surface charge on hydrophilically modified poly(vinylidene fluoride) membrane for microfiltration, Desalination 270 (2011) 76-83.

[31] D. Rana, T. Matsuura, Surface modifications for antifouling membranes, Chemical reviews 110 (2010) 2448-2471.

[32] S. Nakao, H. Osada, H. Kurata, T. Tsuru, S. Kimura, International Membrane Technology Conference '88Separation of proteins by charged ultrafiltration membranes, Desalination 70 (1988) 191-205.

[33] A. Higuchi, N. Iwata, M. Tsubaki, T. Nakagawa, Surface-modified polysulfone hollow fibers, Journal of Applied Polymer Science 36 (1988) 1753-1767.

[34] R. Gerard, H. Hachisuka, M. Hirose, Papers presented at the Conference on Membranes in Drinking and Industrial Water ProductionNew membrane developments expanding the horizon for the application of reverse osmosis technology, Desalination 119 (1998) $47-55$.

[35] M. Ulbricht, K. Richau, H. Kamusewitz, Chemically and morphologically defined ultrafiltration membrane surfaces prepared by heterogeneous photo-initiated graft polymerization1, Colloids and Surfaces A: Physicochemical and Engineering Aspects 138 (1998) 353-366.

[36] L.-Q. Shen, Z.-K. Xu, Z.-M. Liu, Y.-Y. Xu, Ultrafiltration hollow fiber membranes of sulfonated polyetherimide/polyetherimide blends: preparation, morphologies and antifouling properties, Journal of Membrane Science 218 (2003) 279-293. 
[37] B. Tang, T. Xu, M. Gong, W. Yang, A novel positively charged asymmetry membranes from poly(2,6-dimethyl-1,4-phenylene oxide) by benzyl bromination and in situ amination: membrane preparation and characterization, Journal of Membrane Science 248 (2005) 119-125.

[38] X. Zhu, D. Jańczewski, S. Guo, S.S.C. Lee, F.J. Parra Velandia, S.L.-M. Teo, T. He, S.R. Puniredd, G.J. Vancso, Polyion Multilayers with Precise Surface Charge Control for Antifouling, ACS Applied Materials \& Interfaces 7 (2015) 852-861.

[39] L. Tang, W. Gu, P. Yi, J.L. Bitter, J.Y. Hong, D.H. Fairbrother, K.L. Chen, Bacterial anti-adhesive properties of polysulfone membranes modified with polyelectrolyte multilayers, Journal of Membrane Science 446 (2013) 201-211.

[40] M.E. Tadros, I. Mayes, Effects of particle properties on filtration of aqueous suspensions, IN: PROC. INT. SYMP. ON FINE PARTICLES PROCESSING, (LAS VEGAS, U.S.A.: FEB. 24-28, 1980), P. SOMASUNDARAN (ED.) 2 , New York, U.S.A., Am. Inst. Min. Metall. \& Pet. Engrs. Inc., 1980, Chapter 79, p.1583-1593.

[41] J. Davey, A.I. Schäfer, Ultrafiltration to Supply Drinking Water in International Development: A Review of Opportunities, in: E.K. Yanful (Ed.) Appropriate Technologies for Environmental Protection in the Developing World: Selected Papers from ERTEP 2007, July 1719 2007, Ghana, Africa, Springer Netherlands, Dordrecht, 2009, pp. 151-168.

[42] C. Dreszer, J.S. Vrouwenvelder, A.H. Paulitsch-Fuchs, A. Zwijnenburg, J.C. Kruithof, H.C. Flemming, Hydraulic resistance of biofilms, Journal of Membrane Science 429 (2013) 436-447.

[43] S.F. Boerlage, M.D. Kennedy, M.R. Dickson, D.E. El-Hodali, J.C. Schippers, The modified fouling index using ultrafiltration membranes (MFI-UF): characterisation, filtration mechanisms and proposed reference membrane, Journal of Membrane Science 197 (2002) 1-21.

[44] J.C. Schippers, J. Verdouw, The modified fouling index, a method of determining the fouling characteristics of water, Desalination 32 (1980) 137-148.

[45] J. de Grooth, R. Oborný, J. Potreck, K. Nijmeijer, W.M. de Vos, The role of ionic strength and oddeven effects on the properties of polyelectrolyte multilayer nanofiltration membranes, Journal of Membrane Science 475 (2015) 311-319.

[46] F. Diagne, R. Malaisamy, V. Boddie, R.D. Holbrook, B. Eribo, K.L. Jones, Polyelectrolyte and silver nanoparticle modification of microfiltration membranes to mitigate organic and bacterial fouling, Environmental science \& technology 46 (2012) 4025-4033. 
[47] M.D. Miller, M.L. Bruening, Correlation of the Swelling and Permeability of Polyelectrolyte Multilayer Films, Chemistry of Materials 17 (2005) 5375-5381.

[48] J. Meier-Haack, M. Müller, Use of polyelectrolyte multilayer systems for membrane modification, Macromolecular Symposia 188 (2002) 91-104.

[49] M. Elimelech, Z. Xiaohua, A.E. Childress, H. Seungkwan, Role of membrane surface morphology in colloidal fouling of cellulose acetate and composite aromatic polyamide reverse osmosis membranes, Journal of Membrane Science 127 (1997) 101-109.

[50] A. Fane, C. Fell, A. Waters, The relationship between membrane surface pore characteristics and flux for ultrafiltration membranes, Journal of Membrane Science 9 (1981) $245-262$.

[51] S. Rosenfeldt, A. Wittemann, M. Ballauff, E. Breininger, J. Bolze, N. Dingenouts, Interaction of proteins with spherical polyelectrolyte brushes in solution as studied by small-angle x-ray scattering, Physical review E 70 (2004) 061403.

[52] W.M. de Vos, P.M. Biesheuvel, A. de Keizer, J.M. Kleijn, M.A. Cohen Stuart, Adsorption of the protein bovine serum albumin in a planar poly (acrylic acid) brush layer as measured by optical reflectometry, Langmuir 24 (2008) 6575-6584.

[53] X. Zhu, X.J. Loh, Layer-by-layer assemblies for antibacterial applications, Biomaterials science 3 (2015) 1505-1518. 



\section{Chapter 6}

\section{Summary and outlook}

\subsection{Summary}

Access to clean, safe drinking water is still a luxury for millions residing in developing countries. Parts of Asia and Africa are worst affected by water quality issues. Lack of water treatment infrastructure and poverty has limited the access to clean and safe drinking water in these regions that belong to the bottom of pyramid of social and economic growth. On the other hand, there are regions with water distribution networks, but due to poor maintenance and improper management, the water quality delivered by them is insufficient. Hence, to cater the needs of people without access to potable water, the World Health Organization (WHO) highlighted the potential of Point-of-Use (PoU) drinking water treatment systems operated at individual and community levels. Ultrafiltration (UF) membranes have displayed excellent performance as PoU treatment option in terms of pathogen removal, ease of maintenance and cost effectiveness. Still, the performance of UF membranes is hampered by fouling and biofouling. In this work, we studied long term fouling development in low pressure, gravity driven ( $<1$ bar) hollow fiber based ultrafiltration modules simulating PoU treatment systems. The key findings of the present study are highlighted below.

In general, the performance of UF can be affected by three major factors: operational conditions, feed water quality and membrane properties. Within this scope, various parameters that could influence fouling development in low pressure UF are studied. In the first part of the study presented in Chapter 2, various operational modes are investigated such as inside/out vs. outside/in operation and discontinuous vs. continuous filtration, to study their effects on fouling and permeate production with surface water as feed. Inside/out UF membranes, with the separating layer on the bore side, are tested both in inside/out as well as in outside/in mode of operation. Flux stabilization is observed for these hollow fiber UF, operated at gravity pressures of 0.1 bar. Flux values stabilize around $2 \mathrm{~L} / \mathrm{m}^{2} \cdot \mathrm{hr}$ in almost all cases (40 times lower than the clean water permeability values provided by the manufacturer). In most experiments the fouling layer mainly consists of diatoms, in- 
organic particles and a few microbial clusters. Cake layer formation is the main fouling mechanism for inside/out operation, while pore blocking dominated the outside/in operational mode. The intermittent inside/out mode of operation resulted in lower hydraulic resistances compared to outside/in due to the lower foulant load per unit membrane area as well as back diffusion of foulants into the bulk solution. It is shown that the PoU systems investigated can be operated for longer durations ( $>30$ days) without the need for strong chemical cleaning. Overall, the intermittently operated inside/out configuration performed better than continuously operated membrane systems and the outside/in operational mode.

In the second part of the work, presented in Chapter 3, the effects of feed water quality on fouling development are studied by challenging the in-house constructed PoU with the secondary wastewater effluent (WWEf) as feed and comparing inside/out (I/O) vs. outside/in $(\mathrm{O} / \mathrm{I})$ operational modes. The findings shine light on the underlying principles regarding biofouling development in low pressure hollow fiber membranes using WWEf as the feed solution. While the flux declines monotonically for outside/in (O/I) mode, a fluctuating flux trend with fluxes decreasing and increasing over time is observed for the inside/out (I/O) operational mode. It is shown that the fluctuations in the nematode population correlate well with the periodic flux trend in the I/O mode. The biofouling layer accumulated on the membrane surface consists of biotic as well as abiotic components. It is proposed that the predator-prey relationship between nematodes (metazoas) and the microbial community present in secondary WWEf strongly influences the flux behavior. For our system, a threshold nematode population density of $2.2 \times 10^{6}$ counts $/ \mathrm{m}^{2}$ was required to influence the permeate flux behavior. The population of adult nematodes has a larger influence on permeate production compared to the number of juveniles. The effect of seasonal variation on nematode population density and growth is evident. During summer season, at ambient temperatures of $25^{\circ} \mathrm{C}$, a higher population density of nematodes is seen within the fouling layer, whereas at temperatures of $12^{\circ} \mathrm{C}$ or below, the growth of nematodes is retarded and hence population density decreases. It is shown that the presence of active nematodes can lead to a $50 \%$ - $75 \%$ increase in fluxes. Predation by biologically active and fully grown nematodes is suggested as a biofouling mitigation strategy during low pressure membrane filtration. The scientific findings based on the impact of naturally occurring biological interactions of bacterivorous nematodes on membrane biofouling can be helpful in engineering membrane technology. The natural predator-prey interactions can be utilized for designing more efficient and self-sustainable Point-of-Use systems.

Chapters 2 and 3 focused on utilizing gravity pressures for ultrafiltration, as this is relevant for the regions where water supply infrastructure is not in place. However, countries like India and China do have piped water supply, especially in the urban areas. Therefore, in the other sections biofouling development is tested on UF membranes under tap pressures. Continuing with the study on the effect of feed water quality, biofilm formation is studied under varying monovalent to divalent (M:D) cationic ratios in the feed water. The findings are discussed in Chapter 4. Biofilm formation is evaluated in terms of hydraulic resistance and production of EPS components such as polysaccharides and proteins. A nat- 
ural consortium of bacteria native to drinking water is used to grow a biofilm on flat sheet ultrafiltration membranes operated at constant pressures of 0.5 bar. The three different monovalent to divalent (M:D) ratios investigated are 1.31:1, monovalent (M) ions only (no divalent ions), and 2.23:1. The removal of divalent cations from feed water considerably reduces the production of extra cellular polymeric substances (EPS), and especially that of polysaccharides. The hydraulic resistances of biofilms are the lowest in the absence of divalent cations, i.e. with monovalent ions only. Though the presence of magnesium as a divalent cation at M:D 2.23:1 promotes the secretion of polysaccharides, the hydraulic resistances are highest at M:D 1.31:1 in combination with the presence of calcium.

In the final part of the study presented in Chapter 5, membrane surface properties are modified by altering surface charges (positive as well as negative) via layer by layer (LbL) deposition of the polyelectrolytes poly(diallyldimethylammonium)chloride (PDADMAC) and poly(styrenesulfonic acid) (PSS) on UF membranes. The biofouling potential of modified membranes is evaluated by the growth of drinking water bacteria on the membrane surface under dynamic filtration conditions. The results show that the performance of coated membranes is hampered by biofouling with no effect of the positively or negatively charged membrane surface on biofouling potential for drinking water filtration. The bacterial deposition on both positively charged and negatively charged surfaces is confirmed by SEM and ATP analysis. However, with the inclusion of a daily cleaning step (forward flushing) to simulate realistic operating conditions, we observe much higher flux recoveries for the coated membranes compared to the uncoated ones. Though bacterial attachment is similar for both coated and uncoated membranes, the presence of highly hydrated polyelectrolyte multilayers (PEM) on coated membranes weakens the interaction between the bacteria and membrane surface, thereby preventing the irreversible adhesion of bacteria on the surface. Consequently, the biofouling layer is easily removed from these membranes by this simple physical cleaning method. The outcome of the present study clearly shows the importance of conducting bacterial adhesion tests on modified surfaces under dynamic conditions.

\subsection{Outlook}

Clean water scarcity and wastewater treatment is a massive challenge that needs to be addressed for an equitable global growth. Advanced water purification technologies are needed to overcome the global water crisis. Besides technology itself, other factors like the proper implementation of the technology, hygienic storage of treated water and proper maintenance of the treatment system are equally important. These are essential to ensure safe and clean drinking water to individuals and communities in developing countries. Membrane technology has a huge potential for water and wastewater treatment, providing a great scope for future research in design, development and application of the technology. Depending upon application areas, the major goals of membrane technology development 
can be defined as [1]

1. High productivity or permeate fluxes

2. Mechanical, chemical, thermal and temporal stability

3. Anti-fouling

4. Ability to be processed at large scale

5. Cost effective

We demonstrated in this thesis how operational conditions, feed water quality and membrane properties can influence hydraulic resistances and permeate production rates in low pressure hollow fiber ultrafiltration. At this point, we can classify ultrafiltration based PoU systems into two categories: gravity driven ( $\leq 0.1$ bar) and tap pressure driven (0.5-1 bar). The improvements in future design and implementation of membrane based PoU systems greatly depends on the applied feed pressures. Based on the findings presented, we can conclude that biofouling did not hamper the performance of gravity driven UF modules. The major components of the fouling layer were humic acids and biopolymers which can be tackled by either pre-filtration or forward flushing of the membrane modules. However, the performance of such combinations needs to be tested in the field for longer duration than our experimental run of 30 days. During the study on gravity driven hollow fiber membrane modules, we compared inside/out (I/O) operational mode with outside/in $(\mathrm{O} / \mathrm{I})$ mode, using the same membranes with the denser layer on the inside. This resulted in evolution of two different fouling mechanisms i.e. cake layer formation for I/O vs. pore blocking for $\mathrm{O} / \mathrm{I}$ mode. The question that still needs to be addressed concerns the performance of $\mathrm{I} / \mathrm{O}$ vs. O/I with the denser layer on the outside which would rule out the effect of pore size on retention and fouling mechanism. This would help in choosing the appropriate operational mode for a given feed water quality. Secondly, we hypothesized that lower resistances in intermittent operation are due to relaxation of the fouling layer. The ultrafiltration surface mostly retains bacteria, biopolymers, humic acids and diatoms. Hence it would be worth to observe the structural changes within the fouling layer during the relaxation period. We also realized that it is quite important to establish a non-destructive method to image fouling layers. Though SEM gives an indication of the contents of the fouling layer, the drying required for SEM collapses the structure that makes it difficult to correlate the observations with the temporal changes within the fouling layer. Developing a protocol for imaging fouling layer on curved geometries like hollow fibers would be really helpful in interpreting the results and adopting strategies to lower hydraulic resistances.

UF has excellent microbial retention ability, but there are studies that demonstrated that the growth stage of bacteria can affect its retention by UF membrane [2]. The growth stage of bacteria should therefore be taken into account when determining the effectiveness 
of their removal. Besides bacteria, effective retention of viruses by PoU systems is equally important in areas where there is lack of sanitation and hygiene. Major waterborne diseases are known to occur by common viruses like SARS, Hepatitis A, poliovirus etc., and communities are vulnerable to waterborne diseases in absence of clean water and proper sanitation. Hence, a major thrust needs to be given on further improving the capability of UF in retaining and inactivating microbial contaminants. Future research can be done in the direction of improving UF performance in terms of microbial retention and inactivation via incorporation of nanoparticles based on $\mathrm{Ag}, \mathrm{Cu}$ etc. These metals are known to be anti-microbial agents that have the potential to disinfect bacteria attached to the surfaces. The key point is to test such systems on a long term basis ( $>1$ year) to assess the environmental impact of nanoparticles and avoid any potential threats from nanoparticles being released into the water streams. Another approach would be to coat surfaces using cationic polymeric materials attached to anti-microbial groups, also discussed later in this section. An alternative to incorporation of nanoparticles within membrane structures can be exploring the materials made of naturally occurring cellulose based nanofibers that have the potential to retain viruses and provide high permeate fluxes [3, 4]. Development of UF membrane modules for application in PoU systems operated at tap pressures can be directed towards both virus retention and biofouling mitigation.

There are knowledge gaps that still need to be addressed based on the findings of the present work on the effects of predator-prey relationship on permeate fluxes that could help to further improve the permeation rates. It would be interesting to identify the class of bacterivorous nematodes that feed specifically on surface water and wastewater bacteria. During this study, we noticed the interactions between nematodes and bacteria were affected by retarded growth of nematodes due to seasonal variations. A method to overcome the effect of seasonal variations could be studying the population dynamics and feeding patterns of specific bacterivorous nematodes and engineering the membrane system with fully matured nematodes. The system could then be self-sustainable in dealing with the issue of biofouling.

The findings on the effect of varying divalent ionic ratios on the hydraulic resistance of biofouling layer are also promising. Besides the cation ratios, the anionic ratios can be studied in detail to investigate their effects on hydraulic resistance and biofilm structure. In the study, we correlated the reduced hydraulic resistance to absence of divalent cations and crosslinking between $\mathrm{Ca}$ and extra polymeric substances (EPS) released by bacteria. The effect of divalent cations is not limited to crosslinking between EPS molecules in the extra cellular environment but also within the bacterial cell wall itself [5]. Absence of divalent cations combined with the presence or absence of chelating agents would also be an interesting study in developing strategies to minimize biofouling. Apart from measuring operational parameters e.g. permeate flux decline and water quality, it would be worth visualizing the changes within the biofilm structure. For that, it is essential to study the structural development of biofilms in-situ using non-destructive methods of imaging e.g. optical coherence tomography (OCT) and confocal laser scanning microscopy (CLSM). 
The use of CLSM allows to observe specific EPS components like polysaccharides and proteins. This will further provide useful insight into the cohesiveness of the biofilm, which is affected by the polysaccharide concentrations within the biofilm [6].

We have seen in the present research that operating PoU systems at tap pressures leads to inevitable biofilm formation on the membrane surface which hampers the membrane performance considerably. Biofouling experiments on polyelectrolyte coated membranes indicated no direct effect of charges on bacterial adhesion, however it does makes it easier to clean the polyelectrolyte multilayer (PEM) coated surfaces due to hydration of PEM layers, which help in preventing irreversible adhesion of bacteria to the membrane surface. Simple cleaning strategies, e.g. a forward flush, can be adopted in combination with charged surfaces on the membranes to overcome biofouling problems in a PoU module. The hypothesis that hydration of PEM layers is responsible for better cleaning of coated membranes deserves further in-depth study. It needs to be verified to what extent the PEM layers are hydrated in the presence of bacterial deposition. In this part of the study, we did not measure the EPS released by the bacteria that have the potential to aggravate fouling by binding with the PEM layers leading to increased hydraulic resistance. It can also affect cleaning strategy once EPS gets irreversibly attached to the membrane surface. This depends on whether the bacteria is trapped within the PEM layers or loosely deposited on the surface of PEM layers. The structure of the PEM layers and bacterial adhesion can be studied using in-situ epifluorescence microscope or CLSM. An important aspect of the future study would be to correlate the production of EPS with the presence and absence of PEM coatings and with the efficiency of forward flush. We can expect that the fouling layer will undergo major structural changes due to EPS and hydrated PEM layers. Additionally, future research can be oriented towards making novel membrane materials with tunable functionalities e.g. charge reversal. There is also a huge potential to explore other cationic polymeric coatings with antimicrobial groups e.g. quaternary ammonium, phosphonium and guanidinium [7]. Unlike most of the literature studies, the present work shows it is crucial that the modified membranes or materials for water treatment are tested under realistic conditions including dynamic filtration operation and being exposed to a natural consortium of bacteria. Single strain bacterial adhesion studies performed under static conditions often do not give a clear indication of the real-time performance of such systems. The synergistic effects of bacterial strains involved in initial adhesion, colonization and biofilm formation are also neglected in static studies. Therefore, the testing of novel materials and coated surfaces under dynamic filtration conditions would hold the key to their successful implementation in the membrane modules.

\section{References}

[1] A. Lee, J.W. Elam, S.B. Darling, Membrane materials for water purification: design, development, and application, Environmental Science: Water Research \& Technology 2 (2016) 17-42. 
[2] S.B. Sadr Ghayeni, P.J. Beatson, A.J. Fane, R.P. Schneider, Bacterial passage through microfiltration membranes in wastewater applications, Journal of Membrane Science 153 (1999) 71-82.

[3] H. Ma, C. Burger, B.S. Hsiao, B. Chu, Fabrication and characterization of cellulose nanofiber based thin-film nanofibrous composite membranes, Journal of Membrane Science 454 (2014) 272-282.

[4] H. Ma, C. Burger, B.S. Hsiao, B. Chu, Ultrafine Polysaccharide Nanofibrous Membranes for Water Purification, Biomacromolecules 12 (2011) 970-976.

[5] L.A. Clifton, M.W.A. Skoda, A.P. Le Brun, F. Ciesielski, I. Kuzmenko, S.A. Holt, J.H. Lakey, Effect of Divalent Cation Removal on the Structure of Gram-Negative Bacterial Outer Membrane Models, Langmuir 31 (2015) 404-412.

[6] F. Ahimou, M.J. Semmens, G. Haugstad, P.J. Novak, Effect of protein, polysaccharide, and oxygen concentration profiles on biofilm cohesiveness, Applied and environmental microbiology 73 (2007) 2905-2910.

[7] R. Zhang, Y. Liu, M. He, Y. Su, X. Zhao, M. Elimelech, Z. Jiang, Antifouling membranes for sustainable water purification: strategies and mechanisms, Chemical Society Reviews 45 (2016) 5888-5924. 



\section{Samenvatting}

Toegang tot schoon en veilig drinkwater is nog steeds een luxe voor miljoenen mensen in ontwikkelingslanden. Delen van Azië en Afrika worden het meest getroffen door drinkwaterproblemen. Een gebrekkige infrastructuur voor de behandeling van water en armoede beperken de toegang tot schoon en veilig drinkwater in deze gebieden, die behoren tot de onderste laag van sociale en economische groei. Echter zijn er ook regios waar de infrastructuur voor waterlevering aanwezig is, maar door slecht onderhoud en management is de kwaliteit van het aangeleverde water onvoldoende. Om te voorzien in de behoeften van mensen zonder toegang tot schoon drinkwater, wijst de Wereldgezondheidsorganisatie (WHO) op de mogelijkheden van Point-of-Use (PoU) drinkwatersystemen voor toepassingen op individueel- en gemeenschapsniveau. Ultrafiltratiemembranen (UF) laten uitstekende prestaties zien op het gebied van het verwijderen van ziektekiemen, onderhoudsgemak en kosteneffectiviteit. Helaas wordt de prestatie van UF membranen verminderd door vervuiling en biofouling. In dit werk onderzoeken we de vervuiling over langere tijd van gesimuleerde PoU systemen bestaande uit zwaartekrachtgedreven, lagedruk $(<1$ bar $)$ holle-vezel ultrafiltratiemodules. De belangrijkste bevindingen zijn hier uiteengezet.

Algemeen gesproken wordt de prestatie van UF membranen beïnvloed door drie belangrijke factoren: operationele condities, kwaliteit van het voedingswater en membraaneigenschappen. Verschillende parameters die de ontwikkeling van vervuiling in lagedruk-UF kunnen beïnvloeden zijn bestudeerd. In het eerste deel van de studie, gepresenteerd in Hoofdstuk 2, zijn verschillende bedrijfscondities bestudeerd tijdens het filtreren van oppervlaktewater, zoals inside/out versus outside/in-gebruik en continue versus discontinue filtratie, om de effecten van deze condities op vervuiling en permeaatproductie te onderzoeken. Inside/out UF membranen, met de scheidingslaag aan de binnenzijde van de vezel, zijn zowel in inside/out als in outside/in modus getest. Voor deze UF holle vezels is fluxstabilisatie waargenomen bij een zwaartekrachtdruk van 0,1 bar. De fluxwaarden stabiliseren rond de $2 \mathrm{~L} / \mathrm{m}^{2} \cdot \mathrm{hr} \mathrm{u}$ in bijna alle gevallen (40 keer lager dan de schoonwaterpermeabiliteit opgegeven door de fabrikant). De vervuilingslaag bestaat in de meeste experimenten uit diatomeeën, anorganische deeltjes en een aantal microbiële clusters. De vorming van een koeklaag is het dominerende vervuilingsmechanisme bij inside/out filtratie; bij outside/in filtratie domineert de verstopping van poriën. De periodieke inside/out bedrijfsmodus resulteerde in lagere hydraulische weerstand dan de outside/in modus door de lagere hoeveelheid vervuiling per eenheid membraanoppervlakte en de terugdiffusie van 
vervuiling naar de bulkoplossing. Het is aangetoond dat de hier gebruikte PoU-systemen voor langere tijd (>30 dagen) gebruikt kunnen worden zonder sterke chemische reiniging. Over het algemeen presteerde de inside/out configuratie in periodieke modus beter dan systemen in continue modus en de outside/in modus.

In het tweede deel van de studie, gepresenteerd in Hoofdstuk 3, bestuderen we de effecten van de kwaliteit van het voedingswater (secundair afvalwatereffluent, WWEf) op membraanvervuiling in een zelfgebouwd PoU-systeem, waarbij inside/out (I/O) en outside/in (O/I) modi met elkaar zijn vergeleken. De bevindingen werpen licht op de onderliggende principes van de ontwikkeling van biologische vervuiling in lagedruk-hollevezel membranen met WWEf als voedingswater. Voor de O/I modus vermindert de flux gestaag, terwijl voor de I/O modus een fluctuerende trend voor de flux wordt waargenomen, waarbij de flux over de tijd afwisselend toeneemt en afneemt. Het is aangetoond dat deze periodieke fluctuaties in de I/O modus goed overeenkomen met de populatie nematoden op het membraanoppervlak. De biologische vervuiling op het membraanoppervlak bestaat uit zowel biotische als abiotische componenten. De hypothese is dat de roofdier-prooirelatie tussen de nematoden en de microbiële populatie aanwezig in WWEf sterk van invloed is op het fluxgedrag. Voor ons systeem was een drempelwaarde van $2,2 \times 10^{6}$ nematoden $/ \mathrm{m}^{2}$ nodig om het fluctuerende permeatiegedrag te veroorzaken. Het aantal volwassen nematoden heeft een grotere invloed op het fluxgedrag dan het aantal juveniele nematoden. Het effect van de seizoenen op de nematodepopulatie en groei is evident. Tijdens de zomer, bij omgevingstemperaturen van $25^{\circ} \mathrm{C}$, werd een hogere populatiedichtheid van nematoden waargenomen in de vervuilingslaag, terwijl temperaturen onder de $12^{\circ} \mathrm{C}$ de groei van de nematoden vertraagt en de populatiedichtheid vermindert. Het is aangetoond dat de aanwezigheid van actieve nematoden kan leiden tot een fluxtoename van 50-75 \%. Predatie van volwassen, actieve nematoden kan worden ingezet om biologische vervuiling te verminderen tijdens lagedruk-membraanfiltratie. De wetenschappelijke bevindingen gebaseerd op de invloed van de interactie tussen nematoden en biologische vervuiling op membranen kan toegepast worden in de membraantechnologie. De natuurlijke roofdier-prooirelatie kan gebruikt worden voor het ontwikkelen van meer efficiënte en zelfonderhoudende PoUsystemen.

Hoofdstuk 2 en 3 gingen in op zwaartekrachtgedreven applicaties voor ultrafiltratie, belangrijk voor gebieden waar geen infrastructuur voor waterlevering aanwezig is. In gebieden als India of China zijn pijpleidingen voor waterlevering wel aanwezig, vooral in stedelijke gebieden. Daarom is in de andere hoofdstukken de ontwikkeling van biologische vervuiling op UF-membranen onder kraandruk onderzocht. In het verlengde van de studie over voedingswaterkwaliteit is de biofilmvorming bij verschillende monovalente en divalente kationische verhoudingen in de voeding bestudeerd. Deze bevindingen worden behandeld in Hoofdstuk 4. De biofilmformatie is geëvalueerd aan de hand van de hydraulische weerstand en de productie van extracellulaire polymere substanties (EPS) als polysachariden en eiwitten. Een verzameling bacteriën die van nature voorkomt in drinkwater is gebruikt om een biofilm te laten groeien op vlakke ultrafiltratiemembranen bij een constante druk 
van 0,5 bar. De drie verschillende verhoudingen monovalente en divalente ionen (M:D) die onderzocht zijn, zijn 1,31:1, alleen monovalente (M) ionen (geen divalente ionen), en 2,23:1. Het verwijderen van divalente kationen uit het voedingswater vermindert de productie van EPS-componenten en in het bijzonder die van polysachariden aanzienlijk. De hydraulische weerstand van de biofilms is het laagst in afwezigheid van divalente kationen, d.w.z. met alleen monovalente kationen. Hoewel de aanwezigheid van magnesium als divalent kation bij M:D 2,23:1 de uitscheiding van polysachariden bevordert, zijn de hydraulische weerstanden het hoogst bij M:D 1,31:1 in combinatie met de aanwezigheid van calcium.

In het laatste gedeelte van deze studie, gepresenteerd in Hoofdstuk 5, zijn de eigenschappen van membraanoppervlakken gemodificeerd met afwisselende oppervlakteladingen (positief en negatief), aangebracht via het coaten van de polyelektrolyten polydiallyldemethylammoniumchloride (PDADMAC) en polystyreensulfonzuur (PSS) met de laag-bij-laag techniek op UF membranen. De biologische vervuilingpotentiaal van de gemodificeerde membranen is geëvalueerd aan de hand van de groei van drinkwaterbacteriën op het membraanoppervlak bij dynamische filtercondities. De resultaten laten zien dat dat biologische vervuiling de prestaties van gecoate membranen vermindert, waarbij de aangebrachte positieve of negatieve lading geen effect had op de biologische vervuilingpotentiaal voor drinkwaterfiltratie. SEM- en ATP-analyses van zowel positief als negatief gecoate membranen laten afzetting van bacteriën zien. Bij het inbouwen van een dagelijkse reinigingsstap (voorwaarts spoelen) om realistische operatiecondities te simuleren, observeren we een veel hoger fluxherstel voor de gecoate membranen in vergelijking met de membranen zonder coating. Hoewel de hechting van bacteriën gelijk is voor zowel gecoate als niet-gecoate membranen, verzwakt de aanwezigheid van multilagen van de zeer gehydrateerde polyelektrolyt multilagen (PEM) op gecoate membranen de interactie tussen membraanoppervlak en bacteriën, en voorkomt zo de irreversibele adhesie van bacteriën aan het oppervlak. Als gevolg is de biologische vervuilingslaag eenvoudig te verwijderen met deze fysieke reinigingsmethode. De uitkomst van deze studie laat duidelijk zien dat het van belang is de adhesie van bacteriën op gemodificeerde oppervlakten onder dynamische condities te onderzoeken. 



\section{Acknowledgements}

It seems the four years of my $\mathrm{PhD}$ got over in the blink of an eye. As I look back, I can pen it down as a period of immense learning both at scientific and personal level. I would like to express my heartfelt gratitude to people who contributed to my professional and personal growth during these years.

At the outset, I am indebted to Kitty and Antoine for providing me with the opportunity of pursuing a $\mathrm{PhD}$ in the Netherlands. Kitty, your calmness to handle difficult situations and optimism have been a source of inspiration during our almost 4 years-long association. I value the trust you have put into me. My heartfelt gratitude to you dear Antoine for the unending corrections of my thesis chapters, perfecting my power point presentations, and to my utmost surprise even double checking the literature references that I cited in the thesis. I can laugh about our conversations how pregnancy hormones affect the preciseness of writing scientific content. Rob, I cannot thank you enough for accepting to be my promoter in the last month of my PhD. Your strong leadership skills along with your support to the PhDs, positive criticism to the work, are truly inspirational. It was a great learning experience for me even though our association was short term.

I would thank Johannes and Cees for creating a platform of scientific innovation at Wetsus and bringing them in close association with the industrial partners by quarterly theme meeting and congresses. I would like to also thank Wetsus biofouling theme members, both academic and industrial partners who gave constructive criticism to my work and helped me to re-think and improve the quality of my work on a continuous basis. Special thanks to Paula, for keeping us upto date with the agendas and minutes of the meetings, and coordinating it tirelessly. Special word of thanks to my daily supervisor from Wetsus Arie Zwijnenburg, for supervising a part of the $\mathrm{PhD}$ project, teaching me how to make my first membrane modules, spending hours behind electron microscope looking for bacteria on membranes and checking my calculations. Arie, the immense passion you had for your work always inspired your students and colleagues. Your early demise has left a big void in the membrane community.

I would like to express my gratitude to the people with whom I collaborated during my $\mathrm{PhD}$. Wiebe, thank you so much for your insightful comments, guidance and useful feedback on LBL work that helped me to improve. It was a great pleasure for me to work and 
learn under your guidance for this part of my project. Hopefully, I get more opportunities to learn from you. Thank you Hardy for your critical comments on my first manuscript and for the discussions we had on my work, it helped me to improve my work and come up with better experimental ideas after our fruitful discussions. I would express my gratitude to the internship students who helped and supported a lot in my laboratory work. Thank you Stella, Alice, Jeremy and Vishnu. Stella and Jeremy, your sincerity and dedication inspired me at times when I was bogged down by failed experiments.

I believe the laboratory work of my PhD would not have been smooth at all without the help of the efficient and dedicated technical and analytical team of Wetsus. Thank you Wim, Harm, Jan, Harrie, Ernst, Piet, Janneke, Jelmer, Mieke, Marianne and Ton. Special thanks to Agnieszka for teaching me everything in the microlab from making agar plates to gel electrophoresis, it was a great learning experience for me as a non-microbiologist. Thank you HR team and secretarial staff for taking care of administrative issues and being of great help as well. Thank you Rienk for always helping to solve my IT problems. Thank you Gerrit and Claudia for your patience and immediate help at times in placing my orders. Gerben and Riet, your lovely smiles during tea breaks were a good start to monotonous routine.

The moment to thank all the colleagues of Wetsus for their help in answering my scientific questions, eagerness to help whenever I asked and creating a friendly working environment. Thanks to my amazing officemates and nice dinners we had together especially the last one with Bob, Dries, Janneke, Jan Willem and Victor. I would also express gratitude to the MST group members from Twente for always welcoming and guiding whenever I asked questions. Special thanks to Krzyztof, Joris and Shazia for teaching me and taking care of the zeta potential measurements at UT. Thank you Bob and Herman for doing SEM even though I was not physically present at Twente. Thank you Sinem for feeding me during my stay in Enschede. Thank you Janneke for helping with the Dutch summary.

Heartfelt gratitude to Dries, Anna, Terica, Janneke, Joeri and Marjolein for being a part of unforgettable memories of my wedding in India, I guess you were the main attraction instead of the bride and groom. Dries and Marjolein, thank you for letting us experience a European wedding ceremony and Roel deserves the credit for offering a beautiful ride from the Netherlands to Belgium. Lena, special word of thanks for our coffee evenings and subway dinners and for extending help when needed. Prashanth and Varun, I cannot thank you enough for helping me and being there as friends and family whenever I needed. Special thanks to Yeshu and Leo for guidance with Latex.

The moment to express gratefulness to the pillars of my strength, the family. Thanks to my grandparents, for their unconditional love and support that I received since childhood. Thanks to my Mother for instilling courage, strength, dedication, devotion and determination in me, gratitude towards my Father for being an epitome of patience, calmness, humbleness and belongingness. Punu and Nanu you are the most loving siblings that any- 
one can ask for, your efforts and hard work made my wedding a cakewalk for me and I could just enjoy and be a part of the celebration without an iota of stress. Thank you Fateh, Pawan, Lalit and Sweety mamu and Masi for the unconditional love. Gaurav, Ridhi, Prerna, Vipul and Vansh, you are the coolest and funniest cousins. Meeting you all once a year filled me with immense love that I could sustain myself for another year till we met again. Maa and Baba, you made my transition into the married life so smooth, that I never felt as someone new in the family. You always provided me a sense of comfort and belongingness. Thank you for being such amazing parents-in-law.

Finally, my dear husband, Dr Indranil Basu, your presence in my life has changed my perspective towards life. I learnt from you both passion for work and dispassion for material wealth. Every coffee conversation we had in Canada, Germany and the Netherlands felt like a series of talks on wisdom and great knowledge. You are a gift to the society and my vision tells me that many lives would be transformed by you under the guidance of our beloved Master. The words fall short for expressing my gratitude to you for giving me the most beautiful gift, our son 'Harihar'. Dear Harihar, you are a blessing to this world, I very much look forward to your growing up and adding colours to our lives.

Thank you Gurudev Sri Sri Ravi Shankar for making me believe and experience that we all are connected at a deeper level through a common thread of love, that everyone and everything is a part of one single consciousness.

Charu Chawla 



\section{Curriculum Vitae}

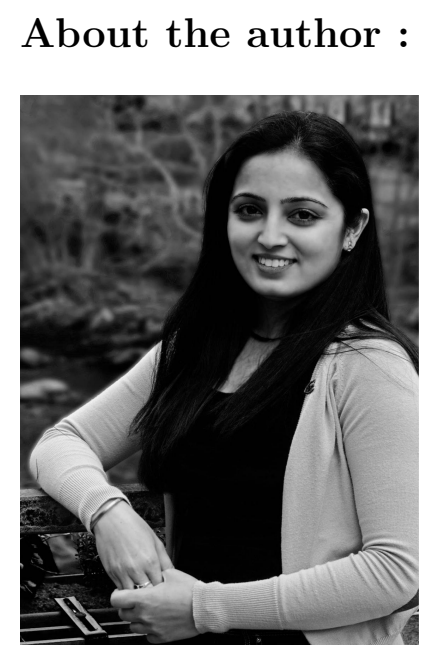

Name

Date of birth

Place of birth

Marital status

Jun 2012 - Jun 2016

Jan 2010 - Jan 2012

Jul 2004 - May 2008
Charu Chawla (Basu)

17.01.1986

Sonipat, India

Married to Dr. Indranil Basu

$\mathrm{PhD}$ in Chemical Engineering, Faculty of Science and Technology, University of Twente (Enschede, NL)

M.E.Sc. in Chemical and Bio-Chemical Engineering, The University of Western Ontario (London, Canada)

B.Tech in Chemical Engineering, D.C.R. University of Science and Technology (Haryana, India) 
ISBN 978-90-365-4303-3 